VINICIUS BERTOLAZZI BISCUOLA

\title{
MODELO MATEMÁTICO HÍBRIDO DETERMINÍSTICO-ESTOCÁSTICO PARA A PREVISÃO DA MACROESTRUTURA DE GRÃOS BRUTA DE SOLIDIFICAÇÃO
}

Tese apresentada à Escola Politécnica da Universidade de São Paulo para obtenção do Título de Doutor em Engenharia 
VINICIUS BERTOLAZZI BISCUOLA

\section{MODELO MATEMÁTICO HÍBRIDO DETERMINÍSTICO-ESTOCÁSTICO PARA A PREVISÃO DA MACROESTRUTURA DE GRÃOS BRUTA DE SOLIDIFICAÇÃO}

Tese apresentada à Escola Politécnica da Universidade de São Paulo para obtenção do Título de Doutor em Engenharia

Área de concentração: Engenharia Metalúrgica e de Materiais

Orientador: Prof. Dr. Marcelo de Aquino Martorano

São Paulo 


\section{FICHA CATALOGRÁFICA}

\section{Biscuola, Vinicius Bertolazzi}

Modelo matemático híbrido determinístico-estocástico para a previsão da macroestrutura de grãos bruta de solidificação / Vinicius Bertolazzi Biscuola São Paulo, 2011.

$235 \mathrm{p}$.

Tese (Doutorado) - Escola Politécnica da Universidade de São Paulo. Departamento de Engenharia Metalúrgica e de Materiais.

1.Modelos Matemáticos 2.Autômatos Celulares 3.Fenômenos de Transporte 4.Transformações de Fase I. Universidade de São Paulo. Escola Politécnica. Departamento de Engenharia de Materiais II.t. 


\section{AGRADECIMENTOS}

Ao professor e orientador Marcelo de Aquino Martorano pela oportunidade, paciência e tempo dispendido nesta longa trajetória.

Aos meus pais por todo o suporte e exemplos transmitidos.

À Marilia, pela compreensão nas horas ausentes e por todo o incentivo. 


\section{RESUMO}

As variáveis de processo determinam as propriedades dos produtos resultantes dos processos de fundição ou de soldagem, que são função da sua macro e microestrutura bruta de solidificação. Um dos parâmetros importantes para se determinar as propriedades de um produto é a posição da transição colunarequiaxial (CET) e, por este motivo, o entendimento dos fenômenos físicos que causam esta transição é essencial. Com o intuito de se prever a formação da CET, surgiram os métodos empíricos e os modelos matemáticos, que são divididos em dois grandes grupos: modelos determinísticos e modelos estocásticos. Estes dois grupos foram bem estudados, porém nunca foram comparados entre si, particularmente em relação à previsão da posição da CET. O presente trabalho tem como um primeiro objetivo preencher esta lacuna através da comparação entre estes modelos. No entanto, o objetivo principal é apresentar, implementar e validar um novo modelo matemático, denominado de híbrido estocástico-determinístico (CADE -"Cellular Automaton Deterministic"), que combine características importantes e vantajosas de cada um dos dois grupos de modelos. Inicialmente, um modelo representante do grupo dos modelos estocásticos foi implementado e validado frente a resultados disponíveis na literatura. Durante esta validação, foi necessária a elaboração de um critério baseado na razão de aspecto dos grãos para a identificação da CET nas macroestruturas calculadas pelo modelo. Estes resultados foram então comparados com os resultados de modelos determinísticos para, após cuidadosa discussão, possibilitar a proposta e implementação do modelo híbrido. Os modelos determinísticos que utilizam o critério mecânico para prever o bloqueio de grãos colunares e a ocorrência da CET mostram regiões colunares em geral maiores que as previstas pelo modelo estocástico. Por outro lado, os modelos determinísticos que utilizam um critério de bloqueio a partir da interação do campo de concentração de soluto ao redor dos grãos prevêem uma CET em posições semelhantes às calculadas pelos modelos estocásticos. O modelo implementado no presente trabalho é capaz de prever a macroestrutura bruta de solidificação e ainda 
utilizar as equações tradicionalmente empregadas nos modelos determinísticos, sem a necessidade de qualquer método extra para prever a posição da frente de crescimento colunar ou o seu bloqueio por grãos equiaxiais.

Palavras-chave: Modelos Matemáticos, Autômato Celulares, Fenômenos de Transporte, Transformações de Fase. 


\section{ABSTRACT}

The processing variables determine many properties of the products obtained by casting and welding processes and these properties, on the other hand, are strongly affected by the as-cast micro and macrostructure. Particularly the position of the columnar-to-equiaxed transition (CET), which determines the amount of columnar and equiaxed grains in the macrostructure, has an important effect on the properties of as-cast parts. Therefore, understanding the important physical phenomena that cause and affect the formation of the CET plays a crucial role in predicting the ascast macrostructure. To predict the CET formation, empirical methods and mathematical models have been developed. These models are frequently divided into two main groups: deterministic and stochastic. Both groups have been thoroughly studied, but a comparison between them was never attempted, especially regarding the prediction of the CET position. One of the main objectives of the present work is to fulfill this gap by carefully comparing these models. Nevertheless, the most important objective is to propose, implement, and validate a hybrid stochastic-deterministic model, referred to as CADE (Cellular Automaton Deterministic), that combines some important and well-known features of each model. Initially, a model from the stochastic group was implemented and validated using results available in the literature and then used to analyze the effects of some processing variables on the CET prediction. To carry out this analyzes, a criteria based on the aspect ratio of the grains was proposed and developed to identify the CET region from macrostructure images calculated by the model. The results were compared with those obtained by deterministic models and finally led to the development of the new proposed model. This new model has some characteristics from each group of mathematical models and, for this reason, was denoted as hybrid. A deterministic model based on a mechanical blocking criterion to block columnar grains and define the CET position showed, for the most part, larger columnar regions than those predicted by the stochastic model. A deterministic model with a solutal blocking criterion to predict the CET showed results similar to those calculated 
with the stochastic model. The model proposed in the present work (CADE) was able to predict the as-cast macrostructure using the well-established deterministic equations, without the need for a new method to track columnar grains or predict their blocking by equiaxed grains.

Keywords: Mathematical Models, Cellular Automaton, Transport Phenomena, Phase Transformations. 


\section{LISTA DE ILUSTRAÇÕES}

Figura 1 - Energia livre em função da temperatura para um metal puro (Ohno, 1976).

Figura 2

- Energia livre total em função do raio para um pequeno super-resfriamento e um super-resfriamento maior (Shewmon, 1969).

Figura 3

- Representação esquemática da nucleação heterogênea sobre um substrato.

Figura 4

- Taxa de nucleação em função do superresfriamento.

Figura 5

- Densidade de núcleos em função do superresfriamento para o modelo de nucleação instantânea.

Figura 6

- Distribuição acumulada de densidade de núcleos em função do super-resfriamento segundo o modelo de nucleação contínua polinomial de Oldfield (1966).

Figura 7

- Função densidade de distribuição de superresfriamentos críticos para nucleação proposta por Rappaz et al. (1986), e Thévoz, Desbiolles e Rappaz (1989).

Figura 8

- Modelo proposto por Greer et al. (2000), para as etapas de crescimento de um núcleo sobre um substrato de diâmetro $\varphi$.

Figura 9

- Distribuição medida do tamanho de partículas sobreposta à distribuição log-normal (Greer, 2003).

Figura 10

- Representação das estruturas de grãos que podem ser encontradas após a solidificação de ligas metálicas (Bower; Flemings, 1967).

Figura 11 - Representação do campo de soluto e conseqüente super-resfriamento constitucional presentes na frente de crescimento. 
Figura 12

Figura 13

Figura 14

Figura 15

Figura 16

Figura 17

Figura 18

Figura 19

Figura 20

Figura 21

Figura 22

Figura 23
- Representação esquemática da teoria da nucleação heterogênea na zona de super-resfriamento constitucional (Spittle, 2006).

- Crescimento e destacamento de braços de dendritas (Hutt; StJohn, 1998).

- Representação esquemática do crescimento e destacamento de grãos segundo a teoria da separação (Ohno, 1975).

- Representação dos grãos no método de Monte Carlo (Spittle; Brown, 1989b)

coincide com o centro da célula.

modelo do CA em três dimensões.

Ravindran, Brown e Spittle (1999).

- Representação esquemática dos modelos de difusão propostos por Rappaz e Thévoz (1987 a e b). (a) Representação do envelope dendrítico; (b) perfil de soluto calculado pelo primeiro modelo (Rappaz; Thévoz, 1987a); (c) substituição do cálculo do perfil pela camada de soluto com espessura (Rappaz; Thévoz, 1987b).

- Representação esquemática do crescimento colunar e equiaxial (Hunt, 1984).

- Velocidade de crescimento em função do gradiente de temperatura, mostrando as regiões colunares e equiaxiais (Hunt, 1984). 
Figura 24 - Representação do envelope dendrítico proposto por Wang e Beckermann (1993a). a) crescimento colunar e b) crescimento equiaxial.

Figura 25 - Comparação das curvas de resfriamento para o crescimento dendrítico obtidas por Rappaz e Thevóz, e Wang e Beckermann (Wang; Beckermann, 1993b)

Figura 26 - Esquema apresentado por Wang e Beckermann (1994), mostrando a frente colunar e os grãos equiaxiais.

Figura 27 - Esquema utilizado por Jacot, Maijer e Cockcroft (2000) para acompanhar a posição da frente colunar, onde os seguimentos de reta representam a frente colunar e os vetores as direções de crescimento.

Figura 28

- Representação do acompanhamento da frente colunar proposto por Browne e Hunt (2004), mostrando as partículas sem massa e a frente colunar.

Figura 29 - Representação esquemática da frente colunar delineada pelas células do CA: a) indicação dos grãos equiaxiais, líquido e temperatura liquidus; b) ampliação da interface colunar (Martorano; Biscuola, 2006).

Figura 30 - Resultado da CET prevista pelo modelo de Martorano e Biscuola (denominado Modelo), comparado com os resultados do autômato celular (macroestrutura ao fundo) e do modelo de Wang e Beckermann (denominado W-B).

Figura 31 - Crescimento colunar e equiaxial para uma liga Al$2 \% \mathrm{Cu}$ solidificada direcionalmente da esquerda para a direita para quatro tempos ( $\mathrm{t} 1 \mathrm{a}$ t4) (Banaszek et al., 2007). 
Figura 32 - Encontro de grãos para tempos fictícios (a) e (b), onde após o encontro há a formação de uma nova interface que para de crescer (McFadden; Browne, 2009).

Figura 33 - Solidificação direcional de uma liga AL-4\%Cu para dois tempos (600s e 900s) prevista pelo modelo de McFadden e Browne (2009).

Figura 34 - Domínio modelado e condições esquemáticas da transferência de calor nas fronteiras.

Figura 35 - Representação esquemática de um volume finito e seu nó, denominado $P$, localizado no seu centro. Os nós $\mathrm{N}, \mathrm{S}, \mathrm{E}$ e $\mathrm{W}$ representam aqueles nos centros dos volumes finitos adjacentes ao contorno norte, sul, leste e oeste, respectivamente.

Figura 36 - Representação do crescimento celular descentrado. A célula inicial de sítio $(v)$ ativou a sua célula vizinha de sítio $(\mu)$, e esta tem o seu quadrado de crescimento descentrado em relação à sua célula.

Figura 37 - Representação esquemática da malha de volumes finitos (VF) utilizada no submodelo macroscópico e da malha de células empregada no submodelo mesoscópico.

Figura 38 - Definição do cálculo de uma dimensão segundo o conceito do calibre (German, 1984).

Figura 39 - Definição do cálculo da razão de aspecto para uma elipse.

Figura 40 - Razão de aspecto em função da posição juntamente com as macrografias calculadas.

- Representação de uma elipse no sistema cartesiano. 
Figura 42 - Teste de influência do tamanho da malha (indicada pelo número de células ao longo do menor eixo da elipse, apresentado logo abaixo da figura) no cálculo da razão de aspecto $\phi$.

Figura 43

- Gráfico da razão de aspecto $\phi$ em função do número de células para o teste de refino de malha.

Figura $44 \quad$ - Teste de rotação das elipses, onde $\phi$ representa a razão de aspecto obtida através do método desenvolvido e $\omega$, o ângulo de rotação.

Figura 45 - Gráfico da razão de aspecto $\phi$ em função do ângulo de rotação da elipse $\omega$.

Figura 46 - Representação esquemática do conceito do envelope dendrítico (Wang; Beckermann, 1993a).

Figura 47 - Desenho esquemático de um envelope de grão e suas pseudo-fases (Martorano; Beckermann; Gandin, 2003).

Figura 48 - Representação esquemática de um quadrado de crescimento em um dado instante, juntamente com o quadrado de crescimento inicial e o quadrado de tamanho máximo que o quadrado de crescimento poderia atingir antes de ser desativado.

Figura 49 - Desenho esquemático da malha de células, onde se mostra a célula para a qual se deseja calcular o comprimento interfacial (verde) e suas quatro vizinhas mais próximas (vermelho) a serem consideradas no cálculo.

Figura 50 - Domínio e sistema de coordenadas utilizados para simular a condução de calor sem mudança de fase.

Figura 51

- Temperatura em função do tempo para três posições durante resfriamento de um domínio quadrado sem mudança de fase. 
Figura 52

Figura 53

Figura 55

Figura 56

Figura 57

Figura 58

Figura 59
- Erro quadrático entre as soluções numéricas e analíticas em função do passo de tempo utilizado no método numérico.

- Formatos do envelope dendrítico obtidos por Gandin e Rappaz (1994) para diversos instantes de tempo (indicados em segundos) durante 0 crescimento sob três condições diferentes indicadas na Tabela 3.

- Formatos do envelope dendrítico durante o crescimento obtidos pelo modelo estocástico tradicional implementado para os mesmos instantes de tempo indicados na Figura 53.

- Macrografias calculadas no teste $1\left(\Delta T_{V, n u c}=10,5 K\right)$.

Resultados fornecidos pelo presente modelo nos instantes (b) 3,5s; (d) 4,5s e (f) 5,5s. Resultados obtidos por Rappaz e Gandin (1993): (a), (c) e (e).

- Macrografias calculadas no teste $2\left(\Delta T_{V, n u c}=8 K\right)$.

Resultados fornecidos pelo presente modelo nos instantes (b) 3,5s; (d) 4,0s e (f) 4,5s. Resultados obtidos por Rappaz e Gandin (1993): (a), (c) e (e).

- Macrografias calculadas no teste $3\left(\Delta T_{V, n u c}=6 K\right)$.

Resultados fornecidos pelo presente modelo nos instantes (b) 3,0s; (d) 3,2s e (f) 3,7s. Resultados obtidos por Rappaz e Gandin (1993): (a), (c) e (e).

- Fluxo de calor através da base do cilindro em função do tempo obtido através da solução inversa da equação de condução de calor.

- Macroestrutura de grãos: (à esquerda e colorida) simulada através do presente modelo; (à direita em preto e branco) resultante do experimento realizado por Gandin e Rappaz (1994). 
Figura 60

\section{Figura 61}

Figura 62

Figura 63

Figura 64

Figura 65

Figura 66
- Comparação entre as temperaturas medidas experimentalmente e os dados resultantes da simulação. Os números indicam a distância do termopar à base refrigerada adjacente ao contorno inferior.

- Erro relativo médio (Erromed) e máximo (Erromax) em função do número de volumes finitos da malha.

- Macrografias para a determinação da malha de CA:

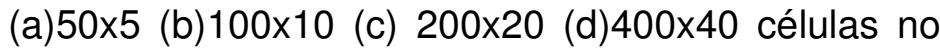
interior de cada volume finito.

- Macrografias calculadas para condições idênticas de simulação (condições de referência). As linhas de cor laranja delimitam a região de transição colunarequiaxial; o ponto demonstra a posição da CET e a linha azul é uma interpolação linear da CET entre as simulações.

- Curvas de resfriamento previstas pelos modelos estocástico (Estoc) e determinístico (Determ) para o caso de referência nas posições de $20,40,60,80,100,120$ e 140 mm a partir da superfície inferior.

152

- Oscilações apresentados nas curvas de temperatura para uma região ampliada da Figura 64. - Posição $\left(\mathrm{y}_{\mathrm{col}}\right)$ e super-resfriamento da frente colunar $\left(\Delta T_{c o l}\right)$ previstos pelos modelos estocástico (Estoc) e determinístico (Determ).

- Curvas de temperatura $(T)$, fração de sólido $\left(\varepsilon_{S}\right)$ e fração de envelopes $\left(\varepsilon_{g}\right)$ em função da distância previstas pelos modelos estocástico (Estoc) e determinístico (Determ) para um tempo de 670s. 
Figura 68

- Comparação entre os perfis de fração de sólido $\left(\varepsilon_{S}\right.$

) apresentados pelos modelos estocástico (Estoc), determinístico (Determ) e pelo modelo de Scheil para $\mathrm{t}=670 \mathrm{~s}$ (Scheil). As posições de CET para os modelos também estão representadas.

Figura 69 - Posição da CET calculada através do modelo determinístico e estocástico e região de transição calculada pelo modelo estocástico em função do super-resfriamento para a nucleação. As macroestruturas obtidas através do modelo estocástico também estão apresentadas.

Figura 70

- Posição da CET calculada através do modelo determinístico e estocástico e região da CET calculada pelo modelo estocástico em função do super-resfriamento para a nucleação. As macroestruturas obtidas através do modelo estocástico também estão apresentadas.

Figura 71 - Posição $\left(\mathrm{y}_{\mathrm{col}}\right)$ e super-resfriamento da frente colunar $\left(\Delta T_{c o l}\right)$ previstos pelos modelos estocástico (Estoc) e determinístico (Determ).

Figura 72 - Posição da CET calculada através do modelo determinístico com bloqueio de soluto (Deterministico), com bloqueio mecânico (Hunt-0,49) e estocástico, e macroestrutura e posição da CET calculada pelo modelo estocástico em função do super-resfriamento para a nucleação.

Figura 73 - Macroestruturas calculadas pelo modelo estocástico em função da densidade de número de substratos, juntamente com a posição da CET calculada pelos modelos determinísticos e estocástico. 
Figura 74

Figura 75

Figura 76

Figura 77

Figura 78

Figura 79

Figura 80

Figura 81

Figura 82

Figura 83

Figura 84

Figura 85
- Posição da CET calculada através do modelo determinístico com bloqueio de soluto (Deterministico), com bloqueio mecânico (Hunt-0,49 e Hunt-0,20) e estocástico, e macroestrutura e posição da CET calculada pelo modelo estocástico em função do super-resfriamento para a nucleação.

- Macroestruturas calculadas pelo modelo estocástico em função da densidade de número de substratos, juntamente com as posições da CET calculadas pelos modelos determinísticos (Deterministico, Hunt-0,49 e Hunt-0,20) e estocástico.

- Macroestruturas calculadas pelo modelo estocástico, nos tempos indicados. modelo estocástico.

- Posição da CET em função da largura relativa de distribuição $\left(\Delta T_{V, \sigma} / \Delta T_{V, n u c}\right)$ para $\Delta T_{V, n u c}=3 \mathrm{~K}$.

- Posição da CET em função da largura relativa de distribuição $\left(\Delta T_{V, \sigma} / \Delta T_{V, n u c}\right)$ para $\Delta T_{V, n u c}=4 \mathrm{~K}$.

- Posição da CET em função da largura relativa de distribuição $\left(\Delta T_{V, \sigma} / \Delta T_{V, n u c}\right)$ para $\Delta T_{V, n u c}=5 \mathrm{~K}$.

- Curvas de resfriamento para as condições de referência e um desvio padrão $\Delta T_{V, \sigma}=0,3 \mathrm{~K}$.

- Curvas de resfriamento para as condições de referência e um desvio padrão $\Delta T_{V, \sigma}=0,9 \mathrm{~K}$.

- Curvas de resfriamento para as condições de referência e um desvio padrão $\Delta T_{V, \sigma}=1,5 \mathrm{~K}$.

- Ilustração do domínio unidimensional considerado. 
Figura 86 - Comparação das curvas de resfriamento obtidas por Guillemot et al. (2004) (CAFE) e pelo modelo estocástico implementado no presente trabalho (Estoc) para as distâncias indicadas em relação à superfície de extração de calor.

Figura 87 - Comparação das curvas de fração de sólido $\left(\varepsilon_{S}\right)$ obtidas por Guillemot et al. (2004) (CAFE) pelo modelo estocástico implementado (Estoc) e pela equação de Scheil (aplicada à curva de temperatura da posição $80 \mathrm{~mm}$ ) para as distâncias indicadas em relação à superfície de extração de calor.

Figura 88

- Macroestrutura de grãos, perfil de temperatura e perfil de fração de sólido $\left(\varepsilon_{S, V F}\right)$ previstos pelo modelo estocástico. O perfil de fração de sólido previsto pelo modelo de Scheil também está mostrado $(\mathrm{t}=670 \mathrm{~s})$.

Figura 89 - Macroestrutura de grãos, perfil de temperatura e perfil de fração de sólido previstos pelo modelo estocástico $\left(\varepsilon_{S, V F}\right)$. O perfil de fração de sólido previsto pelo modelo de Scheil também está mostrado ( $\mathrm{t}=670 \mathrm{~s})$.

Figura 90 - Macroestrutura de grãos, perfil de temperatura e perfil de fração de sólido previstos pelo modelo estocástico $\left(\varepsilon_{S, V F}\right)$. O perfil de fração de sólido previsto pelo modelo de Scheil também está mostrado ( $\mathrm{t}=670 \mathrm{~s})$.

Figura 91 - Curvas de concentração em função da distância para o modelo determinístico em um tempo de 670s (líquido interdendrítico $\mathrm{Cl}^{*}$ e líquido extradendrítico $\mathrm{Cl})$. 
Figura 92

Figura 93

Figura 94

Figura 95

Figura 96

Figura 97

Figura 98
- Comparação da imagem do envelope de grão após crescimento calculado pelo modelo mesoscópico (verde) com a solução analítica (fronteira vermelha). As figuras a, c e d foram obtidas para uma malha de 201x201 células, enquanto nas outras utilizaram-se $401 \times 401$ células. As orientações do grão inicial nestas simulações foram: $0^{\circ}\left(a\right.$ e b), $15^{\circ}$ (c e d) e $45^{\circ}$ (e e f).

- Comparação entre os resultados de $S_{e}$ obtidos pelo

CADE para malhas de 201×201 (Se CA200) e $401 \times 401$ células (Se CA400) com a solução analítica (Se calculado) para um grão com orientação de 45․

- Comparação entre os resultados de $\varepsilon_{g}$ obtidos pelo modelo CADE para malhas de 201x201 (Eg CA200) e de 401x401 células (Eg CA400) e a solução analítica (Eg Calculado) para o crescimento de um grão isolado com orientação de $45^{\circ}$.

190

- Representação de uma seção do envelope cúbico considerado.

192

- Evolução da fração de envelope em função do tempo prevista pelo modelo CADE (Eg-CADE200x200) e pelo modelo determinístico (Eg-Det), assumindo um envelope cúbico com orientação de $30 \div$

- Crescimento do grão com orientação de 30: (a) no instante anterior ao toque nas bordas do domínio; (b) no instante do toque e (c) posterior ao toque.

- Evolução da concentração de área interfacial de envelope e líquido extradendrítico em função do tempo prevista pelo modelo CADE (Se-CADE200x200) e pelo modelo determinístico (Se-Det) com um envelope cúbico e orientação cristalográfica de $30 \div$. 
Figura 99 - Evolução da fração de sólido em função do tempo prevista pelo modelo CADE (Es-CADE-200x200) e pelo modelo determinístico (Es-Det) com um envelope cúbico de orientação $30^{\circ}$.

Figura 100 - Curvas de resfriamento em função do tempo previstas pelo modelo CADE (T-CADE-200×200) e pelo modelo determinístico (T-Det) com um envelope cúbico de orientação $30^{\circ}$.

Figura 101 - Evolução da concentração de área interfacial de envelope em função do tempo prevista pelo modelo CADE (Se-CADE-200x200) e pelo modelo determinístico (Se-Det) com um envelope cúbico de orientação $0^{\circ}$.

Figura 102 - Crescimento do grão com orientação de $0^{\circ}$ no instante anterior ao encontro com as bordas do domínio (a); e posterior ao encontro (b).

Figura 103 - Velocidade de crescimento em função do tempo prevista pelo modelo CADE (V-CADE-200x200) e pelo modelo determinístico (V-Det) para um envelope cúbico de orientação $0^{\circ}$.

Figura 104 - Gráfico da concentração de soluto no líquido extradendrítico $(\mathrm{Cl})$ e extradendrítico $\left(\mathrm{Cl}^{\star}\right)$ em função do tempo previsto pelo modelo CADE (-CADE200x200) e pelo determinístico (Det) com um envelope cúbico e orientação cristalográfica de 0 ․

Figura 105 - Curvas de resfriamento adimensionalisadas para o modelo CADE com envelope cúbico e o modelo determinístico de Wang e Beckermann (1993b) para três densidades de núcleos $\left(\mathrm{n}_{\max }\right)$.

Figura 106 - Evolução da concentração de área interfacial de envelopes $\left(\mathrm{S}_{\mathrm{e}}\right)$ prevista pelos modelos $\operatorname{CADE}\left(\mathrm{S}_{\mathrm{e}^{-}}\right.$ CADE-200x200) e determinístico ( $S_{e}$-Det) para um grão central com orientação de $30^{\circ}$. 
Figura 107 - Evolução da fração de envelopes $\left(\varepsilon_{g}\right)$ prevista pelos modelos CADE $\left(\varepsilon_{g}-\mathrm{CADE}-200 \times 200\right)$ e determinístico ( $\varepsilon_{g}$-Det) para um grão central com orientação cristalográfica de $30^{\circ}$.

Figura 108 - Evolução da fração de sólido $\left(\varepsilon_{S}\right)$ prevista pelos modelos CADE ( $\varepsilon_{S}$-CADE-200x200) e determinístico ( $\varepsilon_{S}$-Det) para um grão central com orientação cristalográfica de $30^{\circ}$.

Figura 109 - Evolução da concentração de soluto no líquido extradendrítico $\left(\mathrm{C}_{\mathrm{l}}\right)$ prevista pelos modelos CADE $(\mathrm{Cl}$ -CADE-200x200) e determinístico (Cl-Det) para um grão central com orientação cristalográfica de $30^{\circ}$.

Figura 110 - Curvas de temperatura previstas pelos modelos CADE (T-Det) e determinístico (T-CADE-200x200) para um grão central com orientação cristalográfica de $30^{\circ}$.

Figura 111 - Frações volumétricas de sólido e envelopes em função do tempo para o modelo híbrido (CADE200x200) e o modelo determinístico (Det) calculadas para 30 grãos.

Figura 112 - Concentração de área interfacial de envelopes em função do tempo para o modelo híbrido (Se-CADE200x200) e o modelo determinístico (Se-Det) calculada para 30 grãos.

Figura 113 - Concentração de soluto no líquido extradendrítico em função do tempo para o modelo híbrido (ClCADE-200x200) e o modelo determinístico (Cl-Det) calculada para 30 grãos.

Figura 114 - Curvas de temperatura em função do tempo para o modelo híbrido (T-CADE-200x200) e o modelo determinístico (T-Det) calculadas para 30 grãos. 
Figura 115 - Macroestrutura de grãos calculada para o modelo CADE para a nucleação e crescimento de 30 grãos distribuídos aleatoriamente no domínio.

Figura 116 - Evolução da macroestrutura entre os instantes de tempo 1 e 8 s prevista pelo modelo CADE durante a simulação da nucleação e crescimento de 30 grãos.

Figura 117 - Representação esquemática da velocidade da frente colunar em função da distância.

Figura 118 - Curvas de resfriamento previstas pelos modelos estocástico (Estoc), determinístico (Determ) e o novo modelo proposto (CADE) para o caso de referência nas posições de 20,40,60,80,100,120 e 140 definidos a partir da superfície inferior do domínio.

Figura 119 - Oscilações apresentadas nas curvas de resfriamento para uma região ampliada da Figura 118.

Figura 120 - Posição da CET em função do super-resfriamento para nucleação no interior do domínio para: (a) novo modelo proposto (CADE) e as macroestruturas simuladas; (b) modelo determinístico com bloqueio de soluto (Deterministico), e modelo estocástico (Estocastico) juntamente com a macroestrutura obtida.

Figura 121 - Posição $\left(\mathrm{y}_{\mathrm{col}}\right)$ e super-resfriamento da frente colunar $\left(\Delta T_{c o l}\right)$ previstos pelos modelos: (a) CADE; (b) Estocástico (Estoc) e determinístico (Determ).

Figura 122 - Representação do domínio e sistema de coordenadas utilizados para a simulação de transferência de calor bidimensional.

Figura 123 - (a) Macroestrutura obtida por Martorano e Biscuola (2006) utilizando um modelo estocástico; (b) mapa de razão de aspecto; (c) sobreposição dos dados e definição da posição da CET. 
LISTA DE ILUSTRAÇÕES

Figura 124 - Posição da CET definida pelo modelo proposto por Martorano e Biscuola (2006) - Model; Wang e Beckermann (1994) - W-B; sobrepostos na macroestrutura simulada por Martorano e Biscuola (2006).

Figura 125 - (a) Macroestrutura simulada pelo novo modelo; (b) mapa de razão de aspecto; (c) sobreposição dos dados e definição da posição da CET. 


\section{LISTA DE TABELAS}

Tabela 1 - Resultados de Super-resfriamentos para alguns metais (Kurz; Fisher, 1998).

Tabela 2 - Dados utilizados no problema de condução.

Tabela 3 - Dados referentes aos testes de crescimento realizados por Gandin e Rappaz (1994).

Tabela 4 - Dados utilizados na simulação isotérmica: parâmetros utilizados para a nucleação no contorno (S) e no interior do domínio (V); composição média ( $C_{0}$ ) e tamanho da malha de células do modelo mesoscópico.

Tabela 5 - Propriedades da liga Al7\%Si utilizada na comparação com resultados experimentais obtidos por (Gandin; Rappaz, 1994).

Tabela 6

- Parâmetros de simulação definidos para comparação com resultados experimentais obtidos por (Gandin; Rappaz, 1994).

Tabela 7 - Propriedades da liga Al7\%Si utilizada no caso de referência.

Tabela 8 - Propriedades da liga Al7\%Si utilizada no caso de referência.

Tabela 9 - Parâmetros de simulação para definição dos parâmetros de nucleação.

Tabela 10 - Parâmetros para distribuição dos substratos para nucleação instantânea no caso de referência (os subscritos indicam a posição de aplicação destes parâmetros, sendo: $\mathrm{V}$ no interior da cavidade e $\mathrm{S}$ na parede do molde).

Tabela 11 - Propriedades da liga Al7\%Si utilizada no caso de referência. 
Tabela 12 - Parâmetros de simulação definidos para o caso de referência.

Tabela 13 - Parâmetros para distribuição dos substratos para nucleação instantânea no caso de referência (os subscritos indicam a posição de aplicação destes parâmetros, sendo: $\mathrm{V}$ no interior da cavidade e $\mathrm{S}$ na parede do molde).

Tabela 14 - Propriedades da liga Al-7\%Si utilizada na simulação de Guillemot et al. (2004).

Tabela 15 - Parâmetros de simulação utilizados por Guillemot et al. (2004).

Tabela 16 - Propriedades da liga Al-5\%Si (Wang; Beckermann, 1993b).

Tabela 17 - Propriedades da liga Al-3\%Cu utilizada na simulação de Martorano e Biscuola (2006).

Tabela 18 - Parâmetros de simulação utilizados por Martorano e Biscuola (2006).

Tabela 19 - Parâmetros para distribuição dos substratos para nucleação utilizados por Martorano e Biscuola (2006) (os subscritos indicam a posição de aplicação destes parâmetros, sendo: $\mathrm{V}$ no interior e $\mathrm{S}$ nas bordas esquerda e inferior do domínio).

Tabela 20 - Parâmetros de simulação utilizados por Martorano e Biscuola (2006). 


\section{LISTA DE ABREVIATURAS E SIGLAS}

\begin{tabular}{|c|c|}
\hline ASTM & $\begin{array}{l}\text { Sociedade Americana para Testes e Materiais ("American } \\
\text { Society for Testing and Materials") }\end{array}$ \\
\hline CA & Autômato Celular ("Cellular Automaton") \\
\hline CADE & $\begin{array}{l}\text { Autômato Celular Determinístico ("Cellular Automaton } \\
\text { Deterministic") }\end{array}$ \\
\hline CET & $\begin{array}{l}\text { Transição Colunar-Equiaxial ("Columnar-to-Equiaxed } \\
\text { Transition") }\end{array}$ \\
\hline Determ & Determinístico \\
\hline DFD & Diferença Finita Direta \\
\hline Estoc & Estocástico \\
\hline Erromax & Erro relativo máximo \\
\hline Erromed & Erro relativo médio \\
\hline FDM & Método das diferenças finitas ("Finite Difference Method") \\
\hline FE & Elementos Finitos ("Finite Elements") \\
\hline REV & $\begin{array}{l}\text { Volume Elementar Representativo ("Representative } \\
\text { Elementary Volume") }\end{array}$ \\
\hline F & Volume Finito \\
\hline
\end{tabular}




\section{LISTA DE SÍMBOLOS}

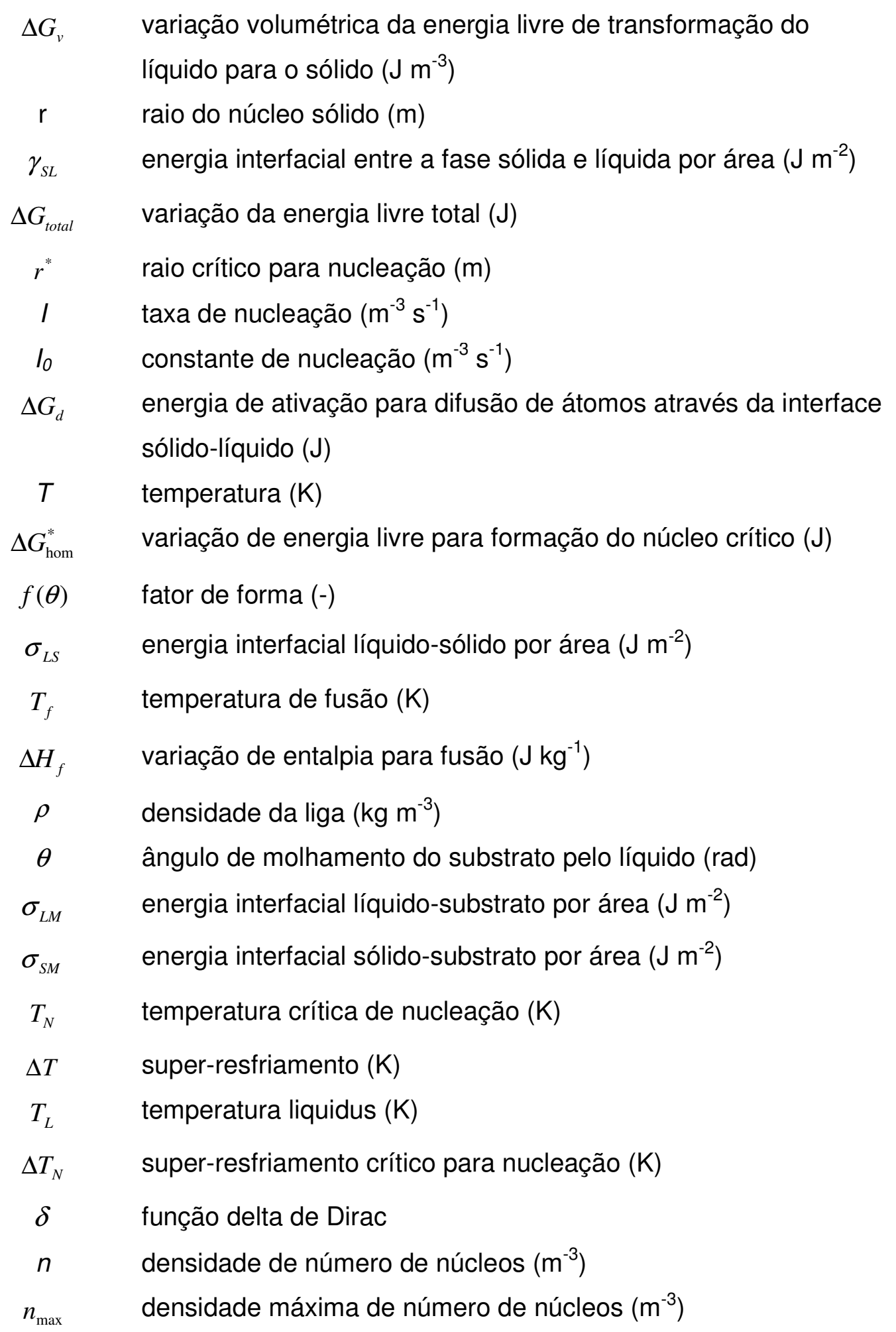




\begin{tabular}{|c|c|}
\hline$K_{1}$ & constante $\left(\mathrm{m}^{-3} \mathrm{~K}^{-2}\right)$ \\
\hline$d n$ & função densidade de distribuição de super-resfriamentos críticos \\
\hline$\overline{d \Delta T}$ & para a nucleação $\left(\mathrm{m}^{-3} \mathrm{~K}^{-1}\right)$ \\
\hline$\Delta T_{n u c}$ & temperatura média de nucleação $(\mathrm{K})$ \\
\hline$\Delta T_{\sigma}$ & desvio padrão $(\mathrm{K})$ \\
\hline$\varphi$ & diâmetro das partículas de inoculante (m) \\
\hline$\Delta T_{f g}$ & super-resfriamento crítico para o crescimento livre $(\mathrm{K})$ \\
\hline$\Delta S_{V}$ & entropia de fusão por unidade de volume $\left(\mathrm{J} \mathrm{K}^{-1} \mathrm{~m}^{-3}\right)$ \\
\hline$\varphi_{0}$ & largura característica da distribuição $(\mathrm{m})$ \\
\hline$\sigma$ & desvio padrão geométrico (-) \\
\hline$\delta n$ & aumento da densidade de número de núcleos $\left(\mathrm{m}^{-3}\right)$ \\
\hline$p_{V}$ & probabilidade de nucleação (-) \\
\hline$r_{V}$ & número aleatório (-) \\
\hline$V_{C A}$ & volume da célula $\left(\mathrm{m}^{3}\right)$ \\
\hline$G$ & gradiente de temperatura $\left(\mathrm{K} \mathrm{m}^{-1}\right)$ \\
\hline$H$ & entalpia por unidade de volume $\left(\mathrm{J} \mathrm{m}^{-3}\right)$ \\
\hline$t$ & tempo (s) \\
\hline$h$ & $\begin{array}{l}\text { coeficiente de transferência de calor na interface metal-molde } \\
\left(\mathrm{W} \mathrm{K}^{-1} \mathrm{~m}^{-2}\right)\end{array}$ \\
\hline$\kappa$ & condutividade térmica $\left(\mathrm{W} \mathrm{K}^{-1} \mathrm{~m}^{-1}\right)$ \\
\hline$T_{W}$ & temperatura do molde $(\mathrm{K})$ \\
\hline$\Delta x$ e $\Delta y$ & dimensões dos lados de um volume finito $(\mathrm{m})$ \\
\hline$\delta x$ e $\delta y$ & $\begin{array}{l}\text { distâncias (nos respectivos eixos x e y) entre os nós dos } \\
\text { volumes finitos }(\mathrm{m})\end{array}$ \\
\hline$\delta$ & passo de tempo (s) \\
\hline$\varepsilon_{S}$ & fração de sólido (-) \\
\hline$\kappa^{L}$ & condutividade térmica da fase líquida $\left(\mathrm{W} \mathrm{K}^{-1} \mathrm{~m}^{-1}\right)$ \\
\hline$\kappa^{S}$ & condutividade térmica da fase sólida $\left(\mathrm{W} \mathrm{K}^{-1} \mathrm{~m}^{-1}\right)$ \\
\hline$C_{p}$ & calor específico $\left(\mathrm{J} \mathrm{kg}^{-1} \mathrm{~K}^{-1}\right)$ \\
\hline$L_{i}$ & metade do lado do envelope $(\mathrm{m})$ \\
\hline$V(\Delta T)$ & velocidade de crescimento da ponta do braço de dendrita $\left(\mathrm{m} \mathrm{s}^{-1}\right)$ \\
\hline
\end{tabular}




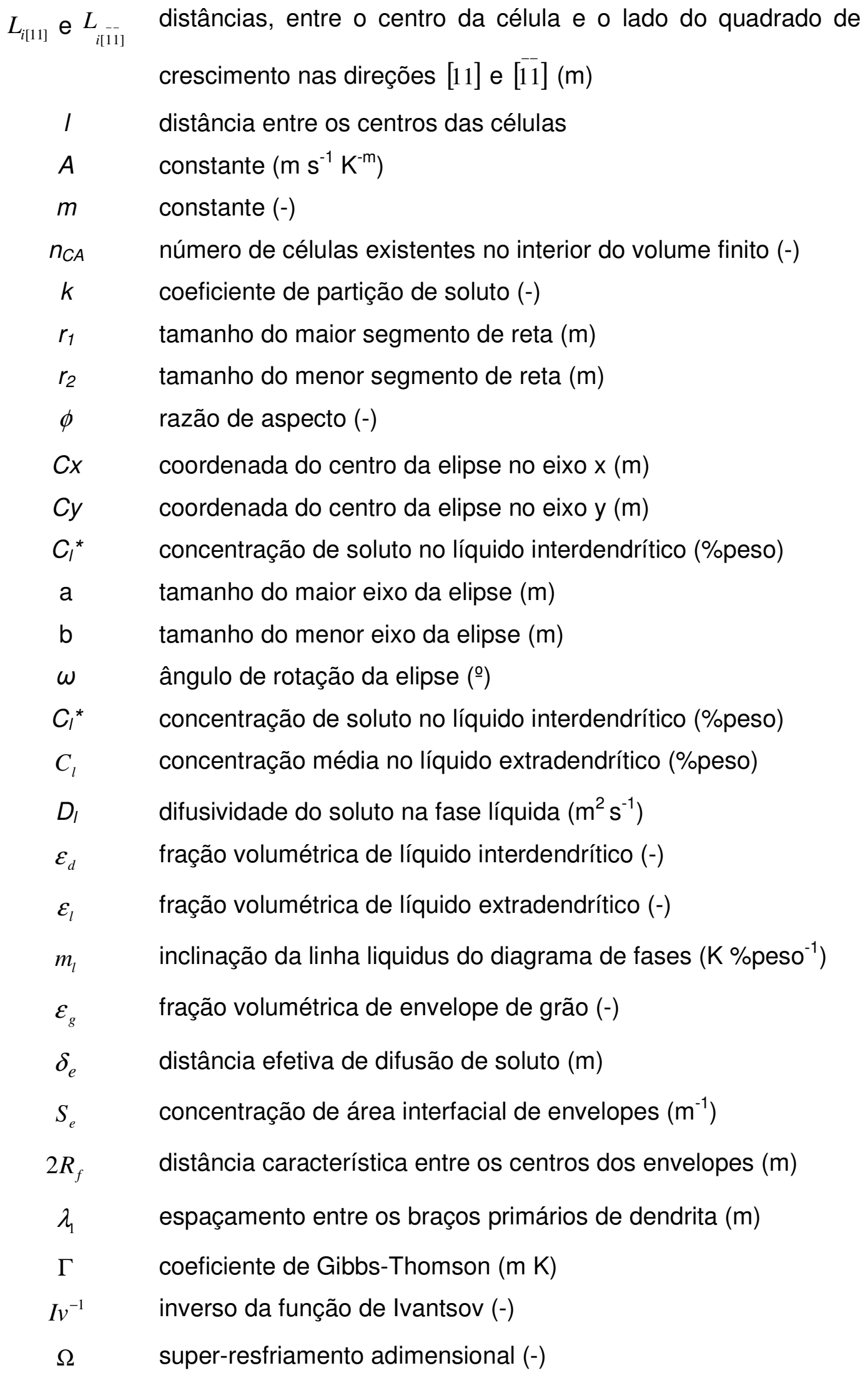




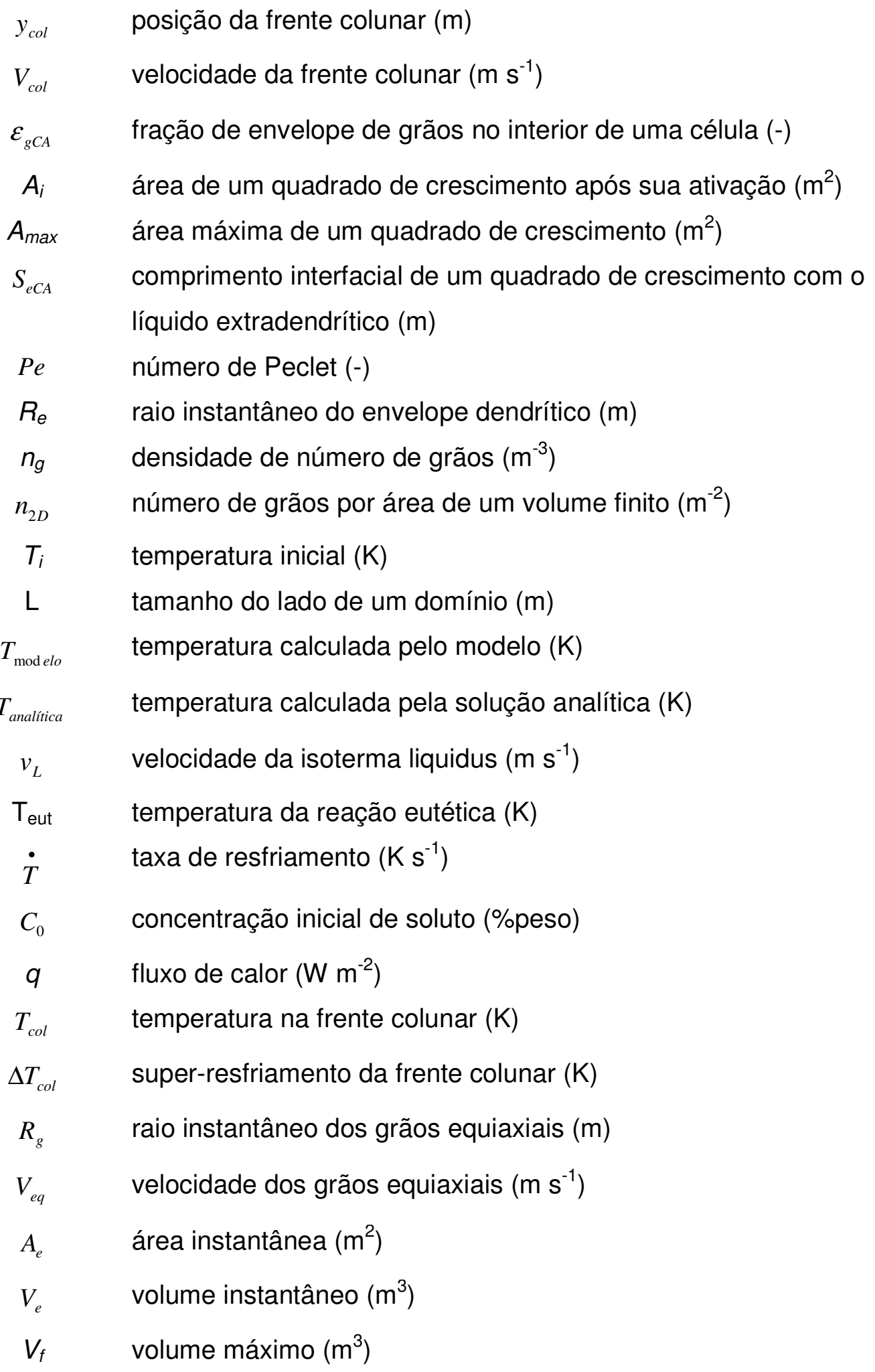




\section{SUMÁRIO}

1 - INTRODUÇÃO

2 - OBJETIVO

3.1 Nucleação de Grãos nos Modelos de Solidificação

3.1.1 Nucleação Homogênea

3.1.2 Nucleação Heterogênea

3.1.3 Nucleação Instantânea

3.1.4 Nucleação Contínua Polinomial

3.1.5 Nucleação Contínua Normal

3.1.6 Nucleação Exponencial e Log-Normal

3.2 Mecanismos para a Transição Colunar-Equiaxial (CET)

3.2.1 Nucleação Heterogênea na Zona de Super-resfriamento Constitucional 50

3.2.2 Explosão de Núcleos ("Big Bang”) 52

3.2.3 Destacamento de Braços de Dendritas 53

3.2.4 Cristais Cadentes $\quad 54$

3.2.5 Teoria da Separação $\quad 55$

3.3 Modelos Matemáticos para a Transição Colunar-Equiaxial 56

3.3.1 Modelos Estocásticos 56

3.3.1.1 Modelos estocásticos precursores 56

3.3.1.2 Modelos de autômato celular na escala mesoscópica 58

3.3.1.3 Modelos de autômato celular na escala microscópica $\quad 65$

$\begin{array}{lll}\text { 3.3.2 Modelos Determinísticos } & 68\end{array}$

4 - METODOLOGIA

4.1 Modelo Estocástico Tradicional

4.1.1 Submodelo Macroscópico $\quad 85$

4.1.2 Submodelo Mesoscópico 88

$\begin{array}{ll}\text { 4.1.2.1 Crescimento dos envelopes } & 91\end{array}$ 
4.1.3 Acoplamento entre Submodelos Macroscópico e Mesoscópico 92

4.1.4 Seqüência de Execução dos Passos do Algoritmo 95

4.2 Definição da Transição Colunar-Equiaxial em uma Macroestrutura de Grãos 96

4.2.1 Análise da Razão de Aspecto (“aspect ratio")

4.2.1.1 Influência do Tamanho da Malha

103

4.2.1.2 Influência da Rotação

104

4.3 Modelo Determinístico

4.4 Modelo Híbrido Estocástico-Determinístico (CADE)

4.4.1 Equações de Conservação do Submodelo Macroscópico 112

$\begin{array}{ll}\text { 4.4.2 Submodelo Mesoscópico } & 114\end{array}$

4.4.2.1 Nucleação 114

4.4.2.2 Velocidade de Crescimento 115

4.4.2.3 Cálculo da Fração de Grãos e da Concentração de Área Interfacial de Envelope 116

$\begin{array}{lll}\text { 4.4.3 Equações Suplementares } & 119\end{array}$

4.4.4 Discretização das Equações de Conservação 121

$\begin{array}{ll}\text { 4.4.5 Seqüência de Execução do Algoritmo } & 124\end{array}$

5 - RESULTADOS E DISCUSSÃO 127

5.1 Análise do Modelo Estocástico Tradicional 127

$\begin{array}{lll}\text { 5.1.1 Validação do Modelo Estocástico } & 127\end{array}$

5.1.1.1 Submodelo Macroscópico 128

5.1.1.2 Submodelo Mesoscópico - Crescimento 131

5.1.1.3 Submodelo Mesoscópico - Nucleação e Crescimento 134

5.1.2 Comparação com Resultados Experimentais 139

5.2 Comparação entre Modelo Estocástico e Modelo Determinístico 144

5.2.1 Condições de Simulação do Caso de Referência 145

5.2.1.1 Parâmetros de Nucleação 146

5.2.1.2 Malha de Volumes Finitos 147

5.2.1.3 Malha do Autômato Celular (CA) 148 
5.2.2 Simulação nas Condições de Referência

5.2.3 Comparação das Posições da Transição Colunar-Equiaxial

5.3 Efeito da Largura da Distribuição de Super-resfriamentos

\subsection{Acoplamento Meso-Macroscópico do Modelo Estocástico}

5.4.1 Resultados do Modelo de Guillemot et al. (2004)

5.4.2 Análise do acoplamento meso-macroscópico do modelo estocástico

\subsection{Modelo CADE}

186

5.6.1 Verificação do crescimento de grão no modelo mesoscópico

5.6.2 Modelo Determinístico e CADE com Envelope Cúbico

5.6.3 Comparação com modelo Determinístico (0D)

5.6.4 Comparação com os Modelos Determinístico e Estocástico (1D) 


\section{1 - INTRODUÇÃO}

As propriedades finais de um produto proveniente dos processos de fundição ou de soldagem são determinadas por sua macro e microestrutura brutas de solidificação e, conseqüentemente, pelas condições de processo. A existência de grãos colunares, caracterizados pelo formato alongado, e de grãos equiaxiais, que possuem um formato mais esférico, na estrutura bruta de solidificação resulta na presença de uma região de transição, chamada de transição colunar-equiaxial (CET - "Columnar-to-Equiaxed Transition"). A posição desta região é importante para o projeto de produtos fundidos, porque determina a quantidade em que estes grãos aparecem, afetando sensivelmente as propriedades finais. Por exemplo, a região de grãos equiaxiais geralmente apresenta propriedades mais isotrópicas do que a região de grãos colunares.

Por este motivo, é crítico que se entenda os fenômenos físicos que regem a formação desta microestrutura e que, com isso, seja possível controlar o tipo de estrutura final. Diferentes mecanismos foram propostos ao longo dos tempos para explicar o aparecimento da CET durante a solidificação, sendo geralmente aceita a teoria de que esta é provocada pelo bloqueio do crescimento dos grãos colunares pelos grãos equiaxiais (Flood; Hunt, 1988). A previsão da CET pode ser obtida por métodos empíricos ou modelos matemáticos, que são freqüentemente divididos em dois grupos: modelos determinísticos e modelos estocásticos.

O primeiro grupo caracteriza-se pela utilização de equações determinísticas, ou seja, que não envolvem variáveis aleatórias. Estas equações são solucionadas nas escalas de tamanho micro e macroscópica e não procuram simular os grãos individualmente, mas sim de forma média. Estes modelos apresentam algumas dificuldades, como, por exemplo, a necessidade de se definir um critério para o bloqueio da frente colunar pelos grãos equiaxiais e o desenvolvimento de algoritmos complexos para sua aplicação em situações de duas ou três dimensões.

O grupo dos modelos estocásticos diferencia-se do anterior por possuir algum tipo de variável aleatória em alguma de suas etapas de cálculo. Estes modelos acompanham a nucleação e o crescimento de cada grão, simulando-se assim a macroestrutura completa de grãos sem a necessidade de se definir um 
critério para o bloqueio dos grãos colunares. Entretanto, ao contrário dos modelos determinísticos, os modelos estocásticos não informam diretamente a posição da CET, que deve ser determinada a partir da macroestrutura calculada. Os modelos estocásticos necessitam de uma capacidade computacional relativamente grande, dificultando a consideração de fenômenos como a convecção do líquido, o transporte de soluto e a movimentação dos grãos.

No grupo dos modelos estocásticos encontram-se os modelos de autômato celular ("cellular automaton"). Estes foram utilizados na previsão da macroestrutura de grãos e seus resultados foram comparados com resultados obtidos experimentalmente (Gandin; Rappaz, 1994; Cho; Hong, 1997; Lee; Hong, 1997; Takatani; Gandin; Rappaz, 2000; Lee; Lee; Hong, 2000; Jarvis; Brown; Spittle, 2000a; Zhu; Hong, 2001; Zhu; Kim; Hong, 2001; Gandin, 2001; Zhu; Hong, 2002; Vandyoussefi; Greer, 2002; Wang; Jin; Zheng, 2002; Liu et al., 2006), apresentando boa concordância. Alguns autores analisaram a influência dos parâmetros de nucleação (Rappaz; Gandin, 1993; Gandin; Charbon; Rappaz, 1995; Lee; Lee; Hong, 2000; Cho; Okane; Umeda, 2001; Zhu; Hong, 2001; Zhu; Kim; Hong, 2001; Wang; Lee; McLean, 2003; Dong; Lee, 2005), da convecção e da rejeição de soluto (Lee; Lee; Hong, 2000; Shin; Hong, 2002; Liu et al., 2006) na macroestrutura de grãos.

Diversos modelos determinísticos foram implementados para a previsão da CET (Hunt, 1984; Flood; Hunt, 1987a; Flood; Hunt, 1987b; Wang; Beckermann, 1994; Martorano; Beckermann; Gandin, 2003) e alguns foram comparados com resultados obtidos experimentalmente (Wang; Beckermann, 1994; Martorano; Beckermann; Gandin, 2003). Martorano, Beckermann e Gandin (2003) compararam o seu modelo com os resultados experimentais obtidos por Gandin (2000a) para ligas Al-Si e examinaram em detalhes as variações de fração de sólido e de grão na estrutura, bem como ilustraram a região com líquido super-resfriado. Porém utilizaram neste modelo (Martorano; Beckermann; Gandin, 2003) o conceito de nucleação instantânea.

Vários aspectos dos dois grupos de modelos foram examinados, mas nenhuma análise comparativa entre os seus resultados, principalmente com relação à previsão da CET, foi realizada. 


\section{2 - OBJETIVO}

O objetivo do presente trabalho é, a partir de uma cuidadosa e detalhada comparação entre modelos determinístico e estocástico, propor, implementar e validar um novo modelo matemático, denominado de híbrido estocásticodeterminístico (CADE - "Cellular Automaton Deterministic"). Este modelo híbrido deve combinar características importantes e vantajosas destas duas classes de modelos já existentes e permitir a previsão da macroestrutura final de grãos, mostrando a transição colunar-equiaxial, sob os efeitos de diversos tipos de variáveis importantes para os processos de fundição. 


\section{3 - REVISÃO DE LITERATURA}

A nucleação de grãos é o processo primordial para a determinação da macroestrutura final de solidificação já que esta determina o momento de aparição dos grãos, a quantidade de grãos e conseqüentemente o tamanho destes. Por este motivo muito autores fizeram revisões a cerca deste assunto (Flodd; Hunt, 1988; Stefanescu, 1995; Hutt; StJohn, 1998; Hutt et al., 1999; Spittle, 2006).

Segundo McClurg (1997) a solidificação é a formação espontânea de uma fase estável a partir de outra metaestável, como a formação de uma fase condensada a partir de um vapor (condensação), formação de vapor a partir de uma fase condensada (cavitação) e formação de fase sólida a partir de uma solução líquida (cristalização).

O processo de solidificação ocorre através da nucleação e crescimento da fase sólido, ou seja, alguns átomos agrupam-se e formam um núcleo e, pela adição de mais átomos, o núcleo pode crescer e tornar-se um grão. Os grãos formados crescem e adquirem formatos diversos, que são geralmente classificados em equiaxial e colunar. A predominância de um determinado formato de grão em uma dada região depende, entre outros, dos mecanismos que causam a transição colunar-equiaxial. Estes mecanismos estão intimamente relacionados com 0 crescimento dos grãos e com a nucleação principalmente de grãos equiaxiais. A previsão da transição colunar-equiaxial através de modelos matemáticos deve então simular a nucleação e o crescimento dos dois tipos de grãos mencionados. Desta forma, nos próximos itens será apresentada uma revisão de literatura sobre estes aspectos. No item 3.1.1 o modelo de nucleação homogênea é apresentado e em seguida nos itens seguintes alguns modelos de nucleação heterogênea utilizados nos modelos de solidificação serão apresentados. Os mecanismos de formação da macroestrutura de grãos bruta de solidificação serão apresentados no item 3.2. Finalmente, os modelos estocásticos e determinísticos para a previsão da transição colunar-equiaxial serão discutidos no item 3.3. 


\subsection{Nucleação de Grãos nos Modelos de Solidificação}

\subsubsection{Nucleação Homogênea}

Segundo McClurg (1997) a primeira explicação qualitativa para a existência da nucleação homogênea é atribuída a Gibbs e data de 1887, e em 1926 a taxa de nucleação foi então calculada por Volmer e Weber.

Observando-se a curva de energia livre por volume para a fase sólida e a líquida em função da temperatura, apresentada na Figura 1, conclui-se que a única temperatura em que as duas fases podem coexistir é a temperatura de fusão, e que para temperaturas maiores a única fase estável é a líquida e para temperaturas menores a fase sólida se torna a única estável. Porém, este efeito não é visualizado na prática e pode ser explicado pelo fato de que a energia livre apresentada na Figura 1 não leva em consideração a energia associada à formação da nova interface entre as duas fases.

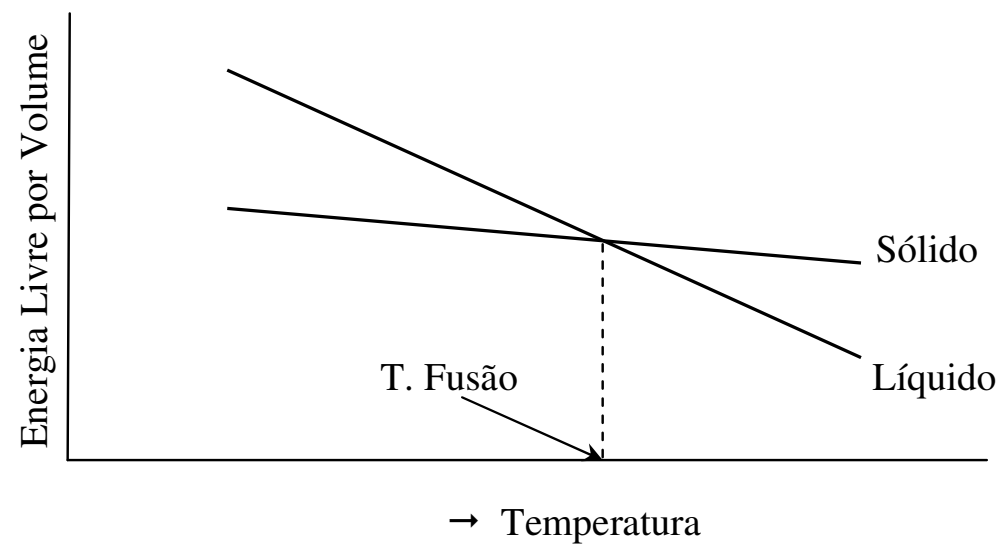

Figura 1 - Energia livre em função da temperatura para um metal puro (Ohno, 1976).

Considerando-se que, segundo Shewmon (1969), a energia livre associada à criação de uma fase sólida na líquida em função do raio é dada por:

$$
\Delta G_{v} \frac{4}{3} \pi r^{3}
$$


onde $\Delta G_{v}$ é a variação volumétrica da energia livre de transformação do líquido para o sólido e $r$ é o raio do novo núcleo sólido. A energia associada à criação da nova interface é dada por (Shewmon, 1969):

$$
\gamma_{S L} 4 \pi r^{2}
$$

onde $\gamma_{S L}$ é a energia interfacial entre a fase sólida e líquida por área. Resultando que a variação da energia livre total $\left(\Delta G_{\text {total }}\right)$ para a criação da nova fase é:

$$
\Delta G_{\text {total }}=\Delta G_{v} \frac{4}{3} \pi r^{3}+\gamma_{S L} 4 \pi r^{2}
$$

Percebe-se que para temperaturas abaixo do ponto de fusão a energia livre de transformação (primeiro termo do lado direto da equação) que é negativa, varia em função do cubo do raio enquanto a energia associada à criação da nova interface (último termo do lado direito da equação) que é positiva, varia em função do quadrado do raio, ou seja, como pode ser visto na Figura 2, apesar da energia associada à criação de uma interface diminuir o potencial para a transformação de fase, a sua taxa de crescimento em função do raio é menor que a taxa de crescimento da energia associada à criação da nova fase. Este fato faz com que exista um raio, chamado de raio crítico e representado por $r^{*}$, a partir do qual a variação de energia livre para a criação da nova fase se torna negativa e a nova fase tenha potencial para existir.

Deve-se também levar em consideração que a variação da energia livre para a criação da nova fase $\left(\Delta G_{v}\right)$ é função da temperatura, e se torna mais negativa em função do aumento do super-resfriamento, como mostrado na Figura 2. 


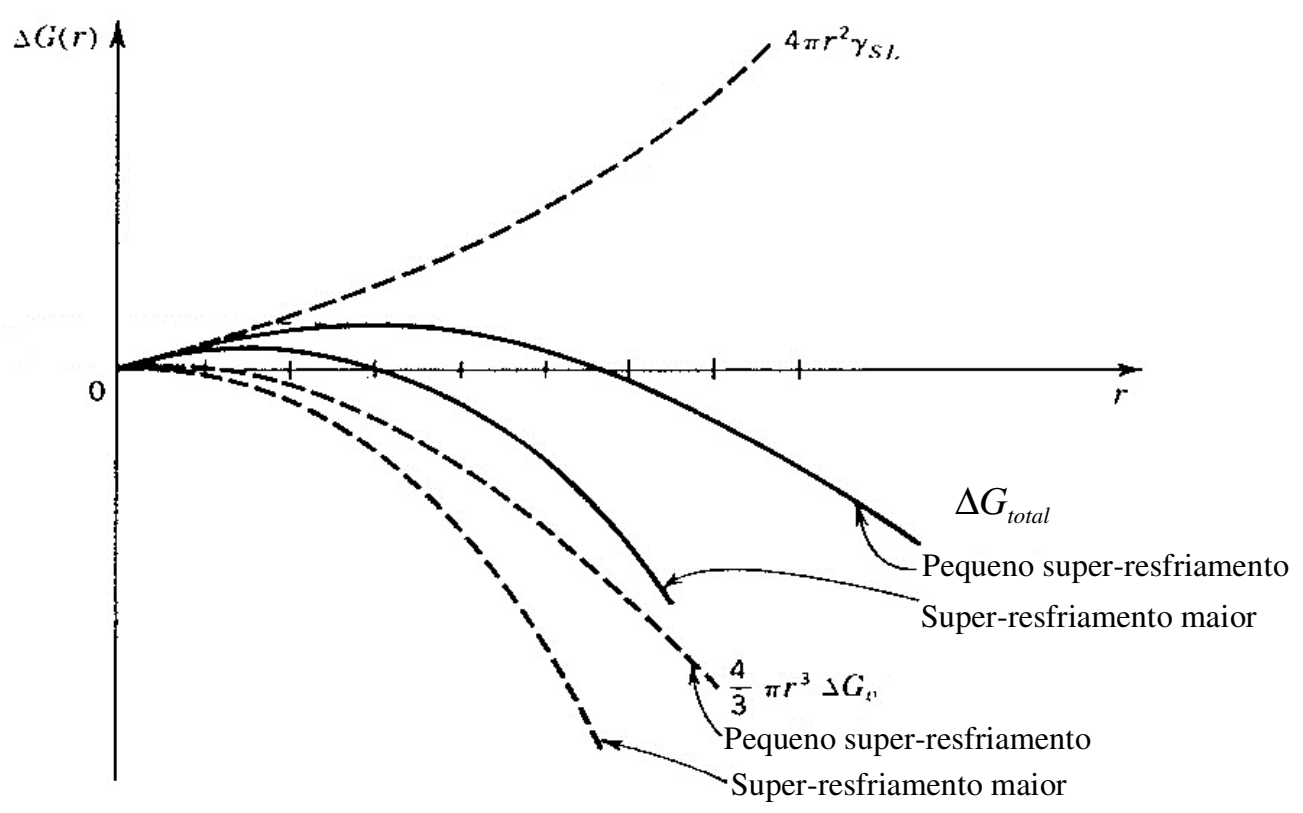

Figura 2 - Energia livre total em função do raio para um pequeno super-resfriamento e um superresfriamento maior (Shewmon, 1969).

Em geral o modelo de nucleação homogênea não é utilizado devido aos valores de super-resfriamentos necessários para a aparição dos núcleos, conforme pode ser visto na Tabela 1 para alguns metais.

Tabela 1 - Resultados de Super-resfriamentos para alguns metais (Kurz; Fisher, 1998).

$$
\text { Energia de }
$$

Super-resfriamento superfície por área,

\begin{tabular}{lcc}
\multicolumn{1}{c}{ Metal } & máximo $\stackrel{\circ}{ }{ }^{\circ}$ & $\mathrm{mJ} \mathrm{m}-2$ \\
\hline Alumínio & 195 & 121 \\
Manganês & 308 & 206 \\
Ferro & 295 & 204 \\
Cobalto & 330 & 234 \\
Níquel & 319 & 255 \\
Cobre & 236 & 177 \\
Prata & 227 & 126 \\
\hline
\end{tabular}




\subsubsection{Nucleação Heterogênea}

A nucleação heterogênea ocorre em regiões preferenciais tais como inclusões e paredes do molde. A nucleação preferencial sobre a superfície destes substratos possibilita o aparecimento de quantidades significativas de núcleos da fase sólida em super-resfriamentos menores do que o necessário para a nucleação homogênea. Segundo Rappaz (1989) a teoria da nucleação heterogênea foi primeiramente delineada por Turnbull e Fisher em 1948 e segundo Kurz e Fisher (1998) a taxa de nucleação (I) é dada por:

$$
I=I_{0} \exp \left(-\frac{\Delta G_{d}+\Delta G_{\mathrm{hom}}^{*} f(\theta)}{R T}\right)
$$

onde $I_{0}$ é uma constante; $\Delta G_{d}$ é a energia de ativação para difusão de átomos através da interface sólido-líquido; $T$ é a temperatura e $\Delta G_{\mathrm{hom}}^{*}$ é a variação de energia livre para formação do núcleo crítico dada por:

$$
\Delta G_{\mathrm{hom}}^{*}=\frac{16 \pi \sigma_{L S}^{3} T_{f}^{2}}{3 \Delta H_{f}^{2} \rho^{2}\left(T-T_{f}\right)^{2}}
$$

e $f(\theta)$ é o fator de forma dado por:

$$
f(\theta)=\frac{(2+\cos \theta)(1-\cos \theta)^{2}}{4}
$$

onde $\sigma_{L S}$ é a energia interfacial líquido-sólido por área; $\rho$ é a densidade da liga; $T_{f}$ é a temperatura de fusão; $\Delta H_{f}$ é a variação de entalpia para fusão e $\theta$ é o ângulo de molhamento do substrato pelo líquido, representado esquematicamente na Figura 3, que pode ser obtido através da equação de Young, mostrado abaixo:

$$
\sigma_{L M}=\sigma_{S M}+\sigma_{L S} \cdot \cos \theta
$$


onde $\sigma_{L M}$ é a tensão superficial líquido-substrato por área; $\sigma_{S M}$ é a energia interfacial sólido-substrato por área.

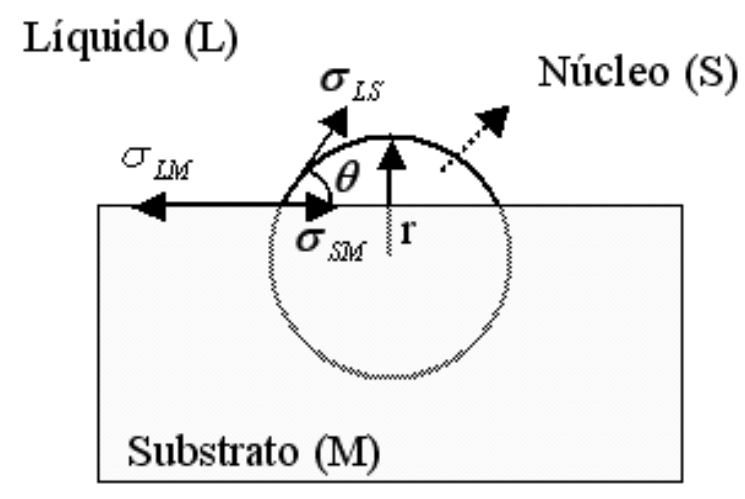

Figura 3- Representação esquemática da nucleação heterogênea sobre um substrato.

Ao analisar-se a taxa de nucleação dada pela equação [4], percebe-se que há um aumento abrupto em uma determinada faixa de temperatura (Figura 4). Nesta faixa ocorre a chamada "saturação" de sítios e considera-se que a temperatura crítica de nucleação $\left(T_{N}\right)$ foi atingida. A cada temperatura, pode-se associar um super-resfriamento $\Delta T$, definido por:

$$
\Delta T=T_{L}-T
$$

onde $T_{L}$ é a temperatura liquidus da liga. Desta forma, pode-se também associar um super-resfriamento à temperatura crítica, denominado super-resfriamento crítico para nucleação $\Delta T_{N}$. 


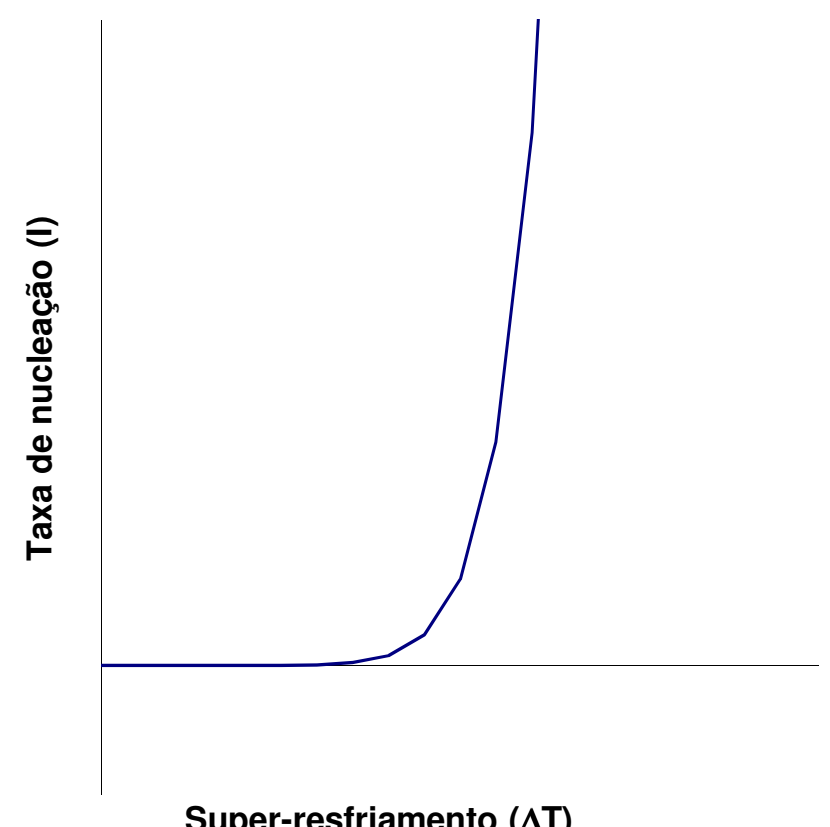

Figura 4- Taxa de nucleação em função do super-resfriamento.

\subsubsection{Nucleação Instantânea}

O modelo de nucleação instantânea visa simplificar a implementação do modelo clássico da nucleação heterogênea, apresentado no item 3.1.2. Como no modelo clássico todos os núcleos aparecem em uma faixa estreita de superresfriamento (Figura 4), Rappaz e Stefanescu (1988) utilizaram a função delta de Dirac $(\delta)$ e escreveram:

$$
\frac{d n}{d T}=n_{\max } \delta\left(T-T_{N}\right)
$$

onde $n$ é a densidade instantânea de núcleos; $n_{\max }$ é a densidade máxima de núcleos e $T_{N}$ é a temperatura crítica para nucleação. A função delta de Dirac possui a seguinte propriedade:

$$
\delta(x)=\left\{\begin{array}{ccc}
0 & p / & x \neq 0 \\
\infty & p / & x=0
\end{array} \text { e } \int_{-\infty}^{+\infty} \delta(x)=1\right.
$$


Como pode ser visto na Figura 5, segundo este modelo não há formação de núcleos em temperaturas inferiores a $T_{N}$ e, quando esta é atingida há a formação de um número relativamente grande de núcleos, atingindo-se assim a densidade máxima, $n_{\max }$, instantaneamente.

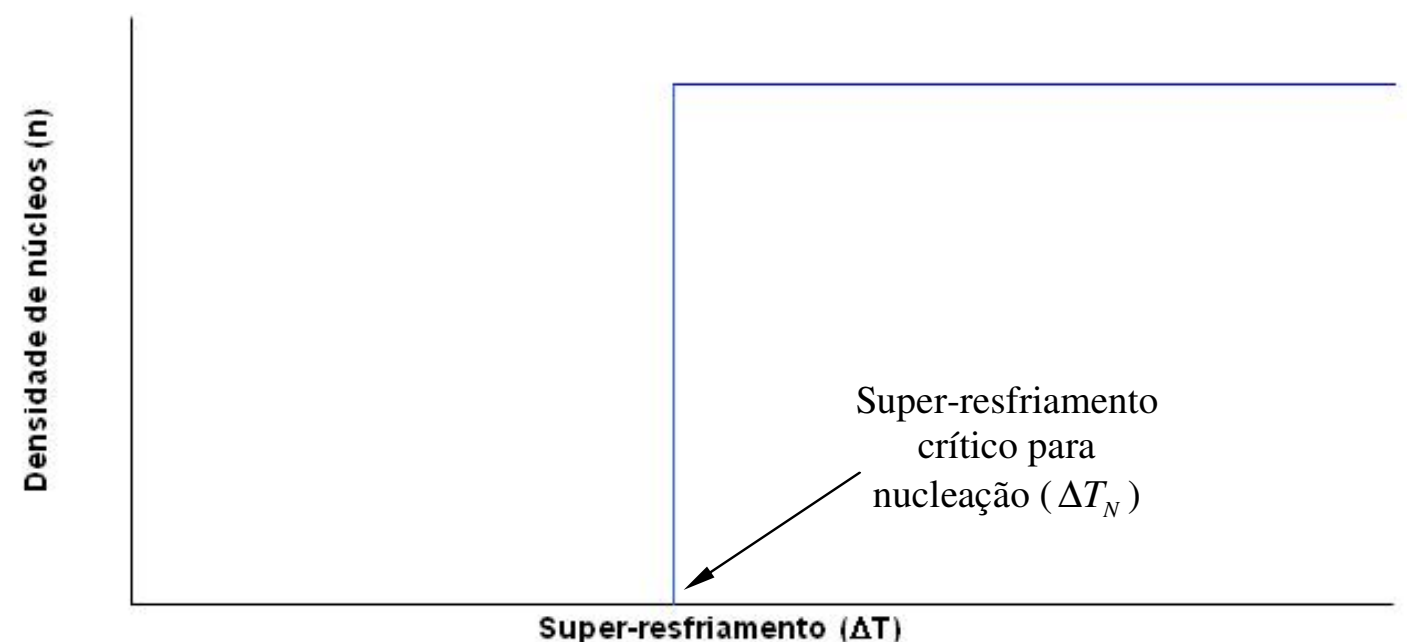

Figura 5- Densidade de núcleos em função do super-resfriamento para o modelo de nucleação instantânea.

A utilização deste modelo resulta em uma quantidade de núcleos e, conseqüentemente, em uma quantidade de grãos que independe das condições de processamento, ou seja, este modelo não é sensível à taxa de resfriamento.

\subsubsection{Nucleação Contínua Polinomial}

Oldfield (1966) propôs que a taxa de variação na densidade de núcleos $(d n)$ com o super-resfriamento fosse dada por:

$$
\frac{d n}{d \Delta T}=K_{1} \Delta T
$$

onde $K_{1}$ é uma constante obtida através de dados experimentais. O termo $\frac{d n}{d \Delta T}$ na equação [11] representa uma função densidade de distribuição de superresfriamentos críticos para a nucleação. 
Neste modelo, chamado de modelo de nucleação contínua polinomial, a quantidade de grãos aumenta continuamente com o aumento do super-resfriamento, possibilitando, entre outros, o cálculo do efeito da taxa de resfriamento no tamanho médio dos grãos da estrutura final.

A distribuição acumulada de densidade de núcleos (Figura 6) pode ser obtida através da integração da equação [11], dada abaixo:

$$
n(\Delta T)=\int_{0}^{\Delta T} \frac{d n}{d \Delta T} \Delta T=\frac{K_{1} \Delta T^{2}}{2}
$$

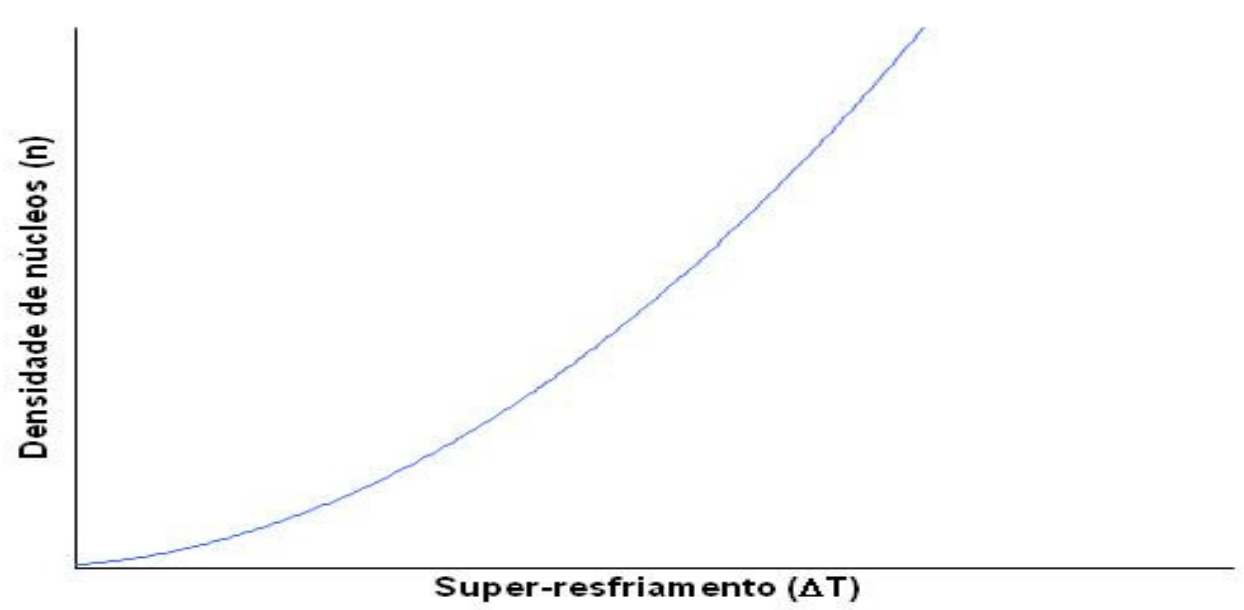

Figura 6- Distribuição acumulada de densidade de núcleos em função do super-resfriamento segundo o modelo de nucleação contínua polinomial de Oldfield (1966).

\subsubsection{Nucleação Contínua Normal}

Rappaz et al. (1986), e Thévoz, Desbiolles e Rappaz (1989) sugeriram um modelo de nucleação contínua, que é baseada no conceito da existência de diferentes tipos de substratos para a nucleação heterogênea. Segundo este conceito, cada substrato possui um super-resfriamento específico para ocorrência da saturação com núcleos.

A função densidade de distribuição de super-resfriamentos críticos para nucleação é dada por uma distribuição normal (Figura 7), como segue:

$$
\frac{d n}{d(\Delta T)}=\frac{n_{\max }}{\sqrt{2 \pi} \Delta T_{\sigma}} \exp \left[-\frac{1}{2}\left(\frac{\Delta T-\Delta T_{n u c}}{\Delta T_{\sigma}}\right)^{2}\right]
$$


onde $n_{\max }$ é a densidade total de número de substratos para a nucleação heterogênea; $\Delta T_{n u c}$ a temperatura média de nucleação e $\Delta T_{\sigma}$ o desvio padrão da distribuição. Estes parâmetros devem ser ajustados a partir de dados experimentais.

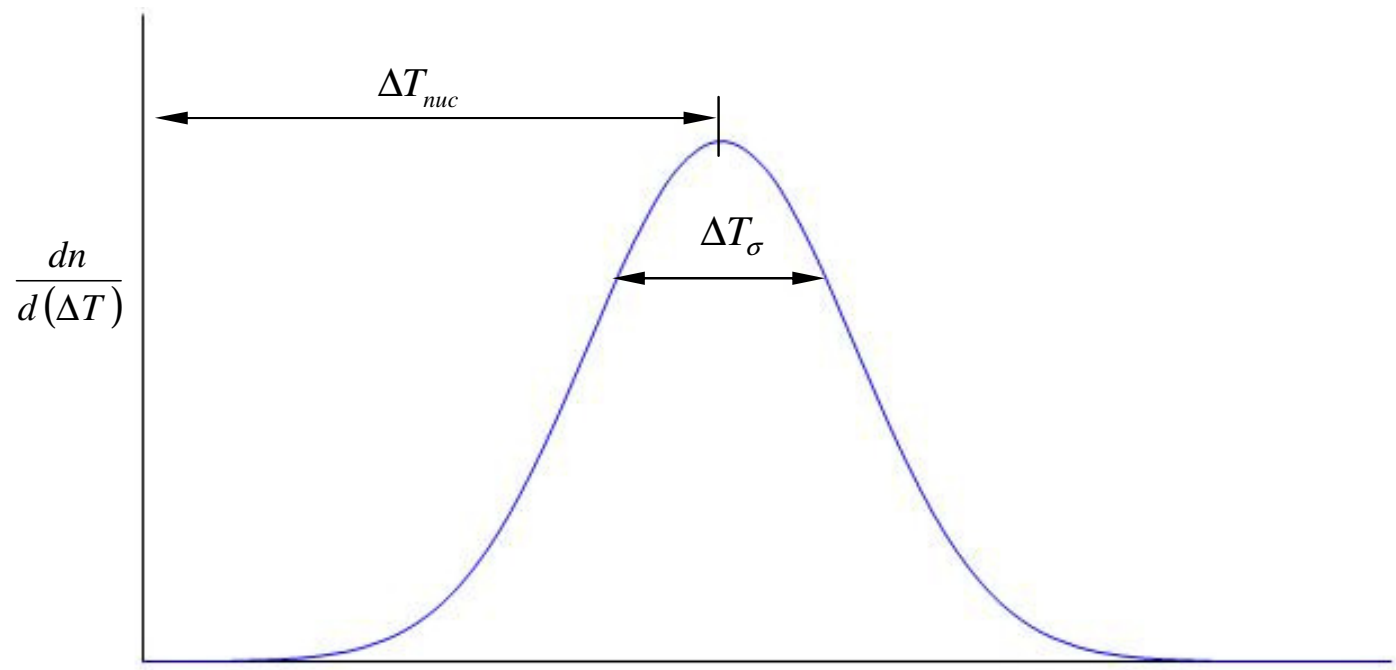

Super-resfriamento $(\Delta T)$

Figura 7- Função densidade de distribuição de super-resfriamentos críticos para nucleação proposta por Rappaz et al. (1986), e Thévoz, Desbiolles e Rappaz (1989).

\subsubsection{Nucleação Exponencial e Log-Normal}

Segundo a teoria de Greer et al. (2000), os núcleos são formados sobre os substratos e crescem lateralmente até atingirem o tamanho deste substrato (Figura 8). 


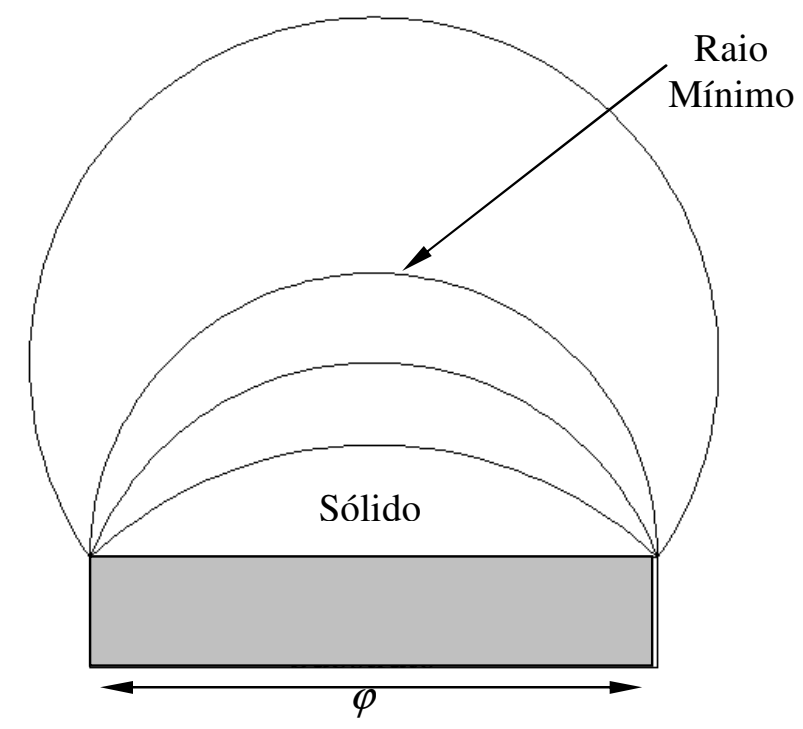

Figura 8- Modelo proposto por Greer et al. (2000), para as etapas de crescimento de um núcleo sobre um substrato de diâmetro $\varphi$.

Durante o crescimento, o raio de curvatura deste núcleo, definido por $r$, diminui e atinge um valor mínimo, igual à metade do diâmetro $\varphi$ das partículas de inoculante ou substratos. Tais núcleos só poderão continuar crescendo livremente ("free growth") após ultrapassarem este estágio de raio mínimo. No entanto, para que o sólido permaneça estável, o raio mínimo não pode ser menor que o raio crítico para nucleação $\left(r^{*}\right)$. Desta forma o crescimento livre do núcleo só é possível quando:

$$
\varphi \geq 2 r^{*}
$$

Com isso, o super-resfriamento crítico para o crescimento livre do núcleo ( $\Delta T_{f g}$ ) pode ser relacionado com o diâmetro do substrato através da equação abaixo (Greer et al., 2000):

$$
\Delta T_{f g}=\frac{4 \sigma_{L S}}{\Delta S_{V} \varphi}
$$

onde $\Delta S_{V}$ é a entropia de fusão por volume.

Neste modelo, Greer et al. (2000) assumiram que o início da recalescência interrompia a nucleação, ou seja, o número final de grãos é aquele presente no momento do início da recalescência. 
Greer et al. (2000), verificaram experimentalmente que o tamanho das partículas de inoculante $\mathrm{TiB}_{2}$ adicionadas em ligas de $\mathrm{Al}$ na forma de uma liga-mãe Al-5\%Ti-1\%B segue a uma distribuição exponencial dada pela seguinte equação:

$$
\frac{d n}{d \varphi}=\frac{n_{\max }}{\varphi_{0}} \exp \left(\frac{-\varphi}{\varphi_{0}}\right)
$$

onde $\varphi$ é o diâmetro da partícula e $\varphi_{0}$ a largura característica da distribuição. Como o diâmetro da partícula é inversamente proporcional ao super-resfriamento necessário para a nucleação, a distribuição de tamanhos pode ser convertida em uma distribuição de super-resfriamentos críticos para a nucleação.

Apesar de terem proposto esta distribuição, os autores (Greer et al., 2000) passaram a utilizar em suas simulações um modelo de distribuição normal de tamanhos de partículas. Quested, Greer e Cooper (2002) verificaram ainda que este tipo de distribuição ocasionava em diâmetros negativos de partículas e, portanto utilizaram uma distribuição log-normal que, segundo German (1984), é a distribuição de tamanho de partículas mais comumente apresentada por materiais particulados. Esta distribuição log-normal é definida por:

$$
\frac{d n}{d \varphi}=\frac{n_{\max }}{\sigma \varphi \sqrt{2 \pi}} \exp -\left(\frac{\left[\ln (\varphi)-\ln \left(\varphi_{0}\right)\right]^{2}}{2 \sigma^{2}}\right)
$$

onde $\sigma$ é o desvio padrão geométrico. Note que as equações [16] e [17], diferentemente da equação [13], representam uma função de densidade de distribuição de diâmetros de partículas. Esta distribuição pode ser vista sobreposta a dados experimentais obtidos por Greer et al. (2000) na Figura 9. 


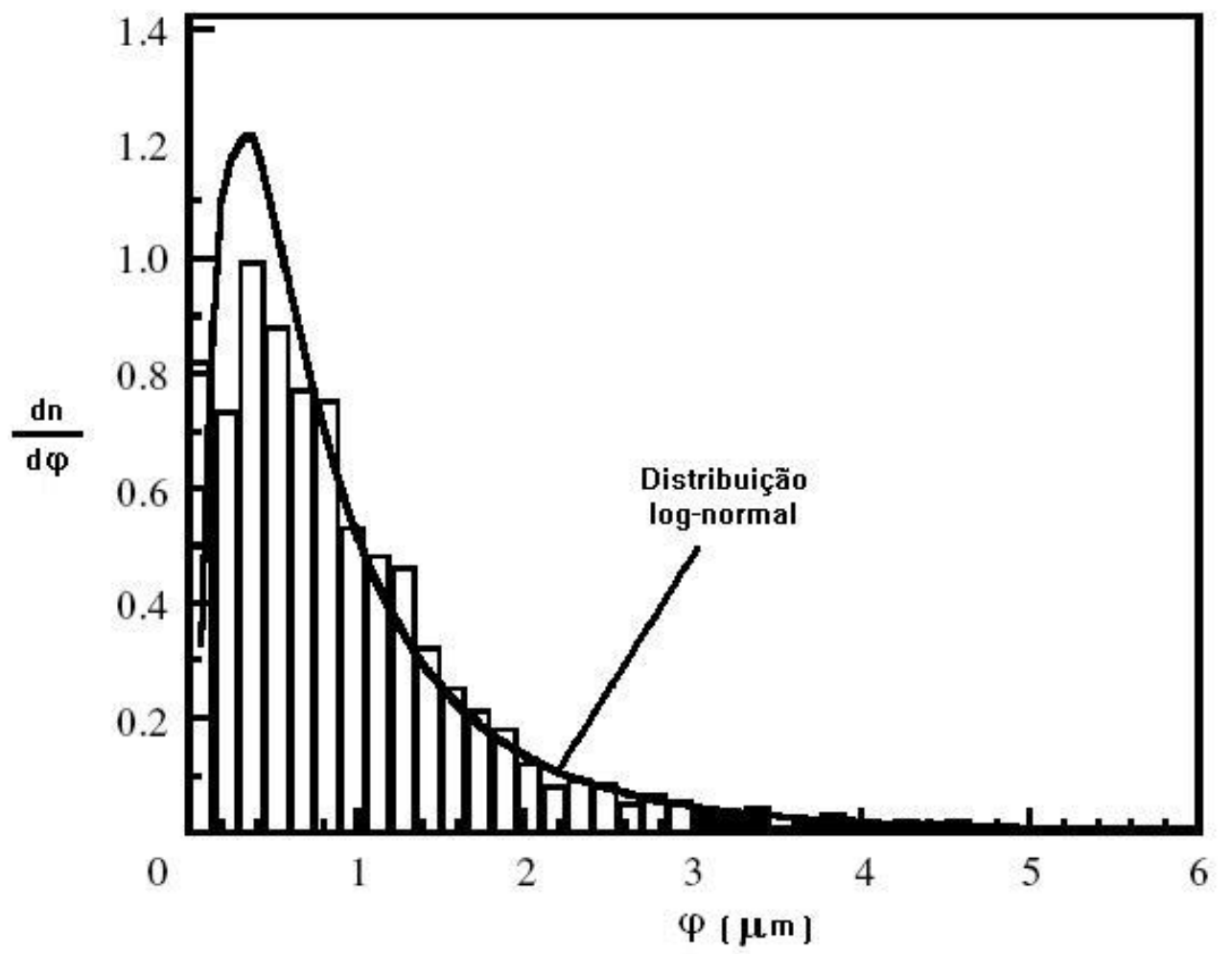

Figura 9 - Distribuição medida do tamanho de partículas sobreposta à distribuição log-normal (Greer, 2003).

\subsection{Mecanismos para a Transição Colunar-Equiaxial (CET)}

A estrutura bruta de solidificação das ligas metálicas pode apresentar uma combinação de três zonas distintas (Flood; Hunt, 1988), que estão descritas a seguir e são mostradas na Figura 10:

- Uma zona coquilhada próxima à superfície do molde, composta por grãos equiaxiais relativamente pequenos;

- Uma zona colunar composta por grãos de formato alongado, alinhados na direção de maior extração de calor e com início na zona coquilhada;

- Uma zona equiaxial formada por grãos equiaxiais, porém com um tamanho médio maior do que o dos grãos equiaxiais da zona coquilhada. 


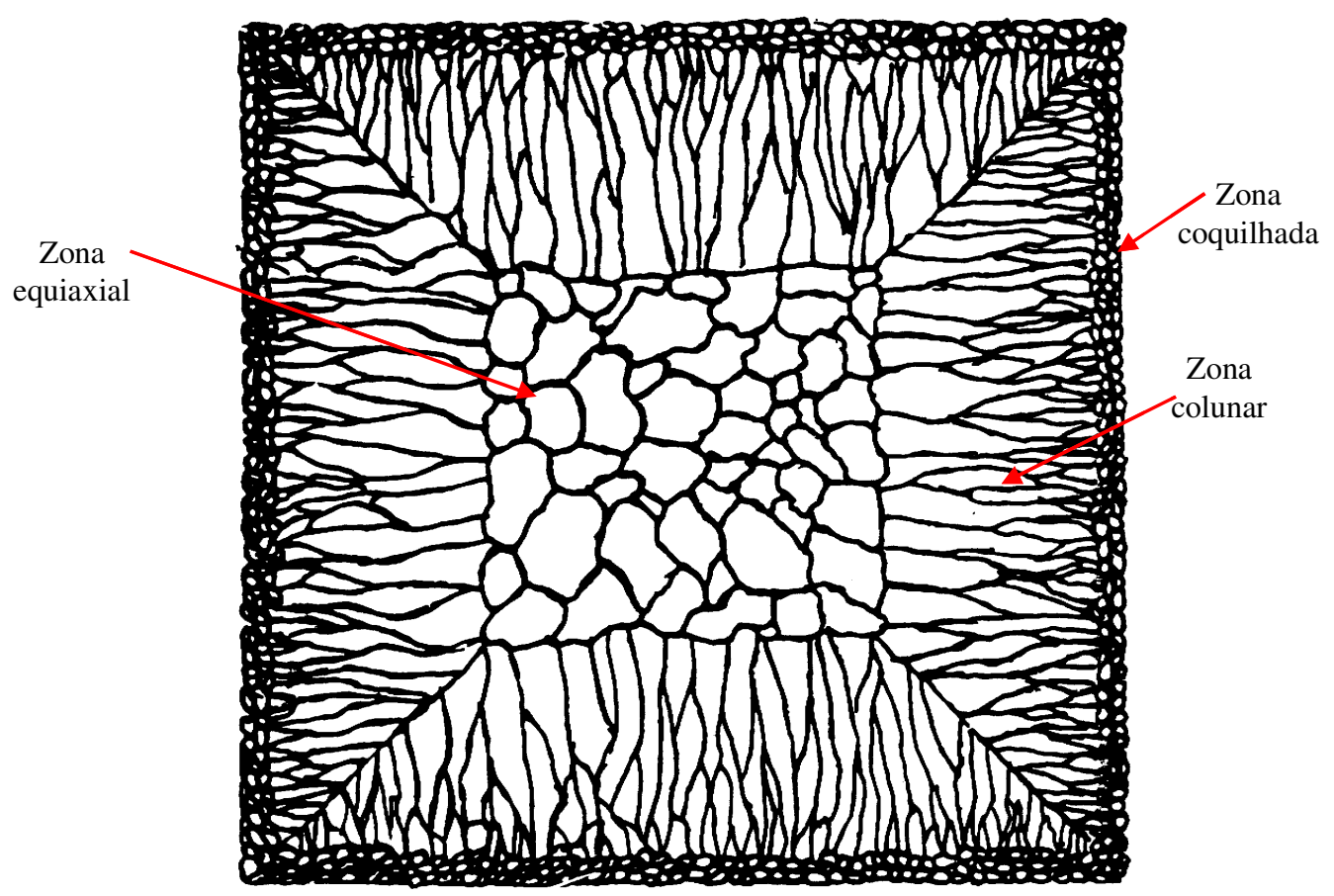

Figura 10- Representação das estruturas de grãos que podem ser encontradas após a solidificação de ligas metálicas (Bower; Flemings, 1967).

Nem sempre todas estas zonas estão presentes, mas se a estrutura bruta contiver grãos colunares e equiaxiais, a região de transição entre eles, chamada de transição colunar-equiaxial (CET), é geralmente estreita.

Durante a solidificação, a CET ocorre quando os grãos equiaxiais crescendo à frente da zona de crescimento colunar impõem certas condições que impedem o crescimento desta frente (Flood; Hunt, 1988). Ainda muito se discute sobre as circunstâncias em que ocorre o bloqueio do crescimento dos grãos colunares pelos grãos equiaxiais e, para isso algumas teorias foram formuladas: bloqueio do crescimento devido à existência de uma barreira mecânica criada pelos grãos equiaxiais, chamado bloqueio mecânico (Hunt, 1984); bloqueio devido a um campo de soluto ocasionado pelos grãos equiaxiais, chamado bloqueio de soluto (Martorano; Beckermann; Gandin, 2003); bloqueio devido a um campo térmico ocasionado pelos grãos equiaxiais, chamado bloqueio térmico (Mc Faden; Browne, 2006 e Banaszek et al., 2007). 
A aparição da zona equiaxial é dependente da nucleação e do crescimento de pequenos núcleos de grãos durante o resfriamento. Muitos autores propuseram mecanismos que tentam explicar a aparição desta zona. Os mecanismos propostos concordam no aspecto de que o crescimento dos núcleos dos grãos equiaxiais ocorre na região super-resfriada constitucionalmente, à frente da zona colunar. Entretanto, existem diferenças em relação aos mecanismos propostos para a origem dos grãos. Estes podem ser divididos em (Hutt; StJohn, 1998):

- Nucleação heterogênea na zona de super-resfriamento constitucional;

- Explosão de núcleos (“Big Bang”);

- Destacamento de braços de dendritas;

- Cristais cadentes;

- Teoria da Separação.

Estes mecanismos estão apresentados detalhadamente a seguir.

\subsubsection{Nucleação Heterogênea na Zona de Super-resfriamento Constitucional}

O mecanismo de nucleação heterogênea na zona de super-resfriamento constitucional foi, segundo Spittle (2006), inicialmente proposto por Northcott em 1938 e posteriormente por Winegard e Chalmers (1954) e baseia-se na idéia da ocorrência de nucleação adiante da frente de crescimento dos grãos colunares. Nesta região, a interface sólida rejeita soluto durante seu crescimento e cria uma camada mais rica em soluto na fase líquida, que tem sua temperatura liquidus diminuída. O perfil de super-resfriamento constitucional na região à frente da frente de crescimento é mostrado na Figura 11, juntamente com o perfil de concentração de soluto.

Quando o super-resfriamento constitucional ultrapassa o super-resfriamento crítico, ocorre a nucleação heterogênea de grãos sobre partículas de substratos presentes nesta região. O crescimento destes grãos impediria o avanço da frente colunar, ocasionando a transição colunar-equiaxial. Uma ilustração esquemática do mecanismo pode ser vista na Figura 12. 
Thomas e Spittle (1971) concluíram, através da observação da nucleação de sólido em uma solução de cloreto de amônio contida em um molde transparente, que a nucleação heterogênea no liquido super-resfriado era responsável pela formação da região equiaxial. Chalmers (1963), Southin (1967), Ohno e Soda (1970) e Ohno (1976) demonstraram após o isolamento mecânico do centro de um molde durante a fundição, que este mecanismo não seria o único responsável pelo crescimento equiaxial.

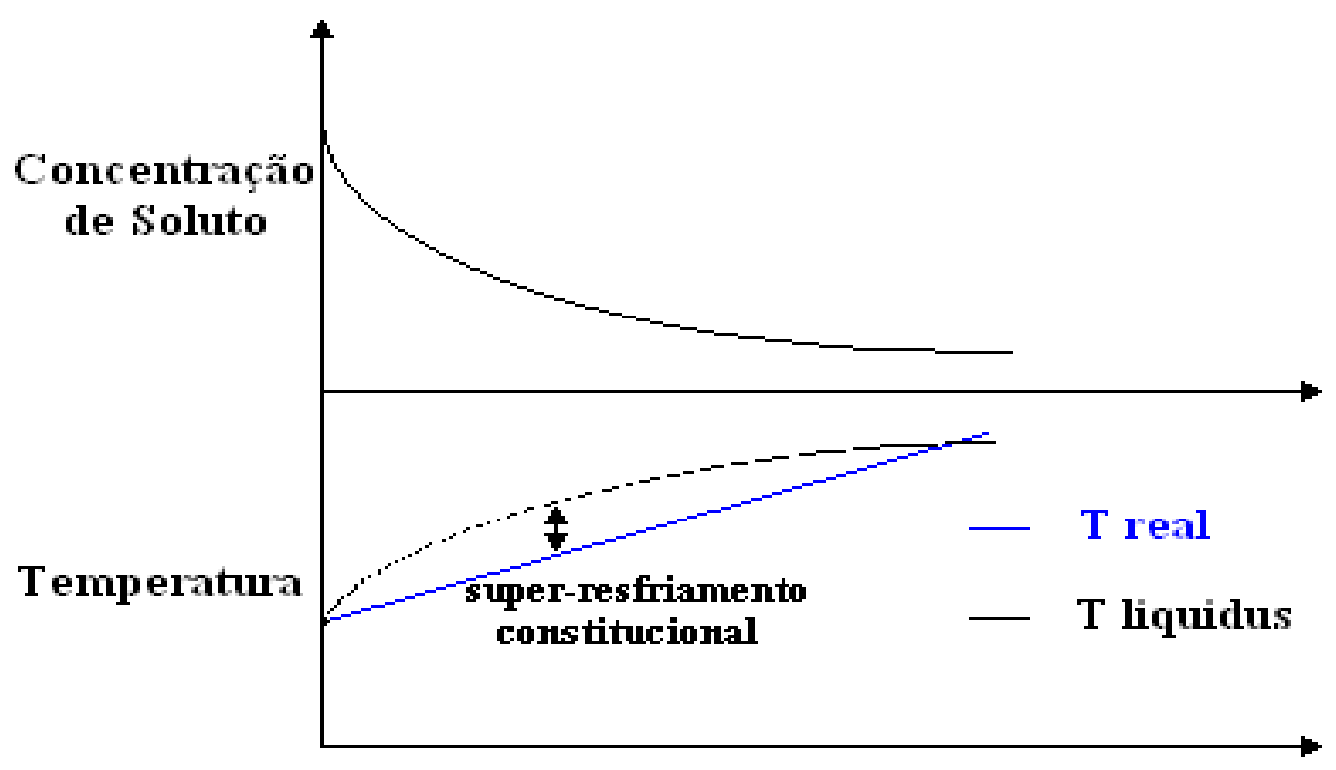

Distância da interface

Figura 11- Representação do campo de soluto e conseqüente super-resfriamento constitucional presentes na frente de crescimento. 


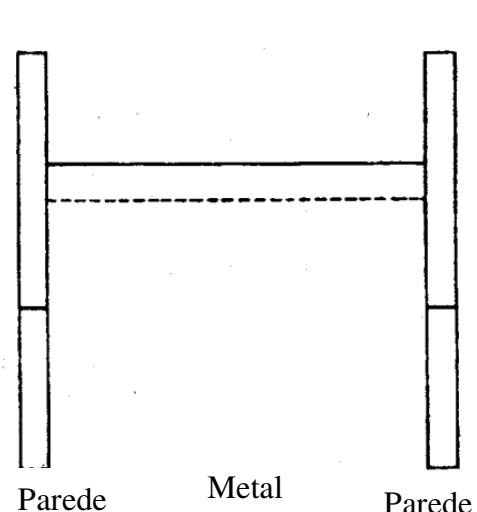

(a)

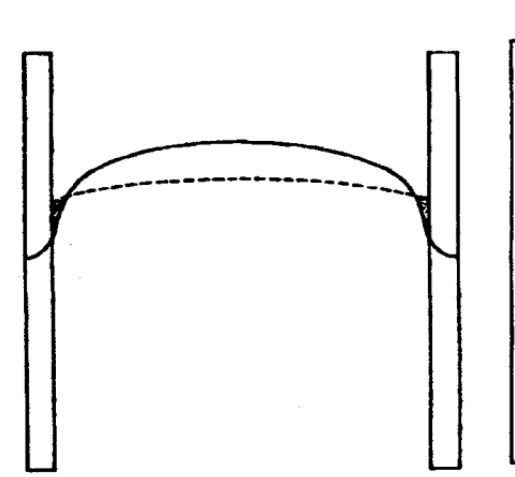

(b)

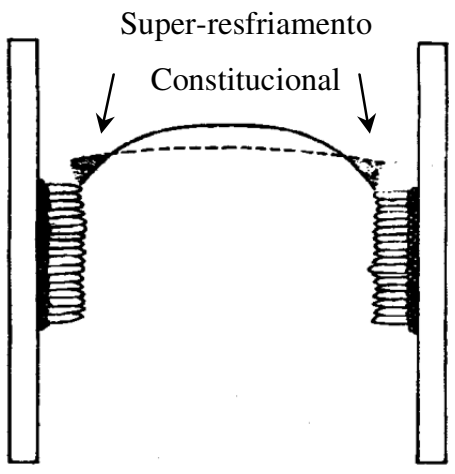

(c)

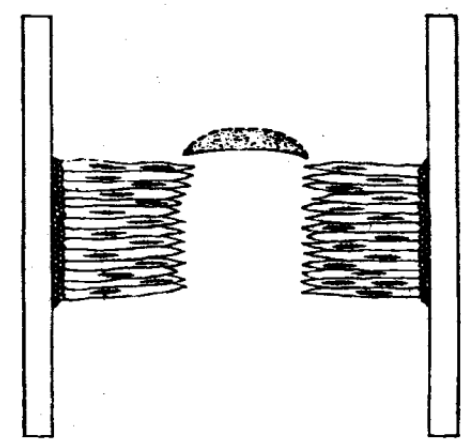

(d)

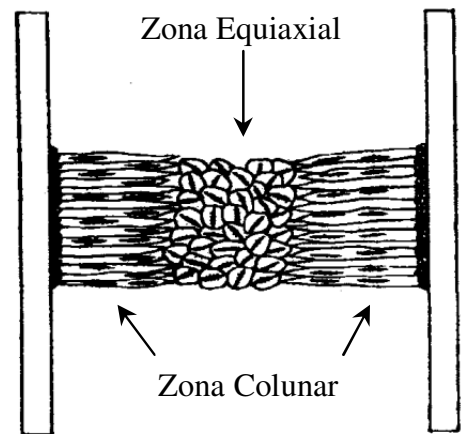

(e)

Figura 12 - Representação esquemática da teoria da nucleação heterogênea na zona de superresfriamento constitucional (Spittle, 2006).

\subsubsection{Explosão de Núcleos ("Big Bang”)}

O modelo de explosão de núcleos ("big bang") foi primeiramente proposto por Genders (1926) e desenvolvido por Chalmers (1964). Segundo este modelo, a nucleação dos grãos equiaxiais ocorre no líquido que é super-resfriado bruscamente junto à parede do molde durante o vazamento. Após sua formação, estes núcleos são carregados para o interior do molde pelas correntes de convecção no metal líquido e podem sobreviver até que o superaquecimento do metal líquido desapareça. A sobrevivência destes núcleos é mais provável com superaquecimentos do metal líquido menores.

Diferentemente da teoria do super-resfriamento constitucional, a teoria da explosão de núcleos ("big bang") utiliza os efeitos de superaquecimento e da convecção nos primeiros estágios da solidificação para explicar a formação dos grãos equiaxiais. Ao aumentar a temperatura de vazamento, há uma redução do 
tamanho da zona equiaxial e, ao reduzir a convecção através da introdução de um campo magnético estático, pode-se também eliminar a zona equiaxial (Flood; Hunt, 1988), confirmando o efeito destas variáveis.

Tarshis, Walker e Rutter (1971) realizaram experimentos com ligas de $\mathrm{Ni}-\mathrm{Cu}$ $(5,10,20$ e $30 \% \mathrm{Cu})$ em condições de resfriamento que produziram desde superresfriamentos relativamente altos $\left(290^{\circ} \mathrm{C}\right)$ a pequenos $\left(0^{\circ} \mathrm{C}\right)$ e, investigaram as macroestruturas das zonas equiaxiais formadas. Estes experimentos produziram uma estrutura refinada para super-resfriamentos relativamente altos ( $190^{\circ} \mathrm{C}$ a $\left.290^{\circ} \mathrm{C}\right)$ e pequenos $\left(0^{\circ} \mathrm{C}\right.$ a $\left.40^{\circ} \mathrm{C}\right)$. Os resultados demonstraram a existência de outro mecanismo para a formação da zona equiaxial, pois não houve uma correlação direta entre o valor do super-resfriamento e o refinamento da estrutura, demonstrado pela estrutura grosseira obtida somente para super-resfriamentos intermediários, como seria previsto pela teoria da explosão de núcleos ("big bang").

\subsubsection{Destacamento de Braços de Dendritas}

A teoria desenvolvida por Jackson et al. (1966) tornou-se uma das mais aceitas segundo Flood e Hunt (1988). Os autores observaram em soluções orgânicas que as correntes de convecção do líquido produziam um grande número de núcleos. Com isto, foi postulado que flutuações de temperatura, concentração e taxa de crescimento ocasionam uma refusão local fazendo com que os braços de dendritas se destaquem do tronco, rumando para o interior do líquido (Figura 13).

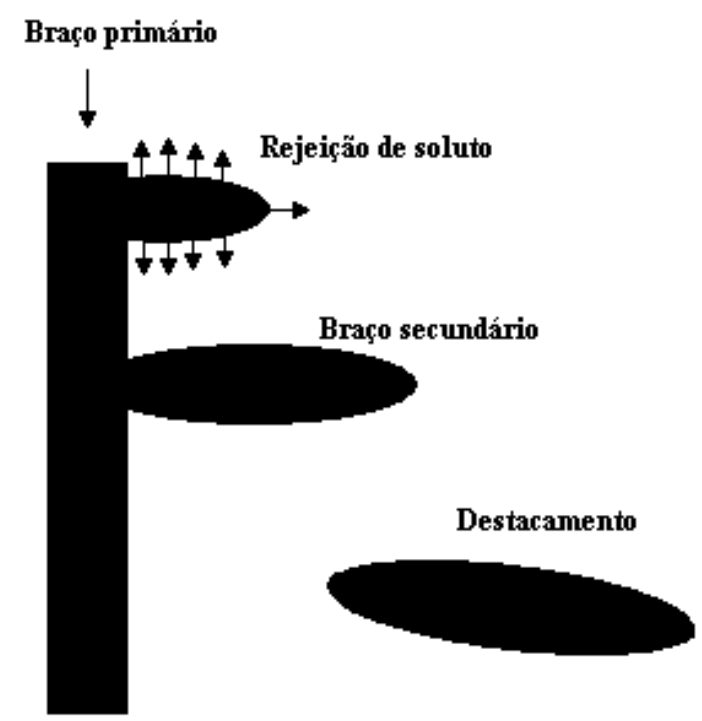

Figura 13- Crescimento e destacamento de braços de dendritas (Hutt; StJohn, 1998). 
A recalescência, tanto localmente ou por todo o molde, foi tida como o principal mecanismo de destacamento de braços de dendritas. A refusão seria promovida pelo aumento local da quantidade de soluto, causando uma diminuição no ponto de fusão do sólido.

O destacamento de braços de dendritas é consistente com a influência da convecção. Ao se reduzir a convecção mediante a aplicação de um campo magnético estático, reduz-se ou elimina-se a zona equiaxial. Contrariamente, ao se aumentar a convecção pela imposição de um campo magnético alternado, promovese a zona equiaxial, reduzindo a extensão da zona colunar.

Ohno, Motegi e Soda (1971), realizaram experimentos em ligas Sn-Bi, Sn$\mathrm{Pb}, \mathrm{Sn}-\mathrm{Sb}$ e Bi-Sn e afirmaram que a zona equiaxial é formada pelo crescimento e posterior separação dos cristais equiaxiais formados na superfície do molde. Este mecanismo ocorre antes mesmo da criação de uma camada de sólido e aproveita-se da convecção mais vigorosa do início do preenchimento.

\subsubsection{Cristais Cadentes}

Southing (1967) realizou experimentos com alumínio e ligas de alumínio com até $2 \%$ de cobre e através de observações das macroestruturas propôs a existência de um novo mecanismo gerador da CET. Segundo o autor, a transferência de calor por radiação na superfície do lingote era a responsável pelo aparecimento de um super-resfriamento nesta região e, conseqüentemente, pela aparição de grãos equiaxiais que seriam responsáveis pela CET.

Desta forma, o modelo de cristais cadentes prevê que a estrutura equiaxial responsável pelo bloqueio do avanço da frente colunar é formada quando dendritas da superfície do lingote decantam no líquido em direção à frente de crescimento colunar. Com o aquecimento da superfície superior do lingote durante a solidificação, Southing (1967) demonstrou o desaparecimento da zona equiaxial, reforçando a sua teoria. 


\subsubsection{Teoria da Separação}

Ohno (1971) afirmou que os mecanismos inerentes à sua Teoria da Separação são os responsáveis pela formação da zona equiaxial. Segundo esta teoria, os núcleos que se formam sobre a parede do molde têm um crescimento mais expressivo ao longo desta superfície, em um primeiro momento. Posteriormente, devido à rejeição de soluto e à impermeabilidade do molde, o crescimento ao longo da superfície se torna inexpressivo. Este fato é explicado pelo acúmulo de soluto junto ao molde, diminuindo assim a velocidade de crescimento nesta região (Figura 14). Devido ao formato destes grãos, estes são facilmente arrancados da superfície do molde, migrando para o interior e posteriormente originando a região equiaxial.
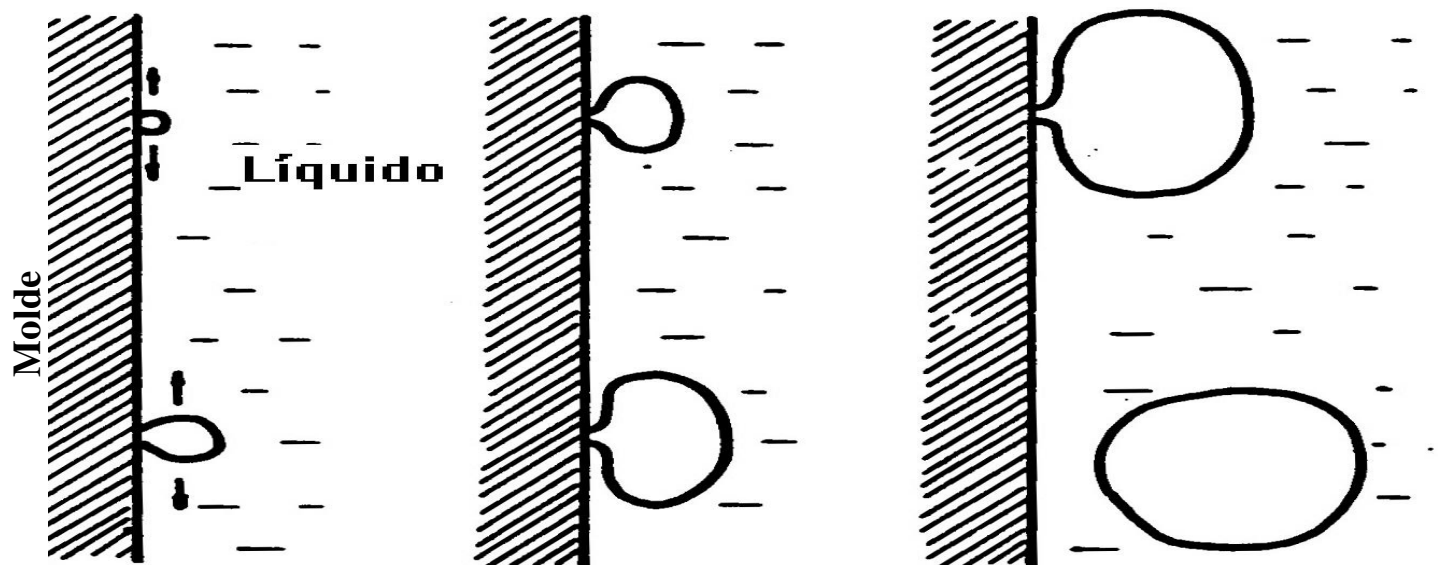

Figura 14- Representação esquemática do crescimento e destacamento de grãos segundo a teoria da separação (Ohno, 1975).

Ohno (1987) realizou uma série de experimentos como uma resposta aos pesquisadores que, apesar de acharem sua teoria válida, acreditavam que o mecanismo realmente importante era o destacamento de braços de dendritas. Ohno, Motegi e Soda (1971), afirmaram que os grãos observados tinham sua origem no desprendimento de grãos da parede do molde e não no destacamento dos braços das dendritas, apresentando o seu mecanismo como o maior responsável pela formação da zona equiaxial.

Segundo a teoria da separação, Ohno e Motegi (1983) explicaram a influência de fatores como: inoculantes, tipo de molde, movimentação do líquido e temperatura de vazamento na estrutura final de solidificação. 


\subsection{Modelos Matemáticos para a Transição Colunar-Equiaxial}

Atualmente, é muito importante que se tenha um controle da estrutura metalúrgica dos materiais fundidos, sendo que uma estrutura formada por pequenos grãos equiaxiais geralmente apresenta melhores propriedades mecânicas. Os modelos matemáticos podem auxiliar na previsão e controle da formação da estrutura bruta de solidificação, fornecendo as condições de processamento necessárias à obtenção da estrutura desejada.

Os modelos matemáticos existentes podem ser divididos em estocásticos ou determinísticos, sendo que os modelos matemáticos estocásticos diferenciam-se dos determinísticos por possuírem algum tipo de variável aleatória em alguma de suas etapas de cálculo. Os modelos estocásticos acompanham a nucleação e o crescimento de cada grão, simulando assim a macroestrutura e conseqüentemente a CET. A primeira proposta de modelos estocásticos baseados no método de Monte Carlo foi feita por Spittle e Brown (1989a, 1989b) e será descrita a seguir juntamente com as propostas subseqüentes.

Posteriormente serão descritos os modelos determinísticos que se caracterizam pela utilização de equações determinísticas, ou seja, que não envolvem variáveis aleatórias. Estas equações são solucionadas nas escalas micro e macroscópica e não procuram simular os grãos individualmente, mas sim de forma média.

\subsubsection{Modelos Estocásticos}

\subsubsection{Modelos estocásticos precursores}

Spittle e Brown (1989a, 1989b) foram os precursores na criação de um modelo estocástico baseado no método de Monte Carlo. Neste modelo, dividiu-se a peça fundida em pequenos triângulos eqüilaterais, os quais os autores denominaram sítios. Estes sítios representavam locais possíveis para a formação dos núcleos da fase sólida. Neste modelo foram levadas em conta as orientações cristalográficas, apenas para diferenciar grãos vizinhos, e a explosão de núcleos ("big bang") como único mecanismo de nucleação considerado. 
No modelo também se simulou aproximadamente o efeito de convecção do líquido na movimentação da fase sólida. Após a verificação da condição de solidificação de um sítio, que foi selecionado de forma aleatória entre todos, o modelo realocava este sítio aleatoriamente pela peça, simulando a convecção. $O$ crescimento do sítio, representando a solidificação, era definido com base em um balanço energético que caso fosse negativo tornava o sítio sólido através da associação de um número diferente de 0 .

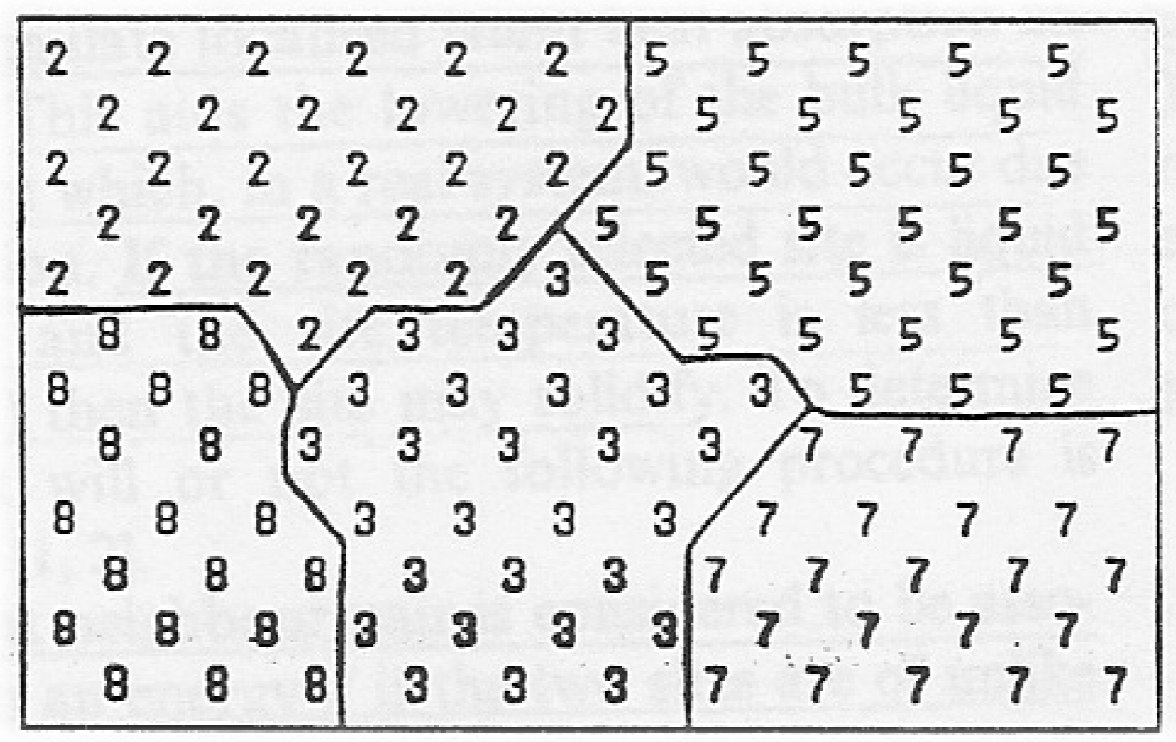

Figura 15 - Representação dos grãos no método de Monte Carlo (Spittle; Brown, 1989b)

Os autores (Spittle; Brown, 1989a; 1989b) verificaram a influencia do superaquecimento, temperatura inicial do molde, composição da liga, coeficiente de partição e inclinação da linha liquidus. Um exemplo da estrutura de solidificação prevista pelo modelo pode ser visto na Figura 16. 


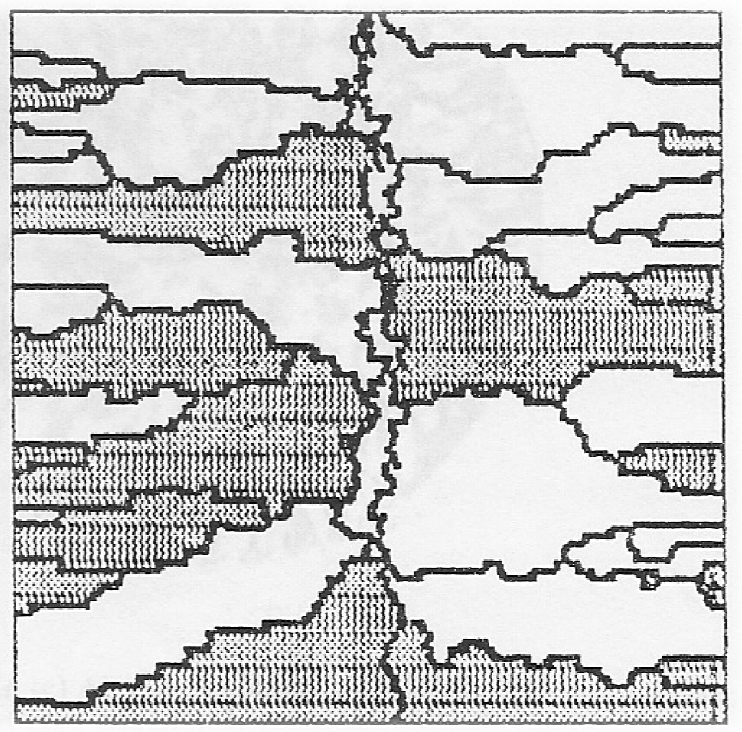

Figura 16 - Exemplo de estrutura calculada pelo Método de Monte Carlo (Spittle; Brown, 1989b).

Entretanto, o método não permitiu a simulação de estruturas que pudessem ser comparadas com estruturas reais devido à ausência de uma relação clara entre o tempo de simulação para o crescimento de cada sítio e o tempo real. Rappaz e Gandin (1993), no intuito de sanar este problema, propuseram um modelo baseado na técnica do autômato celular (CA - "Cellular Automaton"), que será descrita a seguir.

\subsubsection{Modelos de autômato celular na escala mesoscópica}

A técnica do autômato celular é um algoritmo construído com o intuito de simular a evolução temporal/espacial de um sistema através da utilização de regras simples de transformação de sítios de uma matriz (Raabe, 1998), que é uma malha de pontos fixos. Esta matriz é utilizada para mapear alguns parâmetros importantes do sistema, como partículas atômicas, grãos e etc. Cada sítio da matriz tem um estado, dentre uma série de estados possíveis, que representa uma informação importante a respeito do fenômeno em estudo. No caso da modelagem de uma estrutura de grãos de um material, os sítios podem ter um número representando a orientação cristalográfica de um grão e, uma imagem da estrutura de grãos pode ser obtida a partir dos estados e posições de todos os sítios. 
Nesta técnica, o estado inicial de todos os sítios é conhecido e a evolução temporal deste é calculada para cada passo de tempo utilizando-se regras de transformação baseadas no estado de cada sítio e de seus vizinhos e, algumas vezes, também em função de parâmetros como temperatura e concentração.

Este tipo de abordagem, através da utilização da técnica do autômato celular, é muito utilizado em diferentes áreas da ciência dos materiais, pois possibilita o cálculo da evolução da macroestrutura e conseqüentemente a macroestrutura final.

Rappaz e Gandin (1993) propuseram um modelo estocástico baseado na técnica do autômato celular (CA - "Cellular Automaton") onde a região de simulação era dividida em pequenos quadrados, chamados de células. Os autores simularam a nucleação heterogênea através da distribuição de substratos na malha de células. Os substratos apresentavam um super-resfriamento crítico para nucleação que estavam distribuídos segundo uma distribuição normal (item 3.1.5). Quando este super-resfriamento crítico era ultrapassado para um determinado substrato, ocorria a formação de um núcleo de sólido na célula onde este substrato estava localizado.

Como pode ser visto no item 3.1.5, a distribuição normal de superresfriamentos críticos é construída a partir de três parâmetros: o super-resfriamento médio ( $\left.\Delta T_{n u c}\right)$, o desvio padrão $\left(\Delta T_{\sigma}\right)$ e a densidade de número de substratos $\left(n_{\max }\right)$, que será igual à densidade máxima possível de número de grãos caso no máximo um único grão possa se formar sobre um substrato. Dois conjuntos de parâmetros diferentes foram utilizados: um para o interior da cavidade do molde e outro para a superfície. De acordo com este modelo, o número de novos núcleos formados por unidade de volume $(\delta n)$ após um decréscimo de temperatura $(\Delta T)$ é dado por:

$$
\delta n=\int_{T}^{T-\Delta T}\left[\frac{d n}{d(\Delta T)}\right] \cdot d(\Delta T)
$$

Desta forma, a partir do super-resfriamento, $\Delta T$, é possível calcular o aumento da densidade de número de núcleos, $(\delta n)$, que multiplicado pelo volume da região simulada, resulta no número de núcleos que devem ser distribuídos.

A distribuição dos núcleos ao longo da malha de células é feita aleatoriamente. Primeiramente calcula-se o número de núcleos que devem ser 
distribuídos devido ao aumento do super-resfriamento; com este valor calcula-se uma probabilidade de nucleação, $p_{V}$, através da equação [19]. A cada célula associa-se um número, $r_{V}$, escolhido aleatoriamente. Finalmente, a nucleação de uma célula ainda líquida ocorre se $r_{V}$ for menor ou igual a $p_{V}$.

$$
p_{V}=\delta n V_{C A}
$$

onde $V_{C A}$ é o volume da célula.

A orientação cristalográfica associada ao grão nucleado em uma célula é escolhida aleatoriamente entre 48 classes englobando orientações de $-45^{\circ}$ a $45^{\circ}$. Após a nucleação, um quadrado é associado à célula. Este quadrado, chamado de quadrado de crescimento, representa um grão dendrítico e possui uma orientação cristalográfica definida pelo ângulo entre suas diagonais e o eixo horizontal x. Estas diagonais representam as direções cristalográficas [10] e [01].

Os quadrados crescem mediante 0 incremento dos seus lados e, conseqüentemente, encontram os centros das células vizinhas. Neste instante, as células vizinhas são "ativadas" e a elas associa-se um quadrado de crescimento com a mesma orientação da célula que a ativou.

Em um trabalho posterior, Gandin e Rappaz (1994) apresentaram um modelo que consistia de uma parte macroscópica responsável pelo cálculo da transferência de calor e uma parte mesoscópica para o cálculo do crescimento, da nucleação e da liberação do calor latente de solidificação. Este modelo foi denominado CAFE ("Cellular Automaton Finite Element”). A nucleação foi simulada e novamente através de uma distribuição normal de super-resfriamentos críticos para a nucleação.

A transferência de calor foi tratada através da solução numérica da equação diferencial de transferência de calor pelo método dos elementos finitos, utilizando-se uma malha de elementos triangulares. As etapas de crescimento e de nucleação foram tratadas pelo método do autômato celular (CA) semelhante ao utilizado no modelo anterior.

Neste trabalho, os autores (Gandin; Rappaz, 1994) melhoraram o método do CA para modelar situações que envolviam gradientes de temperatura. Neste modelo, associou-se um quadrado de crescimento à célula ativada por nucleação, 
mas associaram-se retângulos de crescimento às células por ele ativadas, como mostrado na Figura 17. Observa-se que este processo mantém a orientação original do grão sem a necessidade das constantes correções realizadas no modelo anterior (Rappaz; Gandin, 1993).

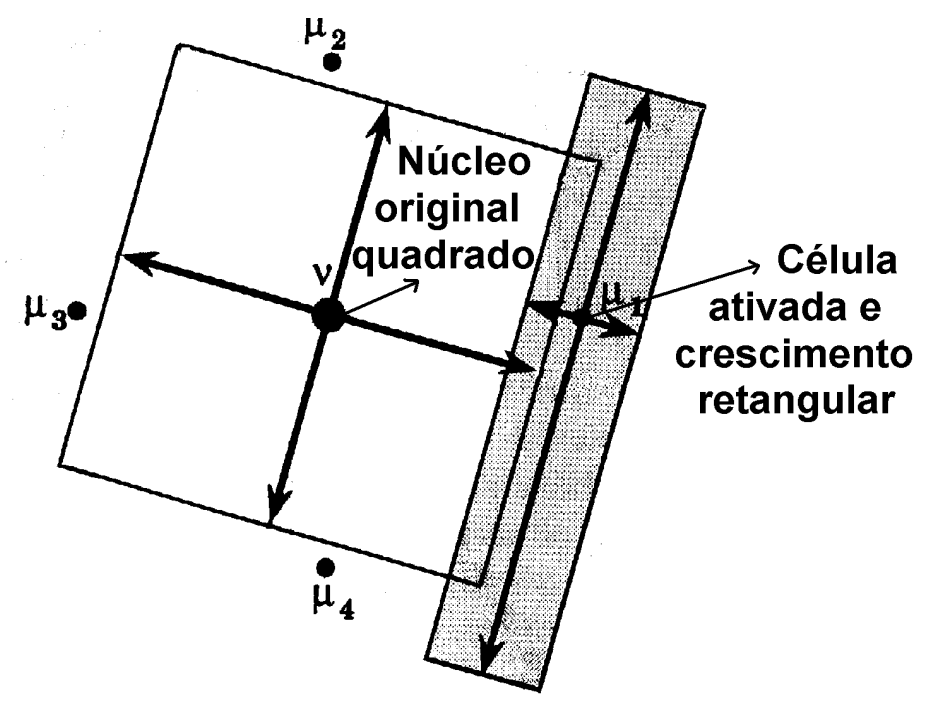

Figura 17- Modelo de CA onde se utiliza o retângulo de crescimento.

Primeiramente, o novo modelo foi testado e certificado quanto à sua capacidade de simular o crescimento de um envelope dendrítico sem alterações em sua orientação. Posteriormente, algumas simulações foram comparadas com experimentos realizados, mostrando uma boa aderência. Gandin, Schaefer e Rappaz (1996) ainda validaram o crescimento do autômato celular mediante a comparação de seus resultados com os de um modelo analítico.

Gandin, Charbon e Rappaz (1995) utilizaram o modelo proposto anteriormente (Gandin; Rappaz, 1994) para simular a nucleação e o crescimento dos grãos equiaxiais, e introduziram também a nucleação e o crescimento de grãos eutéticos através de outro modelo. Neste modelo, os autores alteraram o formato do envelope do grão, que passou a ser circular, e utilizaram um método para acompanhar a interface do grão. A velocidade normal de crescimento da interface passou a depender do super-resfriamento local.

O modelo desenvolvido por Gandin e Rappaz (1994) foi utilizado por Rappaz et al. (1996) para prever a estrutura de grãos formada na fabricação de pás de turbinas, na solda por laser e no lingotamento contínuo. 
Cho e Hong (1997) aplicaram o modelo do autômato celular para a previsão da macroestrutura de grãos em uma solidificação direcional e os resultados foram comparados com dados experimentais de uma liga $\mathrm{Al}-4,5 \% \mathrm{Cu}$. Os resultados apresentaram uma boa aderência. Os autores também compararam resultados do gradiente de temperatura e da velocidade de crescimento com um modelo determinístico, sendo que os últimos resultados analisados não apresentaram uma boa aderência.

Gandin e Rappaz (1997), estenderam o modelo de envelope retangular, implementado em duas dimensões, para simulações em três dimensões. As características deste modelo são semelhantes às do anterior; havendo apenas uma modificação na técnica do CA, simplificando sua implementação para situações em três dimensões. Neste CA, associa-se a todas as células ativadas um quadrado de crescimento que representa o envelope dendrítico (duas dimensões). O quadrado de crescimento associado à célula ativada por nucleação possui o seu centro coincidente com o centro do quadrado de crescimento. As células são ativadas e os seus quadrados de crescimento são arranjados para manter a orientação do quadrado inicial (Figura 18) e, desta forma, os centros dos quadrados de crescimento passam a não coincidir com o centro de suas células. O modelo foi testado em condições de temperaturas uniformes para examinar e validar o novo método de crescimento.

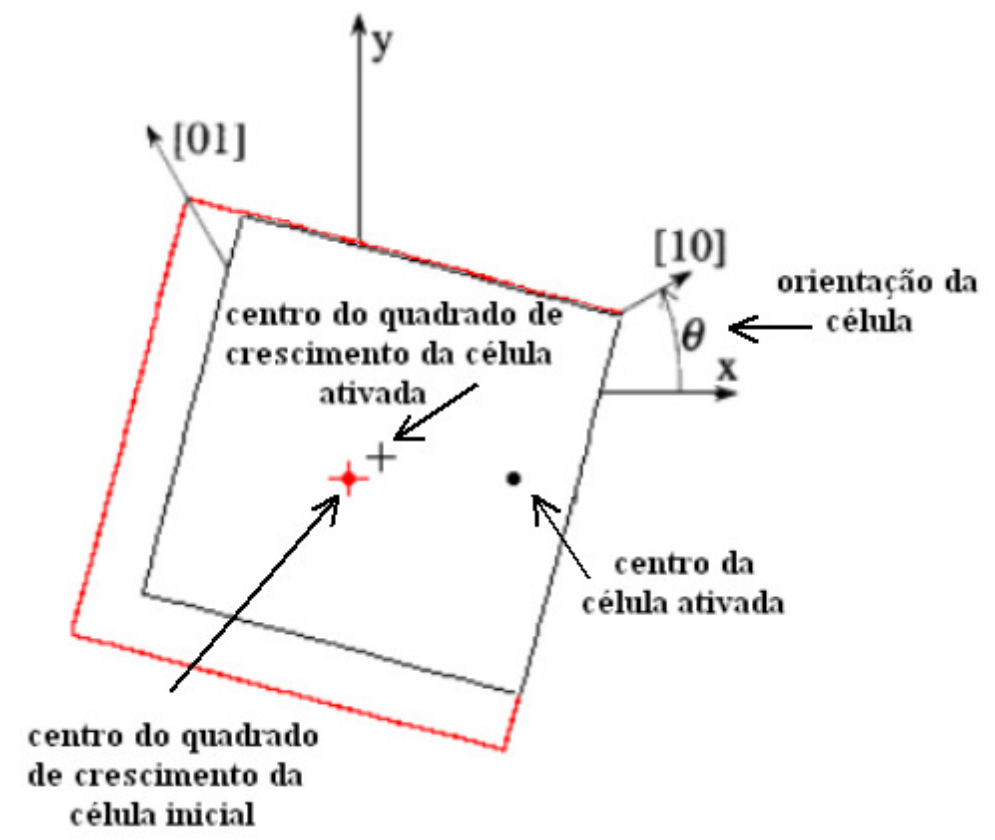

Figura 18- Modelo de CA onde o centro de crescimento não coincide com o centro da célula. 
Lee e Hong (1997) utilizaram o autômato celular para simular as macroestruturas resultantes de um processo de "melt spinning" e verificaram o efeito dos parâmetros do processo, obtendo uma boa aderência com experimentos realizados com uma liga $\mathrm{Al}-\mathrm{Cu}$.

Com o intuito de simular a convecção do líquido, Lee, Lee e Hong (2000) incluíram a resolução da equação da continuidade e de Navier-Stokes no modelo de CA. Os autores (Lee; Lee; Hong, 2000) utilizaram este modelo para calcular o efeito da deflexão dos grãos em crescimento sob o efeito de um fluxo de metal líquido (Al$\mathrm{Cu}$ ). Investigaram também o efeito da concentração de $\mathrm{Cu}$ da liga, o efeito dos parâmetros de nucleação e o efeito da velocidade do metal líquido. Os resultados obtidos foram comparados com resultados experimentais e apresentaram certa discrepância que, segundo os autores, se deve à negligência quanto à permeabilidade dos grãos colunares ao fluido.

Takatani, Gandin e Rappaz (2000) utilizaram um modelo tridimensional de CA baseado em octaedros descentrados e simularam o efeito da movimentação do líquido na estrutura final de grãos. Neste modelo o envelope dendrítico é representado em três dimensões por um octaedro onde, diferentemente do modelo de Gandin e Rappaz (1997), levou-se em conta a velocidade do fluido no crescimento de cada uma de suas diagonais. Desta forma o novo modelo utilizou octaedros irregulares para construir o envelope dendrítico mostrado na Figura 19. Os autores observaram uma boa aderência da estrutura final de uma simulação com macroestruturas obtidas experimentalmente.

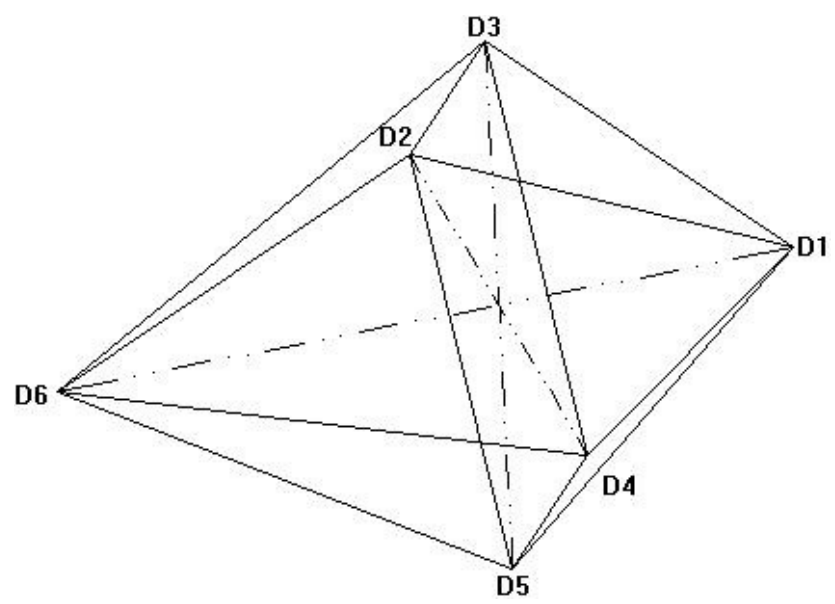

Figura 19- Esquema do envelope dendrítico (octaedro irregular) com suas seis diagonais (D1 a D6) no modelo do CA em três dimensões. 
No modelo criado por Cho, Okane e Umeda (2001), a nucleação foi simulada utilizando-se uma distribuição normal de super-resfriamentos críticos para a nucleação. Igualmente a Gandin e Rappaz (1994), utilizaram-se parâmetros diferentes para as regiões adjacentes à parede do molde e localizadas no interior de sua cavidade. A transferência de calor (parte macroscópica) foi tratada pelo método das diferenças finitas "diretas" (DFD) e o crescimento dos grãos pela técnica do autômato celular, como conduzido por Gandin e Rappaz (1994). Os autores (Cho; Okane; Umeda, 2001) denominaram o modelo de CA-DFD.

Estes autores realizaram diversos testes com o modelo, analisando os efeitos dos seguintes parâmetros que definem a distribuição de super-resfriamentos para a nucleação: (a) densidade total de número de substratos $n_{\max }$; (b) desvio padrão da distribuição $\Delta T_{\sigma}$ e (c) super-resfriamento médio $\Delta T_{\text {nuc }}$. Os resultados indicaram que:

a) Um aumento na densidade de substratos na superfície aumenta o número de grãos colunares, porém não afeta 0 número de grãos equiaxiais;

b) Um aumento na densidade do número de substratos no interior do molde aumenta o número de grãos e, conseqüentemente, diminui o tamanho médio dos grãos equiaxiais;

c) O super-resfriamento médio no interior do molde tem uma grande influência no tipo de estrutura, tornando a estrutura desde totalmente colunar até totalmente equiaxial com a sua variação;

d) O desvio padrão da distribuição de super-resfriamentos na superfície não tem grande influência sobre a macroestrutura;

e) O desvio padrão da distribuição de super-resfriamentos no interior da cavidade do molde exerce influências no comprimento da zona colunar, no tamanho dos grãos equiaxiais e na homogeneidade destes.

Vandyoussefi e Greer (2002) utilizaram o modelo de Gandin e Rappaz (1994) para simular o processo Bridgman de solidificação, mas consideraram a ocorrência da nucleação apenas no interior da cavidade do molde com a utilização do modelo de distribuição normal para nucleação. Os autores analisaram a influência 
da liberação do calor latente de solidificação na macroestrutura e nas curvas de resfriamento e fração de sólido. Examinaram também o efeito da quantidade de inoculante e dos parâmetros do processo nas macrografias obtidas. Comparações com os resultados experimentais obtidos para a liga $\mathrm{Al}-4,15 \% \mathrm{Mg}$ mostraram boa aderência.

Guillemot et al. (2004), alteraram o acoplamento existente no modelo de Gandin e Rappaz (1997) pois, segundo estes autores, o acoplamento existente era "fraco" uma vez que a evolução da fração de sólido não influenciava as curvas de resfriamento. Ainda segundo os autores, o acoplamento existente provocava uma liberação excessiva de calor latente no momento da ativação de uma célula do CA durante o crescimento.

Liu et al. (2006) construíram um modelo estocástico em duas dimensões para a previsão da CET durante a solidificação de grandes lingotes das ligas de Ti contendo de 45 a 48\% de Al. As equações macroscópicas de transferência de calor foram solucionadas pelo método das diferenças finitas (FDM) e para solução dos aspectos microscópicos de nucleação e crescimento, utilizou-se o CA através de uma técnica aproximada.

Os autores definiram o comprimento da zona colunar como sendo igual ao comprimento médio dos grãos colunares que crescem perpendicularmente à superfície do molde. A posição da CET foi assumida igual ao comprimento da zona colunar. Os resultados foram comparados com experimentos realizados e, após validação do modelo, os autores investigaram a influência de algumas variáveis de fundição na posição da CET.

\subsubsection{Modelos de autômato celular na escala microscópica}

Nos últimos anos, os diferentes modelos baseados na técnica do CA que foram propostos apresentaram algumas características comuns, porém distintas das características dos modelos apresentados no subitem anterior. Nos modelos mais recentes, simularam-se fenômenos que ocorrem na escala de tamanho da distância entre os braços de dendrita (escala microscópica), enquanto nos modelos anteriores simularam-se fenômenos com escalas de tamanho da ordem do tamanho de grão (escala mesoscópica). 
Ravindran, Brown e Spittle (1999) utilizaram um modelo de CA em três dimensões para simular dendritas equiaxiais e colunares. Os autores relacionaram a fração de sólido e o tipo de estrutura dendrítica com a condutividade térmica efetiva da zona pastosa.

Pode-se verificar a diferença de escalas de tamanho entre as simulações realizadas pelos modelos de escala microscópica e mesoscópica, comparando-se as imagens resultantes do modelo de Ravindran, Brown e Spittle (1999), apresentadas na Figura 20 e aquela de um modelo estocástico apresentada na Figura 16.

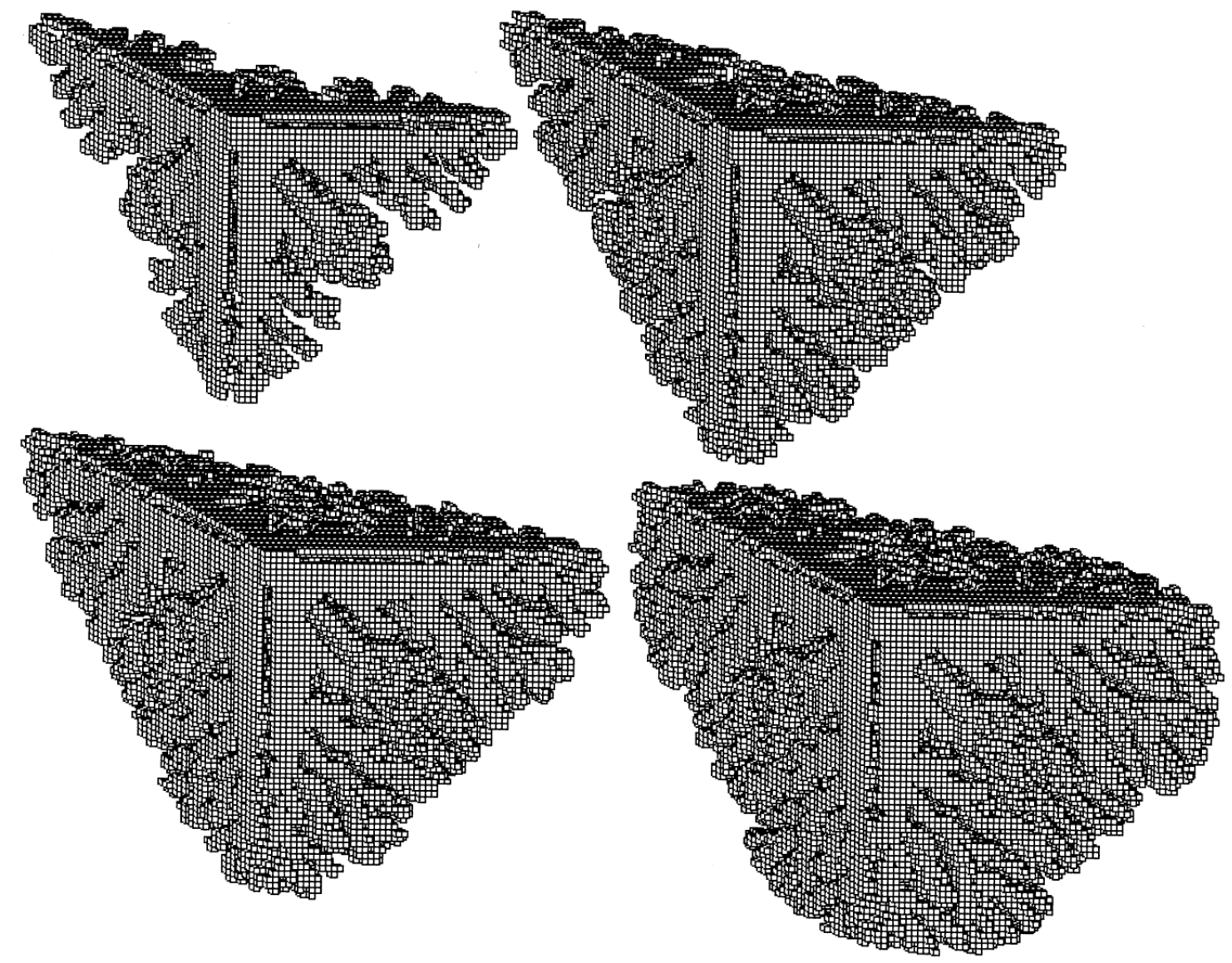

Figura 20 - Microestrutura típica calculada pelo modelo de Ravindran, Brown e Spittle (1999).

A modelagem da solidificação de uma liga ternária multifásica (Al-3,955Cu0,8Mg) foi apresentada por Jarvis, Brown e Spittle (2000a e 2000b). Estes autores utilizaram o CA para modelar o crescimento de uma dendrita colunar em considerando a transferência de calor unidimensional (Jarvis; Brown; Spittle, 2000a), bidimensional (Jarvis; Brown; Spittle, 2000a e 2000b) e tridimensional (Jarvis; Brown; Spittle, 2000a), obtendo o espaçamento dos braços secundários e a variação da 
fração de sólido com a temperatura. Os resultados (Jarvis; Brown; Spittle, 2000a) não concordaram com dados experimentais apresentados. A discrepância foi atribuída aos erros experimentais e as propriedades da liga utilizadas na simulação.

Zhu e Hong (2001) propuseram um modelo de CA microscópico chamado de CA modificado (MCA) onde a redistribuição e a difusão de soluto no líquido e no sólido foram consideradas. Neste novo modelo, diferentemente do modelo autômato celular (Rappaz; Gandin, 1993), os quadrados em crescimento não mais representam um envelope que envolve a rede dendrítica; neste caso foram utilizados para representar o sólido e conseqüentemente delimitar a interface sólido-líquido.

Este modelo é suficientemente refinado para reproduzir tanto o crescimento de braços de dendritas como também dos grãos. Testes realizados com ligas $\mathrm{Al}-\mathrm{Cu}$ mostraram boa aderência entre as estruturas calculadas e simuladas. Em um trabalho posterior Zhu e Hong (2002) estenderam este mesmo modelo para simulações em três dimensões. Zhu, Kim e Hong (2001) utilizaram o MCA para simular o crescimento de dendritas em uma liga $\mathrm{Al}-7 \% \mathrm{Si}$, observando boa aderência a dados experimentais.

Shin e Hong (2002) desenvolveram um modelo do tipo autômato celular modificado com uma interface difusa, ou seja, considerou-se uma variação gradual da fração de sólido na interface. Os autores modelaram a difusão de soluto e a movimentação do fluido e investigaram o comportamento da deflexão nos braços de dendrita de uma liga $\mathrm{Al}-\mathrm{Cu}$.

Brown et al. (2002), utilizaram o modelo de CA microscópico apresentado anteriormente por Jarvis, Brown e Spittle (2000a) para determinar a permeabilidade de um grão durante alguns estágios do crescimento dendrítico, observando boa aderência a dados experimentais.

Wang, Jin e Zheng (2002) desenvolveram um modelo a partir da união do modelo de CA e de Monte Carlo considerando o cálculo da rejeição de soluto. Os autores realizaram simulações e experimentos de solidificação com uma liga Al$4,5 \% \mathrm{Cu}$ em um molde de cobre refrigerado à água. Os resultados se mostraram concordantes.

Wang, Lee e McLean (2003) apresentaram um modelo para simular a influência da difusão de soluto na solidificação de ligas binárias. O campo de soluto 
foi calculado pelo método das diferenças finitas utilizando uma malha que possuía o mesmo tamanho da malha de CA. Os autores incluíram o efeito da curvatura e do super-resfriamento constitucional no crescimento dos quadrados descentrados. Diferentemente do modelo de Rappaz e Gandin (1997), neste modelo os quadrados representam a interface sólido-líquido, ou seja, há somente sólido no interior do quadrado. O modelo foi utilizado para investigar: a influência da densidade de nucleação na base; o efeito da taxa de solidificação e a influência de perturbações nesta taxa, sempre com relação à estrutura resultante da solidificação direcional.

Beltran-Sanchez e Stefanescu (2003) modificaram o modelo do CA calculando a velocidade da interface sólido/líquido a partir do campo de soluto e da condição de Stefan em lugar da equação para crescimento dendrítico proposta por Lipton, Glicksman e Kurz, (1984).

Dong, Yang e Lee (2004), propuseram um modelo de CA para investigar a influência do gradiente térmico e da velocidade de crescimento na ocorrência da CET. O modelo simulou o campo de concentração de soluto na frente de crescimento e a influência deste nos braços primários secundários e terciários. Os autores calcularam um mapa para a ocorrência da CET em função do gradiente de temperatura e da velocidade de crescimento.

Posteriormente Dong e Lee (2005) incorporaram ao modelo de Wang, Lee e McLean (2003) um modelo de nucleação que utiliza uma distribuição normal de super-resfriamentos críticos para nucleação no interior do domínio, a fim de, simular a CET durante a solidificação direcional de ligas Al-Cu. Os autores impuseram um gradiente de temperatura constante e uma velocidade também constante para a movimentação das isotermas e investigaram a existência ou não da CET de acordo com um método, no qual, o bloqueio de mais da metade dos grãos colunares pelos grãos equiaxiais indicava a existência da CET.

\subsubsection{Modelos Determinísticos}

Um dos primeiros modelos determinísticos propostos para a previsão da formação da estrutura de grãos é atribuído à Oldfield (1966), onde um modelo para o crescimento de células eutéticas microscópico e um modelo para a previsão da nucleação das mesmas foram acoplados a um modelo de transferência de calor 
macroscópico resultando em um modelo chamado micro-macroscópico. Fortes simplificações foram assumidas, tais como: presença somente de grãos equiaxiais, grãos esféricos (não dendríticos) e um sistema isotérmico (temperatura uniforme). Os modelos determinísticos foram evoluindo ao longo do tempo e com isso, muitas das simplificações foram eliminadas e importantes fenômenos para a formação da estrutura bruta de solidificação passaram a ser considerados. Maxwell e Hellawell (1975) e Greer et al. (2000) incorporaram outros modelos de nucleação heterogênea para grãos esféricos a fim de prever os tamanhos finais de grãos, porém apesar de não considerarem o crescimento eutético assumiram que o grão dendrítico era uma esfera sólida.

Posteriormente, de acordo com Thévoz, Desbiolles e Rappaz (1989), em 1986 Dustin e Kurz passam a assumir que o grão dendrítico não era totalmente sólido e para isso propuseram uma fração de sólido interna ao grão constante e diferente de 1. Rappaz e Thévoz (1987a) apresentaram um modelo considerando nucleação instantânea, o crescimento dendrítico e a rejeição do soluto, e o utilizaram para prever a recalescência presente nas curvas de resfriamento, porém o sistema era isotérmico. O modelo apesar de simular o crescimento dendrítico não previa a complicada interface dos grãos dendríticos com a fase líquida, pois considerava uma esfera imaginária ao redor do grão dendrítico que tocava as pontas dos braços dendríticos (envelope de grão esférico) e delimitava uma região de fase líquida externa ao envelope, chamada de líquido livre, e as fases sólida e líquido interdendrítico internas à esfera. Este modelo foi então comparado com dados experimentais de temperatura em função do tempo para a solidificação de uma liga Al-Si7\% e apresentou uma boa aderência. Porém o modelo não pode ser usado para o cálculo de vários grãos dendríticos, pois a resolução do perfil do campo de soluto fora do envelope necessitava de uma grande poder computacional, então os autores (Rappaz; Thévoz, 1987b) apresentaram uma simplificação deste modelo. $O$ novo modelo eliminava o cálculo do perfil de soluto fora do envelope dendrítico e o substituía por uma camada de soluto $(\delta)$, esta camada era escolhida de modo a conter o mesmo volume de soluto que o perfil calculado. Uma representação esquemática comparando os dois modelos de difusão propostos pode ser visto na Figura 21. 


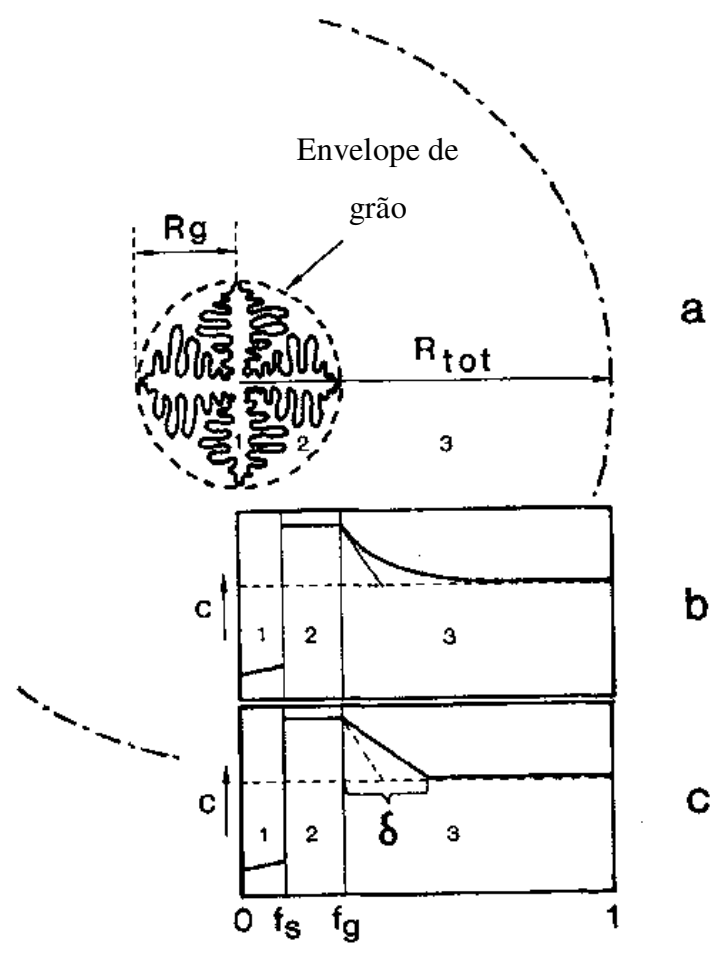

Figura 21 - Representação esquemática dos modelos de difusão propostos por Rappaz e Thévoz (1987 a e b). (a) Representação do envelope dendrítico; (b) perfil de soluto calculado pelo primeiro modelo (Rappaz; Thévoz, 1987a); (c) substituição do cálculo do perfil pela camada de soluto com espessura $\delta$ (Rappaz; Thévoz, 1987b).

Thévoz, Desbiolles e Rappaz (1989) apresentaram um novo modelo baseado no de Rapaz e Thévoz (1987b) onde passaram a calcular a nucleação através da consideração de um modelo de nucleação contínua normal e utilizaram um domínio de solidificação unidirecional. Os resultados obtidos com o modelo foram comparados com alguns dados equiaxiais e apresentaram boa aderência.

Hunt (1984) apresenta em 1984 um modelo para a previsão da CET, neste modelo introduziu-se o cálculo do crescimento dendrítico colunar juntamente com uma nucleação instantânea de grãos equiaxiais, conforme mostrado esquematicamente na Figura 22. 


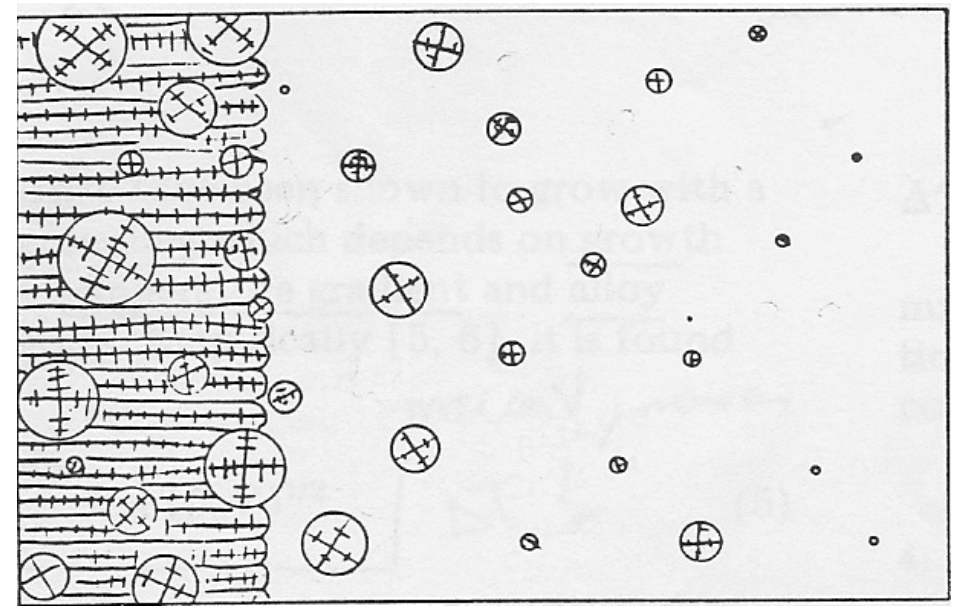

Figura 22 - Representação esquemática do crescimento colunar e equiaxial (Hunt, 1984).

O autor assumiu regime estacionário, juntamente com um perfil de temperatura determinado por um gradiente da mesma e a velocidade da frente colunar foi igualada à velocidade das isotermas. A ocorrência da CET foi atrelada à fração de grãos equiaxiais à frente da região colunar, quando a mesma atingia um valor de 0,49 a frente colunar era barrada. Este tipo de bloqueio ficou conhecido como bloqueio mecânico, e o modelo não era capaz de prever outro bloqueio uma vez que não considerava a rejeição de soluto. Hunt definiu então um critério para a ocorrência da CET baseado nos parâmetros de nucleação, velocidade de crescimento (V) e gradiente de temperatura (G) gerando um mapa de CET, conforme pode ser visto na Figura 23.

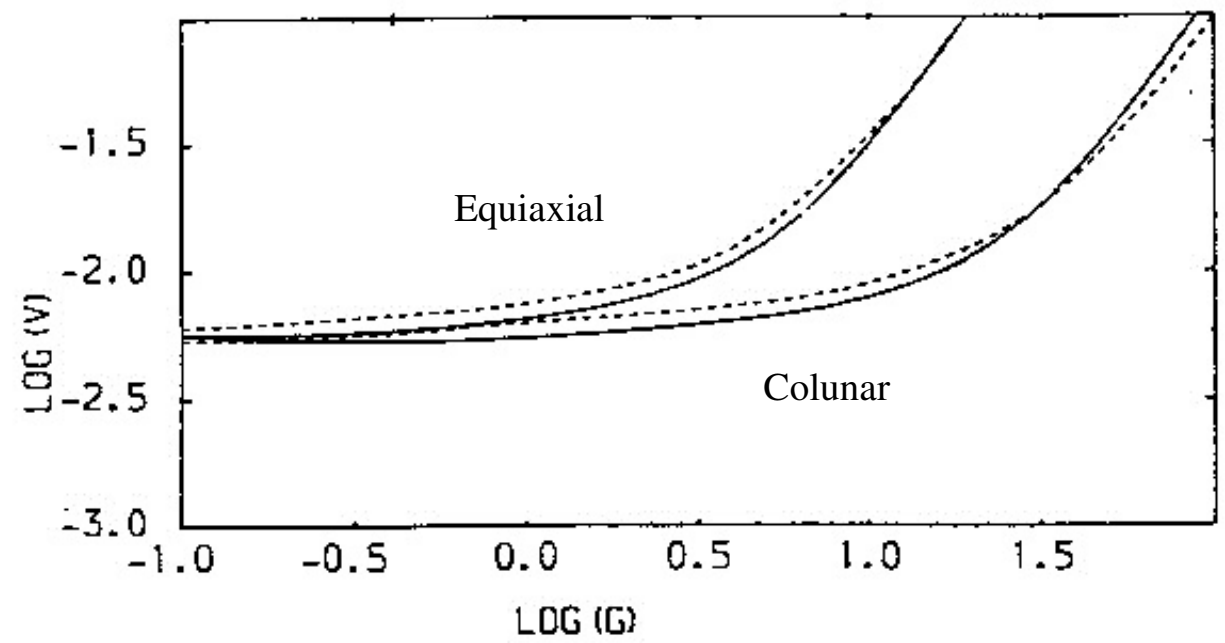

Figura 23 - Velocidade de crescimento em função do gradiente de temperatura, mostrando as regiões colunares e equiaxiais (Hunt, 1984). 
Flood e Hunt (1987a e 1987b) introduziram o cálculo da transferência de calor unidimensional ao modelo de Hunt (1984) que passou a ser tratado com um estado não estacionário. A fração de sólido na região colunar passou a ser calculada pela equação de Scheil e o modelo foi então utilizado para se verificar a influência da concentração, temperatura de vazamento, densidade de grãos equiaxiais e taxa de resfriamento na extensão da zona colunar. Gäumann, Trivedi e Kurz (1997) e Kurz, Bezençon e Gäumann (2001) alteraram o modelo de Hunt (1984) utilizando modelos de crescimento dendríticos mais atuais e que consideravam efeitos de solidificação rápida. Os modelos visavam simular o processo de solidificação durante a soldagem, porém os autores não compararam os dados resultantes da utilização dos modelos com resultados experimentais.

Ni e Beckermann (1991) apresentaram um modelo dos fenômenos de transporte que ocorrem durante a solidificação de uma mistura, sendo o mesmo apresentado para um sistema bifásico. As equações macroscópicas de conservação de massa, momento, energia e espécies para cada fase foram obtidas através da técnica da média volumétrica. Posteriormente Wang e Beckermann (1993a) aplicaram este equacionamento para a solidificação colunar e dendrítica em um sistema isotérmico e verificaram a influência de algumas simplificações nos resultados finais do crescimento colunar e dendrítico. Diferentemente de Rappaz e Thévoz (1987a) o envelope dendrítico foi definido como sendo uma superfície que separava as duas fases líquidas, o líquido interdendrítico e o extradendrítico, como pode ser visto na Figura 24. 
a)
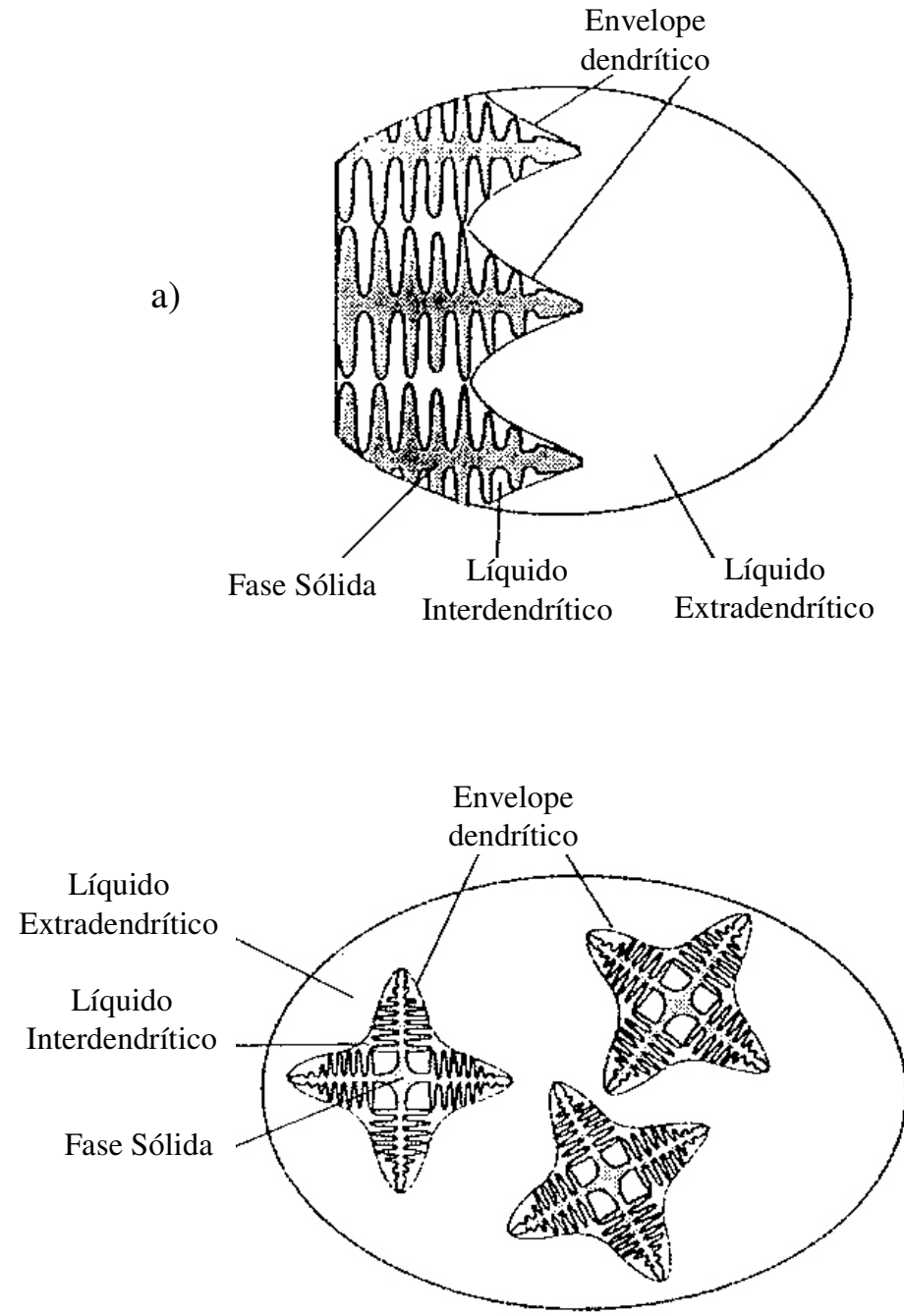

b)

Figura 24 - Representação do envelope dendrítico proposto por Wang e Beckermann (1993a). a) crescimento colunar e b) crescimento equiaxial.

Os autores compararam os resultados do novo modelo com resultados de modelos presentes na literatura, como por exemplo, as curvas de temperatura para o crescimento equiaxial foram comparadas com resultados apresentados por Rappaz e Thévoz (1987a) e estão apresentados na Figura 25. Após verificar as influências de certas simplificações e comparar com resultados dos modelos presentes, os autores publicaram um artigo apresentando o modelo já com certas simplificações (Wang; Beckermann, 1993b). 


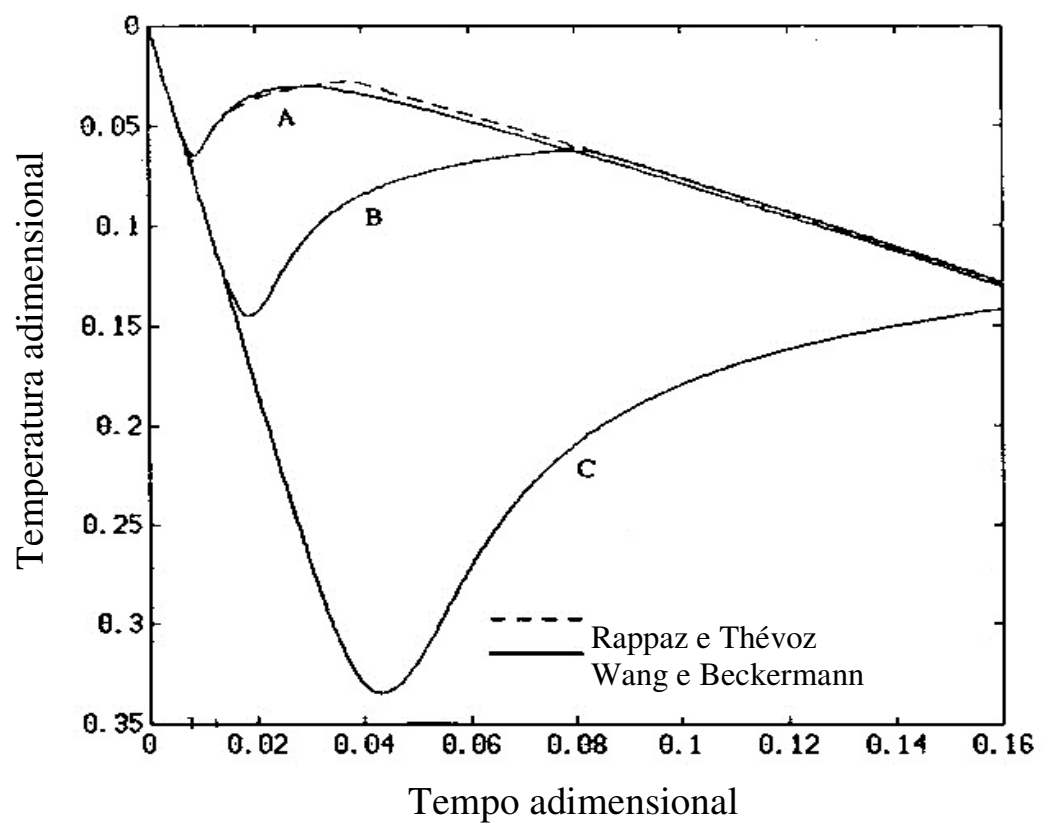

Figura 25 - Comparação das curvas de resfriamento para o crescimento dendrítico obtidas por Rappaz e Thevóz, e Wang e Beckermann (Wang; Beckermann, 1993b).

Finalmente em 1994, Wang e Beckermann (1994) apresentaram o seu modelo para a previsão da CET, considerando difusão de soluto e calor, nucleação instantânea dos grãos equiaxiais na temperatura liquidus e desconsiderando a convecção de soluto e o movimento dos grãos. As estruturas colunares e equiaxiais eram consideradas, conforme esquema apresentado na Figura 26, porém o crescimento colunar não considera a influência da rejeição de soluto em sua velocidade, sendo este efeito considerado somente para o crescimento equiaxial. Para barrar o crescimento da frente colunar e possibilitar o aparecimento da CET, assumiram que o mesmo ocorreria ao se atingir uma fração volumétrica de grãos equiaxiais igual a 0,49, conforme originalmente proposto por Hunt (1984). 


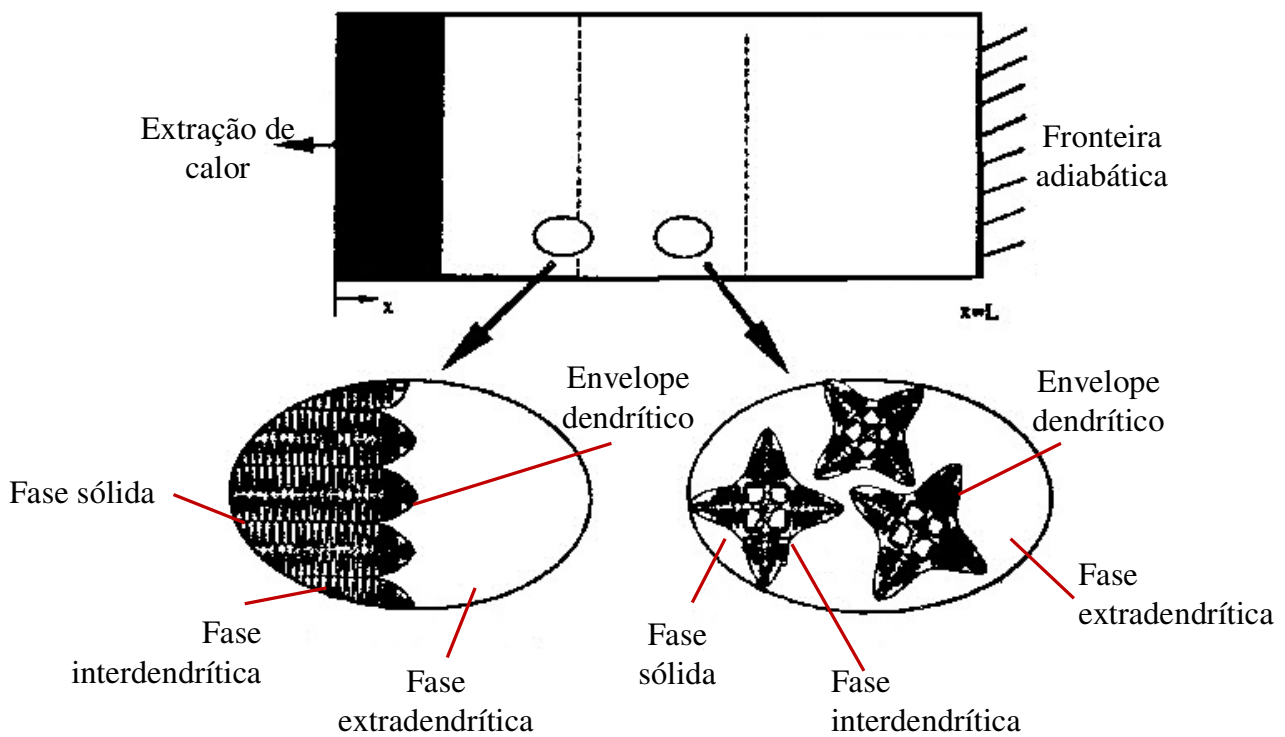

Figura 26 - Esquema apresentado por Wang e Beckermann (1994), mostrando a frente colunar e os grãos equiaxiais.

Wang e Beckermann (1994) fizeram estudos para verificar a influência do coeficiente de transferência de calor, composição da liga, densidade de nucleantes, taxa de resfriamento e temperatura de vazamento do metal na previsão da posição da CET em domínios unidimensionais.

Martorano, Beckermann e Gandin (2003) alteraram o modelo proposto por Wang e Beckermann (1994) para considerar o super-resfriamento para nucleação dos grãos equiaxiais, ao invés da nucleação na temperatura liquidus, e o efeito da interação entre os campos de soluto dos grãos colunares e equiaxiais. Com a consideração desta interação, o modelo foi capaz de prever a CET sem a necessidade do critério de bloqueio mecânico. O modelo foi inicialmente comparado com o modelo de Hunt (1984) e validado através da comparação com dados experimentais.

Os modelos determinísticos também evoluíram para a simulação de outros fenômenos associados à solidificação. Wang e Beckermann (1996) incorporam ao seu modelo a previsão da movimentação dos grãos e convecção. O modelo considerava somente a solidificação de grãos equiaxiais. Em uma série de três artigos os autores (Wang; Beckermann, 1996a, Wang; Beckermann, 1996b, Beckermann; Wang, 1996) apresentaram seu modelo, juntamente com resultados de 
simulações e resultados experimentais, porém afirmaram que muitas das equações utilizadas careciam de mais estudos para uma melhora na precisão das simulações.

Carlson et al. (2006) apresentaram um modelo determinístico para a previsão da formação de porosidades em ligas de alumínio ocasionadas pela difusão de hidrogênio.

Os modelos determinísticos para a previsão da CET mostrados até aqui foram desenvolvidos para domínios onde a extração de calor ocorria de forma unidirecional, pois isto facilita o acompanhamento da frente colunar o que é imprescindível nestes modelos. A posição da frente colunar deve ser acompanhada o tempo todo para se determinar o momento em que esta é barrada, seja pelo método do bloqueio mecânico ou de soluto. Porém, torna-se muito mais complexo acompanhar a frente colunar em domínios onde haja a extração de calor em mais de uma direção (2D e 3D) e para isso, alguns autores propuseram novos métodos para acompanhar a frente colunar, chamados "front tracking" para tentar solucionar este impasse, conforme alguns mostrados a seguir.

Primeiramente Wang e Beckermann (1994) assumiram que a frente colunar sempre acompanhava uma mesma isoterma, desta forma a mesma pôde ser seguida em situações uni e bidimensionais, porém os autores já alertavam para o fato de que este método não poderia ser utilizado em situações mais complexas, como por exemplo, situações com convecção e movimento de sólido. M’Handi et al. (1998) modelaram a CET em duas dimensões para uma situação de fundição contínua. O modelo assumia um estado de regime estacionário e o transporte de calor por convecção, tanto no líquido quanto na zona pastosa, não foi considerado. O modelo macroscópico de transferência de calor foi acoplado a um modelo de crescimento equiaxial muito similar ao de Rappaz e Thévoz (1987b) e a CET ocorria quando a fração de grãos equiaxiais à frente dos grãos colunares atingia 1, valor muito diferente do 0,49 proposto por Hunt (1984). Alguns resultados do modelo foram apresentados, porém não comparados com resultados experimentais.

Jacot, Maijer e Cockcroft (2000) desenvolveram um modelo para acompanhar a posição da frente colunar em regime não estacionário na solidificação bidimensional de ferro fundido. Neste modelo o domínio foi divido em células nas quais a frente colunar era seguida utilizando-se seguimentos de reta posicionados perpendicularmente ao vetor do gradiente de temperatura, conforme mostrado na 
Figura 27. O critério de Hunt (1984) para o bloqueio mecânico fora utilizado e dados de densidade de grãos, fração volumétrica de grãos equiaxiais em função da posição radial e temperatura em função do tempo foram comparados com dados experimentais, e segundo os autores as comparações apresentaram resultados satisfatórios.

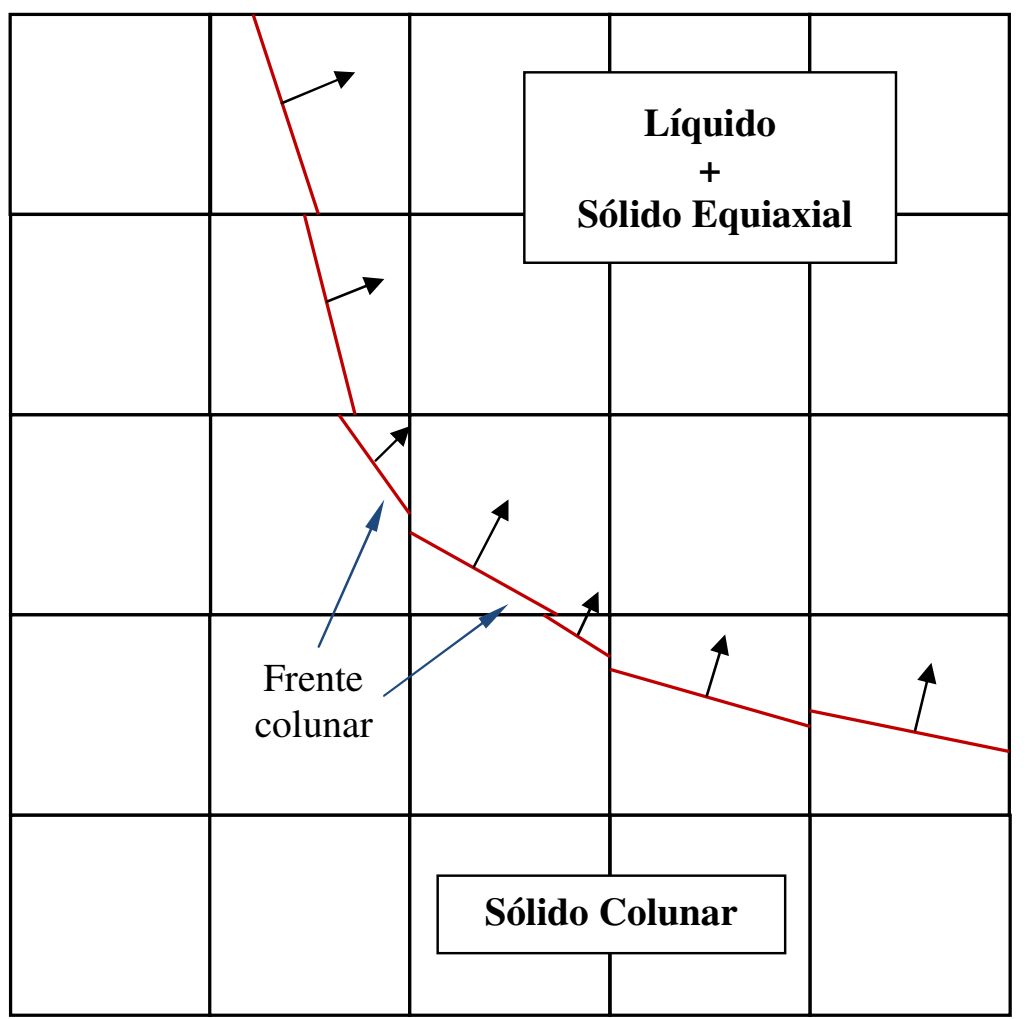

Figura 27 - Esquema utilizado por Jacot, Maijer e Cockcroft (2000) para acompanhar a posição da frente colunar, onde os seguimentos de reta representam a frente colunar e os vetores as direções de crescimento.

Browne e Hunt (2004) propuseram um modelo no qual a frente colunar era demarcada por partículas sem massa, que se moviam segundo a velocidade da ponta da dendrita, conforme esquema apresentado na Figura 28. 


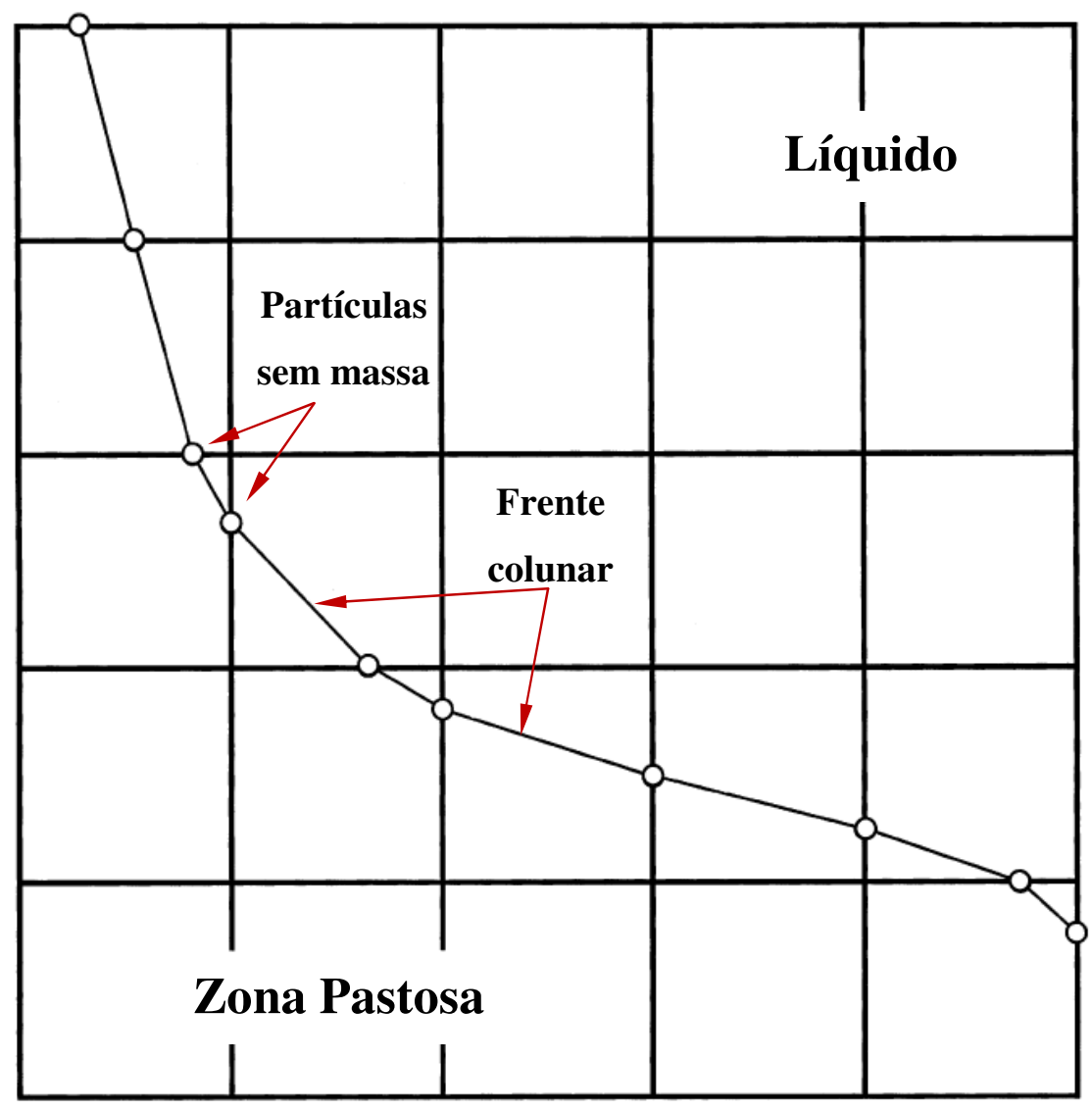

Figura 28 - Representação do acompanhamento da frente colunar proposto por Browne e Hunt (2004), mostrando as partículas sem massa e a frente colunar.

Apesar das dendritas colunares possuírem orientações cristalográficas diferentes, e conseqüentemente velocidades de crescimento diferentes, o modelo só considerava o super-resfriamento local para o cálculo da velocidade de cada partícula. O modelo também foi utilizado para a simulação do crescimento de um grão equiaxial, porém o mesmo não foi utilizado para a previsão da CET. O modelo foi utilizado para a simulação de uma solidificação colunar em um domínio bidimensional, onde a transferência de calor foi calculada. Os resultados previstos pelo modelo foram apresentados, porém nenhuma comparação com resultados experimentais foi relatada. Bowne (2005) utilizando o modelo anteriormente proposto (Browne; Hunt, 2004), correlacionou o super-resfriamento à frente da zona colunar com um índice de probabilidade de ocorrência da zona equiaxial, ou seja, probabilidade de ocorrer a CET. Porém o índice somente indica que caso a zona 
equiaxial exista, a mesma teria uma maior probabilidade de ocorrer em um determinado tempo e região.

Ludwig e Wu (2005) desenvolveram um modelo para a previsão da CET em 2D ou 3D juntamente com a convecção do líquido e a movimentação dos grãos equiaxiais. O domínio foi dividido em volumes de controle, sendo que os mesmos possuíam um índice que indicava a existência, da ponta da dendrita da frente colunar, do tronco das dendritas colunares ou de nenhum dos anteriores. Os volumes finitos também guardavam o tamanho da frente colunar, e quando o tamanho desta se tornava maior que o volume finito a mesma se deslocava para outro volume sempre com a orientação dada paralelamente ao fluxo de calor local. $O$ modelo era capaz de prever o bloqueio mecânico e o bloqueio de soluto. Os autores apresentaram os dados de uma solidificação, porém salientam que o modelo deve ser estudado para se ter certeza de que as simplificações assumidas são possíveis.

Martorano e Biscuola (2006) propuseram um modelo para acompanhar o crescimento colunar baseado no autômato celular originalmente proposto por Gandin e Rappaz (1994), de forma a delinear somente a frente colunar ao invés dos envelopes de grãos individualmente, conforme mostrado na Figura 29.

O modelo prevê o bloqueio do crescimento colunar através do método do bloqueio mecânico, não prevê convecção e transporte dos grãos. Apesar de utilizar o método do autômato celular para a definição da frente colunar, o modelo não necessita da mesma malha refinada que os modelos estocásticos, já que não simula todos os envelopes dendríticos. Outra diferença em relação ao autômato celular original, reside no fato de que a orientação das células varia a cada passo de tempo de modo a sempre se manterem alinhadas com o gradiente de temperatura local, impossibilitando a simulação da orientação dos grãos. Os autores utilizaram o modelo em uma comparação com uma simulação realizada por Wang e Beckermann (1994) para uma solidificação unidirecional, onde os resultados da posição da frente colunar em função do tempo se mostram muito semelhantes, a menos da posição da CET que ficou ligeiramente diferente. 


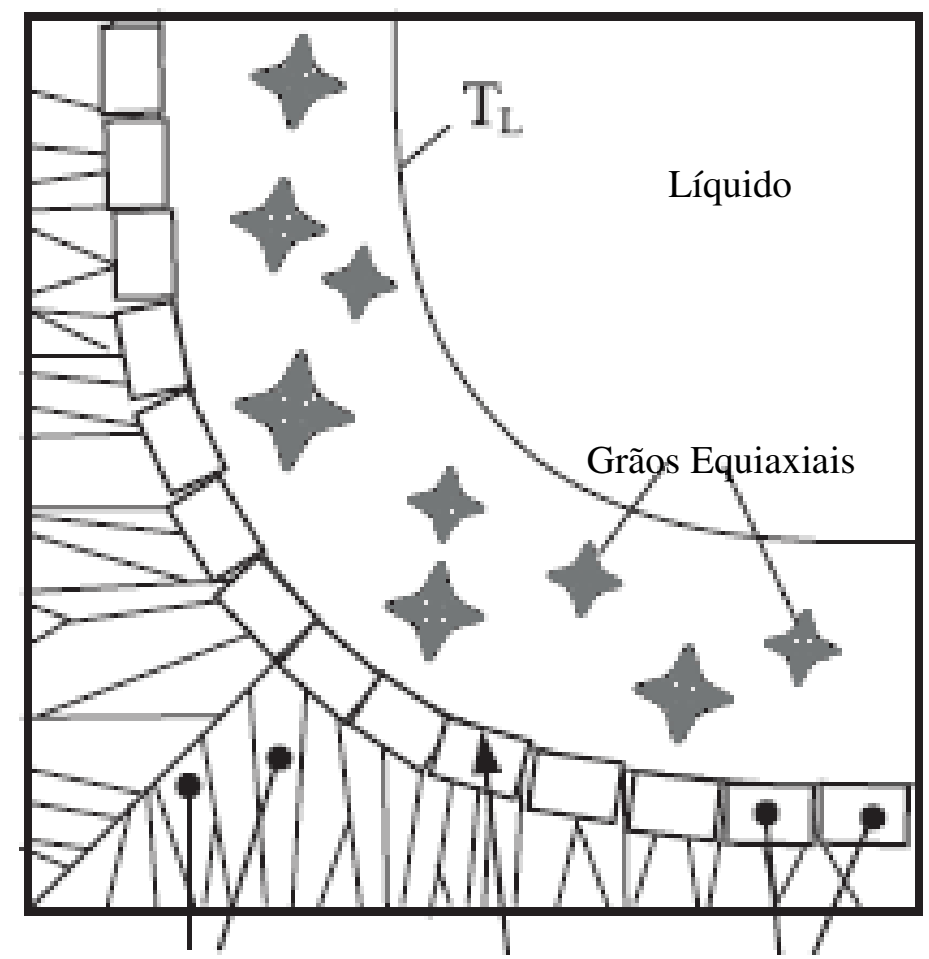

(a)

$$
\text { Grãos Colunares Frente Colunar Células }
$$

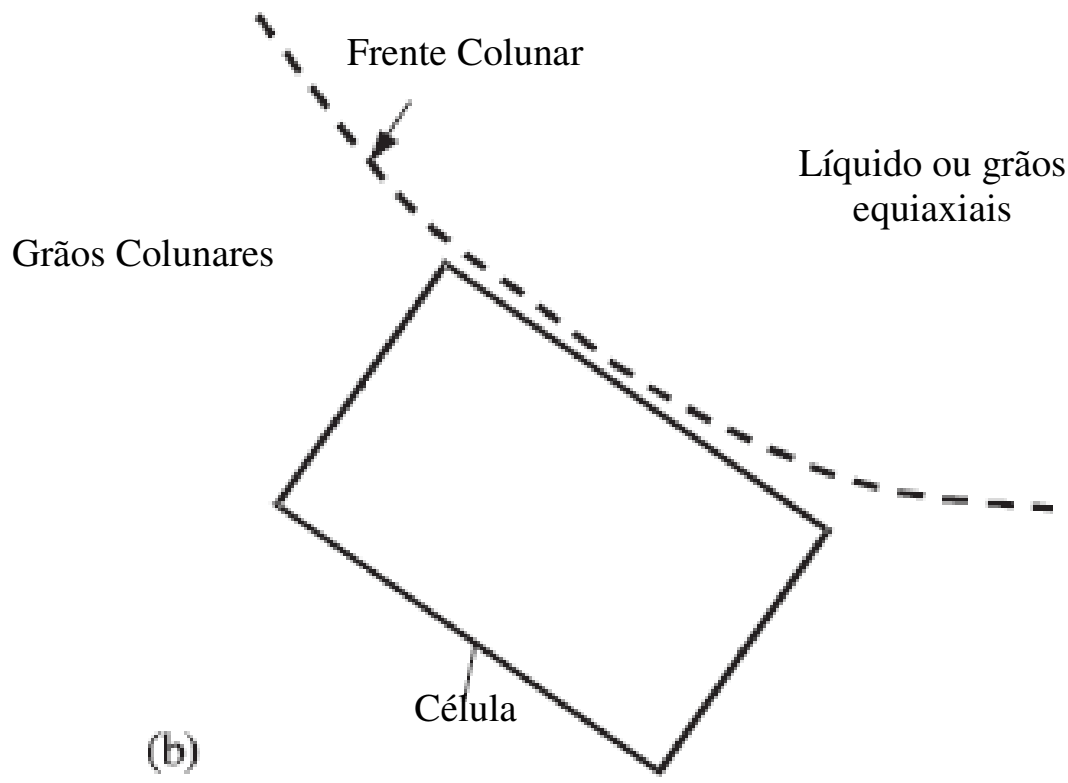

Figura 29 - Representação esquemática da frente colunar delineada pelas células do CA: a) indicação dos grãos equiaxiais, líquido e temperatura liquidus; b) ampliação da interface colunar (Martorano;

Biscuola, 2006). 
Os autores compararam também os resultados do modelo com os resultados do modelo de Wang e Beckermann (1994) e com o modelo do autômato celular de Gandin e Rappaz (1997), conforme mostrado na Figura 30, para a solidificação bidimensional de uma liga Al-3\%Cu em um domínio quadrado.

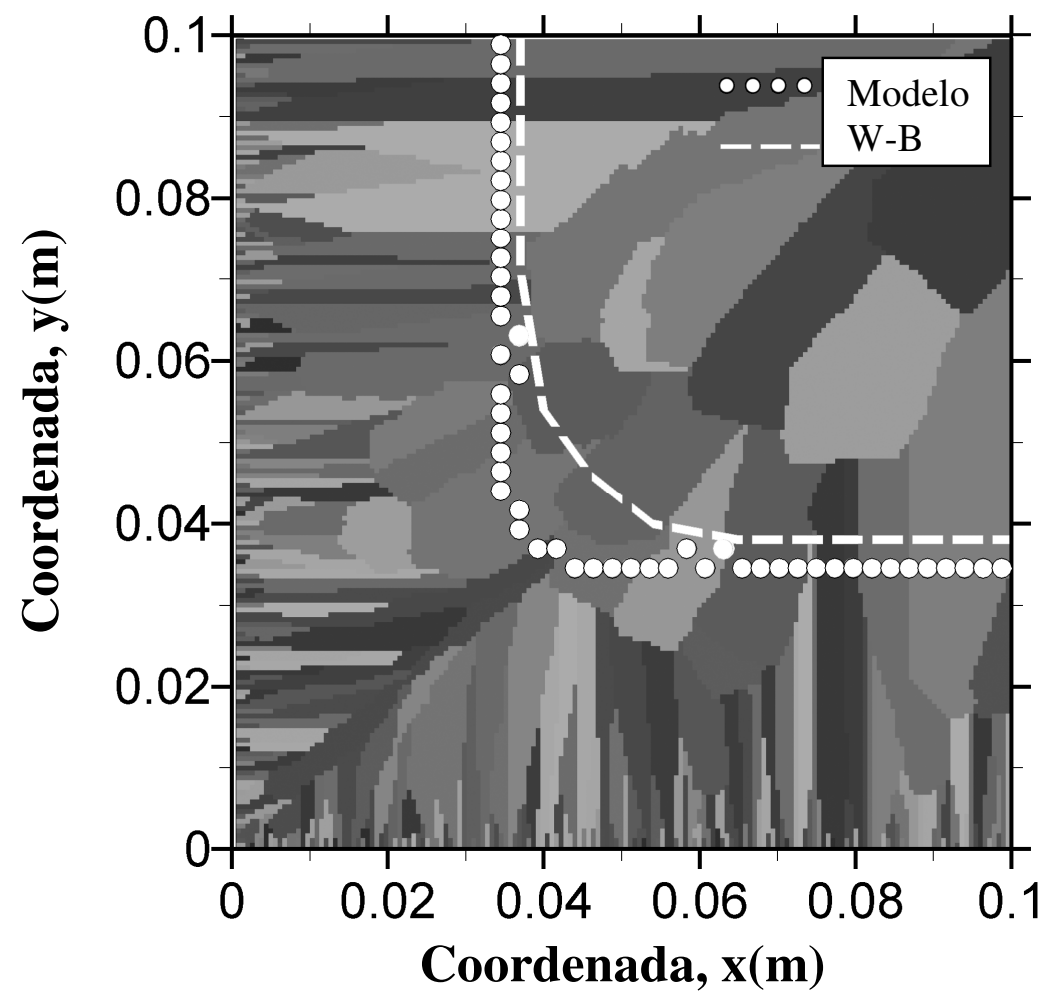

Figura 30 - Resultado da CET prevista pelo modelo de Martorano e Biscuola (denominado Modelo), comparado com os resultados do autômato celular (macroestrutura ao fundo) e do modelo de Wang e Beckermann (denominado W-B).

Banaszek et al. (2007) utilizaram o modelo de Browne e Hunt (2004) para simular a transição colunar-equiaxial em uma solidificação bidimensional. Primeiramente o modelo foi comparado com resultados experimentais em uma solidificação unidirecional de uma liga Al-7\%Si sem convecção, para comparação dos dados de temperatura em função do tempo. Posteriormente os autores simularam uma solidificação em um domínio bidimensional quadrado, com extração de calor pelos quatro lados para uma liga $\mathrm{Al}-4 \% \mathrm{Cu}$. Finalmente os autores simularam simultaneamente $\mathrm{o}$ crescimento da frente colunar e dos grãos equiaxiais para a solidificação unidirecional de uma liga $\mathrm{Al}-2 \% \mathrm{Cu}$, prevendo assim a CET conforme mostra a Figura 31. Durante o crescimento da frente colunar os grãos 
equiaxiais crescendo a frente desta, influenciavam termicamente o seu avanço, diminuindo assim a sua velocidade. Em um dado instante a frente colunar era mecanicamente bloqueada pelos grãos equiaxiais e a CET ocorria.

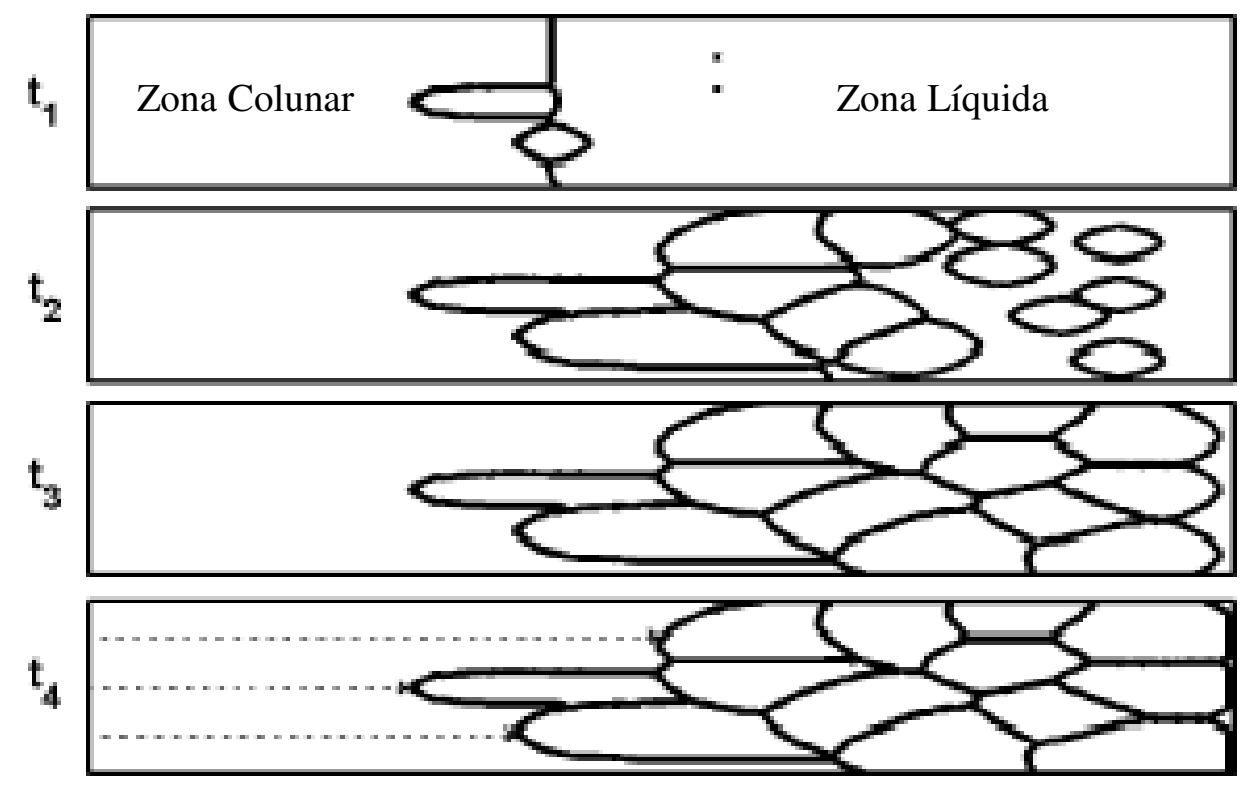

Figura 31 - Crescimento colunar e equiaxial para uma liga Al-2\%Cu solidificada direcionalmente da esquerda para a direita para quatro tempos $\left(t_{1} a_{4}\right)$ (Banaszek et al., 2007).

McFadden e Browne (2009) implementaram algumas alterações no modelo proposto por Browne e Hunt (2004) de modo a tornar a liberação de calor latente mais fisicamente realista em comparação ao modelo inicial, pois passa a simular a equação de Scheil além de incorporar o modelo de nucleação proposto por Quested e Greer (2005). O modelo também foi alterado para incorporar a previsão da CET através do encontro dos grãos onde, conforme mostrado na Figura 32, os grãos crescem até se encontrarem e neste momento a nova interface criada para de crescer. 
a

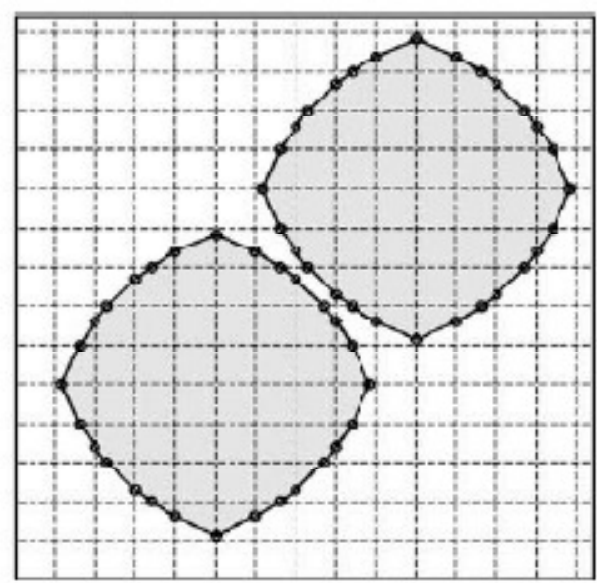

b

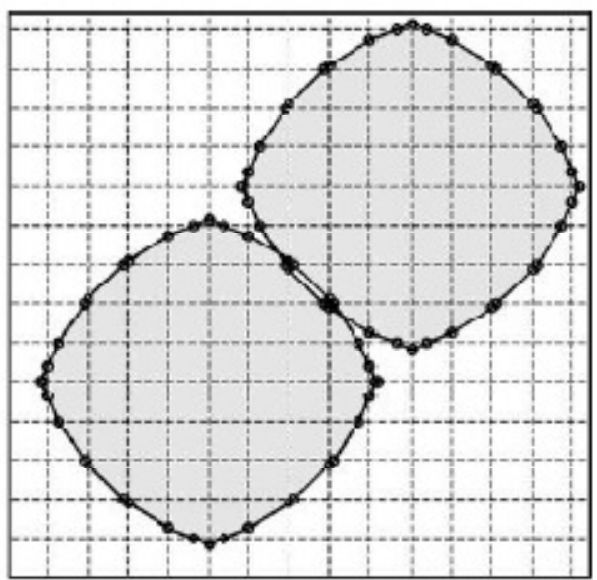

Figura 32 - Encontro de grãos para tempos fictícios (a) e (b), onde após o encontro há a formação de uma nova interface que para de crescer (McFadden; Browne, 2009).

Os autores simularam a CET para o caso da solidificação unidirecional de uma liga $\mathrm{Al}-4 \% \mathrm{Cu}$ em um domínio retangular com extração de calor na fronteira esquerda, os resultados estão mostrados na Figura 33 para dois tempos, 600s e 900s.
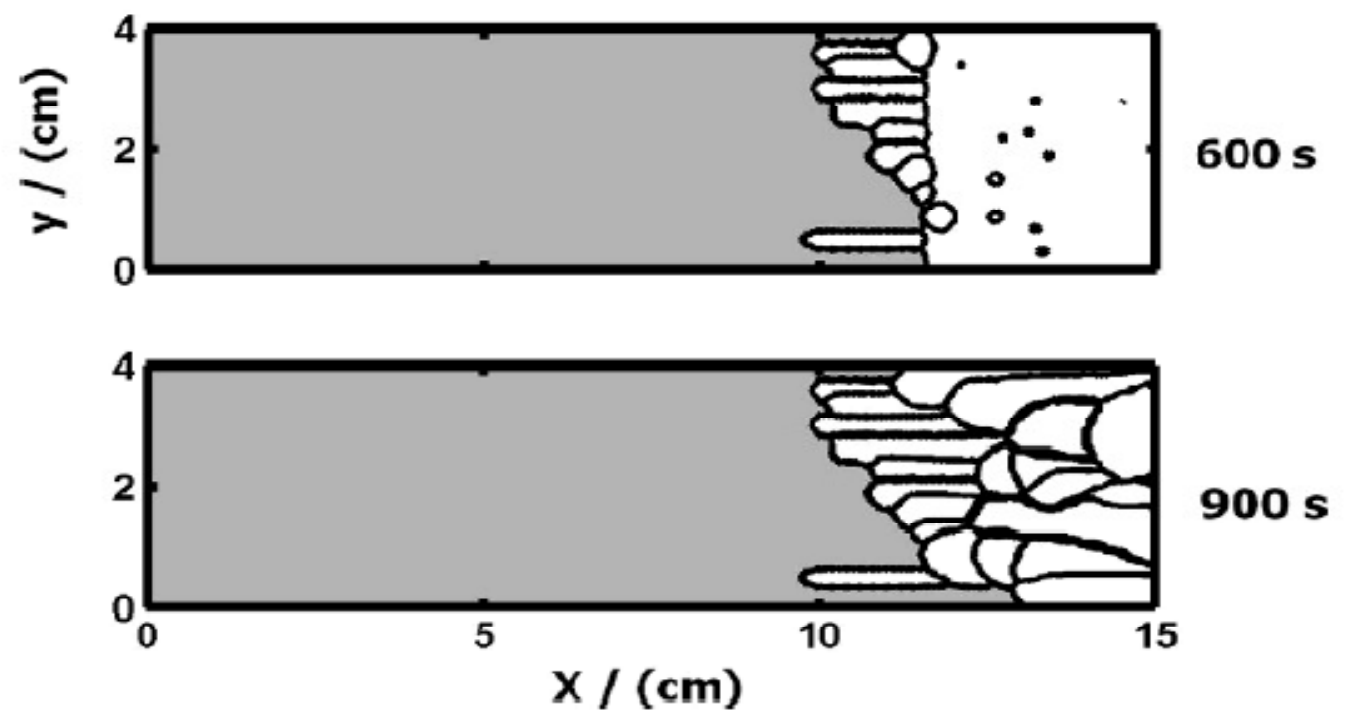

Figura 33 - Solidificação direcional de uma liga AL-4\%Cu para dois tempos (600s e 900s) prevista pelo modelo de McFadden e Browne (2009).

Por fim os autores compararam os resultados de seu modelo com resultados experimentais obtidos por Gandin (2000) para a solidificação unidirecional de uma liga $\mathrm{Al}-7 \% \mathrm{Si}$, e os resultados da posição da CET e as curvas de temperatura se mostraram muito próximas. 


\section{4 - METODOLOGIA}

A estratégia geral adotada no presente trabalho consistiu da divisão do mesmo em duas partes principais. A primeira tem como objetivo avaliar e comparar modelos já propostos na literatura, construídos com base nas abordagens estocástica e determinística, mostrando as características, possíveis problemas e deficiências encontradas. A segunda parte tem o objetivo de propor, implementar e avaliar um novo modelo que combine as características vantajosas destas duas classes de modelos. Desta forma, o conteúdo tanto do item de Metodologia como o de Resultados e Discussão reflete a estratégia adotada.

No presente item, que descreve a Metodologia, todos os modelos empregados no presente trabalho serão apresentados. Inicialmente o equacionamento do modelo estocástico tradicional, que foi implementado em um código computacional, será mostrado. No item posterior, as equações do modelo determinístico serão mostradas, mas deve-se ressaltar que o código computacional relativo a este modelo já estava pronto para utilização, portanto não foi implementado no presente trabalho. Finalmente, será apresentado em detalhes o novo modelo proposto, denominado de híbrido estocástico-determinístico e chamado de CADE.

\subsection{Modelo Estocástico Tradicional}

Um modelo estocástico, que será chamado de modelo estocástico tradicional, foi implementado para possibilitar uma avaliação das características básicas desta classe de modelos. Este modelo estocástico tradicional foi baseado no modelo proposto por Gandin e Rappaz (1997); entretanto, para solucionar a equação diferencial de transferência de calor, o método dos volumes finitos foi utilizado em lugar do método dos elementos finitos empregado por estes autores. Analogamente a Gandin e Rappaz (1997), o modelo foi dividido em duas partes: um submodelo macroscópico, responsável pelo cálculo da transferência de calor, e um submodelo mesoscópico, responsável pelo cálculo da estrutura de grãos, havendo assim a necessidade de um acoplamento posterior entre os submodelos. 
As equações do modelo foram desenvolvidas para a simulação da solidificação em um domínio bidimensional com transferência de calor unidirecional. No domínio retangular escolhido, a extração de calor é assumida ocorrer pela superfície inferior através de, por exemplo, o contato com uma base refrigerada à água, enquanto todas as outras fronteiras foram definidas como adiabáticas, conforme mostra a Figura 34. Neste caso, foram desconsiderados movimentação do sólido, convecção do líquido, formação de rechupe, porosidade ou rejeição de soluto.

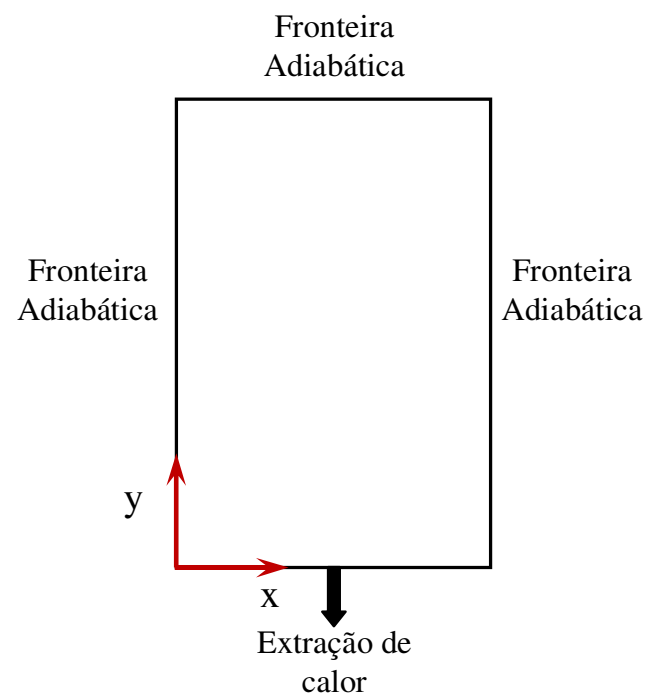

Figura 34 - Domínio modelado e condições esquemáticas da transferência de calor nas fronteiras.

\subsubsection{Submodelo Macroscópico}

No submodelo macroscópico, utilizado para a transferência de calor, foi solucionada a equação de conservação de energia na forma da entalpia $(H)$ escrita em um sistema de coordenadas retangulares fixadas no domínio bidimensional apresentado na Figura 34. A equação está apresentada abaixo:

$$
\frac{\partial H}{\partial t}=\frac{\partial}{\partial x}\left(\kappa \frac{\partial T}{\partial x}\right)+\frac{\partial}{\partial y}\left(\kappa \frac{\partial T}{\partial y}\right)
$$

onde $\mathrm{H}$ é a entalpia por unidade de volume; t é o tempo; T é a temperatura; $\kappa$ é a condutividade térmica e $\mathrm{x}$ e y são as coordenadas espaciais do sistema de referência. 
A equação [20] foi submetida às seguintes condições de contorno (Figura 34):

$$
\begin{gathered}
\frac{\partial T}{\partial x}=0 \text { contornos laterais (esquerdo e direito) } \\
\frac{\partial T}{\partial y}=0 \text { contorno superior } \\
\kappa \frac{\partial T}{\partial y}=h\left(T-T_{W}\right) \text { contorno inferior (metal } / \text { molde) }
\end{gathered}
$$

onde $h$ é o coeficiente de transferência de calor na interface metal-molde; e $T_{W}$ é uma temperatura de referência, por exemplo, a temperatura da água de refrigeração do molde. Como condição inicial, considerou-se uma temperatura uniforme através do domínio.

A equação [20] foi discretizada subdividindo-se o domínio de cálculo em uma malha de volumes finitos utilizando-se o método numérico dos volumes finitos, com uma formulação explícita (Patankar, 1980). A partir deste método, a seguinte equação algébrica foi obtida para um volume localizado no interior do domínio:

$$
\delta H_{V F}^{t+\delta t}=\left(a_{E} T_{E}^{t}+a_{W} T_{W}^{t}+a_{N} T_{N}^{t}+a_{S} T_{S}^{t}+\left[-a_{E}-a_{W}-a_{S}-a_{N}\right] \cdot T_{P}^{t}\right) \cdot \frac{\delta t}{\Delta x \cdot \Delta y}
$$

onde

$$
\begin{aligned}
& a_{E}=\frac{\kappa_{e} \Delta y}{(\delta x)_{e}} \\
& a_{W}=\frac{\kappa_{w} \Delta y}{(\delta x)_{w}} \\
& a_{N}=\frac{\kappa_{n} \Delta x}{(\delta y)_{n}} \\
& a_{S}=\frac{\kappa_{s} \Delta x}{(\delta y)_{s}}
\end{aligned}
$$


sendo que, $\Delta x$ e $\Delta y$ representam as dimensões dos lados de um volume finito; $\delta x$ e dy são as distâncias (nos respectivos eixos $\mathrm{x}$ e y) entre os nós de dois volumes finitos adjacentes (Figura 35); e $\delta$ t é o passo de tempo. Os subscritos presentes em $\delta x$ e $\delta y$ representam as direções para o cálculo destas medidas, ou seja, $(\delta x)_{s}$ representa a distância entre o nó $P$ (centro do volume finito $P$ ) e o nó $S$, no eixo coordenado x. Os subscritos presentes na condutividade térmica representam a face na qual a condutividade térmica é calculada.

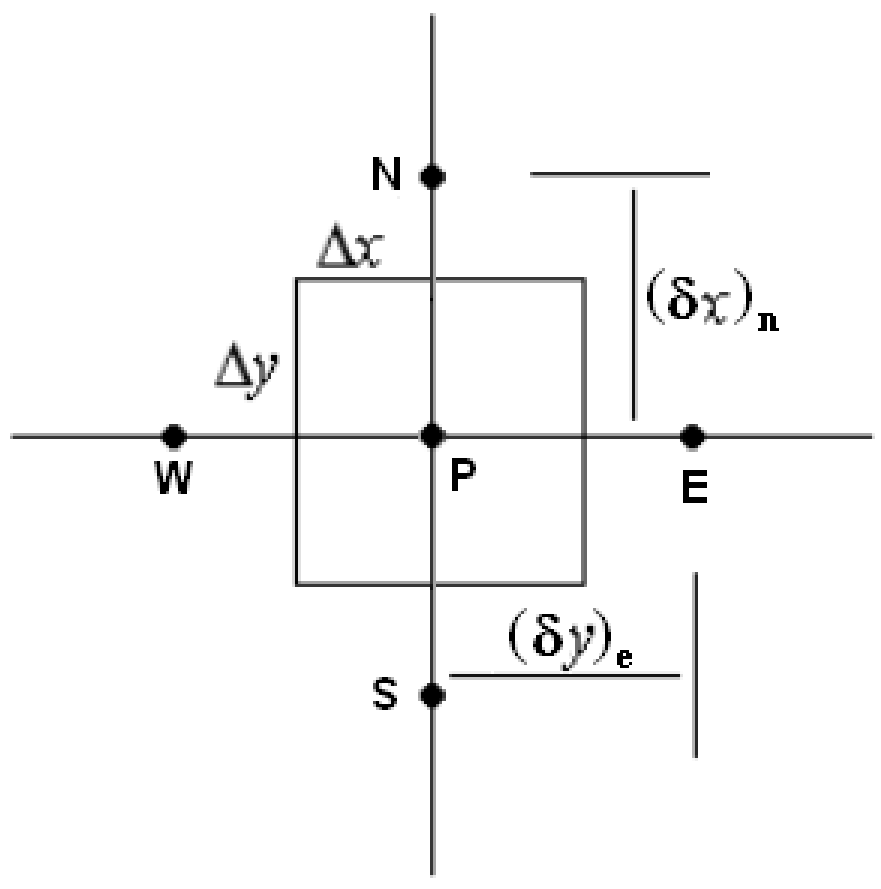

Figura 35- Representação esquemática de um volume finito e seu nó, denominado $\mathrm{P}$, localizado no seu centro. Os nós N, S, E e W representam aqueles nos centros dos volumes finitos adjacentes ao contorno norte, sul, leste e oeste, respectivamente.

A condutividade térmica em uma face do volume é calculada em função da condutividade na posição dos nós $\mathrm{P}$ (centro do volume finito $\mathrm{P}$ ) e no nó do volume adjacente a esta face, denominado de I, resultando em:

$$
\kappa_{i}=2 \kappa_{I} \kappa_{P} /\left(\kappa_{I}+\kappa_{P}\right)
$$

onde $\kappa_{I}$ é a condutividade térmica no nó $/$ e $\kappa_{P}$ a condutividade térmica no nó $P$. 
As condutividades térmicas definidas para o sólido e para o líquido são consideradas diferentes e, desta forma, a condutividade térmica no nó de um volume finito I, depende da sua fração de sólido da seguinte forma:

$$
\kappa_{I}=\varepsilon_{S} \kappa^{S}+\left(1-\varepsilon_{S}\right) \kappa^{L}
$$

onde $\kappa^{L}$ é a condutividade térmica da fase líquida; $\kappa^{S}$ é a condutividade térmica da fase sólida e $\varepsilon_{S}$ é a fração de sólido do volume finito.

Ao se utilizar o método explícito, deve-se obedecer a um critério de estabilidade numérica. No caso de uma malha quadrada como a utilizada no presente trabalho, este critério impõe o seguinte limite máximo para o passo de tempo:

$$
\delta t<\frac{\rho C_{p}(\Delta x)^{2}}{\kappa_{E}+\kappa_{W}+\kappa_{N}+\kappa_{S}} \quad \text { para } \quad \Delta x=\Delta y=\delta x=\delta y
$$

onde: $\rho$ é a densidade e $C_{p}$ é o calor específico.

A equação [24] permite o cálculo da variação de entalpia volumétrica para cada volume da malha do instante $t$ para o instante $t+\delta t$ a partir das temperaturas no instante $t$.

\subsubsection{Submodelo Mesoscópico}

O submodelo mesoscópico foi baseado no método do autômato celular (CA - "Cellular Automaton") e tem a função de prever a formação da macroestrutura de grãos simulando os processos de nucleação e crescimento. Segundo a técnica do CA, o domínio foi subdividido em pequenas células quadradas localizadas no interior de um volume finito (Figura 37), contendo um sítio posicionado em cada centro da célula. Primeiramente, ocorre a nucleação do grão e a conseqüente ativação da célula. Neste momento associa-se à célula um quadrado de crescimento que representa o envelope dendrítico. Este primeiro quadrado tem o seu centro de crescimento coincidente com o centro da célula, onde localiza-se o seu sítio. Cada quadrado possui uma orientação que é dada pelo ângulo entre sua diagonal e o eixo horizontal $x$, sendo este ângulo escolhido aleatoriamente entre 48 classes na faixa de $-45^{\circ}$ e $45^{\circ}$. 
Após a nucleação, o tamanho dos quadrados de crescimento é atualizado após cada passo de tempo para simular o crescimento do envelope. O tamanho da metade do lado de cada envelope (direção cristalográfica [11]) é calculado de acordo com a equação [32].

$$
L_{i}=\frac{1}{\sqrt{2}} \cdot \int_{0}^{t} V\left[\Delta T_{i}(\tau)\right] d \tau
$$

onde $L_{i}$ representa a metade do lado do envelope (Figura 36) e $V(\Delta T)$ é a velocidade de crescimento da ponta do braço de dendrita, que é função do superresfriamento local, $\Delta T$, calculado no centro da célula em questão. Segundo esta representação de envelope, o braço primário de uma dendrita equiaxial está alinhado com a diagonal do quadrado de crescimento. O cálculo da velocidade de crescimento dendrítico está apresentado em detalhes no próximo subitem.

Em um dado instante este quadrado de crescimento encontrará o sítio de uma de suas quatro células vizinhas após um passo de tempo $\delta t$. Quando isto ocorre, a célula que teve o seu sítio tocado pelo quadrado é então ativada e recebe um quadrado de crescimento representando uma propagação do envelope dendrítico e, portanto, será criado com a mesma orientação do envelope que o ativou. Este novo quadrado de crescimento, que tem o seu centro não necessariamente coincidente com o sítio da célula a que pertence (quadrado de crescimento descentrado), passa a crescer com o super-resfriamento calculado na posição do sítio da célula (Figura 36). 


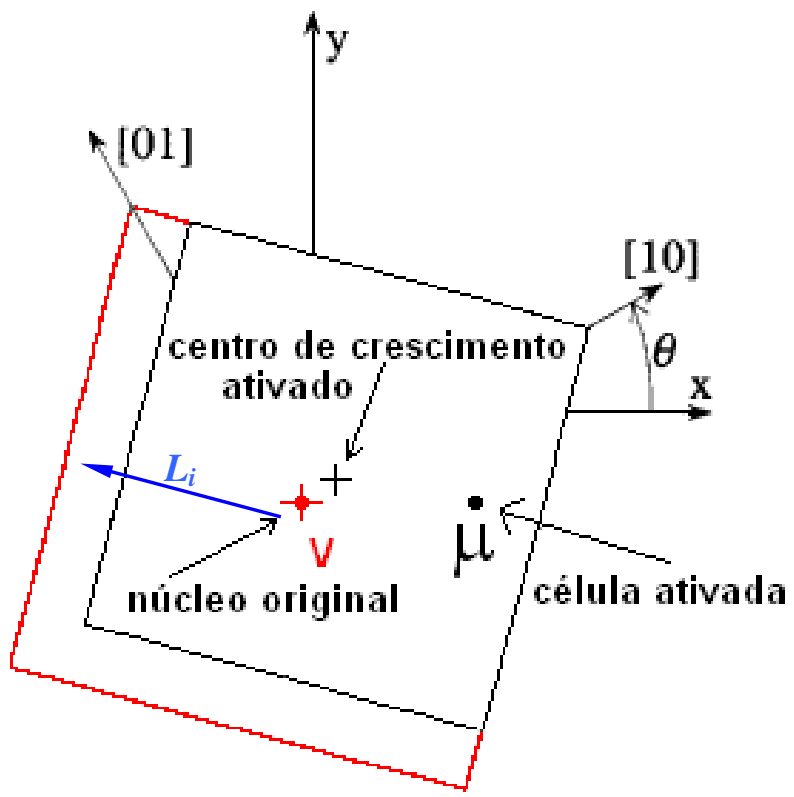

Figura 36- Representação do crescimento celular descentrado. A célula inicial de sítio (v) ativou a sua célula vizinha de sítio $(\mu)$, e esta tem o seu quadrado de crescimento descentrado em relação à sua célula.

Os quadrados de crescimento foram truncados da mesma forma que no modelo de Gandin e Rappaz (1997) e, com isso, o máximo valor inicial que o meio lado de um quadrado de crescimento pode assumir é dado pela equação [33].

$$
L_{i}=\frac{1}{2}\left[\operatorname{Min}\left(L_{i[11]}, \sqrt{2} \cdot l\right)+\operatorname{Min}\left(L_{i[11]}, \sqrt{2} \cdot l\right)\right]
$$

sendo $L_{i[1]}$ e $L_{i[11]}^{--}$as distâncias, definidas no tempo da captura, entre o sítio da célula recém ativada e o lado do quadrado de crescimento que a ativou, nas direções cristalográficas [11] e [11] respectivamente; e $l$ é a distância entre os sítios das duas células envolvidas.

Sabendo-se a distância definida por $L_{i}$, um quadrado com um lado de $2 L_{i}$ é posicionado na nova célula, de forma que a aresta do novo quadrado coincida com a aresta mais próxima do quadrado que a ativou (Figura 36). Deste modo, a posição do centro de crescimento do novo quadrado não coincide necessariamente com a posição do sítio da sua célula. O tamanho do quadrado de crescimento de uma célula é atualizado a cada passo de tempo até que suas quatro células vizinhas 
sejam ativadas. Nesta situação, o seu quadrado de crescimento pára e não mais será atualizado, pois ele agora representa uma pequena parte do interior de um envelope.

\subsubsection{Crescimento dos envelopes}

A velocidade de crescimento da ponta da dendrita, $V$, utilizada no subitem anterior para prever o crescimento do envelope de grão foi calculada utilizando-se uma equação semelhante à empregada por Gandin e Rappaz (1994), apresentada abaixo:

$$
V(\Delta T)=A \times \Delta T^{m}
$$

onde $V(\Delta T)$ representa a velocidade de crescimento da ponta da dendrita, que coincide com a diagonal do quadrado de crescimento; $\Delta T$ é o super-resfriamento calculado na posição do sítio (centro) da célula; $A$ e $m$ são constantes.

\subsubsection{Nucleação dos Grãos}

A nucleação heterogênea dos grãos é tratada utilizando-se duas distribuições normais de super-resfriamentos para nucleação, uma para determinar a nucleação heterogênea sobre a parede interna do molde e outra para a nucleação heterogênea sobre partículas dispersas no interior de sua cavidade. A seguinte densidade de distribuição foi utilizada para determinar a taxa de aumento da densidade de núcleos (núcleos por unidade de volume), denominado $n$, com o aumento do super-resfriamento do líquido $(\Delta T)$ :

$$
\frac{d n}{d(\Delta T)}=\frac{n_{\max }}{\sqrt{2 \pi} \cdot \Delta T_{\sigma}} \exp \left[-\frac{1}{2}\left(\frac{\Delta T-\Delta T_{n u c}}{\Delta T_{\sigma}}\right)^{2}\right]
$$

onde $n_{\max }$ representa a densidade total de número de partículas de substratos possíveis de causar a nucleação; $\Delta T_{n u c}$ define o valor médio do super-resfriamento crítico para nucleações e $\Delta T_{\sigma}$ define o desvio padrão desta distribuição. Portanto, a nucleação foi definida por seis valores $\left(n_{S, \max }, \Delta T_{S, n u c}, \Delta T_{S, \sigma}, n_{V, \max }, \Delta T_{V, n u c}\right.$ e $\left.\Delta T_{V, \sigma}\right)$, 
sendo três para a distribuição na superfície e três para o interior da cavidade do molde.

Logo, a densidade de número de núcleos presente em um líquido onde se atingiu um super-resfriamento $\Delta T$ é dada por:

$$
n(\Delta T)=\int_{0}^{\Delta T}\left[\frac{d n}{d(\Delta T)}\right] \cdot d(\Delta T)
$$

No início da simulação foi escolhida uma célula aleatoriamente, para a qual foi atribuído um super-resfriamento para nucleação, segundo a distribuição normal. Este passo foi repetido até que o número de máximo de núcleos fosse atingido. Se durante este procedimento a célula escolhida já contivesse um valor de superresfriamento para nucleação, comparava-se com o atual e o de menor valor seria atribuído.

Durante a simulação, as células eram verificadas quanto à nucleação; se o super-resfriamento no centro de uma célula fosse maior do que o seu superresfriamento para nucleação, esta deveria ser ativada.

\subsubsection{Acoplamento entre Submodelos Macroscópico e Mesoscópico}

Um acoplamento entre os submodelos macroscópico e mesoscópico foi realizado para possibilitar o cálculo do campo de temperaturas e do crescimento dos envelopes de grão. Neste acoplamento, o submodelo macroscópico fornece a variação de entalpia volumétrica para as células do submodelo mesoscópico $\left(\delta H_{C A}\right)$ a partir do cálculo desta variação na posição dos nós do volume finito ( $\left.\delta H_{V F}\right)$. Como existem diversas células do submodelo mesoscópico no interior de um volume finito (Figura 37), a variação de entalpia volumétrica é interpolada para cada célula a partir das posições dos nós. A fração de sólido no próximo instante de tempo do método numérico $\left(\varepsilon_{s}^{t+\delta t}\right)$ é calculada para cada célula da malha do modelo mesoscópico, utilizando-se a variação de entalpia $\left(\delta \mathrm{H}_{\mathrm{CA}}\right)$. Este cálculo é realizado através de uma equação (equação [39]) obtida a partir da equação abaixo:

$$
\delta H_{C A}^{t+\delta t}=\rho C p\left[T^{t+\delta t}-T^{t}\right]-\Delta H_{f} \rho\left[\varepsilon_{s}^{t+\delta}-\varepsilon_{s}^{t}\right]
$$


onde $\Delta H_{f}$ é o calor latente de fusão. Como a temperatura $T^{t+\delta t}$ também é desconhecida, uma relação entre $T^{t+\delta t}$ e $\varepsilon_{s}^{t+\delta t}$ deve ser fornecida para que se possa solucionar a equação [37]. Esta relação é obtida através do modelo de Scheil (Garcia, 2001), apresentado abaixo:

$$
\varepsilon_{s}=1-\left(\frac{T_{f}-T}{T_{f}-T_{l i q}}\right)^{\frac{1}{(k-1)}}
$$

Substituindo-se esta relação na equação [37], finalmente obtem-se a equação para o cálculo da variação da fração de sólido indicada abaixo:

$$
\delta \varepsilon_{s, C A}^{t+\delta t}=\frac{-\delta H_{C A}^{t+\delta t}}{\rho \cdot C p \cdot\left(T_{L}-T_{f}\right) \cdot(k-1) \cdot\left[1-\varepsilon_{s, C A}^{t}\right]^{(k-2)}+\Delta H_{f} \cdot \rho}
$$

onde $\delta \varepsilon_{s, C A}^{t+\delta t}$ representa a variação na fração de sólido do instante $t$ para o instante $t+$ $\delta t ; \delta H_{C A}^{t+\delta t}$ é a variação da entalpia interpolada na posição do centro da célula a partir dos valores calculados na posição dos nós dos volumes finitos (equação [24]) e ké o coeficiente de partição de soluto. Um esquema que mostra a relação entre a malha de células do submodelo mesoscópico e a malha de volumes finitos do submodelo macroscópico pode ser visto na Figura 37. 


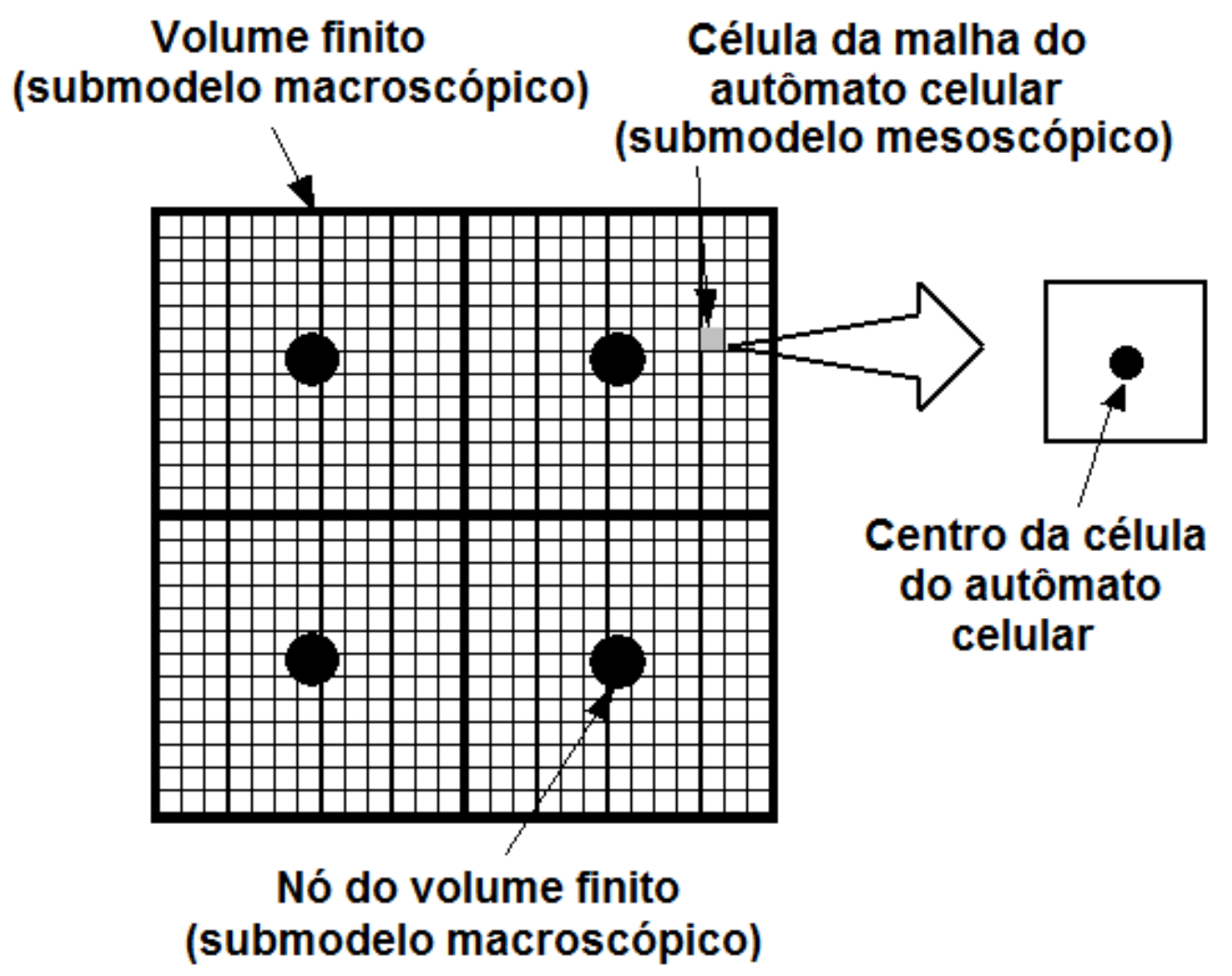

Figura 37- Representação esquemática da malha de volumes finitos (VF) utilizada no submodelo macroscópico e da malha de células empregada no submodelo mesoscópico.

A fração de sólido é atualizada após cada passo de tempo até que se atinja a temperatura da transformação eutética. Neste momento, se a fração de sólido ainda for menor que 1, considera-se uma transformação isotérmica $\left(\Delta T_{C A}=0\right)$ utilizando-se a equação [37] até que a fração de sólido se iguale a 1. A equação utilizada para o cálculo da fração de sólido na transformação isotérmica é então:

$$
\delta \varepsilon_{s, C A}^{t+\delta t}=-\frac{\delta H_{C A}^{t+\delta t}}{\Delta H_{f} \rho}
$$

A variação da fração de sólido em um volume finito é calculada através da média das variações calculadas para todas as células no interior deste volume, resultando em:

$$
\delta \varepsilon_{s, V F}^{t+\delta t}=\frac{\sum \delta \varepsilon_{s, C A}^{t+\delta t}}{n_{C A}}
$$


onde $\mathrm{n}_{\mathrm{CA}}$ é o número de células da malha do submodelo mesoscópico existentes no interior de cada volume finito. $O$ valor de $\delta \varepsilon_{s, V F}^{t+\delta t}$ é utilizado para o cálculo da temperatura no volume finito no tempo $t+\delta t$ através da seguinte equação:

$$
T^{t+\delta t}=\frac{\Delta H_{f} \rho\left[\delta \varepsilon_{s, V F}^{t+\delta t}\right]+\delta H_{V F}^{t+\delta t}}{\rho C_{p}}+T^{t}
$$

onde $\Delta H_{f}$ é o calor latente de fusão por unidade de massa.

\subsubsection{Seqüência de Execução dos Passos do Algoritmo}

O modelo estocástico tradicional descrito foi implementado em um código computacional escrito em linguagem de computador ANSI C e os resultados obtidos através deste código foram gerados em um computador pessoal com microprocessador Pentium $\mathrm{IV}^{\circledR}$. No código computacional utilizou-se o seguinte algoritmo de cálculo:

a) Todos os substratos para a nucleação heterogênea são distribuídos aleatoriamente entre as células e associa-se um super-resfriamento para nucleação segundo a distribuição normal;

b) Os volumes finitos têm a sua temperatura inicial igualada à temperatura de vazamento do metal líquido;

c) A fração de sólido de todas as células da malha do modelo mesoscópico é igualada a zero;

d) Atualiza-se o tamanho de todos os quadrados de crescimento associados às células, ativam-se as células cujos centros são tocados;

e) Calcula-se a variação de entalpia de todos os volumes finitos pelo submodelo macroscópico (equação [24]);

f) Ativam-se as células que possuam substratos com um superresfriamento para nucleação menor ou igual ao observado em seus sítios; 
g) Calcula-se a variação da entalpia no centro de cada célula por interpolação linear a partir da variação de entalpia calculada nos nós dos volumes finitos;

h) Calcula-se a variação da fração de sólido de cada célula ativa do (equação [39]) e, a partir desta, calcula-se a variação da fração de sólido do volume finito (equação [41]);

i) Sabendo-se a variação da fração de sólido para cada volume finito, atualiza-se a temperatura para o instante posterior $\left(T^{t+\delta t}\right)$ para todos os volumes finitos (equação [42]);

j) Retorna-se ao subitem d se o tempo de simulação for menor do que o tempo total desejado.

\subsection{Definição da Transição Colunar-Equiaxial em uma Macroestrutura de Grãos}

O modelo estocástico apresenta, como um de seus principais resultados, a macroestrutura de grãos. Alguns parâmetros quantitativos, como o tamanho de grãos médio e a posição da transição colunar equiaxial (CET - "Columnar-toEequiaxed Transition") podem ser extraídos desta macroestrutura calculada. Existem diversos procedimentos, inclusive normalizados pelo ASTM ("American Society for Testing and Materials"), para se medir o tamanho de grão médio a partir da imagem de uma seção da macroestrutura de grãos. No entanto, não existe uma metodologia que permita definir uma posição para a CET. No presente trabalho, uma definição clara desta posição é importante, pois a posições da CET calculadas por diferentes modelos serão comparadas.

Segundo Vandyoussefi e Greer (2002) e Dong, Yang e Lee (2004), a CET é uma transição gradual, tornando difícil a identificação de uma única posição. Alguns autores tentaram definir um critério para o aparecimento da CET, e conseqüentemente a sua posição, mas não para identificar a sua posição a partir das macroestruturas obtidas em simulações com os modelos estocásticos: Dong, Yang e Lee (2004), e Dong e Lee (2005) assumiram a existência da CET na posição 
em que mais da metade dos grãos colunares eram bloqueados pelos grãos equiaxiais.

Liu et al. (2006) utilizaram um critério não só para definir a existência da CET mas também para definir a sua posição. Estes autores definiram o comprimento da zona colunar como sendo igual ao comprimento médio dos grãos colunares que crescem perpendicularmente à superfície do molde. A posição da CET foi assumida igual ao comprimento da zona colunar. Esta definição poderia ser utilizada, porém os autores não definiram como distinguir um grão como sendo colunar ou equiaxial. Especialmente na região da CET, esta definição não é clara e torna-se subjetiva. Os primeiros critérios apresentados não puderam ser utilizados para definir a posição da CET, pois ambos necessitavam, em uma etapa anterior, de um critério para identificar o tipo de grão. Por este motivo tornou-se necessária a implementação de um método capaz de identificar o tipo de grão e, conseqüentemente a CET, a partir das macrografias obtidas nas simulações. Alguns critérios foram obtidos na literatura (Allen, 1981; German, 1984) e são apresentados a seguir.

A forma de uma partícula e, conseqüentemente de um grão, pode ser expressa por um parâmetro que utiliza a razão entre o diâmetro do menor círculo que envolve a partícula e o diâmetro do círculo que possui a mesma área da partícula (German, 1984). Esta forma de cálculo não foi utilizada no presente trabalho, pois apresenta uma sensibilidade maior às irregularidades do contorno das partículas do que ao seu formato. Outro parâmetro, segundo Allen (1981), é o fator de forma ("shape factor"), que é definido como sendo a razão entre a maior dimensão da partícula ao quadrado e a sua área. Tal parâmetro também apresenta uma alta sensibilidade às irregularidades do contorno das partículas.

Segundo German (1984) a razão de aspecto ("aspect ratio") é o fator mais adequado para identificação da geometria e é definida pela razão entre a maior e a menor dimensão de uma partícula. Valores de razão próximos de 1 representariam partículas esféricas e valores entre 3 e 5, partículas alongadas. Allen (1981) definiu a razão de aspecto como sendo o recíproco daquela definida por German (1984).

A maior e a menor dimensão são definidas pelo conceito de calibre. Segundo este conceito, as dimensões são tomadas ao se inscrever a partícula entre duas linhas paralelas, como mostrado na Figura 38. 


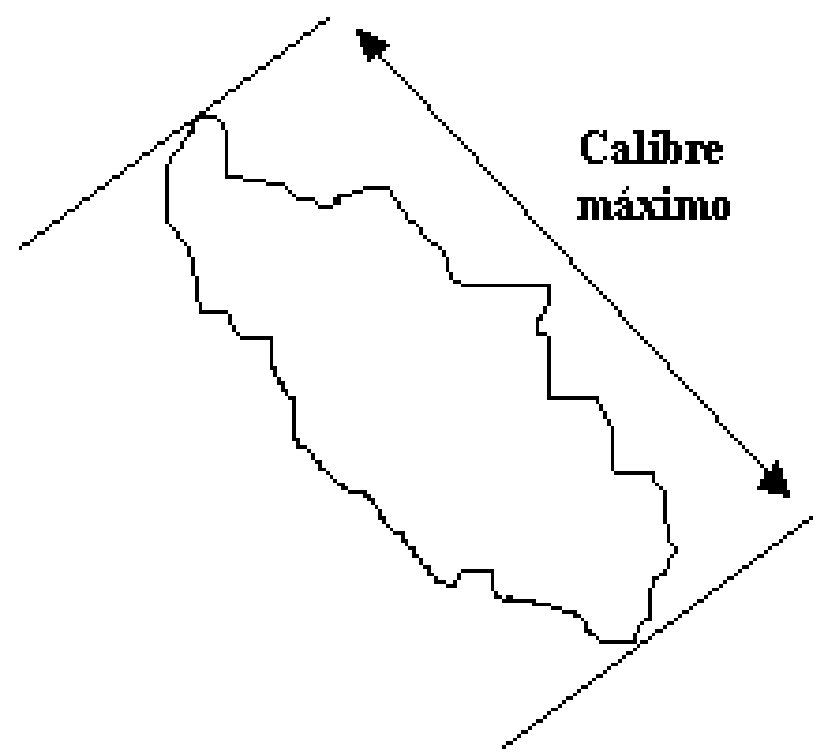

Figura 38- Definição do cálculo de uma dimensão segundo o conceito do calibre (German, 1984).

As definições apresentadas para a razão de aspecto não foram utilizadas no presente trabalho devido à dificuldade de implementação computacional. Após análise dos parâmetros citados acima e das suas respectivas limitações, implementou-se um método que reproduz aproximadamente os valores da razão de aspecto definida por Allen (1981). A nova razão de aspecto implementada consiste no cálculo das duas maiores dimensões ortogonais de um grão, como descrito abaixo:

a) Primeiramente encontra-se o tamanho do maior segmento de reta que pode ser colocado dentro do grão (r1);

b) Encontra-se o maior segmento de reta possível de ser colocado dentro do mesmo grão (r2), mas que seja ortogonal ao primeiro segmento;

c) A razão de aspecto é definida como $\phi=r 2 / r 1$ (Figura 39). 


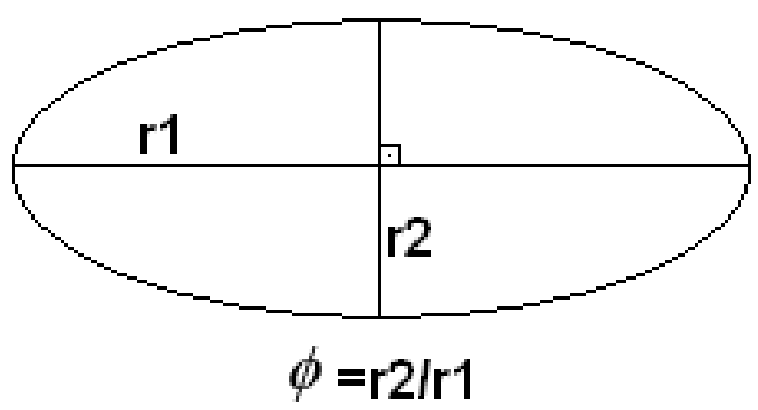

Figura 39- Definição do cálculo da razão de aspecto para uma elipse.

Segundo este método de cálculo da razão de aspecto, os grãos com formato alongado (grãos colunares) apresentam $r 1 \gg r 2$ e, por conseguinte, possuem uma razão de aspecto menor do que 1. Por outro lado, os grãos com um formato próximo ao formato de um círculo (grãos equiaxiais) apresentam as dimensões $r 1$ e $r 2$ próximas e, com isso, possuem uma razão de aspecto mais próxima de um.

A partir da macrografia gerada pelo modelo estocástico define-se a posição da CET da seguinte forma:

a) Calcula-se a razão de aspecto para cada grão como definida anteriormente;

b) Associa-se a cada célula da malha do submodelo mesoscópico (autômato celular) a razão de aspecto do grão ao qual esta pertence;

c) Define-se a razão de aspecto do volume finito como sendo a média das razões de aspecto associadas a todas as células do modelo mesoscópico localizadas em seu interior.

A partir da razão de aspecto em função da distância ao longo de um eixo paralelo à direção de extração de calor (Figura 40), define-se que as regiões que apresentarem uma razão sempre menor que 0,3 são compostas por grãos colunares, enquanto regiões com uma razão sempre maior que 0,4 são formadas por grãos equiaxiais. As regiões com uma razão de aspecto com valores intermediários $(0,3$ a 0,4$)$, ou seja, regiões definidas pela primeira ocorrência do valor 0,3 e a última ocorrência do valor 0,4 representam a região da CET. Nos casos onde a ocorrência do valor 0,4 não está presente, pois este ocorreria além do 
extremo do domínio, define-se o extremo do domínio como o extremo da região de transição.

Os valores definidos para a razão de aspecto $(0,3$ e 0,4$)$ foram adotados após terem sido testados para definir a CET em várias macroestruturas calculadas. Observou-se que estes valores forneciam a localização da CET que concordava com uma definição baseada simplesmente em um exame visual. Desta forma, definiu-se a posição da CET como sendo o centro desta região para possibilitar a comparação com os resultados obtidos pelo modelo determinístico. A Figura 40 apresenta a variação da razão de aspecto ao longo da macroestrutura e a posição da CET para três macroestruturas calculadas pelo modelo estocástico tradicional implementado.

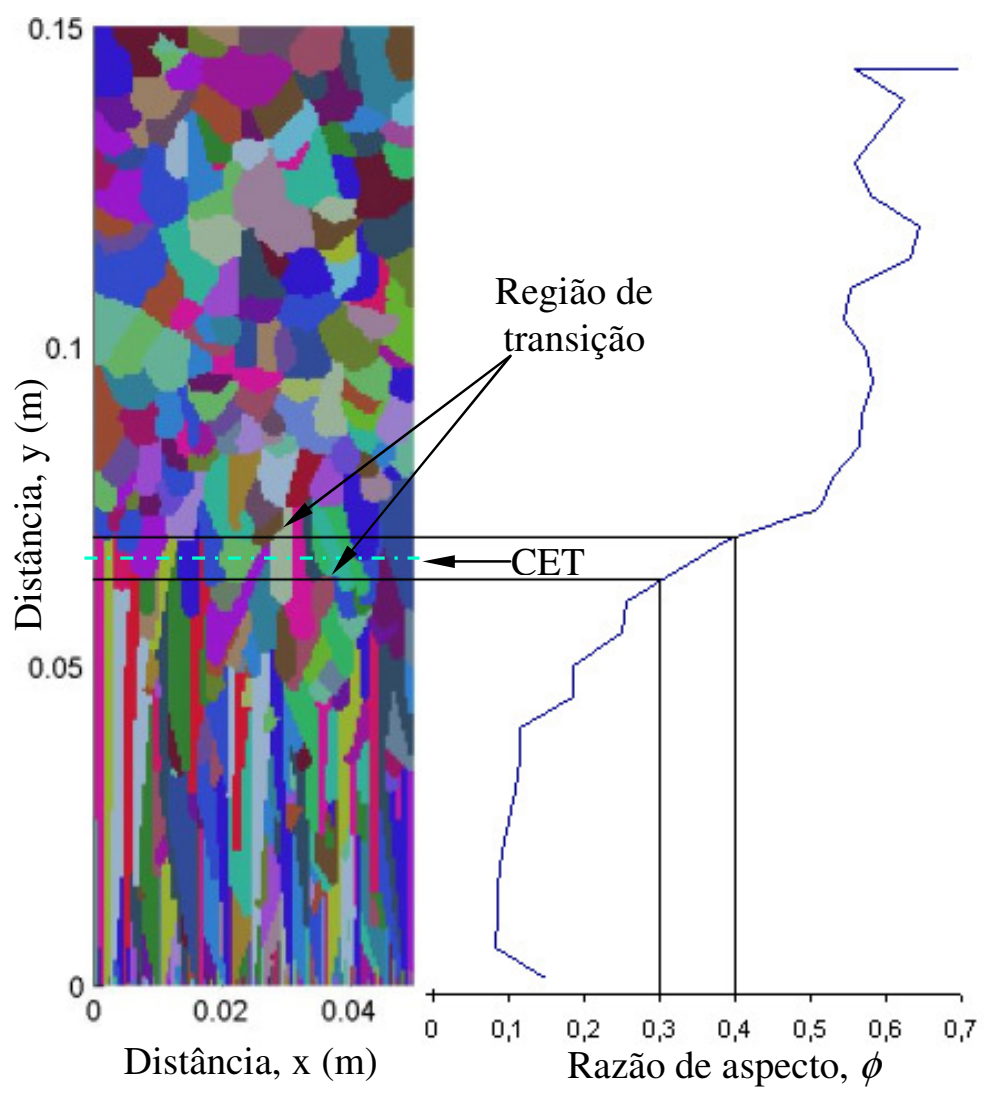



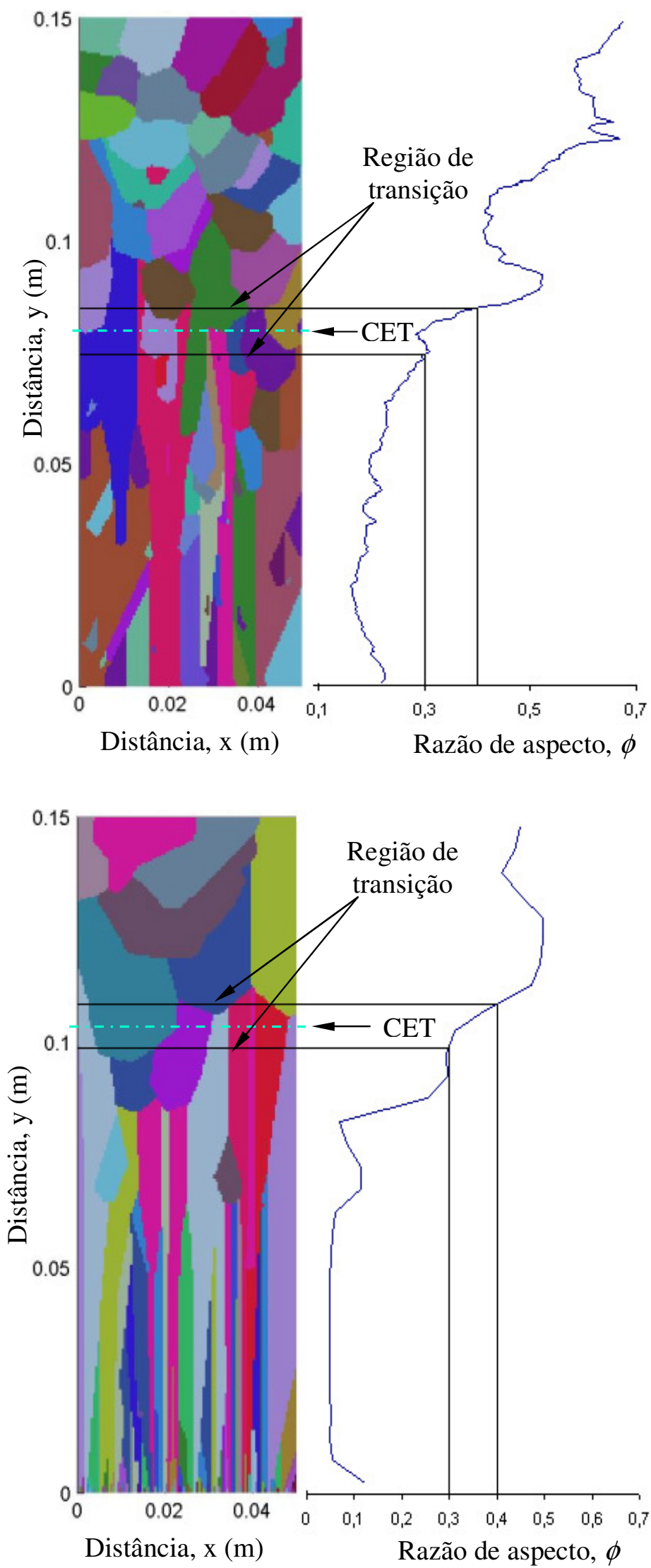

Figura 40- Razão de aspecto em função da posição juntamente com as macrografias calculadas. 


\subsubsection{Análise da Razão de Aspecto ("aspect ratio")}

Para determinar a correta implementação do algoritmo que calcula a razão de aspecto, foi necessário realizar alguns testes para verificar os seguintes preceitos:

a) A razão de aspecto prevista não deve sofrer influência do tamanho da malha de células do modelo mesoscópico acima de um certo número máximo de células, ou seja, a razão de aspecto deve convergir para um único valor mediante ao refino da malha;

b) A razão de aspecto prevista não deve alterar-se com a rotação ou translação da malha.

A realização dos testes foi feita com a utilização da imagem de uma elipse, pois esta pode tanto representar um grão colunar, quanto um grão equiaxial e sua razão de aspecto $(\phi)$ é facilmente calculada pela razão entre o seu menor e maior semi-eixo. A função que representa a elipse é dada a seguir (Figura 41):

$$
\frac{(X-C x)^{2}}{a}+\frac{(Y-C y)^{2}}{b}=1
$$

onde $C x$ e Cy são as coordenadas do centro da elipse nos eixos x e y; a é o tamanho do maior eixo e $b$ é o tamanho do menor.
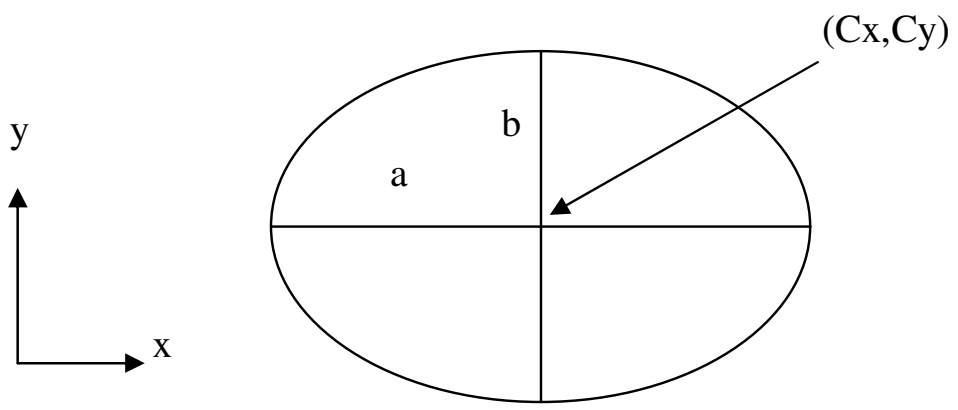

Figura 41- Representação de uma elipse no sistema cartesiano. 


\subsubsection{Influência do Tamanho da Malha}

A malha de células do modelo mesoscópico é utilizada para representar a imagem dos grãos e, conseqüentemente, seu tamanho pode afetar o valor da razão de aspecto. A quantidade de elementos utilizados para representar um grão influencia claramente na definição gráfica do mesmo, como se observa na definição da elipse apresentada na Figura 62. Para se verificar esta influência no cálculo da razão de aspecto, realizaram-se testes com diferentes tamanhos de malhas. Para cada malha escolhida, os seguintes números de células ao longo do menor eixo da elipse foram utilizados: 3, 15, 30, 60, 120 e 180. A elipse utilizada foi definida pelos seguintes parâmetros: eixo maior $b=0,5 \mathrm{~m}$; eixo menor $a=0,3 \mathrm{~m}$ e razão de aspecto $\phi=0,6$. A razão de aspecto calculada e as imagens correspondentes são apresentadas na Figura 42.

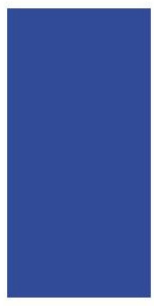

3 $\phi=0,447$

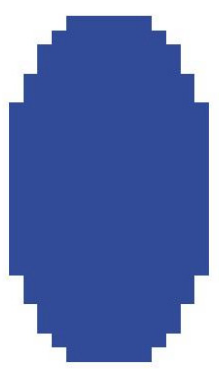

15

$$
\phi=0,567
$$

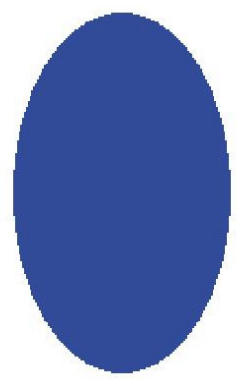

120

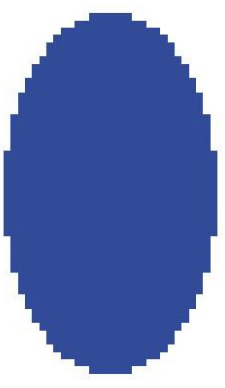

30

$\phi=0,592$

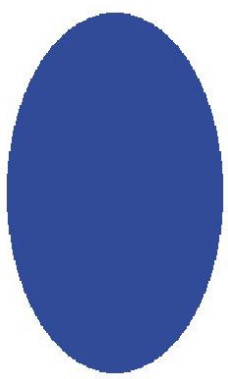

180

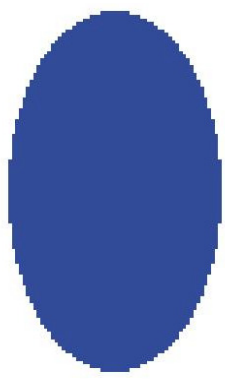

60

$\phi=0,596$

$$
\phi=0,598 \quad \phi=0,599
$$

Figura 42- Teste de influência do tamanho da malha (indicada pelo número de células ao longo do menor eixo da elipse, apresentado logo abaixo da figura) no cálculo da razão de aspecto $\phi$. 
Os dados apresentados na Figura 42 foram compilados em forma de um gráfico na Figura 43, onde se verifica que, ao se aumentar o número de células, atinge-se um patamar no valor da razão de aspecto.

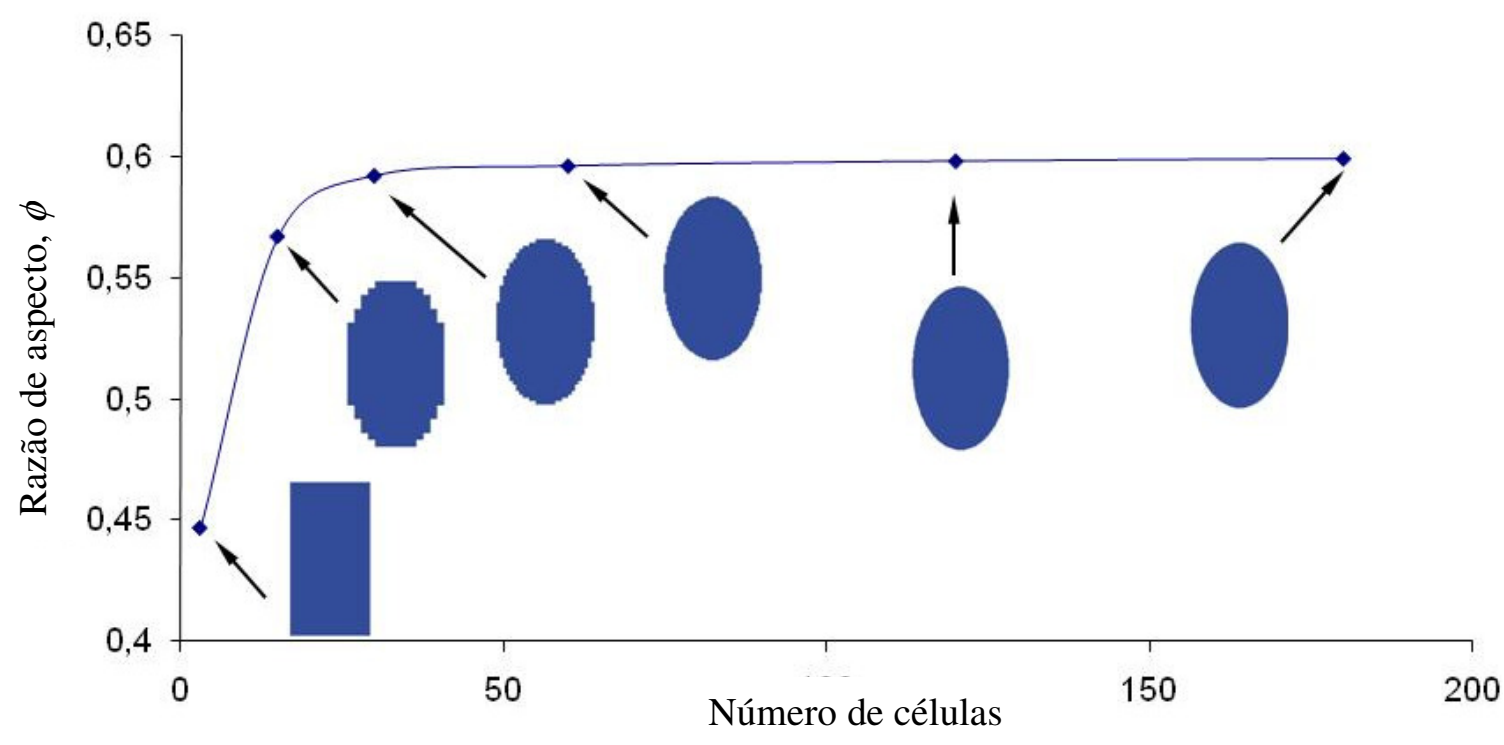

Figura 43- Gráfico da razão de aspecto $\phi$ em função do número de células para o teste de refino de malha.

Após análise dos dados apresentados na Figura 43, nota-se que uma elipse que possua somente 3 células ao longo do seu menor eixo apresenta a razão de aspecto de um retângulo e não de uma elipse. Observa-se que uma elipse que possua 30 células ao longo do seu menor eixo, apresenta uma razão de aspecto calculada com um erro de somente $1,3 \%$, em relação à razão de aspecto real. Apesar de um número de 60 células ser considerado mais adequado, pois apresenta uma melhor resolução da elipse, ele acarretaria em um maior tempo computacional. O número de 30 células encontrado nos testes é necessário para alertar sobre possíveis problemas no cálculo da razão de aspecto das macroestruturas que serão apresentadas no presente trabalho.

\subsubsection{Influência da Rotação}

Um teste foi realizado para verificar o comportamento do método de cálculo da razão de aspecto com relação à rotação da partícula. Uma mesma partícula ao 
ser rotacionada, não deve apresentar variações significativas na sua razão de aspecto, quando uma malha adequada for utilizada.

O teste foi realizado com uma elipse com os mesmos parâmetros do teste anterior ( $a=0,3 \mathrm{~m}$ e $b=0,5 \mathrm{~m})$ e com 30 células ao longo do seu menor eixo. As elipses rotacionadas e seus fatores de forma calculados estão na Figura 44.

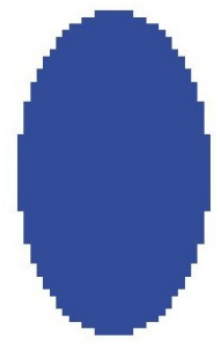

$$
\begin{gathered}
\omega=0^{\circ} \\
\phi=0,592
\end{gathered}
$$

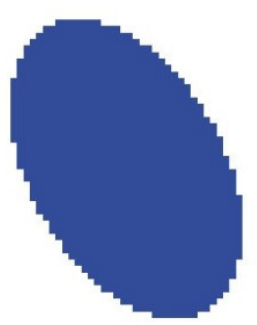

$$
\begin{gathered}
\omega=30^{\circ} \\
\phi=0,586
\end{gathered}
$$

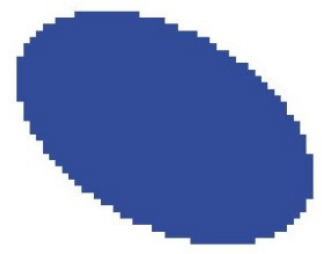

$\omega=60^{\circ}$

$\phi=0,586$

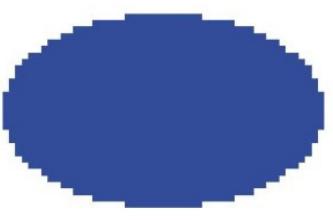

$$
\begin{gathered}
\omega=90^{\circ} \\
\phi=0,592
\end{gathered}
$$

Figura 44- Teste de rotação das elipses, onde $\phi$ representa a razão de aspecto obtida através do método desenvolvido e $\omega$, o ângulo de rotação.

Observa-se na Figura 45 que os valores obtidos para a razão de aspecto em função da inclinação da elipse mostraram uma variação de apenas aproximadamente $1 \%$ entre o máximo e o mínimo. Com este teste certificou-se que grãos que possuem a mesma forma apresentarão razões de aspecto próximas, independente da sua orientação, considerando a utilização de 30 células ao longo do menor eixo da elipse. 


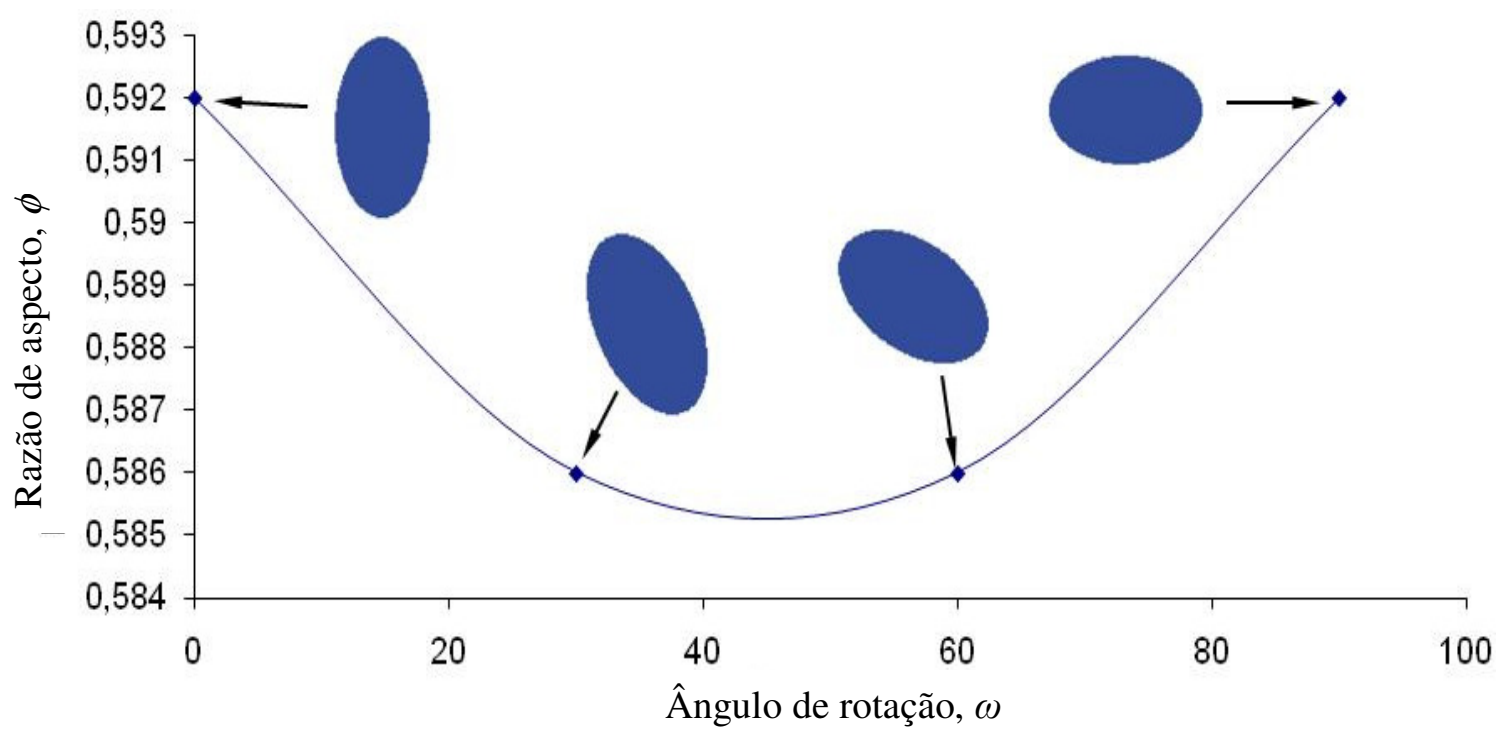

Figura 45- Gráfico da razão de aspecto $\phi$ em função do ângulo de rotação da elipse $\omega$.

\subsection{Modelo Determinístico}

O modelo determinístico proposto por Martorano, Beckermann e Gandin (2003) para previsão da CET foi utilizado na primeira parte do trabalho, com o objetivo de comparar o seu equacionamento e resultados aos do modelo estocástico. Na segunda parte do trabalho, este modelo determinístico foi utilizado em comparações com o novo modelo híbrido proposto. No entanto, o código computacional deste modelo determinístico não foi implementado, por que o código produzido pelos autores foi disponibilizado para sua utilização

As equações principais do modelo determinístico implementado por Martorano, Beckermann e Gandin (2003) serão apresentadas. No modelo determinístico empregado utiliza-se o modelo de nucleação instantânea (item 3.1.3) e assume-se a existência de um envelope de grão que, quando o grão é dendrítico, toca a ponta dos braços de dendrita e delineia cada grão colunar e equiaxial. Segundo este conceito de envelope define-se três pseudofases: a fase sólida (s); a fase líquido interdendrítico (d) e a fase líquido extradendrítico (I). As duas primeiras fases encontram-se dentro do envelope dendrítico. Este conceito está representado na Figura 46. 


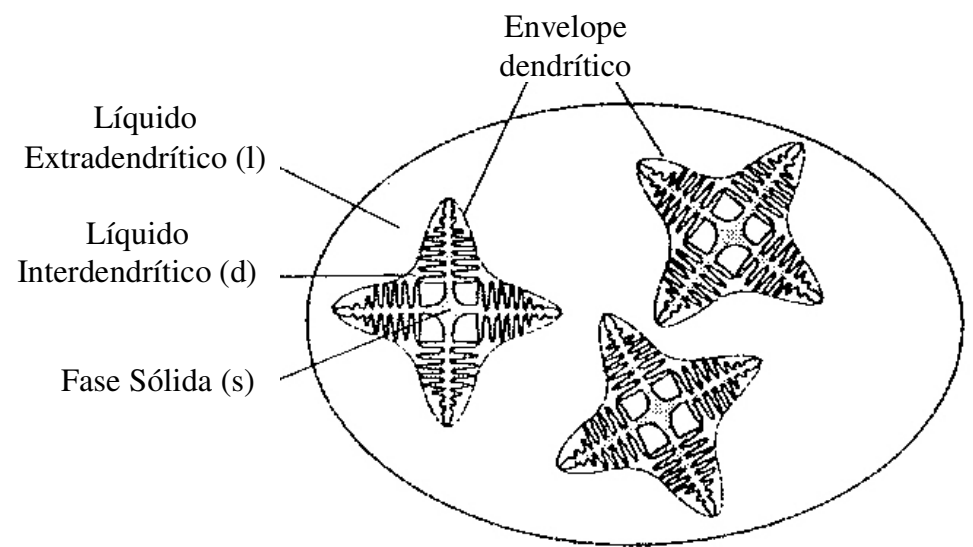

Figura 46 - Representação esquemática do conceito do envelope dendrítico (Wang; Beckermann, 1993a).

No modelo determinístico resolvem-se as equações chamadas de macroscópicas de conservação da energia, de massa e das espécies químicas sem o efeito da convecção no líquido ou movimentação dos grãos. Tais equações são desenvolvidas a partir da definição de um volume elementar representativo (REV "Representative Elementary Volume") macroscópico, onde se encontram as três fases (d, l, s). No interior do REV, é feita uma média volumétrica das equações de conservação tradicionais, chamadas de microscópicas, resultando em equações gerais de conservação macroscópicas. As seguintes hipóteses foram ainda assumidas no modelo de Martorano, Beckermann e Gandin (2003):

a) Transporte unidirecional de calor;

b) Concentração homogênea de soluto $\left(C_{l}^{*}\right)$ no líquido interdendrítico;

c) Equilíbrio termodinâmico entre o líquido interdendrítico e o sólido na posição da interface sólido-líquido, desta forma a concentração de soluto neste líquido pode ser dada em função da temperatura utilizando a equação da linha liquidus do diagrama de fases;

d) Difusão desprezível no sólido;

e) Existência de um equilíbrio térmico entre a fase sólida e a líquida;

f) A temperatura é assumida igual para todas as fases no interior do REV (equilíbrio térmico macroscópico);

g) Convecção no líquido e transporte de grãos desprezíveis; 
h) Densidade das fases sólida e líquida constantes e iguais;

i) Mistura completa no líquido interdendrítico;

j) Difusão macroscópica desprezível.

Aplicando estas hipóteses às equações de conservação macroscópicas, obtém-se o seguinte conjunto de equações finais do modelo determinístico:

$$
\begin{gathered}
\rho C_{P} \frac{\partial T}{\partial t}=\frac{\partial}{\partial y}\left(\kappa \frac{\partial T}{\partial y}\right)+\rho \Delta H_{f} \frac{\partial \varepsilon_{S}}{\partial t} \\
(1-k) C_{l}^{*} \frac{\partial \varepsilon_{S}}{\partial t}=\varepsilon_{d} \frac{\partial C_{l}^{*}}{\partial t}+S_{e} \frac{D_{l}}{\delta_{e}}\left(C_{l}^{*}-C_{l}\right) \\
\frac{\partial\left(\varepsilon_{l} C_{l}\right)}{\partial t}=C_{l}^{*} \frac{\partial \varepsilon_{l}}{\partial t}+S_{e} \frac{D_{l}}{\delta_{e}}\left(C_{l}^{*}-C_{l}\right)
\end{gathered}
$$

onde $C_{l}$ é a concentração média no líquido extradendrítico; $D_{l}$ é difusividade do soluto na fase líquida; $\varepsilon_{S}, \varepsilon_{d}$ e $\varepsilon_{l}$ são as frações volumétricas de sólido, líquido interdendrítico e líquido extradendrítico, respectivamente; $\delta_{e}$ é a distância efetiva de difusão de soluto ao redor dos envelopes dendríticos; $\kappa$ é a condutividade térmica média e depende da condutividade térmica das fases líquida $\left(\kappa^{L}\right)$ e sólida $\left(\kappa^{S}\right)$, sendo calculada por: $\kappa=\left(\varepsilon_{l}+\varepsilon_{d}\right) \kappa^{L}+\varepsilon_{S} \kappa^{S} ; C_{l}^{*}$ é a concentração de soluto no líquido interdendrítico. Esta concentração é calculada pela equação da linha liquidus do diagrama de fases binário como:

$$
C_{l}^{*}=\frac{\left(T-T_{f}\right)}{m_{l}}
$$

onde $m_{l}$ é a inclinação da linha liquidus.

A taxa de variação da fração volumétrica do líquido extradendrítico com o tempo é dada por:

$$
\frac{\partial \varepsilon_{l}}{\partial t}=-\frac{\partial \varepsilon_{g}}{\partial t}=-S_{e} V
$$


onde $\varepsilon_{g}$ é a fração volumétrica de envelope $\left(\varepsilon_{g}=\varepsilon_{s}+\varepsilon_{d}\right) ; V$ é a velocidade de crescimento da ponta do braço da dendrita e $S_{e}$ a área interfacial de envelope por unidade de volume (concentração de área interfacial), que é dada por:

$$
S_{e}=\frac{3\left(1-\varepsilon_{l}\right)^{\frac{2}{3}}}{R_{f}}
$$

sendo $2 R_{f}$ a distância característica entre os centros dos envelopes que é definida diferentemente para o grão equiaxial e o colunar, como dado abaixo:

$$
\text { equiaxial: } R_{f}=\left(\frac{3}{4 \pi n}\right)^{\frac{1}{3}}
$$

$$
\text { colunar: } R_{f}=\lambda_{1} / 2
$$

onde $n$ é a densidade de número de núcleos de grão existentes e $\lambda_{1}$ o espaçamento entre os braços primários de dendrita.

A velocidade de crescimento da ponta da dendrita é obtida através do modelo originalmente proposto por Lipton, Glicksman e Kurz (1984), denominado de LGK e utilizado para o cálculo do crescimento dos envelopes:

$$
V=\frac{D_{l} m_{l}(k-1) C_{l}^{*}}{\Gamma}\left(I v^{-1}(\Omega)\right)
$$

onde $\Gamma$ é o coeficiente de Gibbs-Thomson e $I v^{-1}$ é o inverso da função de Ivantsov, que pode ser aproximada por:

$$
I v^{-1}(\Omega)=0,4567\left(\frac{\Omega}{1-\Omega}\right)^{1,195}
$$

sendo o super-resfriamento adimensional, $\Omega$, definido por:

$$
\Omega=\frac{C_{l}^{*}-C_{l}}{C_{l}^{*}(1-k)}
$$

Neste modelo (Martorano; Beckermann; Gandin, 2003) é necessário um acompanhamento da posição da frente colunar para se decidir quanto à utilização da 
equação [50] ou [51] no cálculo de $R_{f}$ e quanto à posição de ocorrência da CET. Este acompanhamento é realizado segundo a equação abaixo:

$$
\frac{d y_{c o l}}{d t}=V_{c o l}
$$

onde $y_{c o l}$ é a posição da frente colunar e $V_{c o l}$ é a velocidade da frente colunar calculada através da equação [52] utilizando-se as concentrações $C_{l}$ e $C_{l}^{*}$ calculadas na posição da frente.

Nos modelos determinísticos, a CET ocorre quando o crescimento dos grãos colunares é bloqueado e, portanto, o valor de $y_{c o l}$ na equação [55] permanece fixo a partir deste momento, indicando a posição da CET. No modelo determinístico proposto por Martorano, Gandin e Beckermann (2003), o bloqueio dos grãos colunares ocorre quando a sua velocidade, calculada a partir da equação [52], tende a zero. Este processo ocorre quando o soluto rejeitado pelo crescimento dos grãos equiaxiais a frente dos grãos colunares reduz o super-resfriamento para o crescimento dado pela equação [54]. Portanto, diz-se que ocorreu um bloqueio de soluto.

\subsection{Modelo Híbrido Estocástico-Determinístico (CADE)}

Um novo modelo matemático para previsão da formação da macroestrutura de grãos durante a solidificação está sendo proposto neste item. O novo modelo será chamado de híbrido estocástico-determinístico (CADE - "Cellular Automaton Deterministic") e será baseado na combinação do modelo estocástico do autômato celular proposto por Gandin e Rappaz (1997), chamado de CAFE, e do modelo determinístico multifásico propostos por Wang e Beckermann (1994) e Martorano, Beckermann e Gandin (2003). Desta forma, o modelo CADE engloba as características da previsão macroestrutural, inerente ao modelo estocástico do autômato celular e utiliza as sólidas equações de conservação definidas nos modelos determinísticos.

O modelo estocástico do autômato celular implementado no modelo CAFE foi selecionado pelos autores, pois este é considerado o precursor dos modelos 
estocásticos que utilizam o autômato celular para a previsão da macroestrutura de grãos. A combinação dos modelos estocástico e determinístico empregados no modelo CADE apresenta as seguintes vantagens em relação aos modelos determinísticos originais:

- Possibilidade da previsão da CET em duas e três dimensões sem a necessidade de um método para determinar a posição da frente colunar em problemas multidimensionais;

- Obtenção de uma imagem da macroestrutura de grãos;

- Maior facilidade no tratamento da nucleação de grãos quando uma distribuição de super-resfriamentos críticos para nucleação é adotada.

O novo modelo proposto também apresenta algumas vantagens, citadas abaixo, em relação ao modelo estocástico tradicional:

- Previsão da fração de sólido de forma mais consistente com todas as equações do modelo, devido à utilização de um novo acoplamento entre os modelos macroscópico e mesoscópico;

- Utilização das equações de conservação, provenientes dos modelos determinísticos, que já foram desenvolvidas e testadas para simular a solidificação em diversas situações, incluindo o efeito da convecção no líquido e movimentação de grãos;

- Cálculo do fluxo de soluto dos envelopes de grão para o líquido extradendrítico, e conseqüente influência do acúmulo deste soluto para o crescimento dos grãos.

A apresentação do CADE foi dividida em cinco partes: (1) apresentação das equações de conservação do submodelo macroscópico; (2) apresentação do submodelo mesoscópico; (3) apresentação das equações suplementares; (4) discretização das equações de conservação e (5) seqüência de execução do algoritmo. 


\subsubsection{Equações de Conservação do Submodelo Macroscópico}

As equações de conservação utilizadas para definir o submodelo macroscópico são baseadas no modelo de Wang e Beckermann (1994), que assumiram a existência de um envelope que toca a ponta dos braços da dendrita e delineia cada grão colunar e equiaxial (modelo de envelope de grão). O presente modelo também considera um fluxo de soluto que sai do envelope e entra no líquido extradendrítico, sendo que, segundo o conceito de envelope dendrítico, definem-se três pseudofases: a fase sólida (s); a fase líquido interdendrítico (d) e a fase líquido extradendrítico (I). As duas primeiras fases encontram-se dentro do envelope dendrítico. $O$ desenho esquemático de um envelope dendrítico pode ser visto na Figura 47.

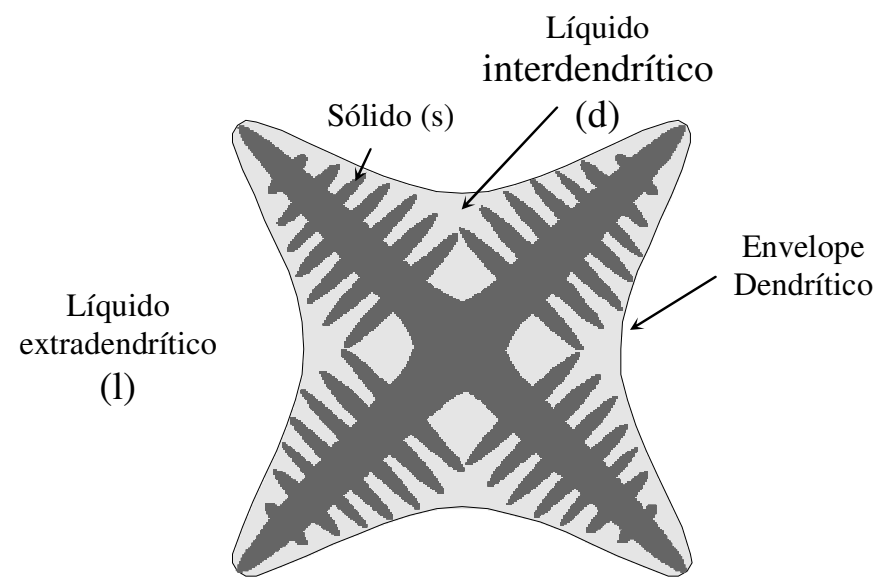

Figura 47 - Desenho esquemático de um envelope de grão e suas pseudo-fases (Martorano; Beckermann; Gandin, 2003).

Primeiramente as equações de conservação de massa, energia e espécies químicas são escritas para as três fases; posteriormente a técnica da média volumétrica é aplicada nestas fases localizadas no interior de um volume elementar representativo (REV - "Representative Elementary Volume"). Durante o desenvolvimento deste equacionamento, as seguintes hipóteses foram aplicadas (Wang e Beckermann, 1994):

a) Transporte unidirecional de calor;

b) Concentração homogênea de soluto $\left(C_{l^{*}}^{*}\right.$ no líquido interdendrítico; 
c) Equilíbrio termodinâmico entre o líquido interdendrítico e o sólido na posição da interface sólido-líquido; desta forma a concentração de soluto neste líquido pode ser dada em função da temperatura utilizando a equação da linha liquidus do diagrama de fases;

d) Difusão de soluto desprezível no sólido;

e) Equilíbrio térmico entre todas as fases no interior do REV (a temperatura de todas as fases é igual em um dado ponto do domínio);

f) Convecção no líquido e transporte de grãos desprezíveis;

g) Densidade das fases sólida e líquida constantes e iguais;

h) Mistura completa no líquido interdendrítico;

i) Difusão macroscópica de soluto no líquido é desprezível.

As equações de conservação obtidas a partir destas hipóteses para um domínio bidimensional (x;y) foram:

$$
\begin{gathered}
\frac{\partial H}{\partial t}=\frac{\partial}{\partial x}\left(\kappa \frac{\partial T}{\partial x}\right)+\frac{\partial}{\partial y}\left(\kappa \frac{\partial T}{\partial y}\right) \\
(1-k) C_{l}^{*} \frac{\partial \varepsilon_{S}}{\partial t}=\varepsilon_{d} \frac{\partial C_{l}^{*}}{\partial t}+s_{e} \frac{D_{l}}{\delta_{e}}\left(C_{l}^{*}-C_{l}\right) \\
\frac{\partial\left(\varepsilon_{l} C_{l}\right)}{\partial t}=C_{l}^{*} \frac{\partial \varepsilon_{l}}{\partial t}+S_{e} \frac{D_{l}}{\delta_{e}}\left(C_{l}^{*}-C_{l}\right)
\end{gathered}
$$

onde $H$ é a entalpia volumétrica; $T$ é a temperatura; $t$ é o tempo; $k$ é o coeficiente de partição de soluto; $C_{l}$ é a concentração média de soluto no líquido extradendrítico; $\varepsilon_{S}, \quad \varepsilon_{d}$ e $\varepsilon_{l}$ são respectivamente as frações volumétricas de: sólido, líquido interdendrítico e extradendrítico cuja soma é igual a $1\left(\varepsilon_{S}+\varepsilon_{d}+\varepsilon_{l}=1\right)$; $\kappa$ é o coeficiente de condutividade térmica, o qual depende das frações de sólido $\left(\varepsilon_{S}\right)$ e de líquido $\left(\varepsilon_{d}+\varepsilon_{l}\right)$; $D_{l}$ é o coeficiente de difusão de soluto no líquido; $\delta_{e}$ é a espessura efetiva de difusão ao redor do envelope dendrítico; $S_{e}$ é a área interfacial por unidade de volume (concentração de área) da interface entre o envelope e o líquido 
extradendrítico e $C_{l}^{*}$ é a concentração de soluto no líquido interdendrítico, que foi assumida uniforme segundo as hipóteses apresentadas.

\subsubsection{Submodelo Mesoscópico}

O submodelo mesoscópico é responsável pelo cálculo da nucleação e crescimento dos grãos e, para isso, utilizou-se o método do autômato celular, no qual o domínio foi divido em pequenas células quadradas, como explicado anteriormente para o modelo estocástico tradicional (item 4.1.2).

O submodelo utilizado no CADE é o mesmo já apresentado na descrição do modelo estocástico tradicional, com alterações na forma do cálculo da velocidade de crescimento dendrítico, e com a inclusão do cálculo da concentração de área interfacial entre os envelopes e líquido extradendrítico $\left(S_{e}\right)$ e do cálculo da fração volumétrica de envelopes $\left(\varepsilon_{g}\right)$. Este submodelo é o responsável por fornecer dados da macroestrutura de grãos para as equações do submodelo macroscópico. Da mesma forma que no modelo estocástico tradicional, no submodelo mesoscópico o domínio foi dividido em pequenas células quadradas com a função de simular a nucleação heterogênea e o crescimento de grãos.

\subsubsection{Nucleação}

O primeiro passo do submodelo mesoscópico é simular a nucleação dos grãos e para isso, da mesma forma que no modelo estocástico tradicional (item 4.1.2.2), utilizou-se um modelo de nucleação heterogênea baseado em duas distribuições normais de super-resfriamento para nucleação: uma para a parede interna do molde e outra para o interior de sua cavidade.

O processo de distribuição de substratos para nucleação também é igual ao apresentado para o modelo estocástico tradicional no item 4.1.2.2, onde no início da simulação se escolhe uma célula ao acaso e para esta é atribuída um superresfriamento para nucleação segundo a distribuição normal. Este processo é repetido tanto para o interior da cavidade quanto para a parede interna do molde, até que o número máximo de núcleos seja atingido. 
No decorrer da simulação, as células são verificadas quanto à presença de alguma partícula de substrato para nucleação em seu interior. Caso alguma partícula exista e ainda não tenha sido ativada por nucleação, o super-resfriamento no centro da célula em questão é verificado e comparado com o super-resfriamento para nucleação atribuído à partícula. Quando o super-resfriamento no centro da célula for maior ou igual ao super-resfriamento da partícula, a célula deverá ser ativada.

O super-resfriamento no centro da célula $(\Delta T)$ é calculado a partir da temperatura no centro da célula $(T)$ através da seguinte equação:

$$
\Delta T=T-T_{L}
$$

onde $T_{L}$ é a temperatura liquidus da liga.

\subsubsection{Velocidade de Crescimento}

A velocidade de crescimento, $V$, utilizada no cálculo do aumento do lado do quadrado de crescimento do autômato celular é calculada pelo modelo originalmente proposto por Lipton, Glicksman e Kurz (1984) (LGK):

$$
V=\frac{D_{l} m_{l}(k-1) C_{l}^{*}}{\Gamma}\left(I v^{-1}(\Omega)\right)
$$

onde $\Gamma$ é o coeficiente de Gibbs-Thomson; $m_{l}$ é a inclinação da linha liquidus do diagrama de fases binário e $I v^{-1}$ é o inverso da função de Ivantsov, que pode ser aproximada por:

$$
I v^{-1}(\Omega)=0,4567\left(\frac{\Omega}{1-\Omega}\right)^{1,195}
$$

sendo o super-resfriamento adimensional definido por:

$$
\Omega=\frac{C_{l}^{*}-C_{l}}{C_{l}^{*}(1-k)}
$$

O super-resfriamento adimensional $(\Omega)$ no centro da célula associada ao quadrado de crescimento é calculado de acordo com a equação [62], onde o $C_{l}^{*}$ é também calculado para o centro desta célula. $\mathrm{O}$ cálculo do $C_{l}^{*}$ é feito a partir da 
equação [69] onde $T$ deve ser a temperatura no centro da célula em questão, calculada por interpolação do campo de temperaturas calculado pelo submodelo macroscópico, e $C_{l}$ é a concentração de soluto do líquido extradendrítico, obtida a partir do campo fornecido também pelo modelo macroscópico, na posição do centro da célula.

Diferentemente do modelo estocástico tradicional, que considera somente a influência da temperatura no crescimento dos quadrados de crescimento, o modelo CADE considera o efeito da rejeição de soluto pelos envelopes ao líquido extradendrítico no crescimento dos grãos, analogamente ao modelo determinístico mostrado no item 4.3.

4.4.2.3 Cálculo da Fração de Grãos e da Concentração de Área Interfacial de Envelope

A fração volumétrica de grãos ou envelopes de grão $\left(\varepsilon_{g}\right)$ é definida como sendo a razão entre o volume total dos envelopes dentro do REV pelo volume deste REV. Porém, o submodelo mesoscópico foi desenvolvido em duas dimensões; portanto, esta fração é calculada pela razão entre a área ocupada pelos envelopes e a área do REV, que, por conveniência, foi assumida igual à área de um volume finito da malha utilizada para resolução numérica das equações do submodelo macroscópico. Deve-se ressaltar que, quando a distribuição da posição dos grãos no espaço é aleatória, a estereologia permite concluir que a fração em área de grãos em uma seção bidimensional de um domínio tridimensional é numericamente igual à fração volumétrica destes grãos. Desta forma, a fração de grãos ou envelope de grãos no interior de uma célula da malha do modelo mesoscópico é calculada pela seguinte equação:

$$
\varepsilon_{g C A}=\frac{\left(2 L_{i}\right)^{2}-A_{i}}{A_{\max }-A_{i}}
$$

onde $L_{i}$ é o tamanho do meio lado do quadrado de crescimento em um dado instante; $A_{i}$ é a área do quadrado de crescimento imediatamente após a sua criação e $A_{\max }$ representa a área máxima que o atual quadrado de crescimento pode atingir até que encontre o sítio no centro de alguma célula vizinha. Na Figura 48 está 
representado esquematicamente o quadrado de crescimento em um dado instante, bem como o seu tamanho inicial, ao qual se associa a área inicial $\left(A_{i}\right)$, e o seu tamanho máximo, que define a área máxima $\left(A_{\max }\right)$. Somente um sítio vizinho, localizado no centro da uma célula vizinha, está representado por questão de simplificação.

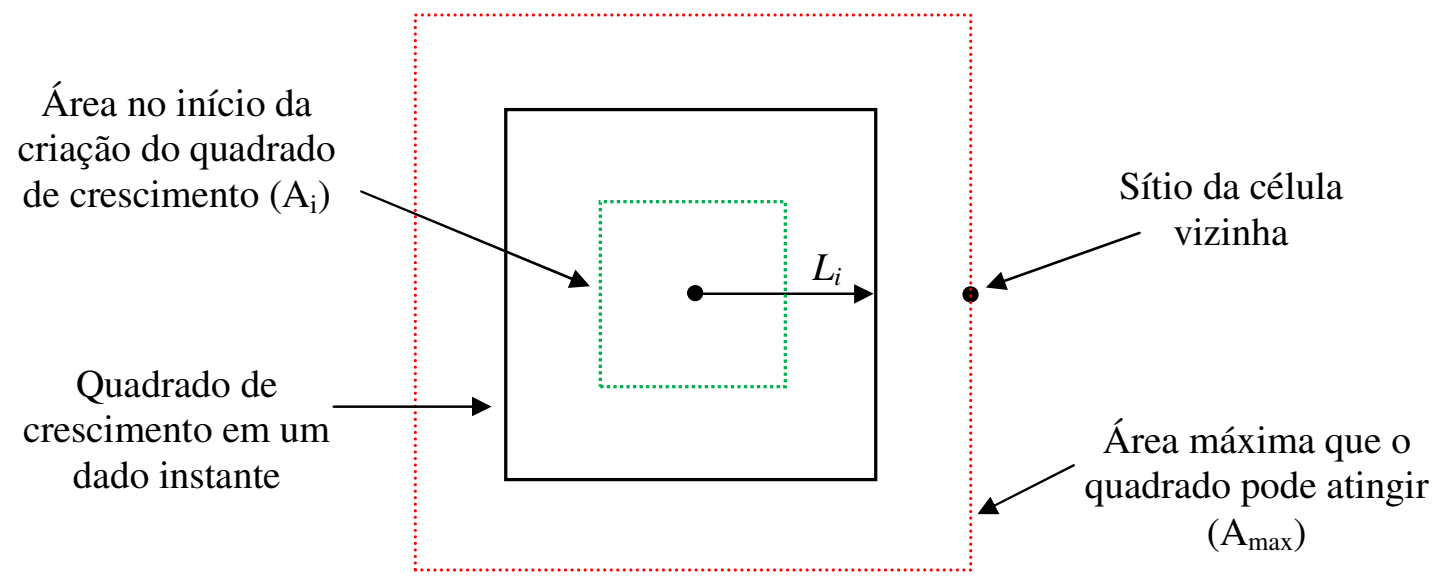

Figura 48 - Representação esquemática de um quadrado de crescimento em um dado instante, juntamente com o quadrado de crescimento inicial e o quadrado de tamanho máximo que o quadrado de crescimento poderia atingir antes de ser desativado.

Após o cálculo da fração de envelopes de grão para cada célula $\left(\varepsilon_{g C A}\right)$, a fração volumétrica de grãos para um volume finito, denominado de $\varepsilon_{g}$, é calculada por:

$$
\varepsilon_{g}=\sum_{0}^{n_{C A}} \frac{\varepsilon_{g C A}}{n_{C A}}
$$

onde $n_{C A}$ é o número de células existentes em um volume finito.

A concentração de área interfacial entre os envelopes e o líquido extradendrítico, $S_{e}$, é calculada a partir da área interfacial dos envelopes existentes no interior do REV dividida pelo volume deste REV. No domínio bidimensional do modelo, $S_{e}$ é calculado pela relação entre o perímetro dos envelopes e a área de um volume finito, que foi adotado igual ao REV; esta relação é ainda multiplicada por 
um fator estereológico de correção, obtendo-se assim o valor para um domínio tridimensional.

O cálculo da concentração da área interfacial associada ao volume finito ( $S_{e}$ ) é realizado a partir da macroestrutura calculada pelo modelo de autômato celular e, para isso, deve-se primeiramente calcular, para cada célula pertencente ao volume finito, o comprimento interfacial do quadrado de crescimento com o líquido extradendrítico, denominado $S_{e C A}$. O cálculo deste comprimento interfacial é dependente da forma pela qual a célula foi ativada, ou seja, deve-se considerar as duas situações possíveis: células ativadas por nucleação ou crescimento.

No caso em que a célula foi ativada por nucleação, o cálculo de $S_{e C A}$ é realizado com a seguinte equação:

$$
S_{e C A}=\frac{2(4-\lambda) L_{i} l}{\sqrt{A_{\max }}}
$$

onde / é a distância entre o centro das células da malha do modelo mesoscópico e $\lambda$ é o número de células vizinhas ativas mais próximas. Para se calcular o número de células ativas, deve-se verificar as quatro células vizinhas, conforme esquematicamente mostrado na Figura 49.

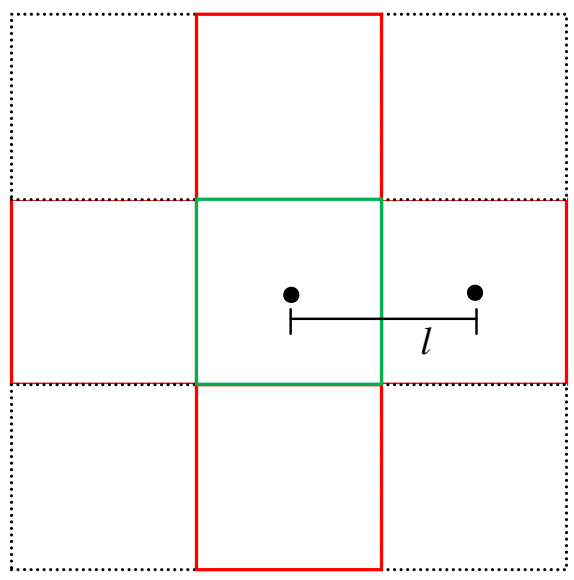

Figura 49 - Desenho esquemático da malha de células, onde se mostra a célula para a qual se deseja calcular o comprimento interfacial (verde) e suas quatro vizinhas mais próximas (vermelho) a serem consideradas no cálculo. 
Para o caso em que uma célula foi ativada por crescimento, o seu $S_{e C A}$ deve ser calculado por:

$$
S_{e C A}=\frac{l}{\cos (\theta)}
$$

onde $\theta$ é a orientação atribuída ao quadrado de crescimento considerado.

Finalmente o $S_{e}$ atribuído ao volume finito é a razão entre a soma do comprimento interfacial do quadrado de crescimento de todas as células associadas ao volume finito e a área do volume finito multiplicada por uma correção estereológica, como segue:

$$
S_{e}=\frac{4}{\pi} \cdot \frac{\left(\sum_{0}^{n_{C A}} S_{e C A}\right)}{l^{2} n_{C A}}
$$

onde $n_{C A}$ é o número de células existentes em um volume finito. Conforme explicado anteriormente, é necessário aplicar uma correção estereológica para se utilizarem os valores obtidos a partir do submodelo mesoscópico, que é bidimensional. Como a macroestrutura de grãos gerada pelo submodelo mesoscópico representa uma seção plana e aleatória através de grãos aleatoriamente posicionados e orientados no espaço tridimensional, a correção é realizada a partir da multiplicação por $4 / \pi$ (Russ; DeHoff, 2000).

Novamente a utilização do autômato celular beneficia as equações do modelo determinístico, pois o mesmo prevê automaticamente o decréscimo da área interfacial entre envelopes de grão e o líquido extradendrítico à medida que os grãos vão se tocando ("impingement"), tornando desnecessária qualquer tipo de correção das equações, como a tradicional correção de Avrami (1939, 1940).

\subsubsection{Equações Suplementares}

Uma equação suplementar é necessária para o cálculo da condutividade térmica utilizada na equação [56], que representa uma condutividade térmica ponderada pelas frações locais das fases. A equação que define a condutividade térmica está mostrada abaixo: 


$$
\kappa=\varepsilon_{S} \kappa^{S}+\left(\varepsilon_{d}+\varepsilon_{l}\right) \kappa^{L}
$$

onde $\kappa^{S}$ é a condutividade térmica da fase sólida e $\kappa^{L}$ é a condutividade térmica da fase líquida.

A concentração média de soluto no líquido interdendrítico $\left(C_{l}^{*}\right)$ é a concentração que este líquido apresenta em equilíbrio com o sólido em uma certa temperatura. Esta concentração é obtida a partir do diagrama de fases, considerando-se uma inclinação da linha liquidus, $m_{l}$, constante (aproximação linear):

$$
C_{l}^{*}=\frac{\left(T-T_{f}\right)}{m_{l}}
$$

A espessura efetiva de difusão presente nas equações [57] e [58] é calculada em função do número de Peclet $P e=V R_{e} / D_{l}$ (onde a velocidade $\mathrm{V}$ deve ser calculada no centro do volume finito considerado) de acordo com (Martorano; Beckermann; Gandin, 2003):

$$
\frac{\delta_{e}}{R_{e}}=\frac{3 R_{e} e^{P e}}{\left(\frac{R_{e}^{3}}{\varepsilon_{g}}-R_{e}^{3}\right)} \int_{R_{e}}^{R_{e} / \varepsilon_{g}^{1 / 3}}\left(\int_{R_{e}}^{r} \frac{e^{-P_{e} \frac{r^{\prime}}{R_{e}}}}{r^{\prime 2}}\right) r^{2} d r
$$

onde $V$ é a velocidade de crescimento da ponta da dendrita calculada utilizando-se o modelo LGK (equação[60]) e $R_{e}$ é o raio instantâneo do envelope dendrítico dado por:

$$
R_{e}=\left(\frac{3 \varepsilon_{g}}{4 \pi n_{g}}\right)^{1 / 3}
$$

onde $n_{g}$ é densidade de número de grãos presentes no volume finito considerado.

Nos modelos determinísticos que assumem a nucleação instantânea, a densidade de número de grãos nucleados $\left(n_{g}\right)$ é igual à densidade do número de partículas de substratos para nucleação $\left(n_{\max }\right)$ assumida, pois todas as partículas são ativadas no mesmo super-resfriamento. Porém, no CADE as partículas podem ser ativadas para nucleação em diferentes super-resfriamentos, o que significa que 
novos grãos podem nuclear em diferentes super-resfriamentos. Desta forma, a simulação do processo de nucleação no CADE pode ser realizada através da definição de uma distribuição qualquer de super-resfriamentos para nucleação entre as partículas de substratos.

As densidades de número de núcleos ou grãos descritas acima levam em consideração o número de grãos ou núcleos por unidade de volume, ou seja, estes parâmetros são definidos para domínios tridimensionais. O modelo proposto aqui (CADE) é definido para duas dimensões e, desta forma, necessita-se de uma conversão dos dados obtidos em duas dimensões para três dimensões, como foi feita para o cálculo de $S_{e}$ e $\varepsilon_{g}$.

Para se calcular a densidade de número de grãos no modelo $\operatorname{CADE}\left(n_{g}\right)$, deve-se primeiramente calcular a razão entre o número de grãos presentes em um determinado volume finito e sua área, obtendo $n_{2 D}$, e posteriormente aplicar uma correção estereológica, resultando em (Rappaz e Gandin, 1993):

$$
n_{g}=\sqrt{\frac{\pi}{6}}\left[n_{2 D}\right]^{3 / 2}
$$

\subsubsection{Discretização das Equações de Conservação}

A discretização das equações de conservação foi feita pelo método numérico dos volumes finitos utilizando-se uma formulação explícita (Patankar, 1980). A equação [56] é a equação de conservação de energia na forma da entalpia em coordenadas retangulares para um domínio bidimensional e foi discretizada utilizando-se o método dos volumes finitos com uma formulação explícita, conforme apresentado no item 4.1.1. A equação discretizada está apresentada abaixo:

$$
\delta H_{V F}^{t+\delta t}=\left(a_{E} T_{E}^{t}+a_{W} T_{W}^{t}+a_{N} T_{N}^{t}+a_{S} T_{S}^{t}+\left[-a_{E}-a_{W}-a_{S}-a_{N}\right] \cdot T_{P}^{t}\right) \cdot \frac{\delta t}{\Delta x \cdot \Delta y}
$$

onde:

$$
a_{E}=\frac{\kappa_{e} \Delta y}{(\delta x)_{e}}
$$




$$
\begin{aligned}
& a_{W}=\frac{\kappa_{w} \Delta y}{(\delta x)_{w}} \\
& a_{N}=\frac{\kappa_{n} \Delta x}{(\delta y)_{n}} \\
& a_{S}=\frac{\kappa_{s} \Delta x}{(\delta y)_{s}}
\end{aligned}
$$

A temperatura de cada volume finito pode ser calculada pela seguinte equação já discretizada:

$$
T^{t+\delta t}=T^{t}+\frac{\Delta H_{f}}{C_{p}}\left(\varepsilon_{S}^{t+\delta t}-\varepsilon_{S}^{t}\right)+\frac{\delta H_{V F}^{t+\delta t}}{\rho C_{p}}
$$

sendo que, $\delta H_{V F}^{t+\delta t}$ é a variação de entalpia por unidade de volume de um volume finito entre os instantes $t$ e $t+\delta t ; \Delta x$ e $\Delta y$ representam as dimensões dos lados de um volume finito; $\delta x$ e $\delta y$ são as distâncias (nos respectivos eixos $x$ e y) entre os nós de dois volumes finitos adjacentes; $\delta$ é o passo de tempo; $\rho$ é a densidade da liga considerada; $C_{p}$ é o calor específico; $T$ é temperatura do volume finito nos instantes $t$ e $t+\delta t ; \Delta H_{f}$ o calor latente de fusão e $\varepsilon_{S}$ é a fração de sólido do volume finito nos instantes $t$ e $t+\delta t$. Os subscritos presentes em $\delta x$ e $\delta y$ representam as direções para o cálculo destas medidas, ou seja, $(\delta x)_{s}$ representa a distância entre o nó $\mathrm{P}$ (centro do volume finito P) e o nó S, no eixo coordenado x. Os subscritos presentes na condutividade térmica representam a face na qual a condutividade térmica é calculada.

Antes de se calcular a temperatura em $t+\delta t$ para um volume finito, deve-se verificar a temperatura atual. Caso a temperatura no instante atual tenha atingido a temperatura de transformação eutética $\left(T_{E}\right)$, deve-se considerar uma transformação isotérmica mantendo-se a temperatura do volume finito fixa e calculando-se o aumento da fração de sólido através da equação [82]. Este procedimento deve ser mantido até que a fração de sólido se torne igual a 1.

A segunda equação apresentada (equação [57]) é utilizada para se calcular a variação da fração de sólido com o tempo e será discretizada utilizando-se uma formulação explícita, como segue: 


$$
(1-k) C_{l}^{* t} \frac{\left(\varepsilon_{S}^{t+\delta t}-\varepsilon_{S}{ }^{t}\right)}{\delta t}=\varepsilon_{d}{ }^{t} \frac{\left(C_{l}^{* t+\delta t}-C_{l}^{* t}\right)}{\delta t}+s_{e}{ }^{t} \frac{D_{l}}{\delta_{e}{ }^{t}}\left(C_{l}^{* t}-C_{l}^{t}\right)
$$

rearranjando a equação obtém-se:

$$
\varepsilon_{S}^{t+\delta t}=\varepsilon_{S}{ }^{t}+\frac{\varepsilon_{d}{ }^{t}\left(C_{l}^{* t+\delta t}-C_{l}^{* t}\right)+s_{e}{ }^{t} \frac{D_{l}}{\delta_{e}^{t}}\left(C_{l}^{* t}-C_{l}^{t}\right) \cdot \delta t}{(1-k) C_{l}^{* t}}
$$

Verificando-se a equação [80] nota-se que é necessária a concentração do líquido interdendrítico no instante de tempo seguinte $\left(C_{l}^{* t+\delta t}\right)$, para se calcular a fração de sólido também no instante de tempo seguinte $\left(\varepsilon_{S}^{t+\delta t}\right)$. Porém, a mesma depende da temperatura no próximo instante $\left(T^{t+\delta \boldsymbol{d}}\right)$ que não está disponível. Este fato é resolvido combinando-se a equação [69] com a equação [78]:

$$
C_{l}^{* t+\delta t}=\frac{T^{t}+\frac{\delta H_{V F}^{t+\delta t}}{\rho C p}+\frac{\Delta H_{f}\left[\varepsilon_{s}^{t+\delta}-\varepsilon_{s}^{t}\right]}{C p}-T_{f}}{m_{l}}
$$

Note que, apesar de aparecer a variação de entalpia no próximo instante de tempo, a mesma é calculada com base em dados do instante atual e, desta forma, não representa qualquer problema para o algoritmo. Substituindo-se a equação [81] na equação[80], finalmente obtém-se a equação final para o cálculo da fração de sólido:

$$
\varepsilon_{S}{ }^{t+\delta t}=\varepsilon_{S}{ }^{t}+\frac{\varepsilon_{d}{ }^{t}\left(\frac{T^{t}+\frac{\delta H_{V F}{ }^{t+\delta t}}{\rho C p}+\frac{\Delta H_{f}\left[\mathcal{\varepsilon}_{s}^{t+\delta}-\varepsilon_{s}^{t}\right]}{C p}-T_{f}}{m_{l}}-C_{l}^{* t}\right)+s_{e}{ }^{t} \frac{D_{l}}{\delta_{e}{ }^{t}}\left(C_{l}^{* t}-C_{l}^{t}\right) \cdot \delta t}{(1-k) C_{l}^{* t}}
$$

Conforme explicado anteriormente, ao se atingir a temperatura de transformação eutética, a variação da fração de sólido deve ser considerada como no caso de uma transformação isotérmica e não deve ser calculada pela equação [82], mas sim da seguinte forma:

$$
\varepsilon_{S}^{t+\delta t}=\varepsilon_{S}^{t}-\frac{\delta H_{V F}^{t+\delta t}}{\Delta H_{f} \rho}
$$


Após o cálculo da fração de sólido para o instante de tempo seguinte $\left(\varepsilon_{S}^{t+\alpha \bar{\alpha}}\right)$, deve-se verificar se o valor encontrado não é maior que a fração de envelope encontrada para o mesmo tempo $\left(\varepsilon_{g}^{t+\AA}\right)$. Caso o valor da fração de sólido seja maior, deve-se igualar a fração de envelopes a este valor através do crescimento forçado das células ativas dentro do volume finito considerado. Cada célula ativa dentro do volume finito tem o seu $\varepsilon_{g C A}$ aumentado igualmente até que o valor da fração de envelopes se iguale à fração de sólido do volume. Este procedimento faz com que o tamanho final do lado de cada célula ativa seja dado pela equação [63].

Finalmente, a equação [58] é utilizada para o cálculo da variação da concentração média de soluto no líquido extradendrítico e pode ser discretizada da seguinte forma:

$$
C_{l}^{t+\tilde{\varepsilon}}=\frac{\varepsilon_{l}^{t} C_{l}^{t}+C_{l}^{* t}\left(\varepsilon_{l}^{t+\dot{\alpha}}-\varepsilon_{l}^{t}\right)+S_{e}^{t} \frac{D_{l}}{\delta_{e}^{t}}\left(C_{l}^{* t}-C_{l}^{t}\right) \cdot \delta t}{\varepsilon_{l}^{t+\tilde{\varepsilon}}}
$$

Nota-se a existência da fração de líquido extradendrítico no instante posterior $\left(\varepsilon_{l}^{t+\AA}\right)$, porém esta fração depende da fração volumétrica de envelopes $\left(\varepsilon_{g}\right.$ ), que é calculada pelo submodelo mesoscópico com base nas informações atuais (equação [64]), através da seguinte equação:

$$
\varepsilon_{g}=1-\varepsilon_{l}
$$

\subsubsection{Seqüência de Execução do Algoritmo}

A resolução numérica das equações do modelo híbrido proposto no presente trabalho foi realizada através de um código implementado na linguagem de computador ANSI C, utilizando um compilador Borland $C_{++}$Builder $^{\circledR}$ e um computador pessoal com microprocessador Intel Core $i 7^{\circledR}$. O código computacional foi baseado em um algoritmo que apresenta a seguinte seqüência de passos:

a) Todos os substratos para nucleação são distribuídos aleatoriamente entre as células e associa-se um super-resfriamento para nucleação a cada substrato segundo uma distribuição normal; 
b) Os volumes finitos têm a sua temperatura inicial igualada à temperatura de vazamento do metal líquido e a concentração igualada à concentração inicial (aplicação da condição inicial);

c) Calcula-se a variação de entalpia de todos os volumes finitos pela equação [73];

d) Ativam-se as células que possuem substratos com um superresfriamento para nucleação menor ou igual ao super-resfriamento real observado em seus centros;

e) Faz-se o crescimento de todas as células ativas segundo o modelo mesoscópico;

f) Calcula-se a concentração de soluto interdendrítico de cada volume através da equação [69], utilizando-se a temperatura no centro de cada volume;

g) Calcula-se o super-resfriamento adimensional presente no centro de cada volume finito (equação[62]), ou seja, o super-resfriamento médio no volume;

h) Calcula-se o inverso do valor da função de Ivantsov (equação [61]) aplicada ao super-resfriamento adimensional calculado no item anterior;

i) Calcula-se a velocidade de crescimento dendrítico médio no volume finito utilizando-se, na equação [60], os valores calculados nos dois itens anteriores;

j) Utiliza-se também o valor do número de Peclet para calcular, através da equação [70], o valor da espessura efetiva de difusão média no volume finito;

k) Calcula-se a fração de sólido no instante posterior $(t+\delta t)$ através das equações [80] ou [83]. A equação [83] será utilizada caso a temperatura do volume finito tenha atingido a temperatura do ponto de transformação eutética e caso a sua fração de sólido ainda não seja unitária; 
I) Calcula-se a fração de envelopes no instante posterior $\left(\varepsilon_{g}^{t+\delta}\right)$ e faz-se uma comparação entre o valor obtido e a fração de sólido obtida no item anterior. Caso a fração de sólido seja maior, deve-se igualar a fração de envelopes a esta através do crescimento forçado das células ativas;

m) Calcula-se a concentração de soluto no líquido extradendrítico através da equação [81];

n) Finalmente, calcula-se a temperatura no próximo instante de tempo através da equação [78] e, caso o tempo final da simulação não tenha sido atingido, retorna-se ao item c. 


\section{5 - RESULTADOS E DISCUSSÃO}

Os resultados obtidos a partir dos modelos descritos no item de Metodologia foram utilizados segundo uma estratégia que consistiu de duas partes: a primeira com o objetivo de examinar o modelo estocástico tradicional e o determinístico e a segunda intencionando uma investigação do novo modelo proposto, denominado CADE.

Na primeira parte: (a) o modelo estocástico tradicional foi validado para verificar sua correta implementação; (b) o acoplamento meso-macro do modelo estocástico foi analisado e o comportamento deste modelo frente a diferentes distribuições de super-resfriamento analisado e (c) as previsões da posição da transição colunar-equiaxial (que representa uma importante característica da macroestrutura de grãos) obtidas pelo modelo estocástico tradicional e pelos modelos determinísticos foram comparadas.

Objetivando uma análise do novo modelo proposto, na segunda parte dos resultados foram apresentadas simulações para primeiramente validar a sua correta implementação e então o modelo foi utilizado em comparações com modelos determinístico e estocástico nas seguintes situações: (a) solidificação isotérmica (OD); (b) transferência de calor unidirecional (1D) e (c) transferência de calor bidimensional.

\subsection{Análise do Modelo Estocástico Tradicional}

\subsubsection{Validação do Modelo Estocástico}

Nas simulações para validação foram inicialmente tratados casos para os quais existem resultados de outros modelos disponíveis na literatura. Posteriormente, simulou-se uma situação para a qual os dados experimentais estavam disponíveis. 


\subsubsection{Submodelo Macroscópico}

O submodelo macroscópico consiste basicamente da resolução da equação diferencial para a condução de calor, equação [20]. A sua análise foi feita mediante a simulação de um caso de condução de calor bidimensional sem mudança de fases (sem solidificação) no domínio bidimensional apresentado na Figura 50 . Este problema foi modelado utilizando-se as condições de contorno e inicial definidas a seguir:

Condição inicial:

$$
\text { para } \mathrm{t}=0 \quad \square \quad T=T_{i}
$$

Condições de Contorno:

$$
\begin{array}{lll}
\text { para } x=L & \square & -\kappa \frac{\partial T}{\partial x}=h\left(T-T_{W}\right) \\
\text { para } x=0 & \square & \frac{\partial T}{\partial x}=0 \\
\text { para } y=L & \square & -\kappa \frac{\partial T}{\partial y}=h\left(T-T_{W}\right) \\
\text { para } y=0 & \square & \frac{\partial T}{\partial y}=0
\end{array}
$$

onde $\kappa$ é a condutividade térmica; $h$ é o coeficiente de transferência de calor na interface; $T_{W}$ é uma temperatura de referência; $T_{i}$ é a temperatura inicial no interior do domínio e $L$ é a dimensão do domínio. 


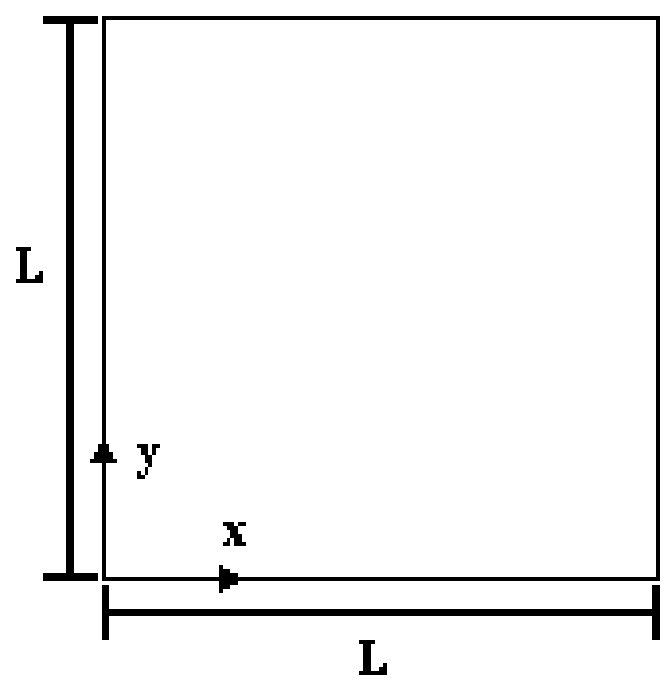

Figura 50- Domínio e sistema de coordenadas utilizados para simular a condução de calor sem mudança de fase.

As propriedades termofísicas e parâmetros empregados no método numérico estão apresentados na Tabela 2.

Foram examinados os resultados do modelo relativos às temperaturas de três posições distintas, sendo elas: $0,05 \times 0,05 \mathrm{~m}, 0,05 \times 0 \mathrm{~m}$ e $0,1 \times 0,1 \mathrm{~m}$, onde 0 primeiro número indica a coordenada $x$ e o segundo, a coordenada $y$. As curvas de temperatura estão apresentadas em função do tempo na Figura 51.

Tabela 2- Dados utilizados no problema de condução.

\begin{tabular}{cc|cc}
\hline Parâmetro & Valor & Propriedade & Valor \\
\hline $\begin{array}{c}\text { Número de Nós da Malha } \\
\text { Numérica }\end{array}$ & $101 \times 101$ & $\rho\left(\mathrm{kg} \mathrm{m}^{-3}\right)$ & 2452 \\
\hline $\begin{array}{c}\text { Lado do Domínio Quadrado }-\mathrm{L} \\
(\mathrm{m})\end{array}$ & 0.10 & $\kappa\left(\mathrm{W} \mathrm{m}^{-1} \mathrm{~K}^{-1}\right)$ & 176 \\
\hline Passo de tempo - $\delta \mathrm{t}(\mathrm{s})$ & 0.001 & $\mathrm{~h}\left(\mathrm{~W} \mathrm{~m}^{-2} \mathrm{~K}^{-1}\right)$ & 1000 \\
\hline Temperatura inicial $-\mathrm{T}_{\mathrm{i}}(\mathrm{K})$ & 1019 & $\mathrm{Cp}\left(\mathrm{J} \mathrm{kg}^{-1} \mathrm{~K}^{-1}\right)$ & 1126 \\
\hline Temperatura do molde $-\mathrm{T}_{\mathrm{W}}(\mathrm{K})$ & 298 & & \\
\hline
\end{tabular}




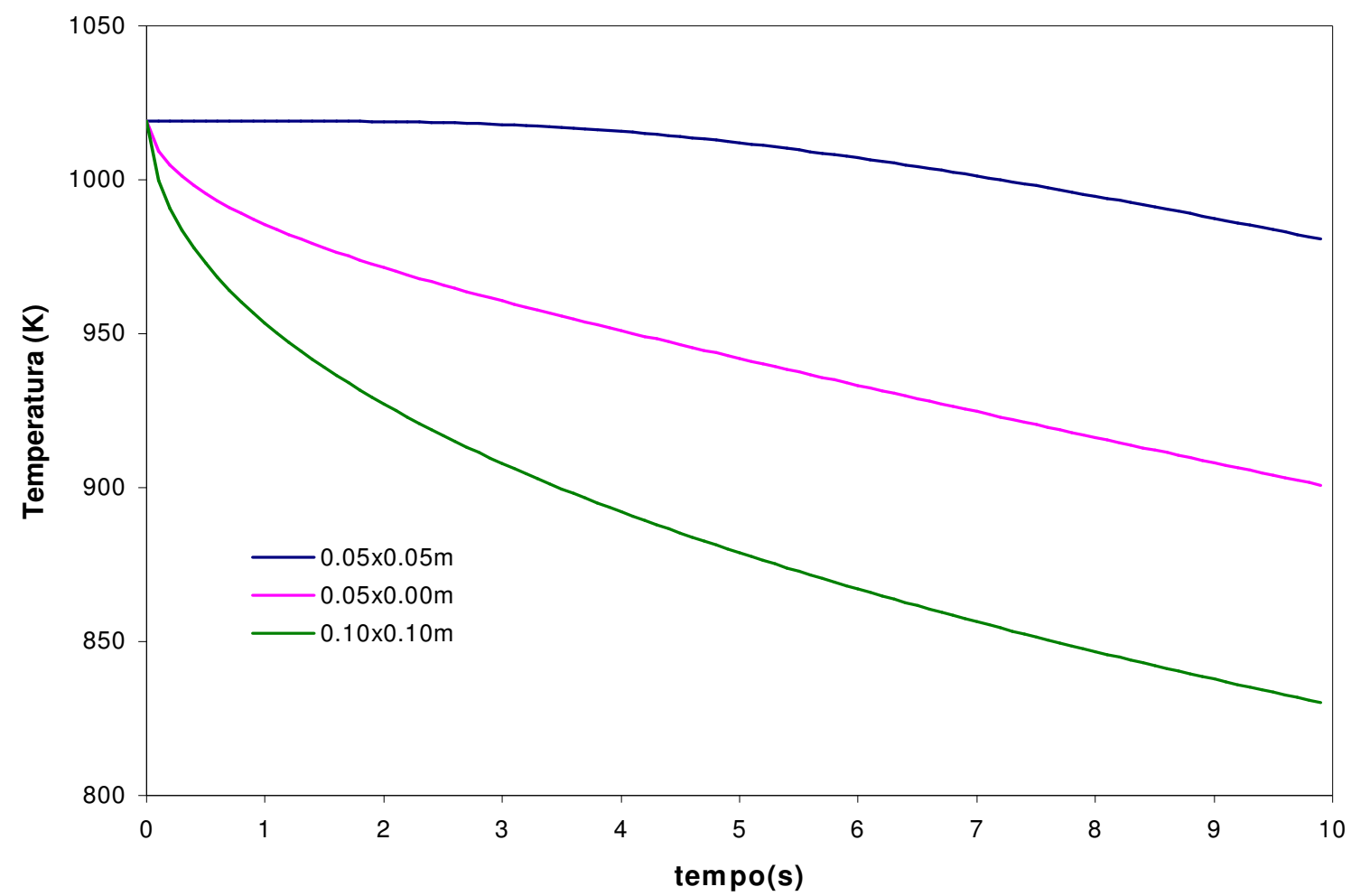

Figura 51- Temperatura em função do tempo para três posições durante resfriamento de um domínio quadrado sem mudança de fase.

Os dados da Figura 51 foram comparados com os resultados de uma solução analítica obtida na literatura para o mesmo problema (Poirier; Geiger, 1994). A convergência da solução numérica para a analítica foi verificada através de três simulações com passos de tempo cada vez menores: $10^{-3}, 10^{-4}$ e $10^{-5} \mathrm{~s}$. Em cada caso, foram obtidos os erros quadráticos entre as curvas de temperatura calculadas pelo modelo $\left(T_{\text {modelo }}^{t}\right)$ e aquelas calculadas pela solução analítica $\left(T_{\text {analitica }}^{t}\right)$, sendo o erro quadrático definido por:

$$
\text { Erro Quadrático }=\left(T_{\text {mod elo }}^{t}-T_{\text {analitica }}^{t}\right)^{2}
$$

O erro quadrático total, definido como a somatória dos erros quadráticos associados a cada instante de tempo e para as três posições $(0,05 \times 0,05 \mathrm{~m}$, $0,05 \times 0,00 \mathrm{~m}$ e $0,10 \times 0,10 \mathrm{~m})$, em função do passo de tempo do método numérico está apresentado na Figura 52. 


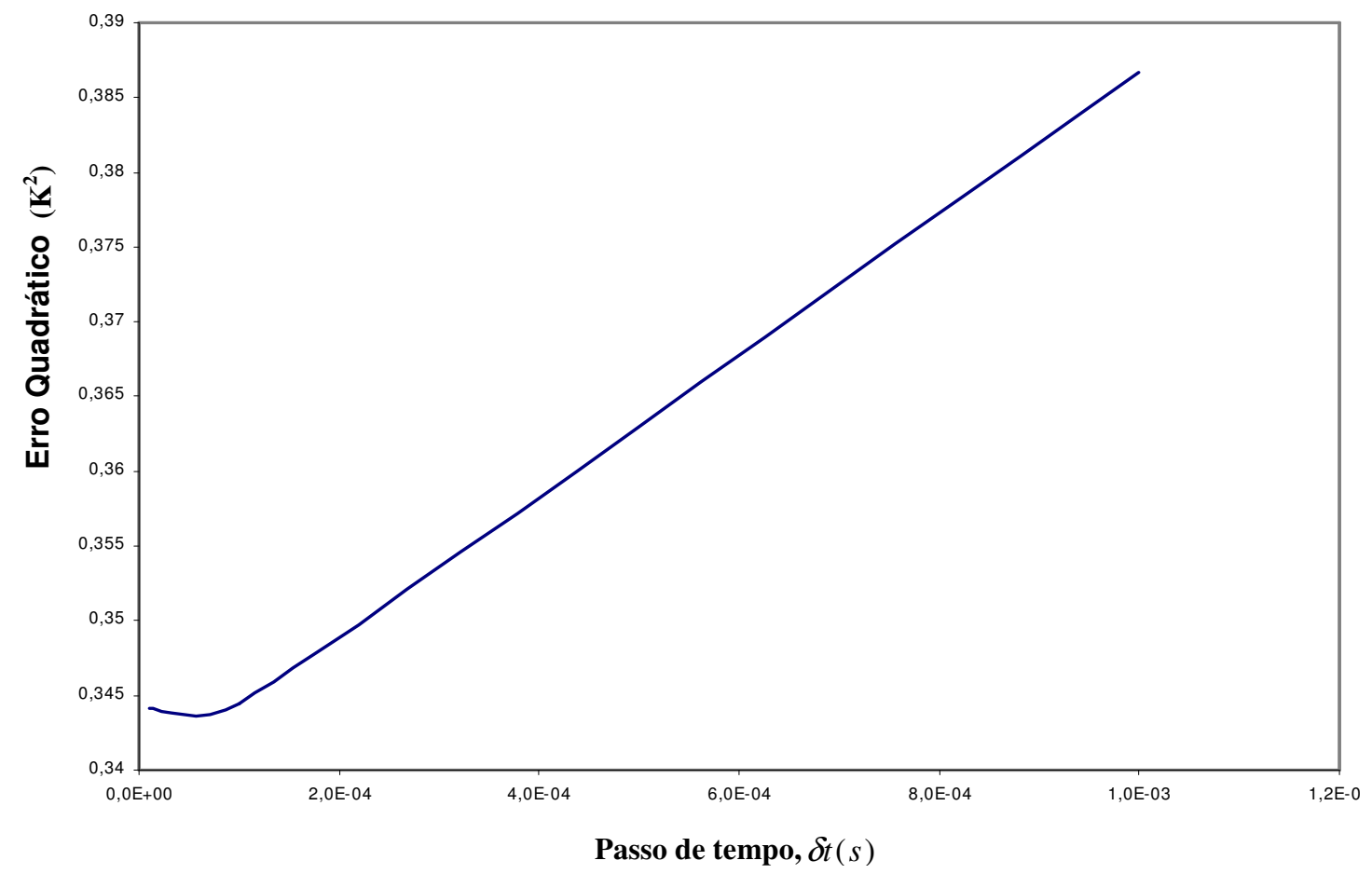

Figura 52- Erro quadrático entre as soluções numéricas e analíticas em função do passo de tempo utilizado no método numérico.

Como se pode observar, o erro quadrático decresceu monotonicamente com a diminuição do passo de tempo, indicando que a solução numérica está convergindo para a solução analítica. Nota-se uma pequena tendência à ascensão do erro quadrático abaixo de um dado passo de tempo, o que provavelmente resulta do aumento nos erros de arredondamento devido ao aumento do número de operações necessárias. Após estas comparações, o modelo de transferência de calor foi aceito como correto, pois seus resultados estavam muito próximos aos da solução analítica.

\subsubsection{Submodelo Mesoscópico - Crescimento}

O algoritmo de crescimento dos envelopes dendríticos, implementado no submodelo mesoscópico, foi analisado separadamente. Este algoritmo deve simular o crescimento de um envelope dendrítico sem que ocorra sua rotação no decorrer do tempo. Para verificar esta condição, foram refeitos os testes realizados por Gandin e Rappaz (1994). Estes testes consistiram em colocar um quadrado de crescimento (envelope dendrítico) no centro de um domínio bidimensional quadrado e verificar o 
seu crescimento tanto em campos uniformes como não uniformes de temperatura. Nos campos de temperatura não uniformes, a velocidade da isoterma liquidus foi calculada pela equação [92].

$$
\left|v_{L}\right|=|\dot{T}| \cdot G^{-1}
$$

onde $v_{L}$ representa a velocidade da isoterma liquidus, $\dot{T}$ a taxa de resfriamento e $G$ o gradiente de temperatura. Os valores dos parâmetros utilizados na equação [92] estão apresentados na Tabela 3.

Tabela 3- Dados referentes aos testes de crescimento realizados por Gandin e Rappaz (1994).

\begin{tabular}{cccc}
\hline Parâmetro & Teste A & Teste B & Teste C \\
\hline $\mathrm{G}\left(\mathrm{K} \mathrm{m}^{-1}\right)$ & 0 & 250 & 500 \\
$\dot{T}\left(\mathrm{~K} \mathrm{~s}^{-1}\right)$ & $-0,01$ & $-0,025$ & $-0,05$ \\
$v_{L}\left(\mathrm{~m} \mathrm{~s}^{-1}\right)$ & - & 0,0001 & 0,0001 \\
\hline
\end{tabular}

Comparando-se os resultados obtidos por Gandin e Rappaz (1994) com seu modelo estocástico, apresentados na Figura 53, e os dados resultantes da simulação com o modelo estocástico tradicional implementado, representados na Figura 54, é possível concluir que os modelos tiveram o mesmo comportamento sob as circunstâncias descritas anteriormente. 


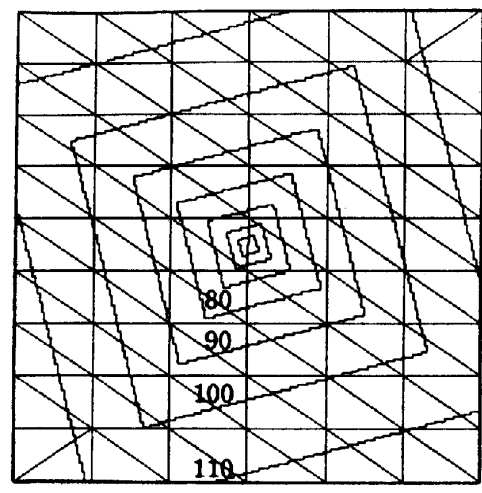

Teste A

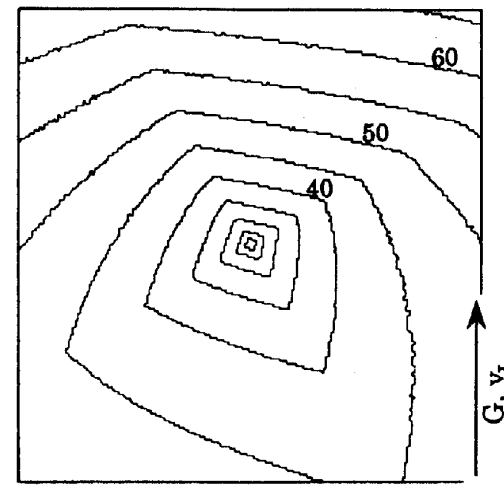

Teste B

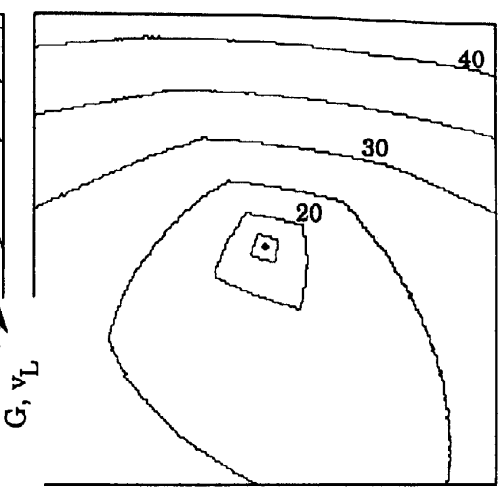

Teste C

Figura 53- Formatos do envelope dendrítico obtidos por Gandin e Rappaz (1994) para diversos instantes de tempo (indicados em segundos) durante o crescimento sob três condições diferentes indicadas na Tabela 3.

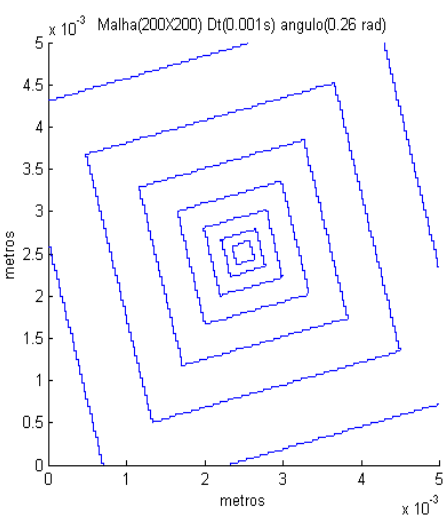

Teste A

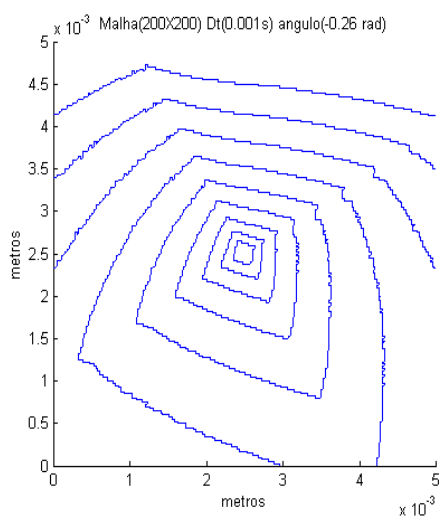

Teste B

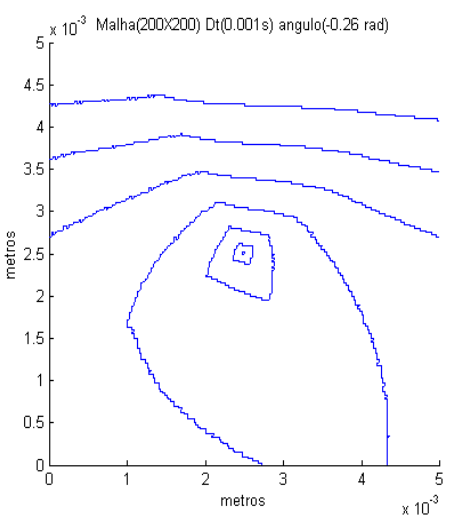

Teste $\mathrm{C}$

Figura 54- Formatos do envelope dendrítico durante o crescimento obtidos pelo modelo estocástico tradicional implementado para os mesmos instantes de tempo indicados na Figura 53.

Pode-se observar que o crescimento em um campo de temperaturas uniforme (Teste A) é simétrico e não há nenhuma alteração na orientação do envelope. Na presença de um gradiente de temperatura (testes B e C), o envelope cresce mais rapidamente nas regiões onde o super-resfriamento é maior, ou seja, nas regiões inferiores dos domínios. Estes resultados mostram que o algoritmo implementado para o crescimento dos envelopes está funcionando conforme esperado. 


\subsubsection{Submodelo Mesoscópico - Nucleação e Crescimento}

Após a análise dos aspectos de crescimento, o próximo passo foi a análise do modelo quanto à nucleação. Esta aferição foi feita mediante a comparação com os resultados apresentados no trabalho realizado por Rappaz e Gandin (1993). O teste consistiu em simular o crescimento de diversos grãos de uma liga Al7\%Si no interior de um domínio bidimensional com temperatura uniforme, porém variável no tempo segundo uma taxa de resfriamento de $\dot{T}=-2.3 \mathrm{~K} \mathrm{~s}^{-1}$. Diferentemente do caso anterior, nestes testes vários grãos (envelopes) estavam presentes. Diversos testes foram realizados com diferentes parâmetros que definem a distribuição normal de super-resfriamentos críticos para nucleação dos grãos (equação [35]).

Nos testes, primeiramente os substratos para a nucleação heterogênea foram distribuídos por todo o domínio. Como descrito na metodologia, a cada substrato foi associado um super-resfriamento crítico para a nucleação através de uma distribuição normal caracterizada por três parâmetros. Nestes testes variou-se somente o super-resfriamento médio para nucleação no interior do domínio $\left(\Delta T_{V, \text { пис }}\right)$, sendo utilizados os seguintes valores: 10,5; 8,0 e 6,0K para os testes 1,2 e 3 respectivamente. Os demais parâmetros foram mantidos iguais e estão apresentados na Tabela 4 para a nucleação no contorno (S) e para a nucleação no interior do domínio (V). O contorno do domínio pode ser entendido como a superfície interna da cavidade de um molde de fundição.

Tabela 4- Dados utilizados na simulação isotérmica: parâmetros utilizados para a nucleação no contorno (S) e no interior do domínio $(\mathrm{V})$; composição média ( $C_{0}$ ) e tamanho da malha de células do modelo mesoscópico.

\begin{tabular}{cccccccc}
\hline $\begin{array}{c}\Delta T_{S, \text { nuc }} \\
{[\mathrm{K}]}\end{array}$ & $\begin{array}{c}\Delta T_{S, \sigma} \\
{[\mathrm{K}]}\end{array}$ & $\begin{array}{c}n_{S, \max } \\
{\left[\mathrm{m}^{-2}\right]}\end{array}$ & $\begin{array}{c}\Delta T_{V, \sigma} \\
{[\mathrm{K}]}\end{array}$ & $\begin{array}{c}n_{V, \max } \\
{\left[\mathrm{m}^{-3}\right]}\end{array}$ & $\begin{array}{c}\dot{T} \\
{\left[\mathrm{~K} \mathrm{~s}^{-1}\right]}\end{array}$ & $\begin{array}{c}\mathrm{C}_{0} \\
{[\% \mathrm{Si}]}\end{array}$ & $\begin{array}{c}\text { Malha } \\
\mathrm{CA}\end{array}$ \\
\hline 0,5 & 0,1 & $2,5 \times 10^{8}$ & 0,1 & $5,5 \times 10^{10}$ & $-2,3$ & 7 & $300 \times 300$ \\
\hline
\end{tabular}

Os resultados simulados no presente trabalho e os fornecidos por Rappaz e Gandin (1993) estão apresentados na Figura 55, Figura 56 e Figura 57. Rappaz e 
Gandin (1993) não informaram os instantes de tempo associados a cada macrografia fornecida durante a solidificação. Portanto, a pequena diferença entre as macrografias simuladas por estes autores e aquelas simuladas no presente trabalho pode estar relacionada ao instante de tempo escolhido para comparação. Entretanto, as macrografias finais podem ser comparadas sem este problema pois são independentes do tempo.

No teste 1, apresentado na Figura 55, as macrografias das figuras (b), (d) e (f) correspondem aos instantes 3,5, 5,0 e 5,5s, respectivamente, e mostram apenas grãos colunares. No teste 2 , o super-resfriamento médio $\left(\Delta T_{V, n u c}\right)$ foi diminuído de forma a ocasionar uma transição colunar-equiaxial (CET). O resultado está representado na Figura 56. No último teste (teste 3) a posição da CET foi alterada em relação aos testes 1 e 2, observando-se uma diminuição da extensão da zona colunar, o que pode ser visto na Figura 57. 


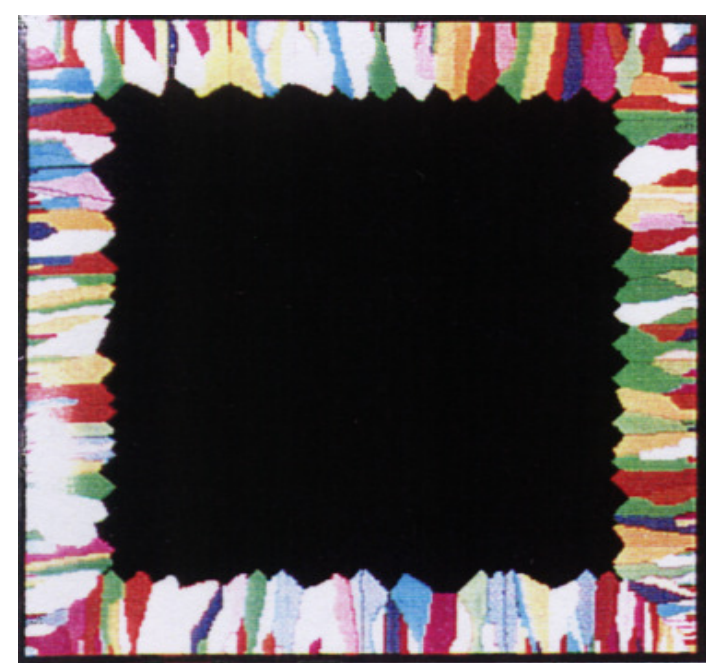

(a)

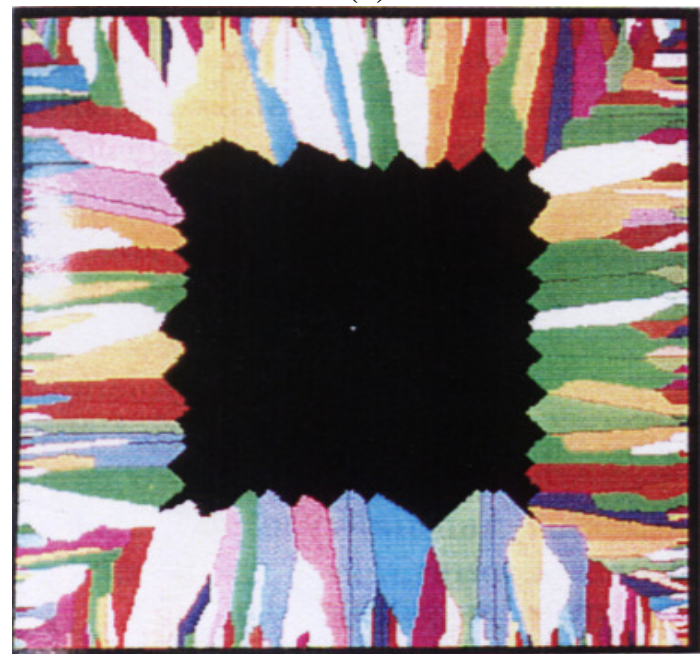

(c)

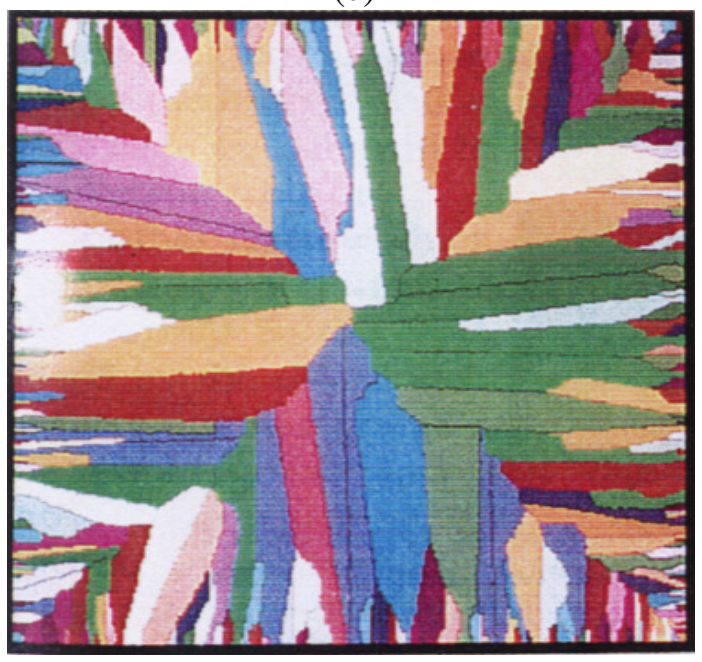

(e)

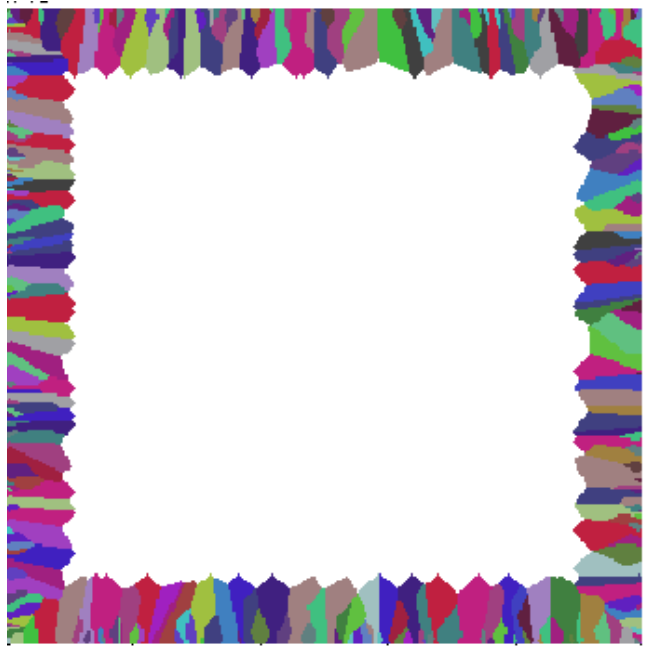

(b)

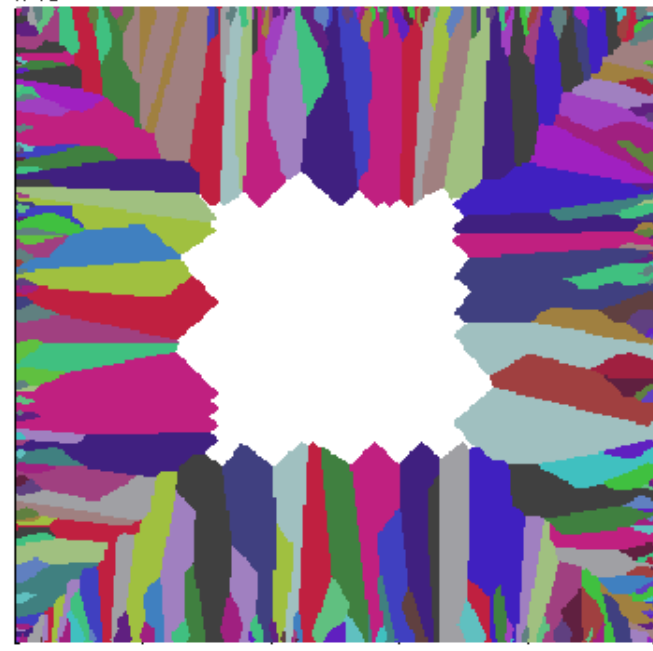

(d)

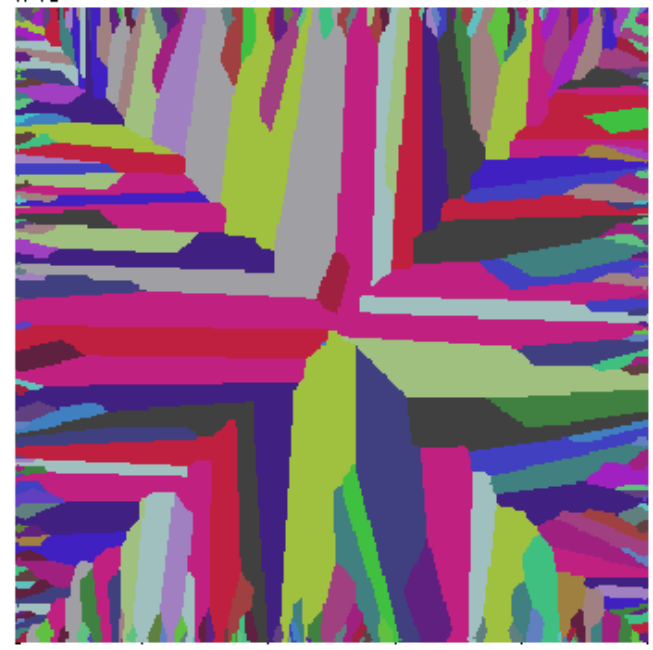

(f)

Figura 55- Macrografias calculadas no teste $1\left(\Delta T_{V, n u c}=10,5 \mathrm{~K}\right)$. Resultados fornecidos pelo presente modelo nos instantes (b) 3,5s; (d) 4,5s e (f) 5,5s. Resultados obtidos por Rappaz e Gandin (1993): (a), (c) e (e). 


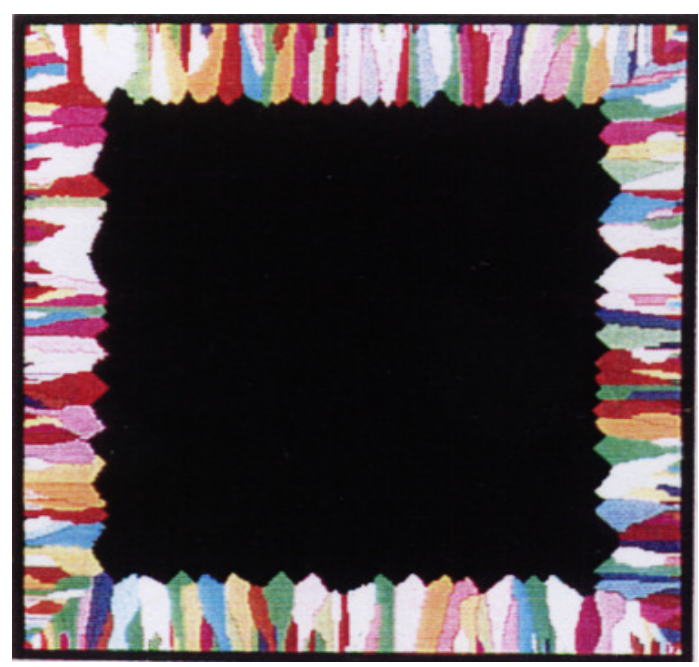

(a)

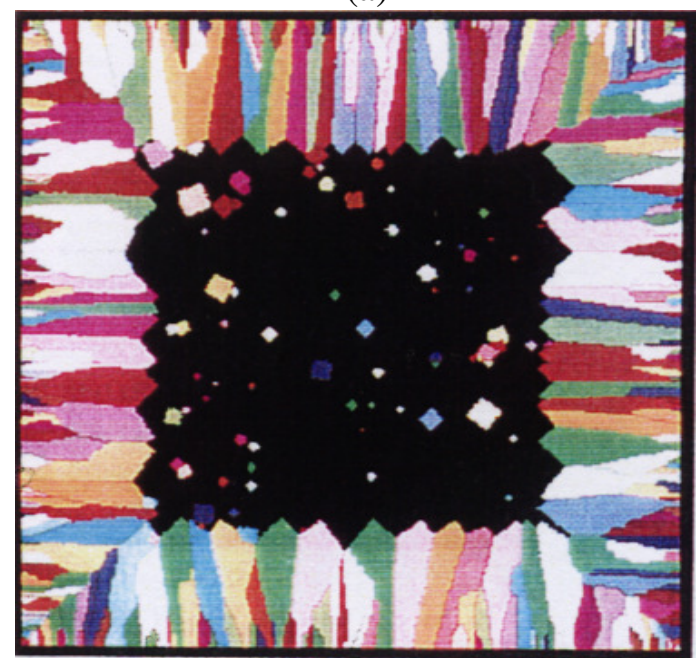

(c)

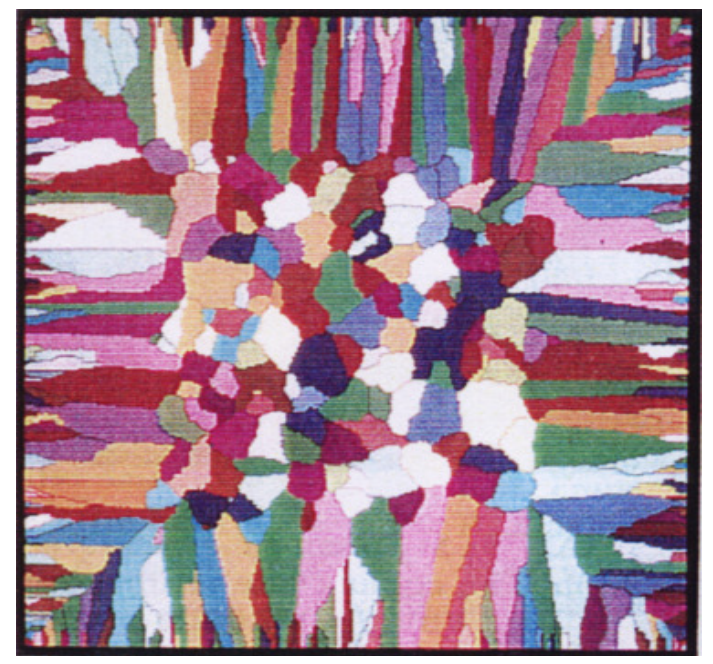

(e)

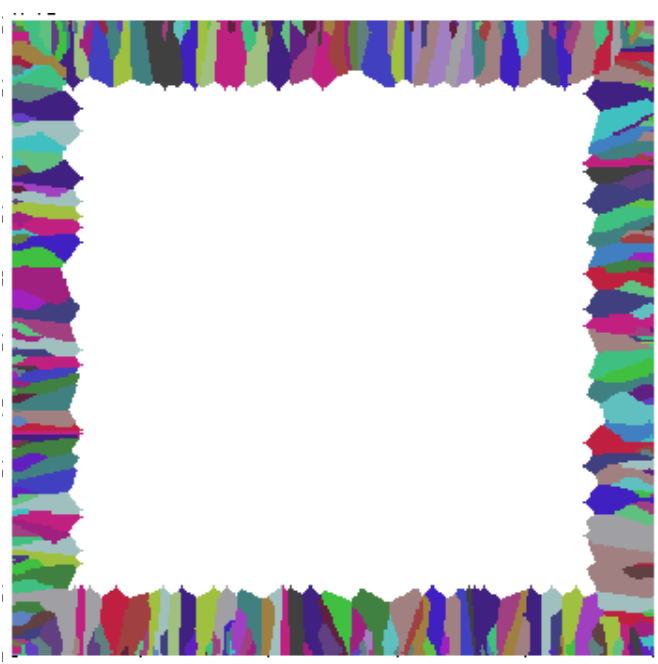

(b)

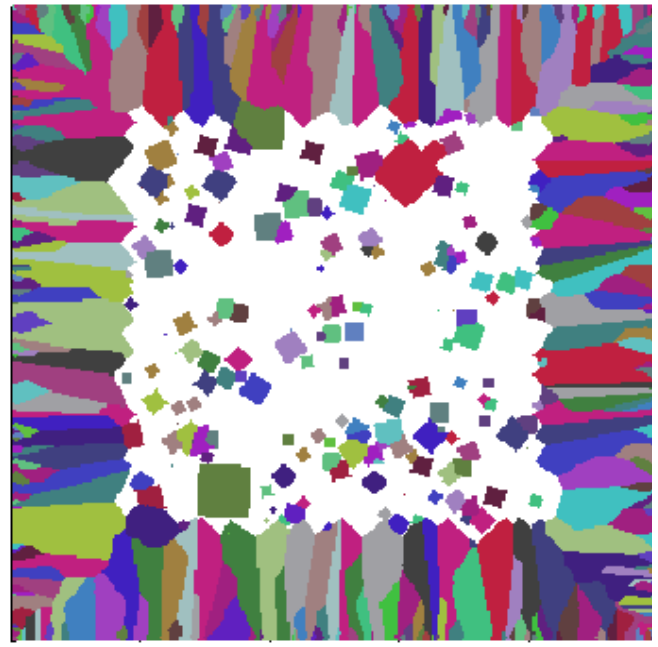

(d)

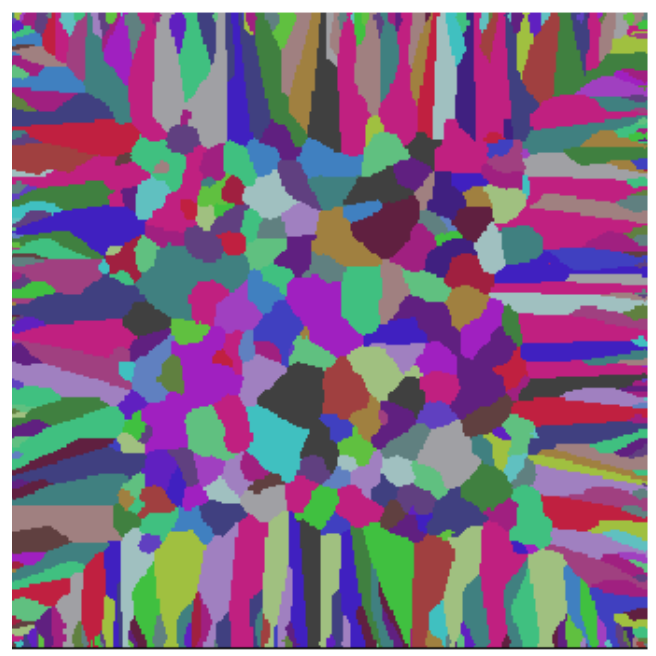

(f)

Figura 56- Macrografias calculadas no teste $2\left(\Delta T_{V, n u c}=8 K\right)$. Resultados fornecidos pelo presente modelo nos instantes (b) 3,5s; (d) 4,0s e (f) 4,5s. Resultados obtidos por Rappaz e Gandin (1993): (a), (c) e (e). 


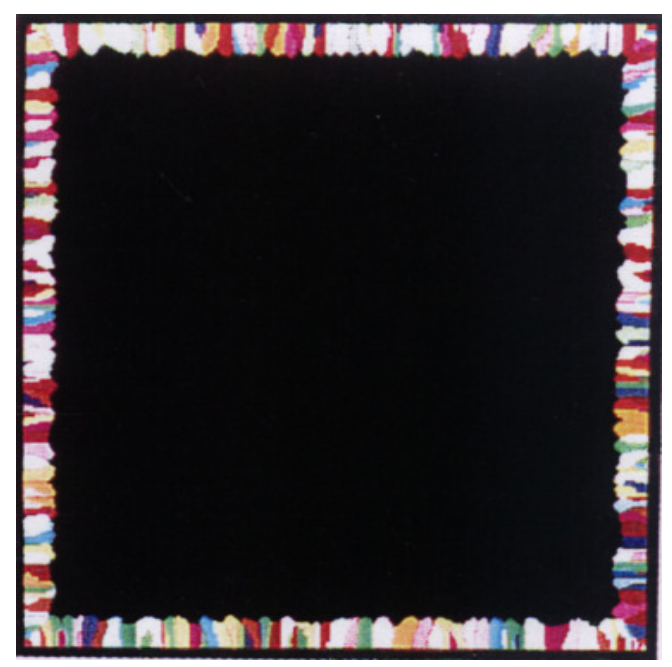

(a)

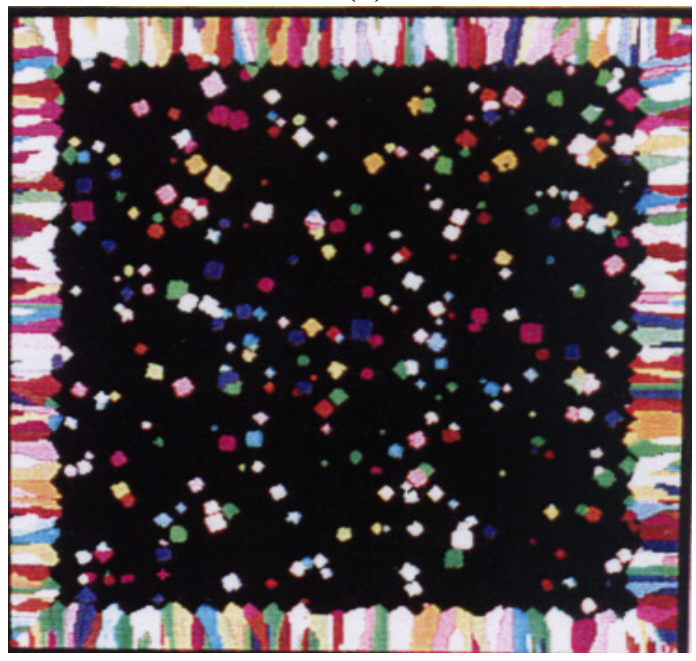

(c)

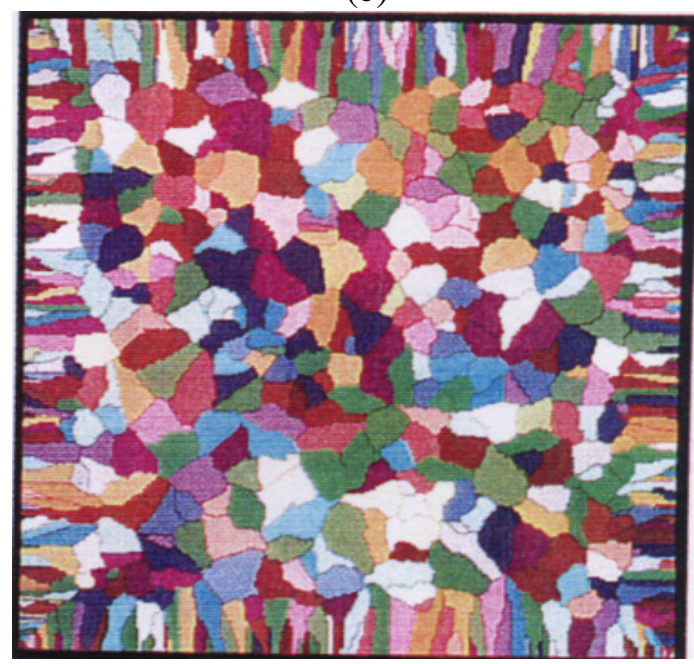

(e)

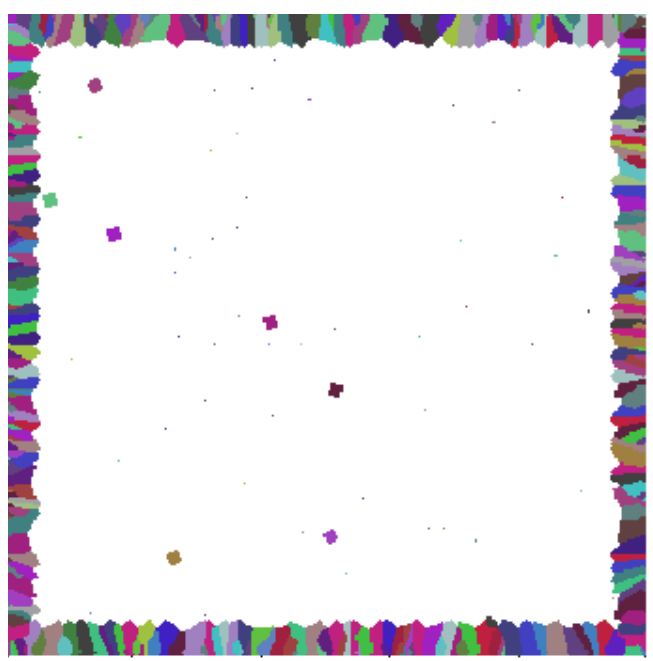

(b)

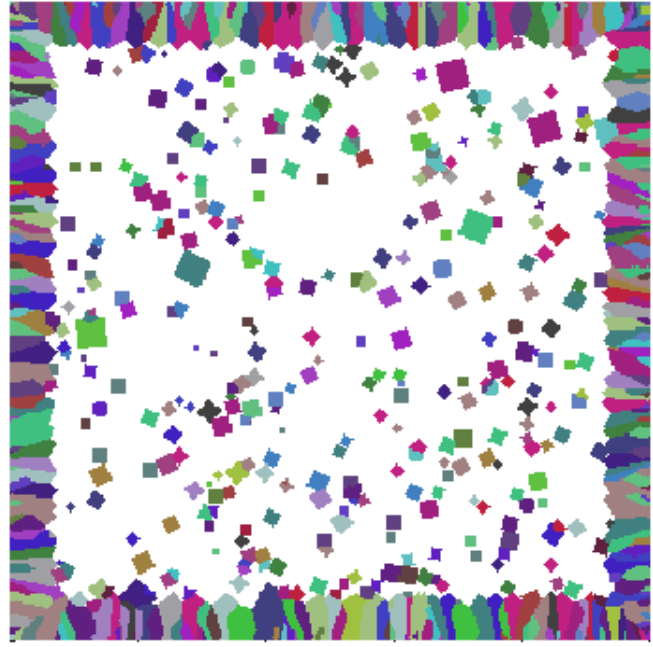

(d)

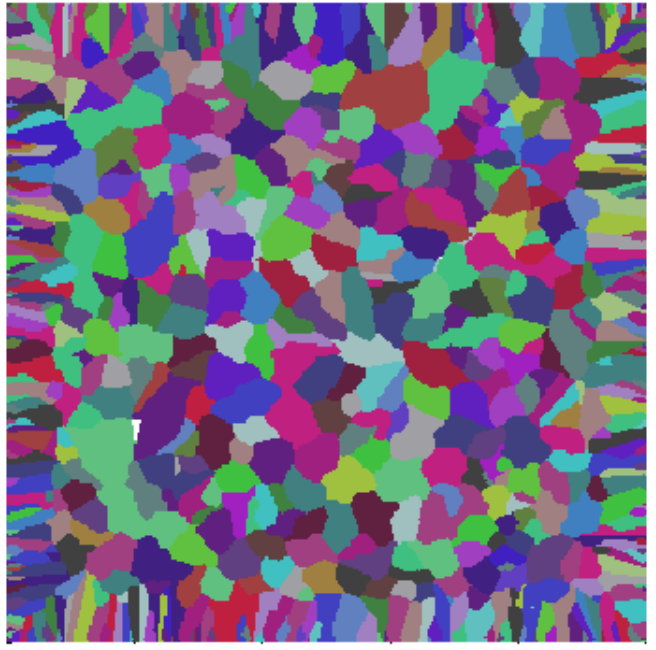

(f)

Figura 57- Macrografias calculadas no teste $3\left(\Delta T_{V, n u c}=6 K\right)$. Resultados fornecidos pelo presente modelo nos instantes (b) 3,0s; (d) 3,2s e (f) 3,7s. Resultados obtidos por Rappaz e Gandin (1993): (a), (c) e (e). 
As macroestruturas calculadas mostraram-se muito sensíveis às variações do super-resfriamento médio para nucleação no interior do volume $\left(\Delta T_{V, n u c}\right)$ de um teste para outro. Com a diminuição deste parâmetro, diminuiu-se o superresfriamento crítico para nucleação dos grãos, o que resultou em um favorecimento da nucleação e crescimento de grãos equiaxiais e, uma conseqüente diminuição da zona colunar. O teste comprovou que o submodelo mesoscópico de nucleação e crescimento foi corretamente implementado, pois as estruturas mostraram-se semelhantes às simuladas por Rappaz e Gandin (1993).

\subsubsection{Comparação com Resultados Experimentais}

Após a análise individual dos submodelos mesoscópico e macroscópico, o último passo foi a validação do modelo completo mediante a comparação de seus resultados com dados de um experimento realizado por Gandin e Rappaz (1994). Este experimento consistiu na fundição de um cilindro metálico de uma liga $\mathrm{Al}-7 \% \mathrm{Si}$ em um sistema de solidificação unidirecional. As condições de solidificação foram muito bem controladas, ocorrendo extração de calor somente pela parte inferior do molde e minimizando-se a convecção. A evolução das temperaturas em função do tempo, medida por sete termopares inseridos no interior do metal, foi fornecida pelos autores (Gandin; Rappaz, 1994). Estas curvas serão utilizadas para comparação com os resultados do presente modelo.

O fluxo de calor na superfície inferior no molde não foi fornecido por Gandin e Rappaz (1994), apesar de ser um parâmetro essencial para a simulação. Por isso, foi necessário estimar a condição de extração de calor utilizando as curvas de resfriamento experimentais fornecidas. O fluxo de calor extraído no contorno inferior foi ajustado no modelo para que as curvas calculadas se aproximassem das curvas medidas. Esta técnica é conhecida como solução inversa da equação de condução de calor.

Segundo a técnica de solução inversa, a partir das curvas de resfriamento medidas, calculou-se o fluxo de calor entre o metal e o molde pelo seguinte método:

a) Calculou-se o fluxo de calor que entra no domínio utilizando as curvas de resfriamento dos dois termopares mais próximos do contorno 
inferior (situados a 20 e $40 \mathrm{~mm}$ do contorno), através da equação $q=\kappa\left(T_{20}-T_{40}\right) /(0,02)$, onde $\kappa$ é a condutividade térmica;

b) Encontrou-se uma equação que melhor representava o fluxo calculado anteriormente em função do tempo e assumiu-se inicialmente que este fluxo era igual ao existente na superfície inferior do domínio de cálculo;

c) Ajustaram-se os coeficientes da equação proposta para o fluxo para que as curvas de temperatura simuladas se aproximassem das curvas medidas.

O fluxo de calor que entra no domínio foi finalmente representado pelas expressões:

$$
\begin{aligned}
& \mathrm{q}\left(\mathrm{W} \mathrm{m}^{-2}\right)=-0.014 * t^{3}+1.75 * t^{2}-25.0 * t+800.0 \text { Para } \mathrm{t}<190 \mathrm{~s} \\
& \mathrm{q}\left(\mathrm{W} \mathrm{m} \mathrm{m}^{-2}\right)=\frac{5 * 10^{15}}{(t-80)^{5}}-\frac{32667510}{(t-80)}-123600 \quad \text { Para } \mathrm{t}>=190 \mathrm{~s}
\end{aligned}
$$

onde $t$ é o tempo dado em segundos. Este fluxo em função do tempo está mostrado na Figura 58.

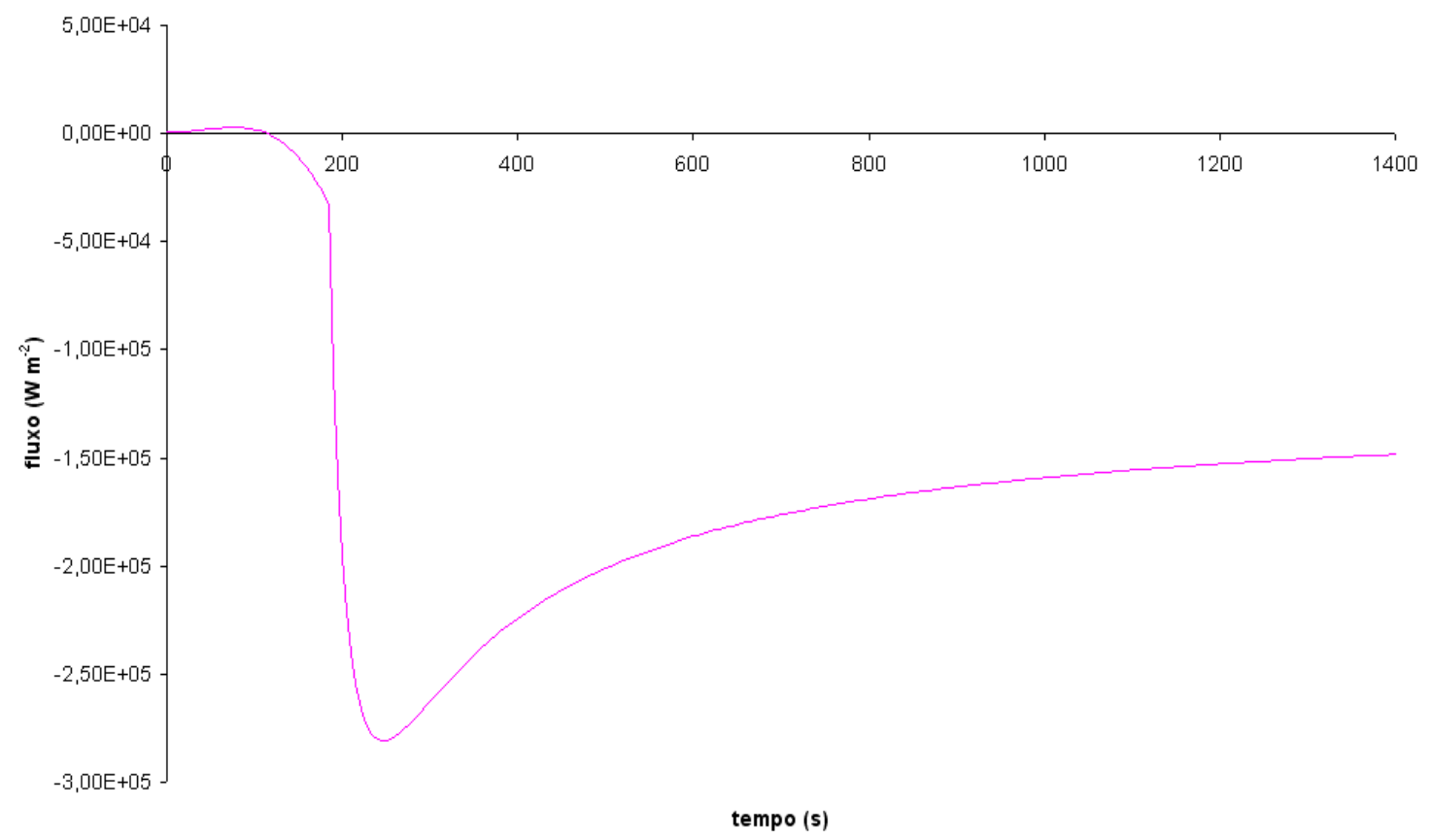

Figura 58- Fluxo de calor através da base do cilindro em função do tempo obtido através da solução inversa da equação de condução de calor. 
A curva apresenta um aumento inicial do fluxo do molde para o metal (entrando no domínio, $q>0$ ), situação que não deveria acontecer já que, no experimento realizado por Gandin (2000a), a base posicionada junto ao contorno inferior só poderia extrair calor. Este erro provavelmente está relacionado com a precisão dos termopares e da interpolação utilizada. Após este aumento, há uma queda brusca e o fluxo inverte-se (fluxo < 0), representando uma extração de calor do metal, como esperado.

Após a definição do fluxo, a macroestrutura foi simulada a partir dos dados da Tabela 5 a Tabela 7 e comparada com a macroestrutura experimental na Figura 59. Pode-se perceber que o modelo prevê corretamente a CET, que ocorreu por volta de $0,11 \mathrm{~m}$, tanto na simulação quanto no experimento.

Nesta mesma simulação, obtiveram-se as curvas de resfriamento nos mesmos locais onde as curvas experimentais foram medidas. Desta forma, comparou-se também a evolução das temperaturas calculadas pelo modelo com os dados do experimento (Figura 60).

Tabela 5- Propriedades da liga AI7\%Si utilizada na comparação com resultados experimentais obtidos por (Gandin; Rappaz, 1994).

\begin{tabular}{cc|cc}
\hline Propriedade & Valor & Propriedade & Valor \\
\hline $\mathrm{k}(-)$ & 0,13 & $C_{0}(\%$ peso $)$ & $7 \%$ \\
\hline$\kappa^{L}\left(\mathrm{~W} \mathrm{~m}^{-1} \mathrm{~K}^{-1}\right)$ & $36,5+0,028 \mathrm{~T}$ & $\mathrm{C}_{\mathrm{p}}\left(\mathrm{J} \mathrm{kg}^{-1} \mathrm{~K}^{-1}\right)$ & 1126 \\
\hline$\kappa^{S}\left(\mathrm{~W} \mathrm{~m}^{-1} \mathrm{~K}^{-1}\right)$ & $233-0,11 \mathrm{~T}$ & $T_{L}(\mathrm{~K})$ & 891 \\
\hline$\Delta H_{f}\left(\mathrm{~J} \mathrm{~kg}^{-1}\right)$ & 387400 & $T_{\text {eut }}(\mathrm{K})$ & 850 \\
\hline $\mathrm{A}\left(\mathrm{m} \mathrm{s}^{-1} \mathrm{~K}^{-\mathrm{m}}\right)$ & $3,4 \times 10^{-6}$ & $T_{f}(\mathrm{~K})$ & 933 \\
\hline $\mathrm{m} \mathrm{(-)}$ & 2,7 & $\rho\left(\mathrm{kg} \mathrm{m}^{-3}\right)$ & 2452 \\
\hline
\end{tabular}


Tabela 6- Parâmetros de simulação definidos para comparação com resultados experimentais obtidos por (Gandin; Rappaz, 1994).

\begin{tabular}{c|c}
\hline Parâmetro & Valor \\
\hline Dimensões do domínio $(\mathrm{m} \times \mathrm{m})$ & $0,07 \times 0,15$ \\
\hline Passo de tempo $(\mathrm{s})$ & 0,002 \\
\hline Superaquecimento $(\mathrm{K})$ & 128 \\
\hline Temperatura do molde $(\mathrm{K})$ & 298 \\
\hline Malha para CA (direções $\mathrm{x}$ e y) & $240 \times 26$ \\
\hline Malha para VF (direções $\mathrm{x}$ e y) & $1 \times 20$ \\
\hline
\end{tabular}

Tabela 7- Dados utilizados na simulação para comparação com resultados experimentais obtidos por (Gandin; Rappaz, 1994): parâmetros utilizados para a nucleação no contorno (S) e no interior do domínio $(\mathrm{V})$; composição média $\left(C_{0}\right)$ e tamanho da malha de células do $\mathrm{CA}$.

\begin{tabular}{cccccc}
\hline$\Delta T_{S, \text { nuc }}[\mathrm{K}]$ & $\Delta T_{S, \sigma}[\mathrm{K}]$ & $n_{S, \max }\left[\mathrm{m}^{-1}\right]$ & $\Delta T_{V, \text { nuc }}[\mathrm{K}]$ & $\Delta T_{V, \sigma}[\mathrm{K}]$ & $n_{V, \max }\left[\mathrm{m}^{-2}\right]$ \\
\hline 0,5 & 0,1 & 3412 & 5,5 & 0,5 & $9,1 \times 10^{6}$ \\
\hline
\end{tabular}




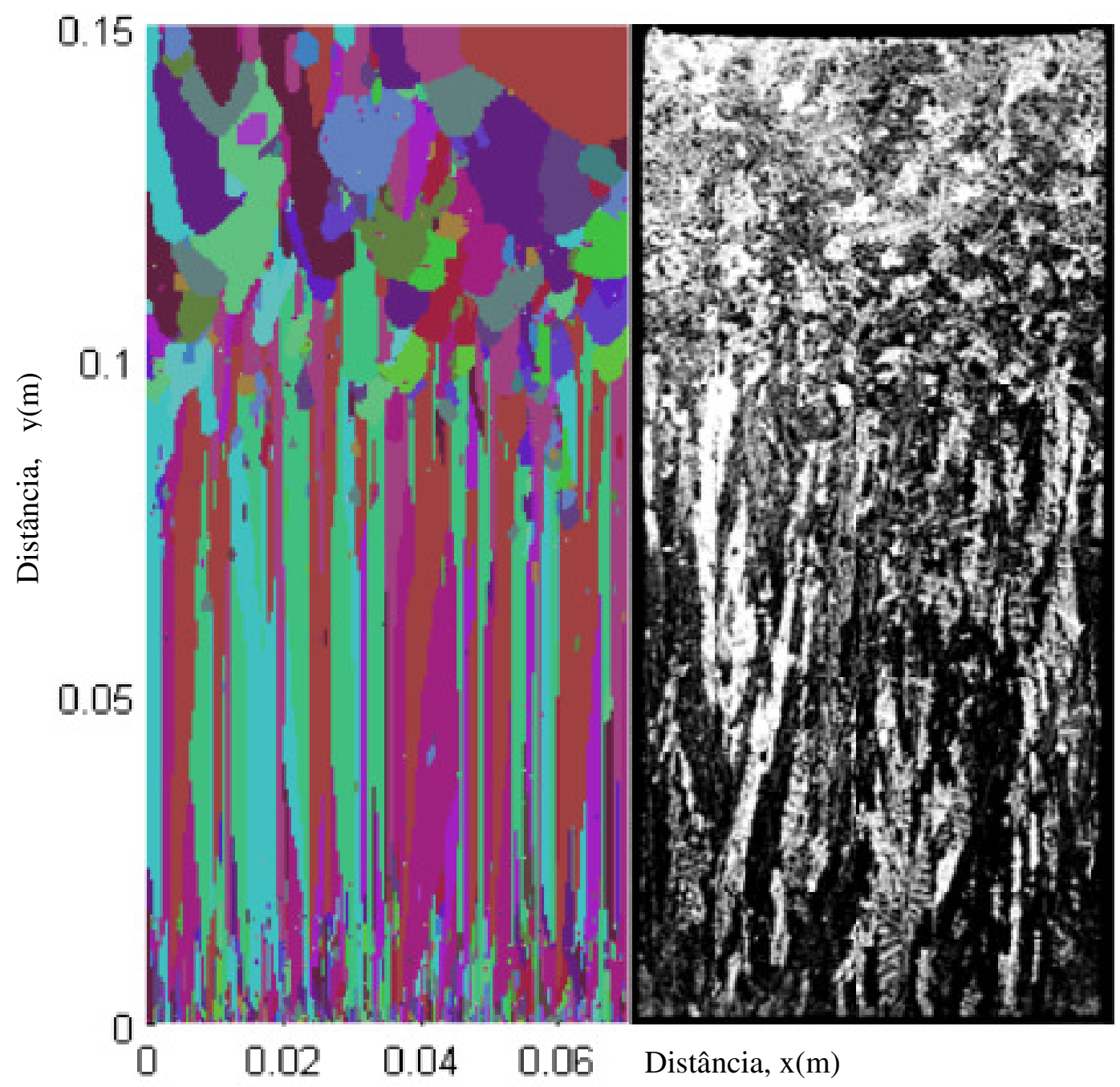

Figura 59- Macroestrutura de grãos: (à esquerda e colorida) simulada através do presente modelo; (à direita em preto e branco) resultante do experimento realizado por Gandin e Rappaz (1994). 


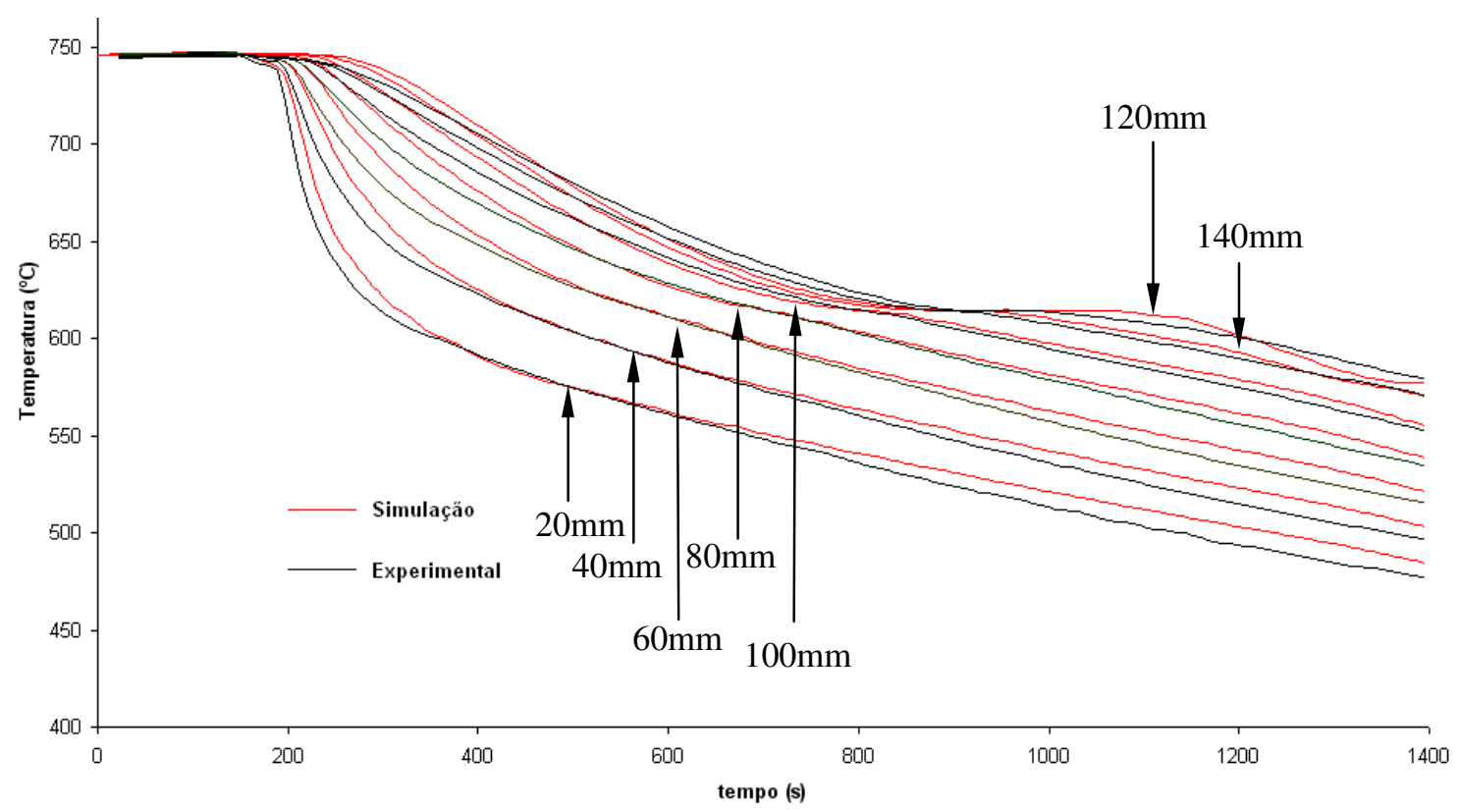

Figura 60- Comparação entre as temperaturas medidas experimentalmente e os dados resultantes da simulação. Os números indicam a distância do termopar à base refrigerada adjacente ao contorno inferior.

Pode-se verificar que as temperaturas calculadas pelo modelo não foram exatamente iguais às medidas experimentais. Esta discrepância pode estar relacionada às imprecisões na obtenção do fluxo de calor apresentado na Figura 58 ou às propriedades físicas utilizadas. Isso, porém, não parece significativo para o cálculo da macroestrutura, pois, a Figura 59 mostra que a macroestrutura calculada e a obtida experimentalmente são muito semelhantes.

Os resultados obtidos e as comparações realizadas acima confirmam a correta implementação do modelo e sua capacidade de previsão da macroestrutura bruta de solidificação.

\subsection{Comparação entre Modelo Estocástico e Modelo Determinístico}

Nos itens anteriores, o modelo estocástico foi testado e validado em diversas situações e um critério foi definido para a determinação da posição da CET nas macroestruturas calculadas. Neste item, finalmente serão realizadas comparações entre as previsões dos modelos estocástico e determinístico nas condições de um caso de referência definido no item 5.2.1. 
Estas comparações serão feitas com base nos seguintes resultados: curvas de temperatura em função do tempo e distância, fração de sólido, fração volumétrica de envelopes de grão e posição da CET (item 5.2.2). Finalmente uma comparação das posições das CET previstas pelos dois modelos em função do superresfriamento para nucleação será realizada (item 5.2.3).

\subsubsection{Condições de Simulação do Caso de Referência}

Inicialmente tem-se o objetivo de comparar os resultados obtidos através dos modelos estocástico e determinístico, para se verificar as principais diferenças, vantagens e desvantagens de cada modelo. Nestas comparações, a liga Al-7\%Si com propriedades descritas na Tabela 8 e algumas condições de simulação, que serão descritas nos próximos subitens, foram utilizadas como referência em diversas simulações.

Primeiramente definiu-se que o caso de referência deveria se assemelhar ao caso simulado e realizado experimentalmente por Gandin e Rappaz (1994). Logo, o tamanho do domínio foi de $0,05 \times 0,15 m$ e a extração de calor ocorreu somente pela superfície inferior do molde.

Tabela 8- Propriedades da liga Al7\%Si utilizada no caso de referência.

\begin{tabular}{cc|cc}
\hline Propriedade & Valor & Propriedade & Valor \\
\hline$\rho\left(\mathrm{kg} \mathrm{m}^{-3}\right)$ & 2452 & $C_{0}(\%$ peso $)$ & $7 \%$ \\
\hline $\mathrm{k}(-)$ & 0,13 & $\mathrm{C}_{\mathrm{p}}\left(\mathrm{J} \mathrm{kg}^{-1} \mathrm{~K}^{-1}\right)$ & 1126 \\
\hline$\kappa^{L}\left(\mathrm{~W} \mathrm{~m}^{-1} \mathrm{~K}^{-1}\right)$ & 60,5 & $T_{L}(\mathrm{~K})$ & 891 \\
\hline$\kappa^{S}\left(\mathrm{~W} \mathrm{~m}^{-1} \mathrm{~K}^{-1}\right)$ & 137,5 & $T_{\text {eut }}(\mathrm{K})$ & 850 \\
\hline$\Delta H_{f}\left(\mathrm{~J} \mathrm{~kg}^{-1}\right)$ & 387400 & $T_{f}(\mathrm{~K})$ & 933 \\
\hline $\mathrm{A}\left(\mathrm{m} \mathrm{s}^{-1} \mathrm{~K}^{-\mathrm{m}}\right)$ & $3 \times 10^{-6}$ & $\mathrm{~m}^{-}(-)$ & 2,7 \\
\hline$D_{l}\left(\mathrm{~m}^{2} \mathrm{~s}^{-1}\right)$ & $6,4 \times 10^{-9}$ & $m_{l}\left(\mathrm{~K} \% \mathrm{i}^{-1}\right)$ & $-6,0$ \\
\hline$\Gamma\left(\mathrm{m} \mathrm{K}^{2}\right.$ & $1,96 \times 10^{-7}$ & $R_{f}(\mathrm{~mm})$ & 3,63 \\
\hline $\mathrm{n}\left(\mathrm{m}^{-3}\right)$ & $5 \times 10^{6}$ & $\lambda_{1}(\mathrm{~mm})$ & 1,5 \\
\hline
\end{tabular}




\subsubsection{Parâmetros de Nucleação}

Nos testes para comparação do comportamento dos dois modelos, utilizouse no modelo estocástico um modelo de nucleação com distribuição normal de super-resfriamentos (equação [13]) tanto para a superfície em contato com o molde, quanto para o interior da cavidade do molde. Adotou-se $\Delta T_{\sigma}=0 \mathrm{~K}$ para simular a nucleação instantânea e possibilitar a comparação com o modelo determinístico. Na superfície do molde adotou-se $\Delta T_{S, n u c}=0 K$. No interior da cavidade definiu-se ainda uma densidade de número de substratos $n_{V, \max }=36300 \mathrm{~m}^{-2}$, correspondendo a um tamanho de grão mínimo de aproximadamente $4 \mathrm{~mm}$. Na superfície do molde adotou-se $n_{S, \max }=2000 \mathrm{~m}^{-1}$. Estes valores resultaram em uma CET bem definida na região central do domínio de cálculo. As condições finais de simulação estão apresentadas na Tabela 9 e Tabela 10.

Tabela 9- Parâmetros de simulação para definição dos parâmetros de nucleação.

\begin{tabular}{|c|c|}
\hline Parâmetro & Valor \\
\hline Dimensões do domínio $(\mathrm{m} \times \mathrm{m})$ & $0,05 \times 0,15$ \\
\hline Passo de tempo (s) & 0,002 \\
\hline Superaquecimento (K) & 100 \\
\hline Temperatura do molde $(\mathrm{K})$ & 298 \\
\hline Malha para CA (direções $x$ e $y$ ) & $100 \times 10$ \\
\hline Malha para VF (direções x e y) & $1 \times 30$ \\
\hline$h\left(W m^{-2} K^{-1}\right)$ & 250 \\
\hline
\end{tabular}

Tabela 10- Parâmetros para distribuição dos substratos para nucleação instantânea no caso de referência (os subscritos indicam a posição de aplicação destes parâmetros, sendo: V no interior da cavidade e $\mathrm{S}$ na parede do molde).

\begin{tabular}{cccccc}
\hline$\Delta T_{S, \text { пuс }}[\mathrm{K}]$ & $\Delta T_{S, \sigma}[\mathrm{K}]$ & $n_{S, \max }\left[\mathrm{m}^{-1}\right]$ & $\Delta T_{V, \text { nuс }}[\mathrm{K}]$ & $\Delta T_{V, \sigma}[\mathrm{K}]$ & $n_{V, \max }\left[\mathrm{m}^{-2}\right]$ \\
\hline 0,0 & 0,0 & 2000 & 3,0 & 0,0 & 36300 \\
\hline
\end{tabular}




\subsubsection{Malha de Volumes Finitos}

A malha de volumes finitos (VF) é composta por volumes quadrados (Figura 37) e é utilizada para discretizar a equação diferencial na forma da entalpia (equação [20]). Ao definir a malha de VF, procurou-se um ponto ótimo entre os erros envolvidos e o tempo de processamento. Diante disso, realizaram-se algumas simulações para a definição da malha de VF, verificando-se o erro em função do tamanho da malha. Nestes testes utilizaram-se dois erros relativos como critério de escolha: o erro relativo médio e o erro relativo máximo. O erro relativo médio é definido como sendo a raiz quadrada do erro quadrático médio, que é calculado a partir da diferença ao quadrado entre as temperaturas calculadas em diversos instantes e posições para uma determinada malha e para uma malha mais refinada. Esta diferença é somada para cada valor de temperatura calculada em 8 posições e dividida pelo número total de dados, extraindo-se a raiz quadrada. $O$ erro relativo máximo é simplesmente a maior diferença encontrada entre os dados de duas malhas consecutivas.

Na realização destes testes utilizou-se uma malha unidimensional de VF na direção x, pois não há extração de calor pelas laterais (como definido no item 5.2.1). As propriedades da liga e os parâmetros de simulação estão listados na Tabela 8, Tabela 9 e Tabela 10. Os erros relativos estão representados na Figura 61. 


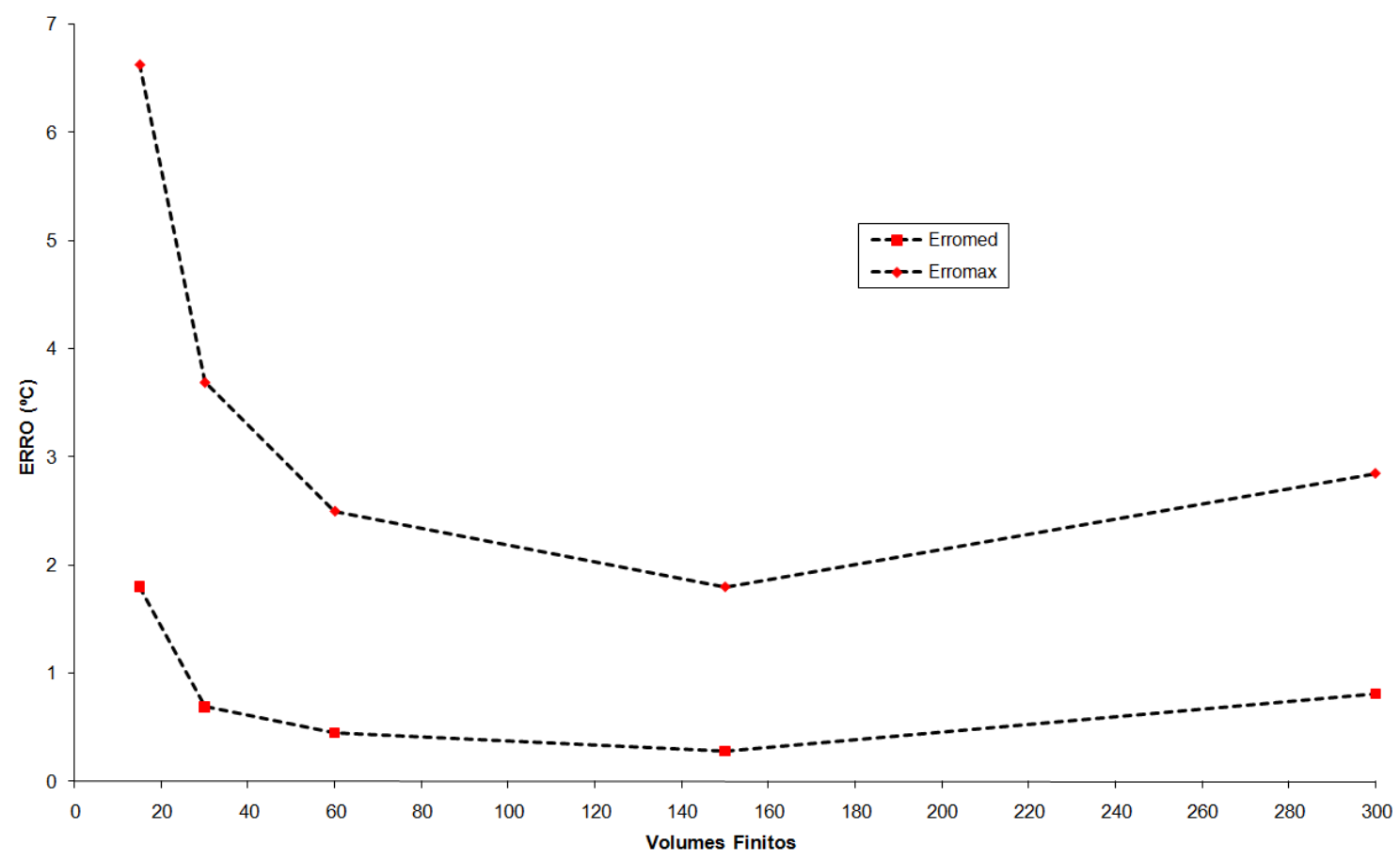

Figura 61- Erro relativo médio (Erromed) e máximo (Erromax) em função do número de volumes finitos da malha.

Após analise da Figura 61, nota-se uma diminuição dos erros relativos em função do refino da malha até um valor mínimo obtido para uma malha de 150 volumes finitos, onde então nota-se uma tendência de crescimento. Esta tendência de crescimento provavelmente se deve a erros de arredondamento, que crescem à medida que se utilizam mais volumes finitos na malha numérica (Fortuna, 2000). Levando-se em consideração os resultados obtidos, decidiu-se utilizar uma malha com 1x30 VF, pois esta apesar de não possuir os menores erros, possui um erro máximo de menos de quatro graus e o tempo de processamento foi relativamente baixo.

\subsubsection{Malha do Autômato Celular (CA)}

A malha do autômato celular (CA) é utilizada no submodelo mesoscópico para a simulação da nucleação e crescimento dos grãos e constitui-se de células quadradas, analogamente à malha de VF. A definição da malha do autômato celular (CA) foi baseada na resolução da macroestrutura gerada e no tempo de processamento. Determinou-se a resolução ideal e o tempo de processamento a 
partir de simulações com diferentes tamanhos de malha. Neste teste foram utilizadas quatro malhas de $\mathrm{CA}$, sendo elas com o seguinte número de células nas direções $\mathrm{x}$

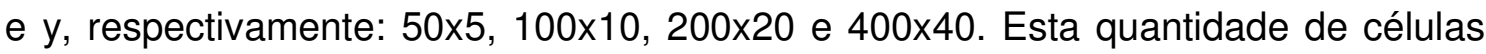
indicada está presente dentro de cada VF, que pertencia a uma malha de $1 \times 30$ volumes, resultando nas seguintes quantidades totais de células: 7500, 30000, 120000 e 480000 células. As macrografias geradas estão na Figura 62 e os parâmetros utilizados para as simulações encontram-se na Tabela 8, Tabela 9 e Tabela 10.

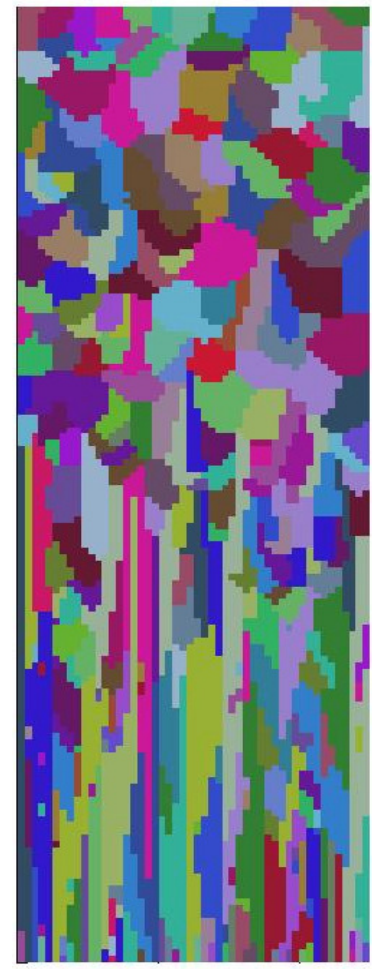

(a)

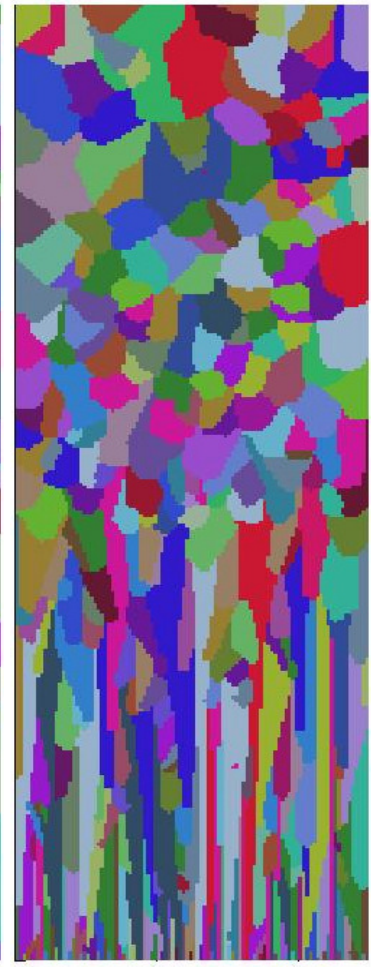

(b)

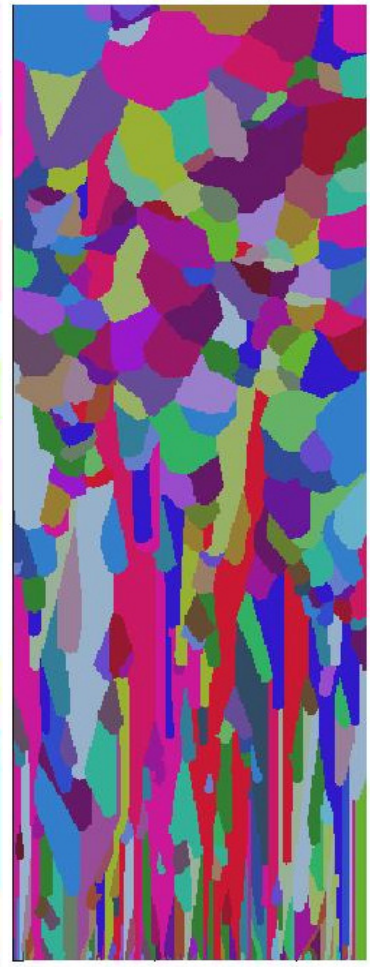

(c)

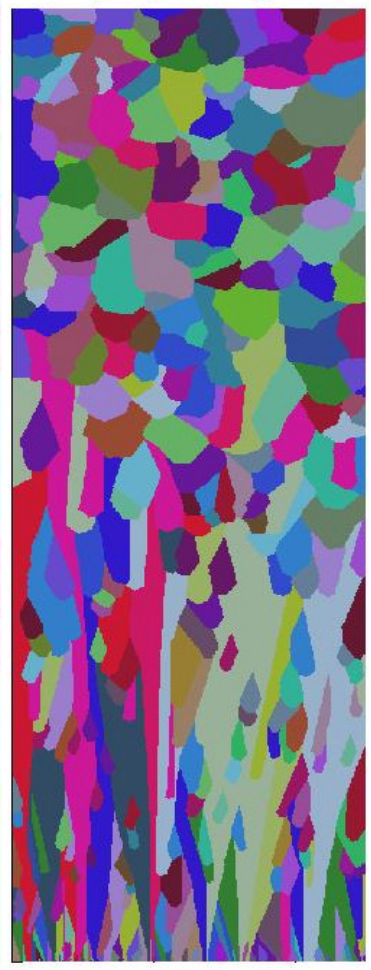

(d)

Figura 62- Macrografias para a determinação da malha de CA: (a) $50 \times 5$ (b) $100 \times 10$ (c) 200x20 (d) $400 \times 40$ células no interior de cada volume finito.

Da mesma forma que a malha de VF, uma malha refinada de CA gastaria um tempo elevado de processamento. No entanto, uma malha grosseira introduziria erros no cálculo da razão de aspecto e não teria resolução suficiente para representar adequadamente o formato dos grãos, como ocorre no caso da Figura 62(a). Por isso, decidiu-se utilizar uma malha de CA de 100x10 no interior de cada 
volume finito. Com isso, o caso de referência foi totalmente definido através dos parâmetros da Tabela 11, Tabela 12 e Tabela 13.

Tabela 11- Propriedades da liga Al7\%Si utilizada no caso de referência.

\begin{tabular}{cc|cc}
\hline Propriedade & Valor & Propriedade & Valor \\
\hline$\rho\left(\mathrm{kg} \mathrm{m}^{-3}\right)$ & 2452 & $C_{0}(\%$ peso $)$ & $7 \%$ \\
\hline $\mathrm{k}(-)$ & 0,13 & $\mathrm{C}_{\mathrm{p}}\left(\mathrm{J} \mathrm{kg}^{-1} \mathrm{~K}^{-1}\right)$ & 1126 \\
\hline$\kappa^{L}\left(\mathrm{~W} \mathrm{~m}^{-1} \mathrm{~K}^{-1}\right)$ & 60,5 & $T_{L}(\mathrm{~K})$ & 891 \\
\hline$\kappa^{S}\left(\mathrm{~W} \mathrm{~m}^{-1} \mathrm{~K}^{-1}\right)$ & 137,5 & $T_{\text {eut }}(\mathrm{K})$ & 850 \\
\hline$\Delta H_{f}\left(\mathrm{~J} \mathrm{~kg}^{-1}\right)$ & 387400 & $T_{f}(\mathrm{~K})$ & 933 \\
\hline $\mathrm{A}\left(\mathrm{m} \mathrm{s}^{-1} \mathrm{~K}^{-\mathrm{m}}\right)$ & $3 \times 10^{-6}$ & $\mathrm{~m}(-)$ & 2,7 \\
\hline$D_{l}\left(\mathrm{~m}^{2} \mathrm{~s}^{-1}\right)$ & $5,5 \times 10^{-9}$ & $m_{l}\left(\mathrm{~K} \% \mathrm{Si}^{-1}\right)$ & $-6,0$ \\
\hline$\Gamma\left(\mathrm{m} \mathrm{K}^{-1}\right.$ & $1,96 \times 10^{-7}$ & $R_{f}(\mathrm{~mm})$ & 3,63 \\
\hline $\mathrm{n}\left(\mathrm{m}^{-3}\right)$ & $5 \times 10^{6}$ & $\lambda_{1}(\mathrm{~mm})$ & 1,5 \\
\hline
\end{tabular}

Tabela 12- Parâmetros de simulação definidos para o caso de referência.

\begin{tabular}{c|c}
\hline Parâmetro & Valor \\
\hline Dimensões do domínio $(\mathrm{m} \times \mathrm{m})$ & $0,05 \times 0,15$ \\
\hline Passo de tempo $(\mathrm{s})$ & 0,002 \\
\hline Superaquecimento $(\mathrm{K})$ & 100 \\
\hline Temperatura do molde $(\mathrm{K})$ & 298 \\
\hline Malha para CA (direções $\times$ e y) & $100 \times 10$ \\
\hline Malha para VF (direções $\times \mathrm{e} \mathrm{y})$ & $1 \times 30$ \\
\hline $\mathrm{h}\left(\mathrm{W} \mathrm{m} \mathrm{m}^{-2} \mathrm{~K}^{-1}\right)$ & 250 \\
\hline
\end{tabular}

Tabela 13- Parâmetros para distribuição dos substratos para nucleação instantânea no caso de referência (os subscritos indicam a posição de aplicação destes parâmetros, sendo: $V$ no interior da cavidade e $\mathrm{S}$ na parede do molde).

\begin{tabular}{cccccc}
\hline$\Delta T_{S, \text { nuс }}[\mathrm{K}]$ & $\Delta T_{S, \sigma}[\mathrm{K}]$ & $n_{S, \max }\left[\mathrm{m}^{-1}\right]$ & $\Delta T_{V, n u c}[\mathrm{~K}]$ & $\Delta T_{V, \sigma}[\mathrm{K}]$ & $n_{V, \max }\left[\mathrm{m}^{-2}\right]$ \\
\hline 0,0 & 0,0 & 2000 & 3,0 & 0,0 & 36300 \\
\hline
\end{tabular}




\subsubsection{Simulação nas Condições de Referência}

O modelo estocástico do autômato celular utiliza uma variável aleatória (depende de probabilidades) para definir as orientações dos grãos e o posicionamento dos substratos para a nucleação heterogênea no interior do domínio. Logo, a posição da CET prevista pelo modelo pode sofrer algum efeito da aleatoriedade quando as simulações são executadas diversas vezes nas mesmas condições. Os testes conduzidos abaixo visam identificar este efeito.

Nestes testes realizaram-se dez simulações sob condições de entrada idênticas, iguais às de referência (item 5.2.1). Determinou-se a posição da CET em cada macrografia obtida em cada uma das dez simulações através da razão de aspecto calculada ao longo da estrutura. As macrografias, a faixa de transição colunar-equiaxial e a posição da CET estão representadas na Figura 63.

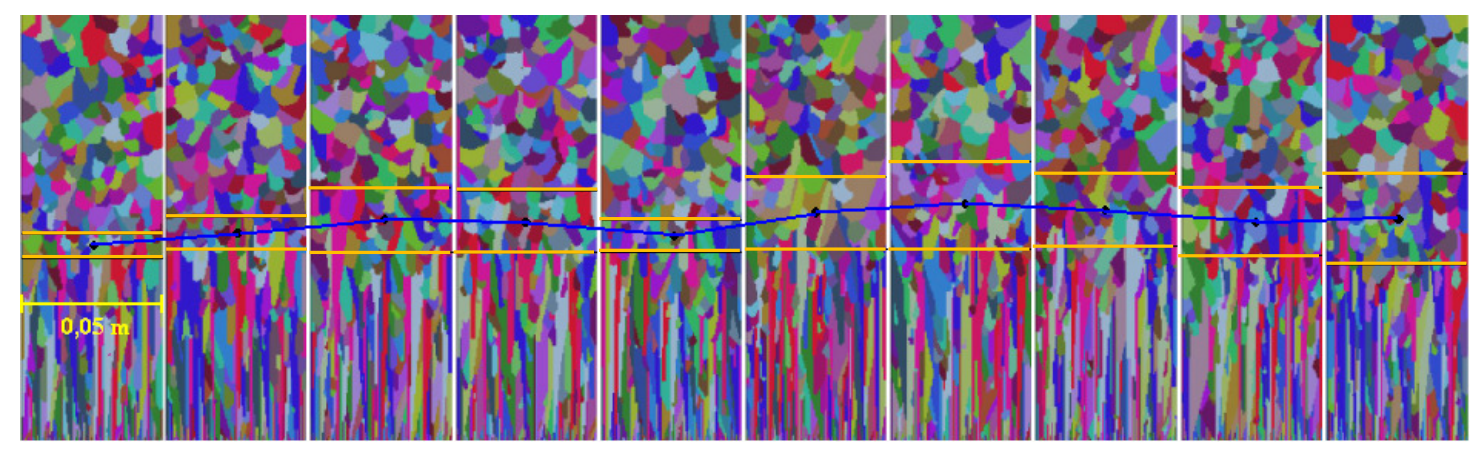

Figura 63- Macrografias calculadas para condições idênticas de simulação (condições de referência).

As linhas de cor laranja delimitam a região de transição colunar-equiaxial; o ponto demonstra a posição da CET e a linha azul é uma interpolação linear da CET entre as simulações.

Nas macrografias pode-se identificar duas linhas: a linha inferior representa o limite onde a razão de aspecto $\phi=0,3$ e a superior representa $\phi=0,4$, como descrito no item 4.2. A posição da CET, identificada por um ponto, foi definida no centro da região delimitada por estas linhas. Observa-se que a sua posição variou entre as macrografias de um valor máximo de $\approx 1,5 \mathrm{~cm}$, representando uma variação de aproximadamente $10 \%$ do tamanho do domínio causada apenas pelas variáveis aleatórias do modelo. 
Após a identificação do efeito da aleatoriedade na previsão da CET realizada pelo modelo estocástico, os seus resultados foram comparados com os resultados obtidos pelo modelo determinístico implementado por Martorano, Beckermann e Gandin (2003) nas condições de referência (item 5.2.1). As curvas de resfriamento estão mostradas na Figura 64. A aderência apresentada entre as curvas é muito boa, mas há discrepâncias principalmente nas curvas de resfriamento localizadas no topo (100, 120 e 140 mm). É importante ressaltar que as diferenças encontradas são menores que os erros de medida típicos para termopares comerciais, que são da ordem de $1,5^{\circ} \mathrm{C}$.

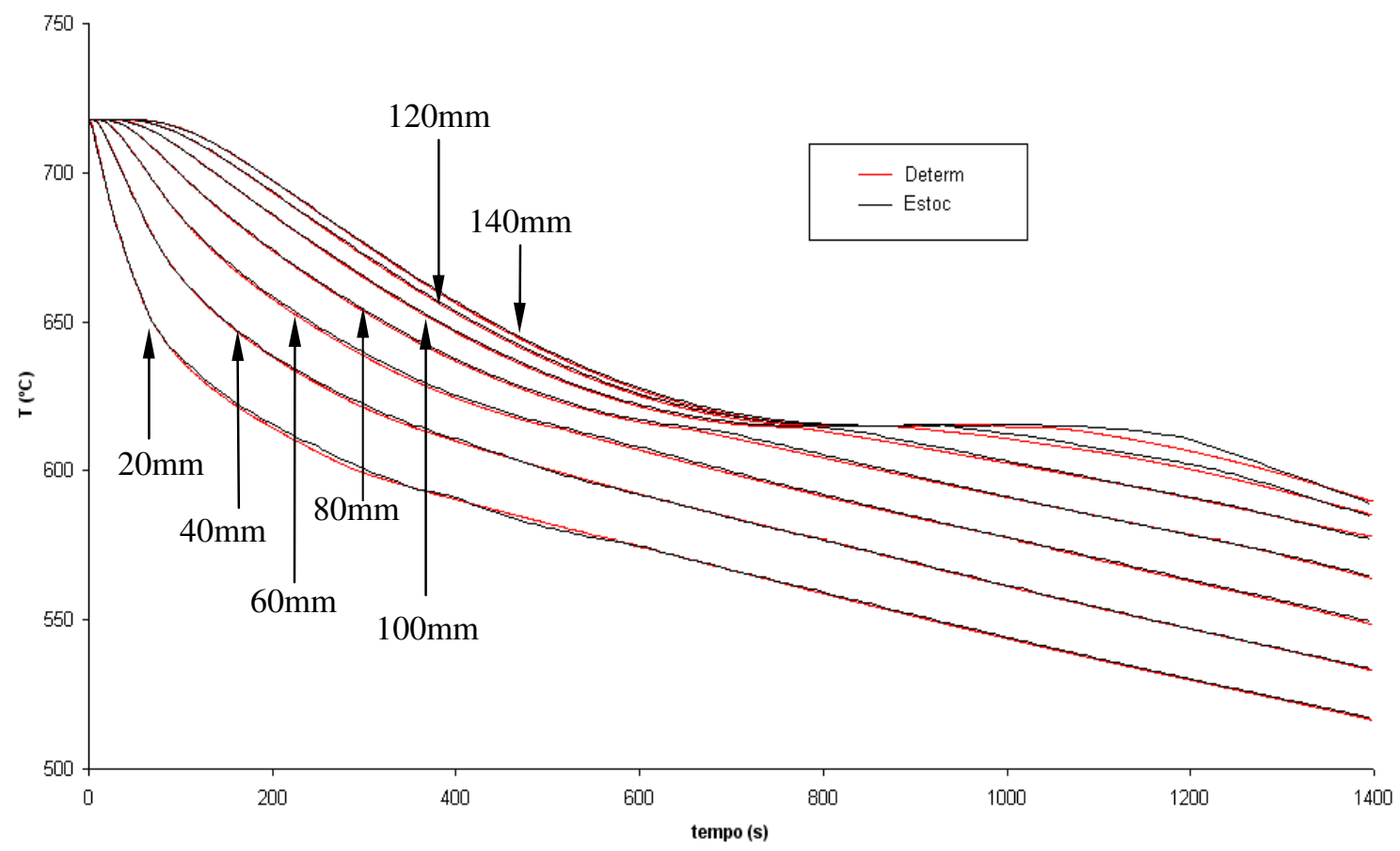

Figura 64- Curvas de resfriamento previstas pelos modelos estocástico (Estoc) e determinístico (Determ) para o caso de referência nas posições de 20,40,60,80,100,120 e 140 mm a partir da superfície inferior.

$\mathrm{Na}$ ampliação destas curvas de resfriamento (Figura 65), é possível observar a existência de oscilações ("wiggles") nos instantes iniciais de solidificação. Tais oscilações, segundo Martorano, Beckermann e Gandin (2003), são provenientes da utilização do modelo de nucleação instantânea e não são originárias de erros numéricos, ou seja, não serão eliminadas com um refinamento da malha ou com a diminuição do passo de tempo. Como se pode observar, os modelos estocásticos e determinísticos apresentaram oscilações nas mesmas posições e 
com os mesmos formatos, mas o modelo estocástico apresentou oscilações com duas freqüências diferentes.

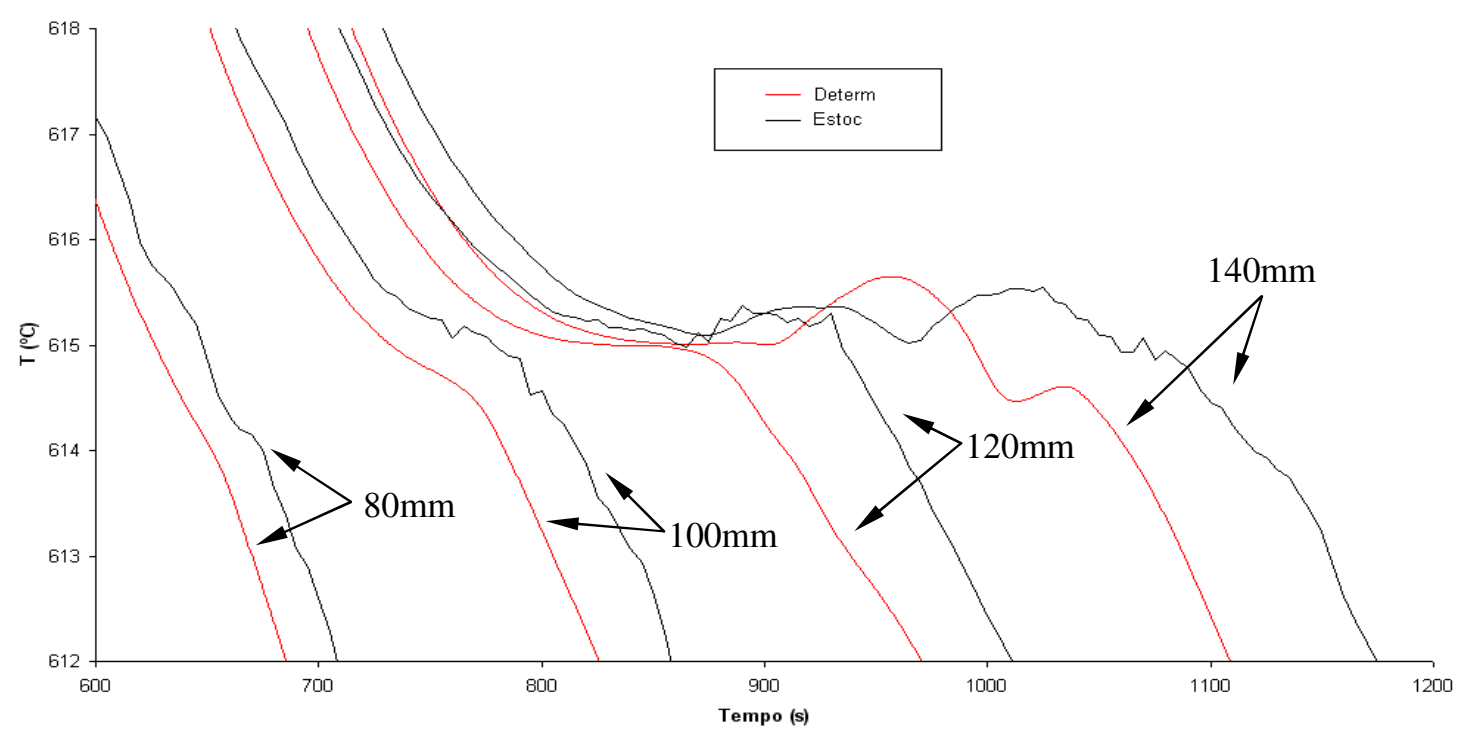

Figura 65- Oscilações apresentados nas curvas de temperatura para uma região ampliada da Figura

64.

A posição da frente colunar e o seu super-resfriamento em função do tempo obtidos pelos dois modelos para o caso de referência estão comparados na Figura 66 , sendo que o super-resfriamento da frente colunar é definido como:

$$
\Delta T_{c o l}=T_{L}\left(C_{0}\right)-T_{c o l}
$$

onde $T_{L}\left(C_{0}\right)$ é a temperatura liquidus dada pelo diagrama de fases para a concentração inicial, $C_{0}$, e $T_{c o l}$ é a temperatura real na frente colunar. 


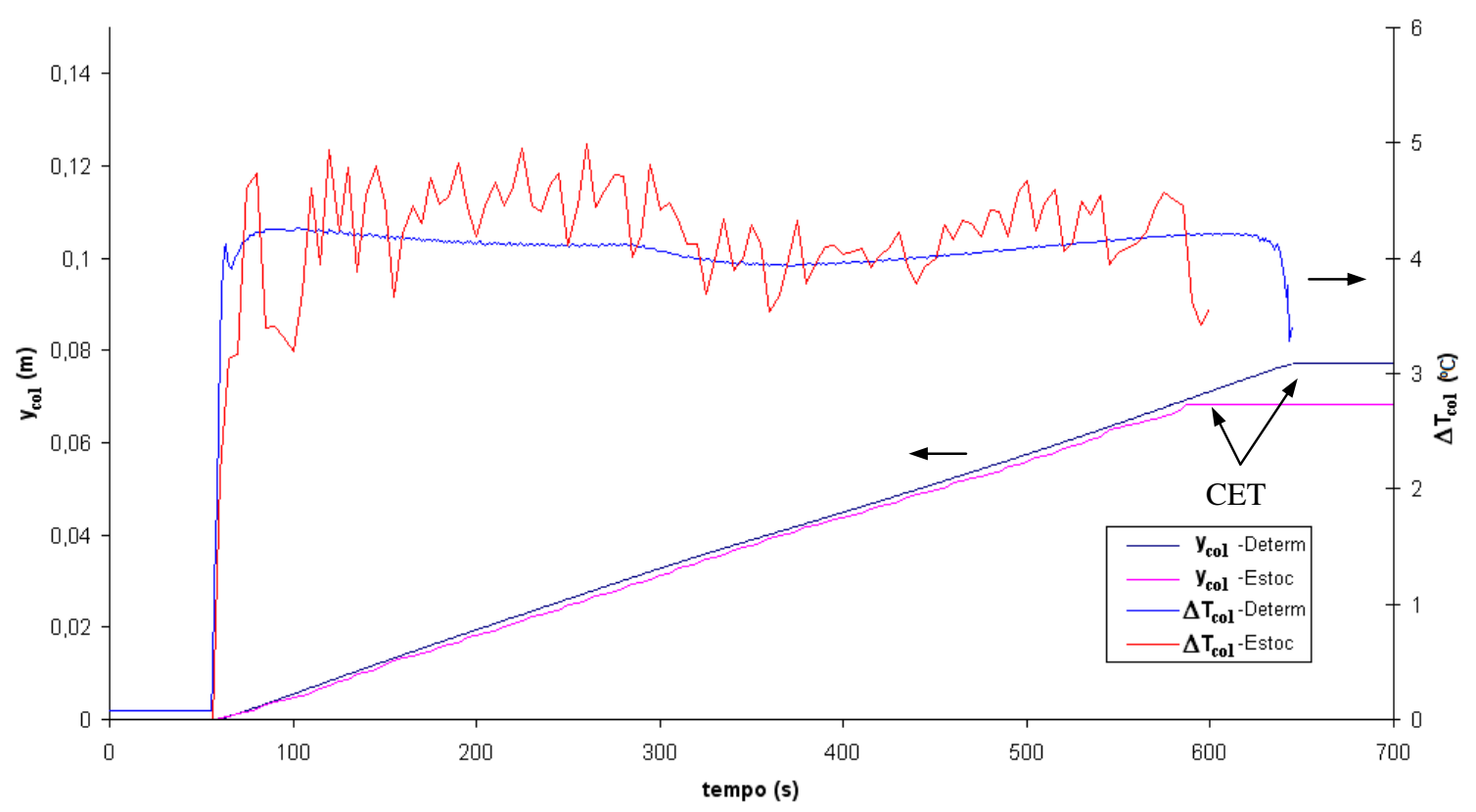

Figura 66- Posição $\left(\mathrm{y}_{\mathrm{col}}\right)$ e super-resfriamento da frente colunar $\left(\Delta T_{c o l}\right)$ previstos pelos modelos estocástico (Estoc) e determinístico (Determ).

A curva de super-resfriamento da frente colunar do modelo estocástico apresentou uma oscilação que é inerente ao método do autômato celular. Porém, nota-se que estas oscilações ocorrem em torno da curva calculada pelo modelo determinístico e, ao se calcular o super-resfriamento médio presente nesta frente,

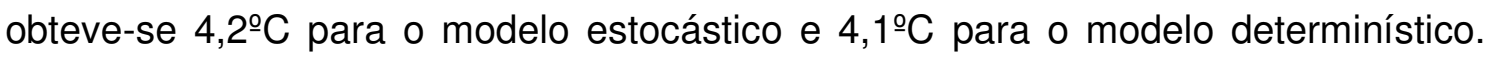
Não se observam oscilações significativas na curva da posição da frente colunar fornecida pelo modelo estocástico em função do tempo. Esta curva está muito próxima daquela fornecida pelo modelo determinístico, exceto pela posição de ocorrência da CET. Nota-se que o tempo para a ocorrência da CET foi menor no modelo estocástico.

Pode-se identificar duas quedas bruscas na curva de super-resfriamento da frente colunar do modelo estocástico $(t=100 \mathrm{~s}$ e $t=585 \mathrm{~s})$; uma delas $(\mathrm{t}=585 \mathrm{~s})$ pode estar relacionada com uma liberação de calor latente relativamente grande devido à nucleação de um número de grãos equiaxiais relativamente alto, que acabam causando a CET e iniciando a formação da região equiaxial. 
Outra análise dos resultados foi feita através dos perfis de fração de sólido, temperatura e fração de envelopes em função da posição para um tempo de 670 s. Os resultados encontram-se na Figura 67.

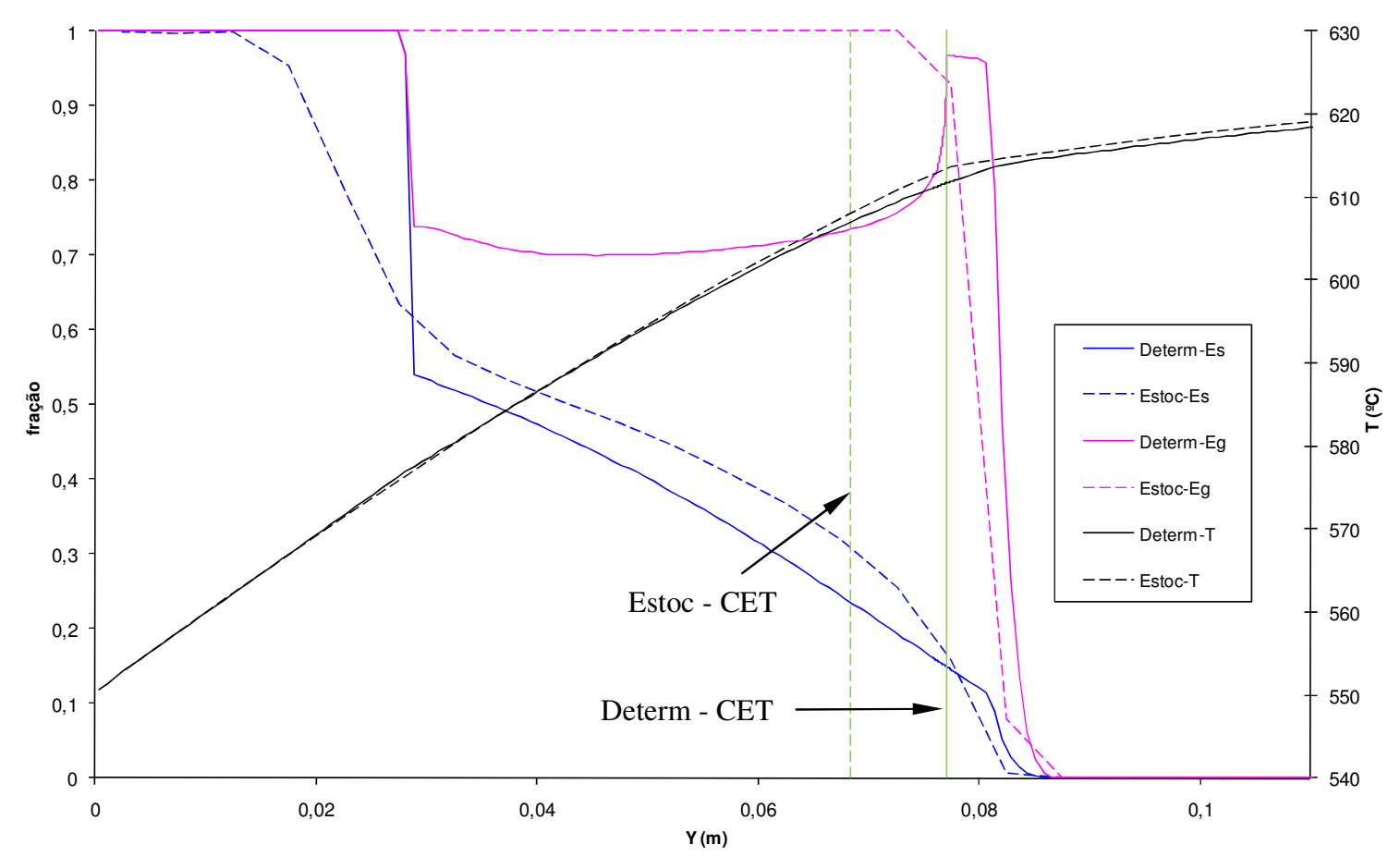

Figura 67- Curvas de temperatura $(\mathrm{T})$, fração de sólido $\left(\mathcal{E}_{S}\right)$ e fração de envelopes ( $\left.\mathcal{E}_{g}\right)$ em função da distância previstas pelos modelos estocástico (Estoc) e determinístico (Determ) para um tempo de 670 s.

Nota-se que tanto as temperaturas como a fração de sólido prevista pelo modelo estocástico são mais elevadas que as previstas pelo modelo determinístico. Tal fato demonstra uma falta de coesão com a hipótese de Scheil (Garcia, 2001) utilizada em ambos os modelos, onde temperaturas maiores deveriam ocasionar uma diminuição na fração de sólido. Este aspecto será melhor discutido posteriormente.

Comparando-se as frações de envelopes $\left(\varepsilon_{g}\right)$ da Figura 67, nota-se que a fração de envelopes do modelo determinístico atinge um patamar, ou seja, o seu crescimento é obstruído devido à rejeição de soluto para o líquido extradendrítico, $C_{\text {l }}$. As equações [52] a [54] mostram que a velocidade de crescimento dos envelopes decresce com o aumento de $\mathrm{C}_{\mid}$e este aumento poderá ser observado mais adiante na Figura 91 . No modelo estocástico não se considera a rejeição de soluto $\left(C_{l}=C_{0}\right)$ e, 
portanto, o super-resfriamento para o crescimento aumenta constantemente com a diminuição da temperatura.

$\mathrm{Na}$ construção de ambos os modelos adotou-se o modelo de Scheil para previsão da fração de sólido. Na Figura 68 os perfis de temperatura e fração de sólido dos modelos são comparados com os resultados de fração de sólido previstos pelo modelo de Scheil (equação [38]) utilizando-se os perfis de temperatura apresentados pelos modelos. As posições previstas para a CET em cada modelo também estão indicadas.

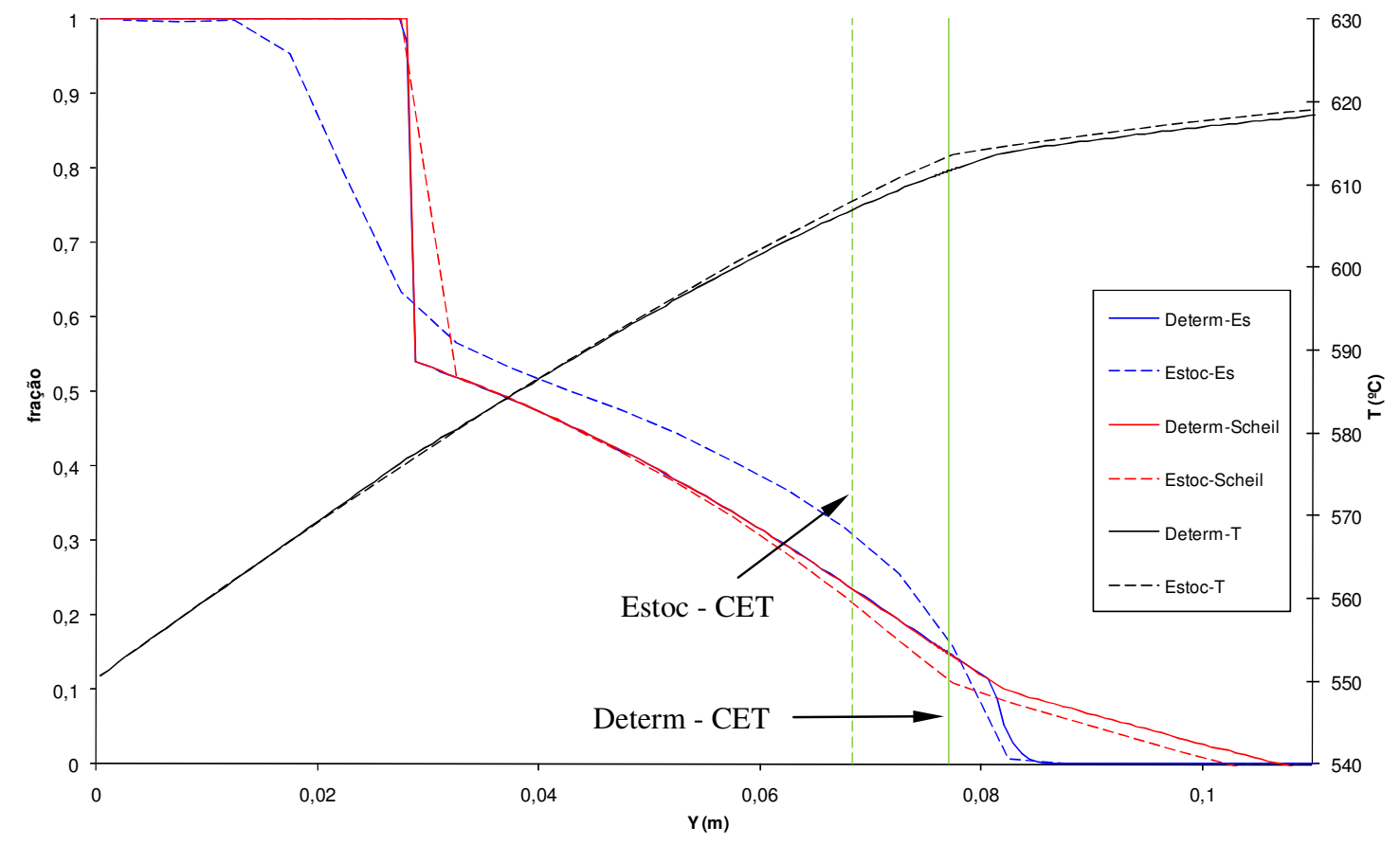

Figura 68- Comparação entre os perfis de fração de sólido $\left(\mathcal{E}_{S}\right)$ apresentados pelos modelos estocástico (Estoc), determinístico (Determ) e pelo modelo de Scheil para $t=670$ s (Scheil). As posições de CET para os modelos também estão representadas.

As curvas de fração de sólido obtidas pelo modelo de Scheil para as temperaturas previstas pelos modelos determinístico e estocástico (Scheil-Determ e Scheil-Estoc) apresentaram-se próximas, pois as temperaturas calculadas pelos modelos também estão próximas. As frações de sólido previstas pelo modelo determinístico e pelo modelo de Scheil apresentaram uma ótima aderência, podendo-se apenas notar um desvio na região acima de 0,08m, que será estudado no item 5.5. O modelo estocástico, no entanto, apresentou uma fração de sólido 
completamente diferente daquela fornecida pelo modelo de Scheil. Esta discrepância será examinada no item 5.4.

\subsubsection{Comparação das Posições da Transição Colunar-Equiaxial}

Após a análise das simulações nas condições de referência, as posições da transição colunar-equiaxial (CET) previstas pelos dois tipos de modelos, estocástico e determinístico, foram comparadas em uma série de testes onde se utilizaram novamente as condições de referência descritas no item 5.2.1, porém o superresfriamento para nucleação foi alterado na faixa de 0 a $5 \mathrm{~K}$. No modelo estocástico o super-resfriamento para a nucleação é definido por $\Delta T_{V, n u c}$, enquanto que no modelo determinístico este super-resfriamento é definido por $T_{L}-T_{N}$.

Deve-se ressaltar que, apesar do modelo estocástico utilizar um modelo de nucleação baseado na distribuição normal de super-resfriamentos (enquanto o modelo determinístico utiliza o modelo de nucleação instantânea), as condições de referência apresentadas no item 5.2.1 $\left(\Delta T_{\sigma}=0 K\right)$ tornam os dois modelos de nucleação equivalentes, possibilitando a comparação dos resultados obtidos pelos modelos determinístico e estocástico.

$\mathrm{Na}$ Figura 69 estão apresentadas as macrografias obtidas pelo modelo estocástico e as respectivas regiões e posições da CET. As posições da CET calculadas pelo modelo determinístico também estão apresentadas. 


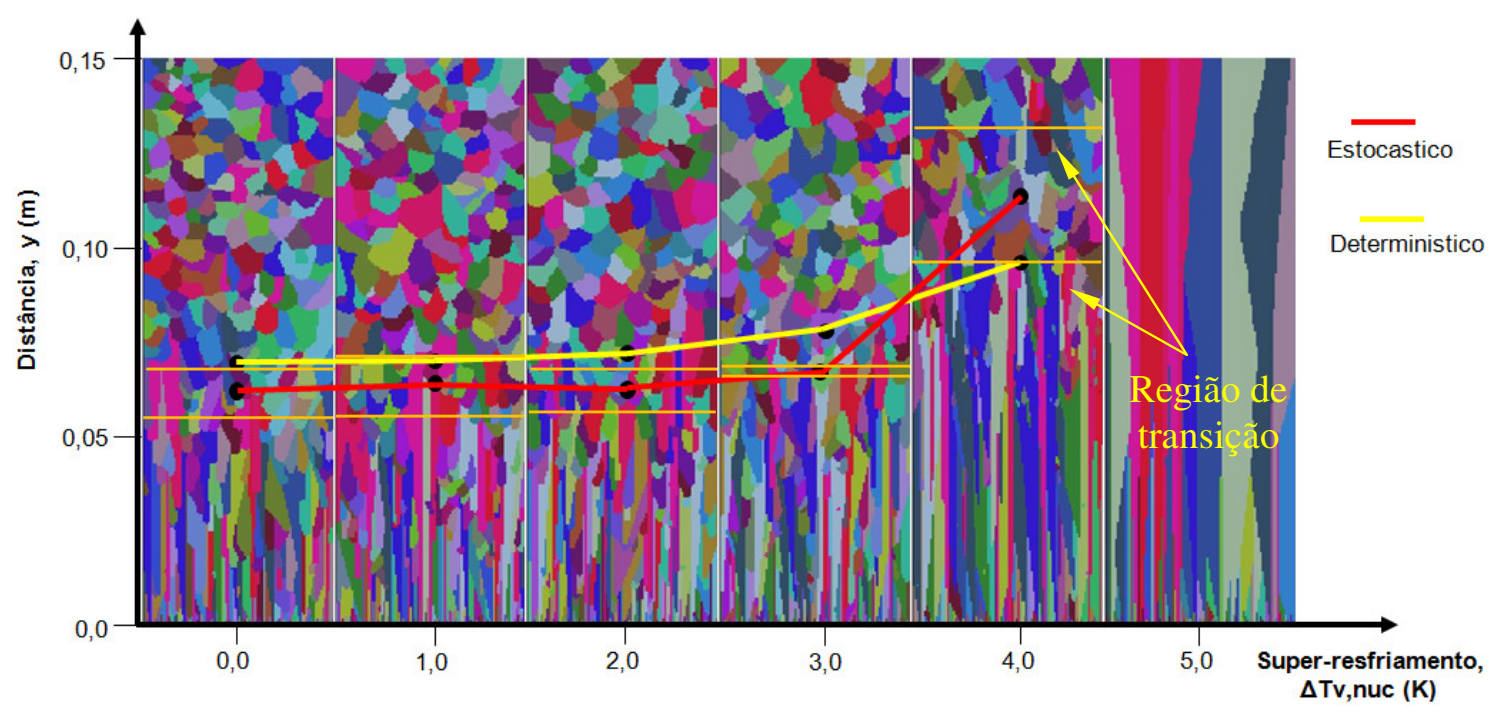

Figura 69- Posição da CET calculada através do modelo determinístico e estocástico e região de transição calculada pelo modelo estocástico em função do super-resfriamento para a nucleação. As macroestruturas obtidas através do modelo estocástico também estão apresentadas.

Os modelos apresentaram previsões da posição da CET próximas. Observa-se uma elevação brusca nas curvas ao redor de $4 \mathrm{~K}$, indicando que acima deste super-resfriamento existem apenas grãos colunares, sem grãos equiaxiais ou CET. Martorano, Beckermann e Gandin (2003) já haviam mostrado tal comportamento para o modelo determinístico e, com estes resultados, nota-se que o comportamento também é observado no modelo estocástico.

Realizaram-se simulações com super-resfriamentos variando na faixa de 4 a 4,5K em intervalos de 0,1K para se obter uma melhor definição do comportamento do modelo próximo deste super-resfriamento máximo. Estes dados encontram-se na Figura 70. Apesar das inúmeras diferenças entre os dois tipos de modelos, observou-se uma diferença de apenas $0,3 \mathrm{~K}$ no máximo super-resfriamento onde a CET ainda está presente. 


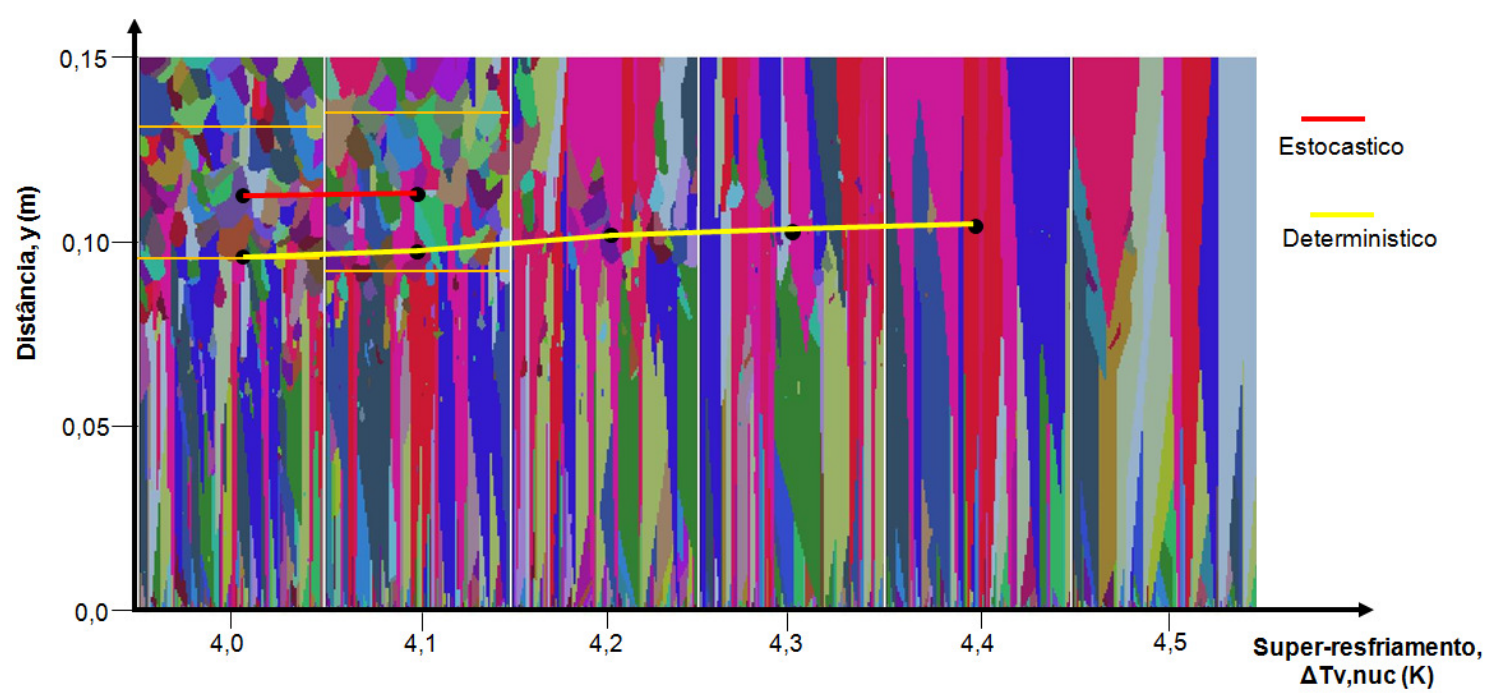

Figura 70- Posição da CET calculada através do modelo determinístico e estocástico e região da CET calculada pelo modelo estocástico em função do super-resfriamento para a nucleação. As macroestruturas obtidas através do modelo estocástico também estão apresentadas.

O máximo super-resfriamento onde a CET está presente no modelo estocástico $(4,1 \mathrm{~K})$ mostrou-se condizente com o super-resfriamento médio presente na frente colunar (4,2K), mostrado na Figura 66. A nucleação dos grãos equiaxiais só é possível quando o super-resfriamento para a sua nucleação for menor ou igual ao super-resfriamento presente na frente colunar. O mesmo raciocínio, porém, não pôde ser aplicado ao modelo determinístico, já que o máximo super-resfriamento onde a CET está presente $(4,4 \mathrm{~K})$ é maior que o super-resfriamento médio presente na frente colunar $(4,1 \mathrm{~K})$, também mostrado no item 5.2.2. Para se analisar este fato, a posição da frente colunar e o seu super-resfriamento em função do tempo foram obtidos pelos dois modelos para o caso com super-resfriamento de nucleação igual a 4,4K (Figura 71).

O super-resfriamento médio da frente colunar permaneceu em 4,2K para o modelo estocástico, mas houve uma diminuição de $0,1 \mathrm{~K}$ para 0 modelo determinístico $(4,1 \mathrm{~K})$. Apesar da diminuição do super-resfriamento médio no modelo determinístico em relação ao caso de referência, o super-resfriamento instantâneo mostrou um aumentou com o tempo e atingiu o seu valor máximo de 4,5K (desconsiderando-se as oscilações apresentadas próximo ao instante da CET). O super-resfriamento de 4,5K encontrado para o modelo determinístico justifica o 
aparecimento da CET no caso onde o super-resfriamento para nucleação possui o valor de $4,4 \mathrm{~K}$.

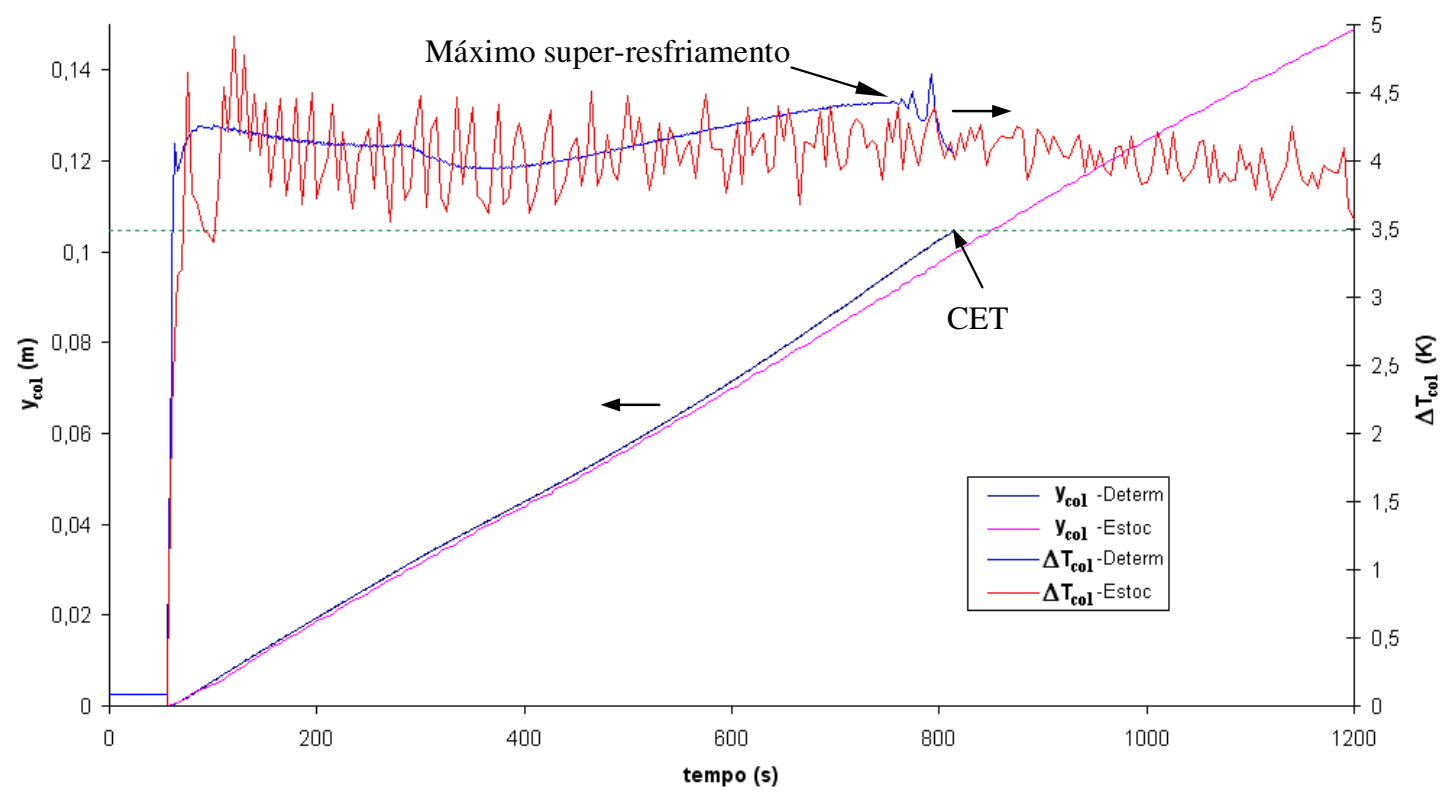

Figura 71- Posição ( $\left.\mathrm{y}_{\text {col }}\right)$ e super-resfriamento da frente colunar $\left(\Delta T_{c o l}\right)$ previstos pelos modelos estocástico (Estoc) e determinístico (Determ).

\subsubsection{Bloqueio mecânico}

No item acima foram comparados os comportamentos de previsão de CET para dois modelos, sendo um modelo estocástico e outro determinístico. No entanto, ambos diferem no método de bloqueio da frente colunar: o modelo determinístico utilizado considera o bloqueio de soluto (Martorano; Beckermann; Gandin, 2003), enquanto o estocástico utiliza uma forma de bloqueio mecânico. Desta forma, não se poderia concluir se a diferença da previsão da CET encontrada se deve totalmente à diferença do método de bloqueio ou também está relacionada ao equacionamento utilizado em cada modelo. Para investigar um pouco mais sobre a diferença encontrada na previsão da CET, um modelo determinístico com bloqueio mecânico baseado no modelo proposto por Hunt (1984) e explicado abaixo foi utilizado também para comparação com os resultados já apresentados na Figura 69.

Para o desenvolvimento das equações principais do modelo determinístico implementado, baseado no modelo proposto por Hunt (1984) e doravante chamado 
de Hunt-modificado, utilizou-se o modelo de nucleação instantânea (item 3.1.3) e as suposições e hipóteses já apresentadas para o modelo determinístico de Martorano, Beckermann e Gandin (2003) no item 4.3.

As principais equações para o modelo determinístico Hunt-modificado estão apresentadas abaixo:

$$
\begin{gathered}
\rho C_{P} \frac{\partial T}{\partial t}=\frac{\partial}{\partial y}\left(\kappa \frac{\partial T}{\partial y}\right)+\rho \Delta H_{f} \frac{\partial \varepsilon_{S}}{\partial t} \\
\frac{\partial \varepsilon_{l}}{\partial t}=-\frac{\partial \varepsilon_{g}}{\partial t}=-S_{e} V \\
\varepsilon_{S}+\varepsilon_{d}+\varepsilon_{l}=1
\end{gathered}
$$

onde $\rho$ é a densidade da liga considerada; $C_{p}$ é o calor específico; $T$ é a temperatura; $t$ é o tempo; $\Delta H_{f}$ o calor latente de fusão; $\varepsilon_{S}, \varepsilon_{d}$ e $\varepsilon_{l}$ são as frações volumétricas de sólido, líquido interdendrítico e líquido extradendrítico, respectivamente; $\kappa$ é a condutividade térmica média e depende da condutividade térmica das fases líquida $\left(\kappa^{L}\right)$ e sólida $\left(\kappa^{S}\right)$, sendo calculada por: $\kappa=\left(\varepsilon_{l}+\varepsilon_{d}\right) \kappa^{L}+\varepsilon_{S} \kappa^{S} ; \varepsilon_{g}$ é a fração volumétrica de envelope $\left(\varepsilon_{g}=\varepsilon_{s}+\varepsilon_{d}=1-\varepsilon_{l}\right) ; S_{e}$ a área interfacial de envelope por unidade de volume (concentração de área interfacial); e $V$ é a velocidade de crescimento da ponta do braço da dendrita e calculada pelo modelo abaixo, originalmente proposto por Lipton, Glicksman e Kurz (1984) (LGK):

$$
V=\frac{D_{l} m_{l}(k-1) C_{l}^{*}}{\Gamma}\left(I v^{-1}(\Omega)\right)
$$

onde $\Gamma$ é o coeficiente de Gibbs-Thomson; $m_{l}$ é a inclinação da linha liquidus do diagrama de fases binário e $I v^{-1}$ é o inverso da função de Ivantsov, que pode ser aproximada por:

$$
I^{-1}(\Omega)=0,4567\left(\frac{\Omega}{1-\Omega}\right)^{1,195}
$$

sendo o super-resfriamento adimensional definido por: 


$$
\Omega=\frac{C_{l}^{*}-C_{l}}{C_{l}^{*}(1-k)}
$$

onde $C_{l}^{*}$ é a concentração média de soluto no líquido interdendrítico em uma certa temperatura, sendo esta calculada a partir do diagrama de fases, considerando-se a inclinação da linha liquidus constante e dada por $m_{l}$.

$$
C_{l}^{*}=\frac{\left(T-T_{f}\right)}{m_{l}}
$$

A concentração de área interfacial é corrigida pelo fator de Avrami (1939, 1940) para considerar o encontro de grãos, como definido por Hunt (1984) (mas não utilizado por Martorano, Gandin e Beckermann (2003)), sendo dada por:

$$
S_{e}=\left(1-\varepsilon_{g}\right) \frac{3\left(1-\varepsilon_{l}\right)^{\frac{2}{3}}}{R_{f}}
$$

onde $2 R_{f}$ é a distância característica entre os centros dos envelopes, definida diferentemente para o grão equiaxial e o colunar, como dado abaixo:

$$
\begin{aligned}
& \text { equiaxial: } R_{f}=\left(\frac{3}{4 \pi n}\right)^{\frac{1}{3}} \\
& \text { colunar: } R_{f}=\lambda_{1} / 2
\end{aligned}
$$

onde $n$ é a densidade de número de núcleos de grão existentes e $\lambda_{1}$ o espaçamento entre os braços primários de dendrita.

Neste modelo, assim como no modelo de Martorano, Beckermann e Gandin, 2003, é necessário um acompanhamento da posição da frente colunar para se decidir quanto à utilização da equação [104] ou [105] no cálculo de $R_{f}$ e quanto à posição de ocorrência da CET. Este acompanhamento é realizado segundo a equação abaixo:

$$
\frac{d y_{c o l}}{d t}=V_{c o l}
$$


onde $y_{c o l}$ é a posição da frente colunar e $V_{c o l}$ é a velocidade da frente colunar calculada através da equação [99] utilizando-se as concentrações $C_{l}$ e $C_{l}^{*}$ calculadas na posição da frente.

A principal diferença entre o modelo de Martorano, Beckermann e Gandin (2003) e o modelo de Hunt modificado reside no cálculo da fração de sólido interna aos envelopes de grão. Da mesma forma que proposto por Hunt (1984), o modelo de Hunt modificado utiliza a equação de Scheil para prever a evolução da fração de sólido interna aos envelopes $\left(\varepsilon_{S} / \varepsilon_{g}\right)$, obtendo-se a seguinte equação para a evolução da fração de sólido com o tempo:

$$
\frac{\partial \varepsilon_{S}}{\partial t}=\frac{\varepsilon_{d}}{(1-k) C_{l}^{*}} \frac{\partial C_{l}^{*}}{\partial t}+S_{e} V\left(1-\left(\frac{C_{l}^{*}}{C_{0}}\right)^{\frac{1}{k-1}}\right)
$$

onde $C_{0}$ é a concentração inicial da liga. Ao se assumir que a fração de sólido interna aos envelopes de grão obedece à equação de Scheil, considera-se que não há transferência de soluto entre os envelopes e o meio externo. Desta forma, a concentração de soluto média interna aos envelopes é exatamente igual à concentração de soluto no líquido extradendrítico e ambas são iguais à concentração inicial de soluto $\left(C_{0}\right)$ na liga. Com esta hipótese, o crescimento dos envelopes não considera a rejeição de soluto e, portanto, não ocorre o chamado bloqueio de soluto (Martorano; Beckermann; Gandin, 2003). Assim como no modelo de Hunt (1984), o crescimento colunar do modelo de Hunt modificado é bloqueado ao se atingir uma fração de grãos equiaxiais de 0,49 à sua frente.

O modelo determinístico de Hunt modificado foi utilizado para simular as mesmas condições de referência descritas no item 5.2.1, porém o superresfriamento para nucleação foi alterado na faixa de 0 a $5 \mathrm{~K}$, conforme já realizado anteriormente e apresentado na Figura 69. A comparação da posição da CET em função do super-resfriamento para a nucleação obtida com o modelo estocástico tradicional (Estocastico), com o modelo determinístico proposto por Martorano, Beckermann e Gandin (2003) e com o modelo estocástico de Hunt modificado (Hunt$0,49)$ pode ser vista na Figura 72. 


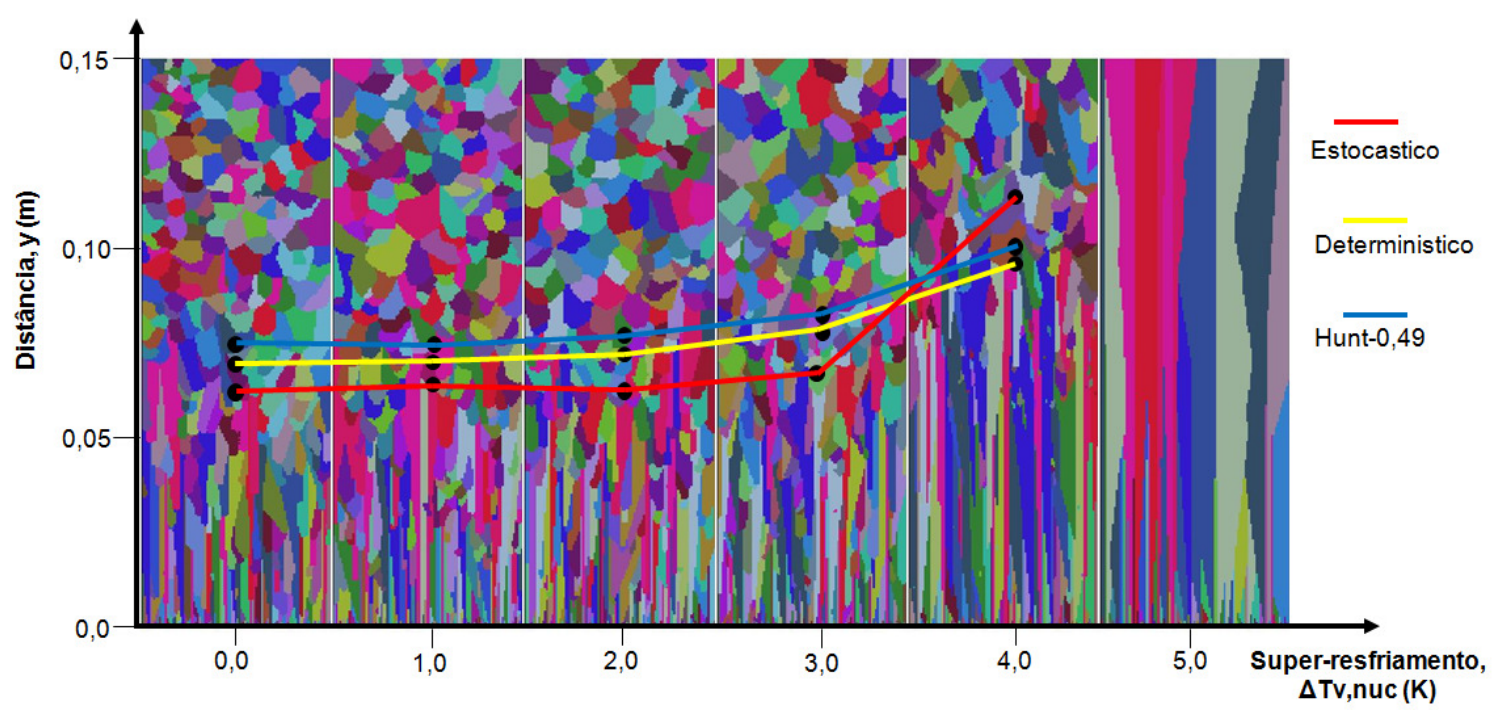

Figura 72 - Posição da CET calculada através do modelo determinístico com bloqueio de soluto (Deterministico), com bloqueio mecânico (Hunt-0,49) e estocástico, e macroestrutura e posição da CET calculada pelo modelo estocástico em função do super-resfriamento para a nucleação.

Nota-se que todos os modelos prevêem um aumento no tamanho da região colunar em função do aumento do super-resfriamento para nucleação, resultando em uma estrutura completamente colunar para super-resfriamentos maiores que $4 \mathrm{~K}$. Este comportamento, também mostrado por Martorano, Beckermann e Gandin (2003), também é observado nas macroestruturas calculadas pelo modelo estocástico. A região colunar prevista pelo modelo determinístico com bloqueio de soluto é menor que aquela prevista com o modelo de Hunt modificado para uma fração de bloqueio de 0,49. Isto está em conformidade com os mapas de CET calculados por Martorano, Beckermann e Gandin (2003), os quais mostram que a CET do modelo determinístico com bloqueio de soluto ocorre em gradientes de temperatura maiores, correspondendo a menores tempos para o bloqueio e menores regiões colunares em condições de solidificações unidirecionais transientes.

A posição da CET prevista pelos modelos determinísticos mostra uma maior região colunar do que para o modelo estocástico, a menos quando o superresfriamento para nucleação foi igualado a 4K. Na Figura 73, a posição da CET calculada é apresentada para um super-resfriamento fixo para nucleação de $3 \mathrm{~K}$, mas com variação da densidade total de substratos para nucleação. Novamente, o tamanho da região colunar para o modelo determinístico com bloqueio de soluto é 
sempre menor que aquela para o bloqueio mecânico e o tamanho desta diferença aumenta para valores maiores de densidade.

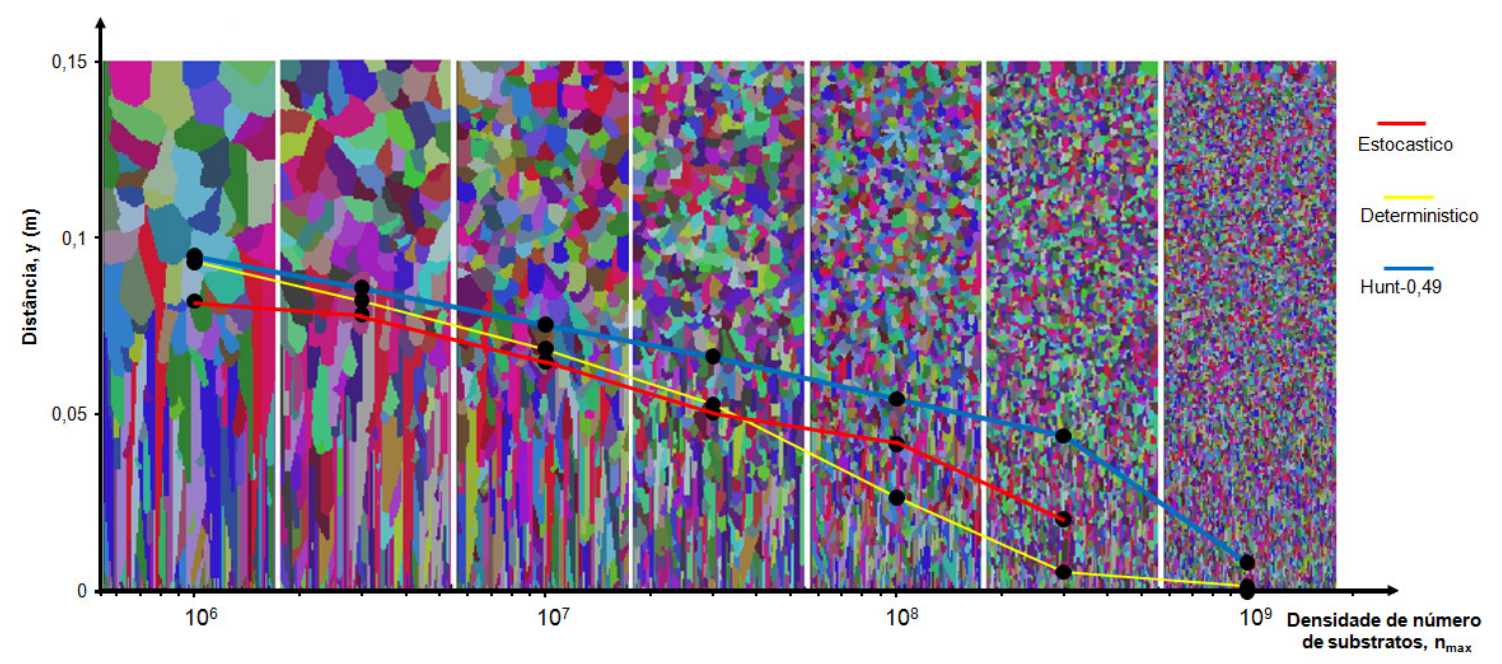

Figura 73 - Macroestruturas calculadas pelo modelo estocástico em função da densidade de número de substratos, juntamente com a posição da CET calculada pelos modelos determinísticos e estocástico.

Novamente observa-se que o tamanho da região colunar prevista com o modelo determinístico com bloqueio mecânico (Hunt-0,49) é maior que aquele previsto com os outros modelos (Estocastico e Deterministico). Com a análise das duas figuras anteriores observa-se que aparentemente existe uma relação entre as previsões de CET do modelo estocástico e do modelo determinístico com bloqueio de soluto, pois as posições parecem estar defasadas de um número aproximadamente constante. Para se verificar esta hipótese foram testados alguns valores de fração de envelope dendrítico que levam ao bloqueio mecânico no modelo de Hunt modificado em detrimento ao valor originalmente proposto de 0,49 (Hunt, 1984), obtendo-se um novo valor de 0,20.

A Figura 72 e Figura 73 estão novamente apresentadas na Figura 74 e Figura 75, respectivamente, porém incluindo-se as posições da CET previstas pelo modelo de Hunt modificado com a nova fração de grãos equiaxiais de 0,20 para definir quando o bloqueio mecânico dos grãos colunares ocorre. 


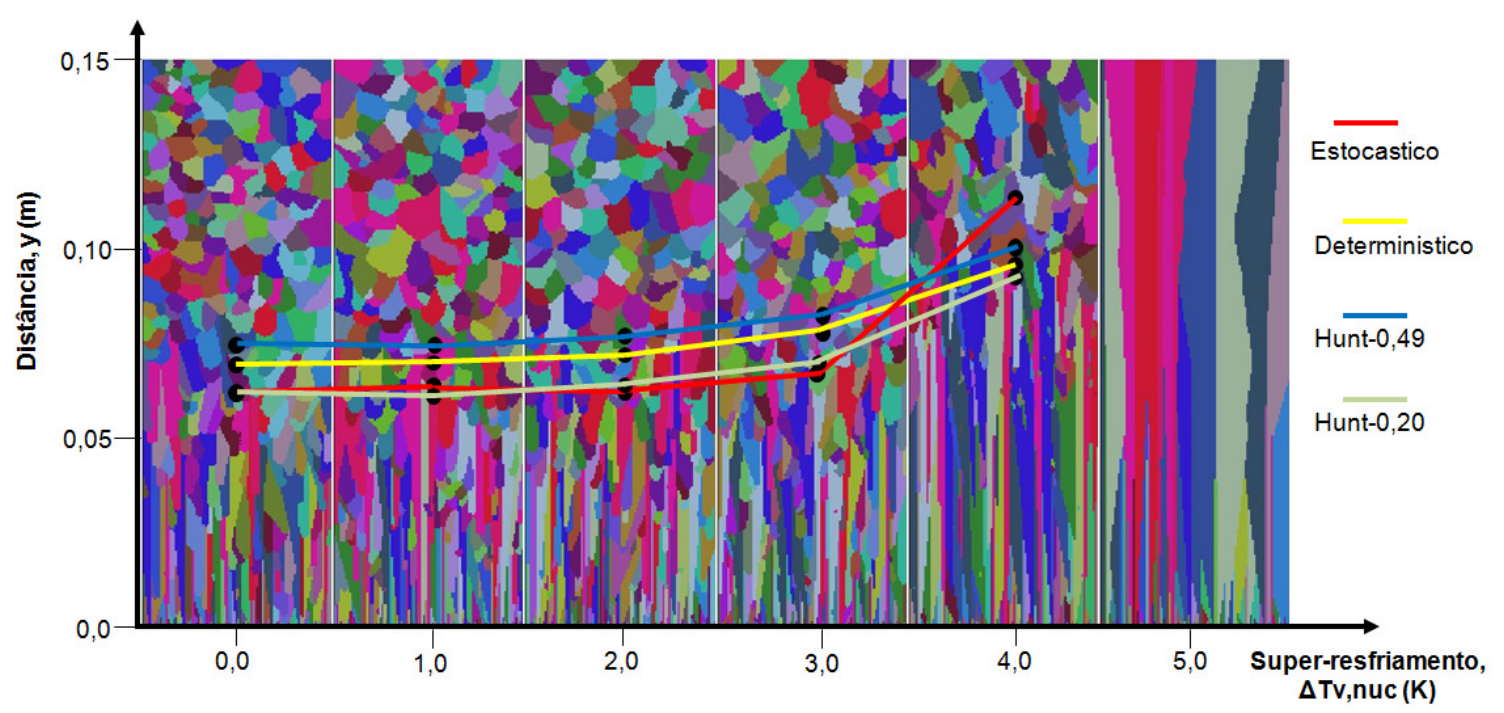

Figura 74 - Posição da CET calculada através do modelo determinístico com bloqueio de soluto (Deterministico), com bloqueio mecânico (Hunt-0,49 e Hunt-0,20) e estocástico, e macroestrutura e posição da CET calculada pelo modelo estocástico em função do super-resfriamento para a nucleação.

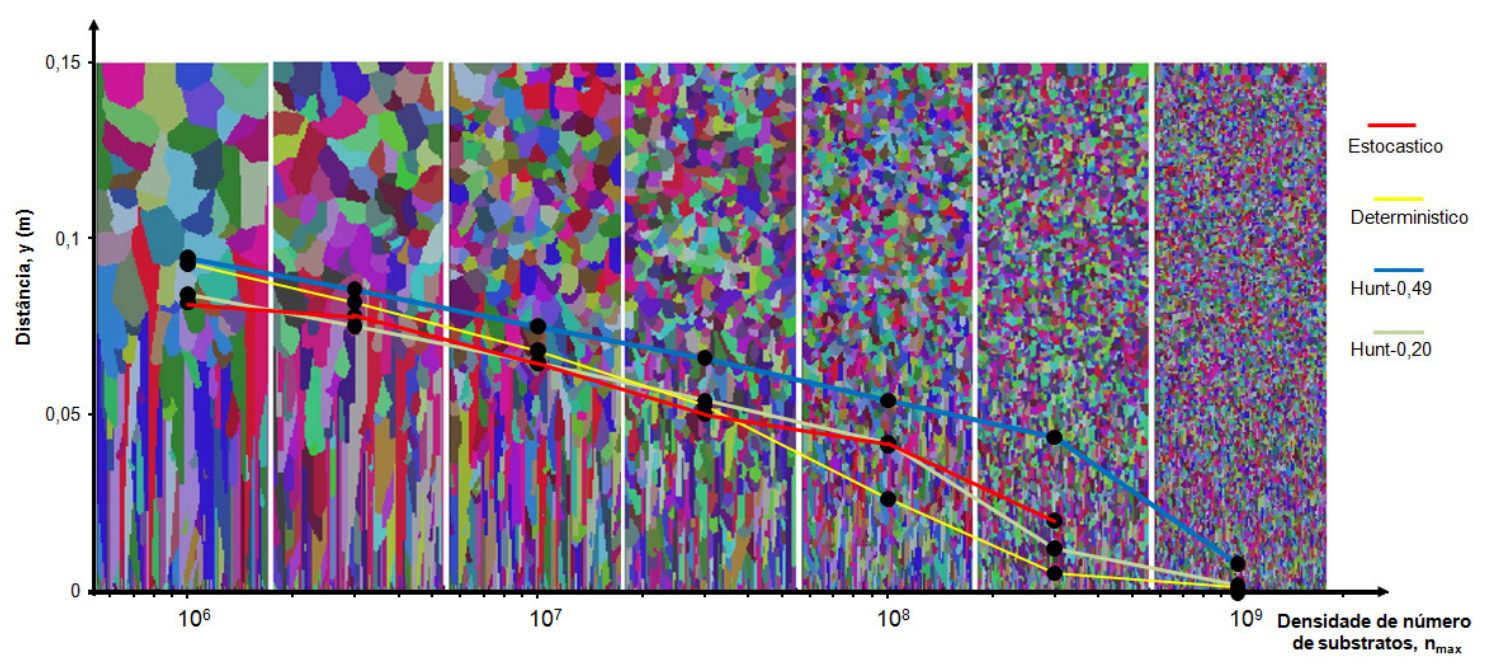

Figura 75 - Macroestruturas calculadas pelo modelo estocástico em função da densidade de número de substratos, juntamente com as posições da CET calculadas pelos modelos determinísticos (Deterministico, Hunt-0,49 e Hunt-0,20) e estocástico.

Nota-se que, após a alteração da fração de envelopes para bloqueio de 0,49 para 0,20 , as posições de CET previstas pelo modelo estocástico e pelo modelo de Hunt modificado apresentaram boa concordância. Esta melhor concordância mostra que o bloqueio que ocorre no modelo estocástico corresponde ao bloqueio mecânico por uma fração de grãos equiaxiais de 0,2 no modelo determinístico, ao 
invés de 0,49 proposto por Hunt (1984). No próximo item tenta-se justificar a nova fração encontrada para bloqueio.

\subsubsection{Modelo geométrico para o bloqueio da frente colunar}

No modelo estocástico tradicional, a velocidade de crescimento dos grãos depende do super-resfriamento em relação à temperatura liquidus da concentração média da liga $\left(C_{0}\right)$; desta forma, o bloqueio por soluto nunca ocorreria neste tipo de modelo. Portanto, o bloqueio da frente colunar deve ocorrer de acordo com o mecanismo de bloqueio mecânico, analogamente ao modelo de Hunt (1984). No entanto, a Figura 72 e Figura 73 mostraram que a fração tradicional de bloqueio mecânico igual a 0,49 (Hunt-0,49) resulta em regiões colunares que são maiores que aquelas previstas pelo modelo estocástico.

Para se verificar como se dá o bloqueio mecânico da frente colunar no modelo estocástico, analisaram-se algumas macroestruturas, calculadas pelo modelo estocástico próximo ao instante de bloqueio da frente colunar, como pode ser visto na Figura 76.

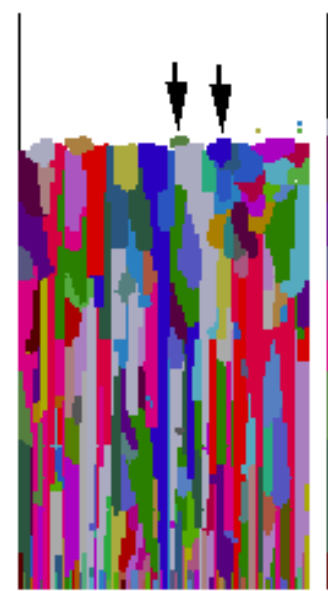

$650 \mathrm{~s}$

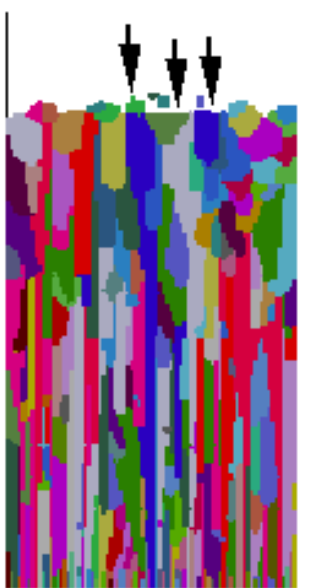

690 s

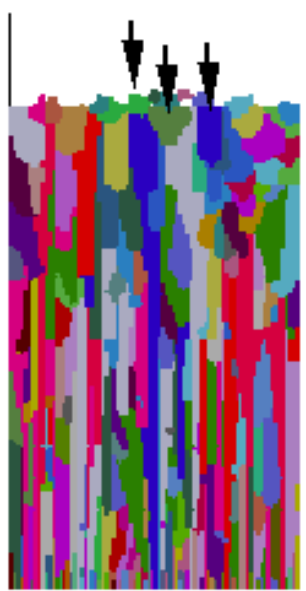

$700 \mathrm{~s}$

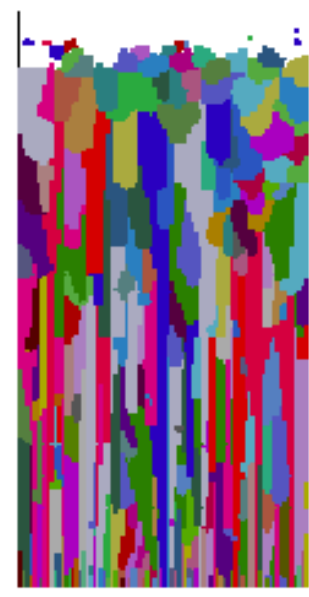

$750 \mathrm{~s}$

Figura 76 - Macroestruturas calculadas pelo modelo estocástico, nos tempos indicados.

No instante 650s, a frente colunar está avançando em direção ao topo, quando dois grãos equiaxiais indicados pelas setas nucleiam. Estes grãos crescem lateralmente em $\mathrm{t}=690 \mathrm{~s}$, e se tocam no instante de tempo de $700 \mathrm{~s}$, bloqueando 
assim localmente a frente colunar. Outro grão que ajudou neste processo é mostrado também nos tempos $t=690$ s e 700 s. No tempo de 750 segundos, o mesmo tipo de bloqueio ocorre ao longo de toda a frente colunar, provocando a CET. Na Figura 77, propõe-se um simples modelo geométrico consistente com o bloqueio mecânico visualizado na Figura 76 para o cálculo de uma nova fração de bloqueio da frente colunar.

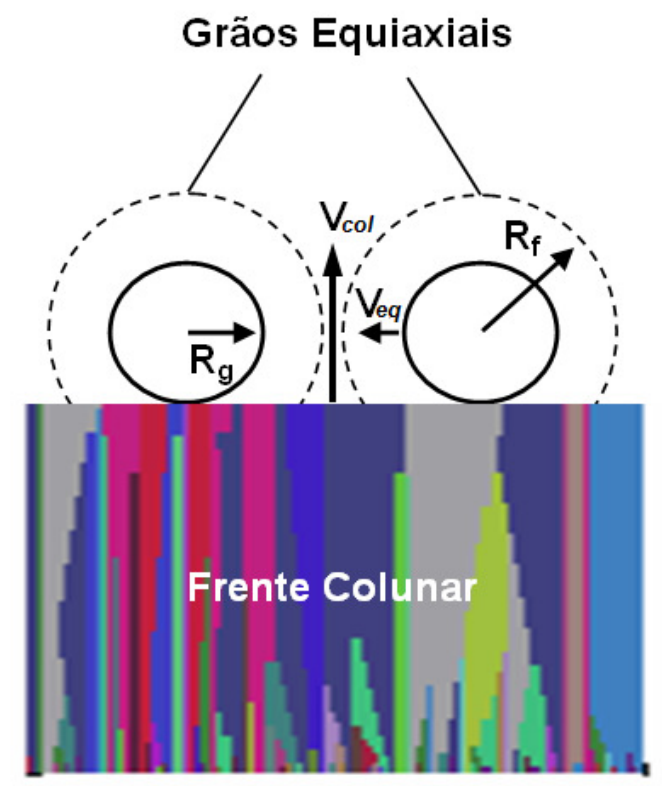

Figura 77 - Modelo geométrico do bloqueio mecânico para o modelo estocástico.

De acordo com o modelo geométrico, a frente colunar é bloqueada quando não puder percorrer uma distância $R_{g}$ antes que dois grãos adjacentes se toquem. Isto ocorre quando:

$$
\frac{R_{g}}{V_{c o l}}>\frac{R_{f}-R_{g}}{V_{e q}}
$$

onde $R_{g}$ é o raio instantâneo dos grãos equiaxiais quando estes encontram a frente colunar; $V_{c o l}$ é a velocidade da frente colunar; $V_{e q}$ é a velocidade dos grãos equiaxiais; e $R_{f}$ é metade da distancia média entre os centros dos grãos equiaxiais, calculada pela relação $\frac{R_{g}}{R_{f}}=\varepsilon_{g}^{1 / 3}$ para um domínio tridimensional. Substituindo-se esta relação na equação [110], obtém-se: 


$$
\frac{\varepsilon_{g}{ }^{1 / 3}}{V_{c o l}}>\frac{1-\varepsilon_{g}{ }^{1 / 3}}{V_{e q}}
$$

Para se definir os valores das velocidades é necessário levar em consideração que o modelo estocástico simula as orientações cristalográficas dos grãos. Segundo a teoria do crescimento competitivo, os grãos colunares com a sua orientação cristalográfica ([01] ou [10]) alinhada com a direção da maior extração de calor apresentariam a maior velocidade e sobrepujariam os demais após certo tempo de crescimento. Desta forma, considera-se que $V_{c o l}=V$, sendo $V$ a velocidade de crescimento da ponta da dendrita. Para o caso dos grãos equiaxiais, a menor velocidade relativa aconteceria quando ambos os grãos estivessem também alinhados com a direção de maior extração de calor, desta forma teríamos que $V_{e q}=\frac{V}{\sqrt{2}}$. Considerando as duas velocidades, a frente colunar seria bloqueada quando $\varepsilon_{g}>0,201$.

Porém no outro extremo, a maior velocidade relativa ocorreria quando os grãos tivessem sua orientação cristalográfica ([01] ou [10]) rotacionada de 45 em relação à direção de maior extração de calor. Desta forma, teria-se $V_{e q}=V$. Considerando as duas velocidades, a frente colunar seria bloqueada quando $\varepsilon_{g}>0,125$.

Desta forma, aplicando o modelo geométrico do bloqueio mecânico ao modelo estocástico, a frente colunar seria bloqueada para valores de fração de envelopes equiaxiais entre 0,201 e 0,125. Conseqüentemente, conclui-se que a fração de bloqueio calculada por este modelo geométrico está em melhor concordância com o modelo estocástico do que a fração de bloqueio proposta por Hunt (1984), igual a 0,49.

\subsection{Efeito da Largura da Distribuição de Super-resfriamentos}

Como apresentado no item 4.1.2.2, no modelo estocástico considera-se que os super-resfriamentos críticos para nucleação sobre partículas dispersas no líquido 
estão distribuídos segundo uma distribuição normal. Esta distribuição é caracterizada por três parâmetros (equação [13]): a densidade total de número de substratos para a nucleação heterogênea $n_{\max }$; o super-resfriamento médio para nucleação $\Delta T_{\text {nис }}$ e o desvio padrão da distribuição $\Delta T_{\sigma}$. A largura da distribuição é definida pelo valor de $\Delta T_{\sigma}$ (Figura 7).

A influência de $\Delta T_{n u c}$ na macroestrutura final de grãos foi apresentada na Figura 69, mantendo-se $\Delta T_{\sigma}=0$. Nos próximos itens a influência da largura da distribuição (desvio padrão) na previsão da posição da CET (item 5.3.1) e nas curvas de resfriamento (item 5.3.2) será estudada.

\subsubsection{Posição da CET}

Nas simulações realizadas neste item, foram utilizadas as condições de referência (item 5.2.1), porém os valores de $\Delta T_{V, n u c}$ e principalmente $\Delta T_{V, \sigma}$ foram alterados dentro de uma determinada faixa. Nos primeiros testes fixou-se $\Delta T_{V, n u c}$ e variou-se $\Delta T_{V, \sigma}$. Os resultados encontram-se na Figura 78, Figura 79, Figura $80 \mathrm{e}$ Figura 81.

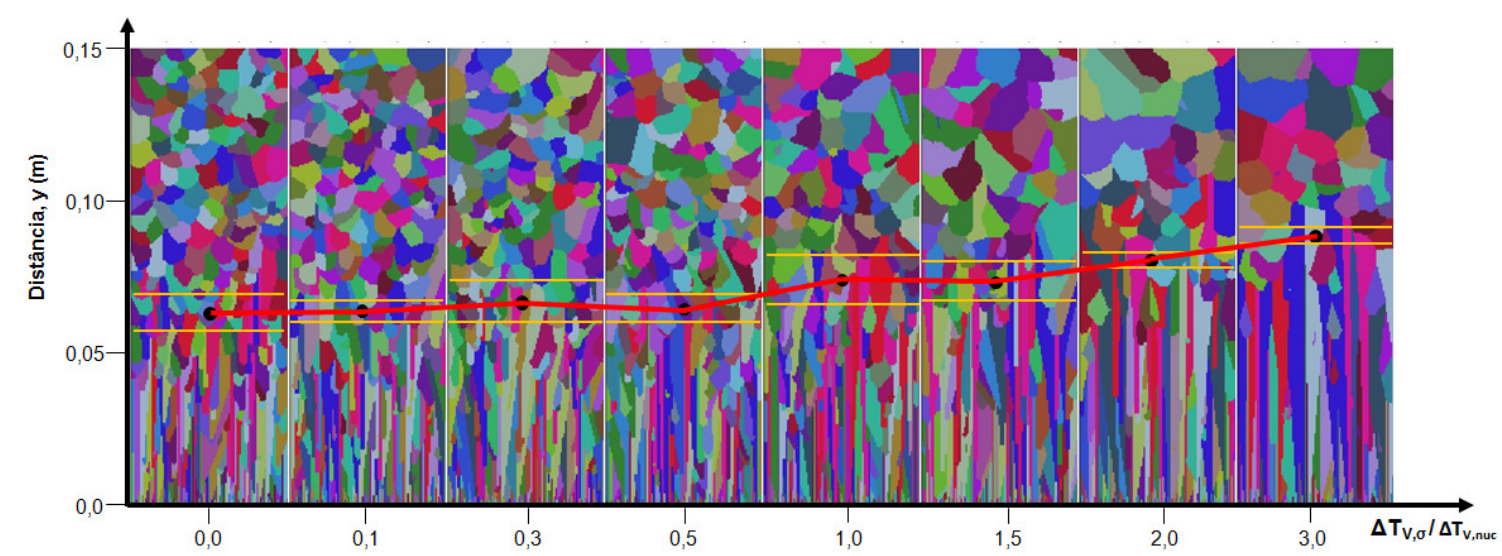

Figura 78- Posição da CET em função da largura relativa de distribuição ( $\Delta T_{V, \sigma} / \Delta T_{V, n u c}$ ) para

$$
\Delta T_{V, n u c}=2 \mathrm{~K} \text {. }
$$




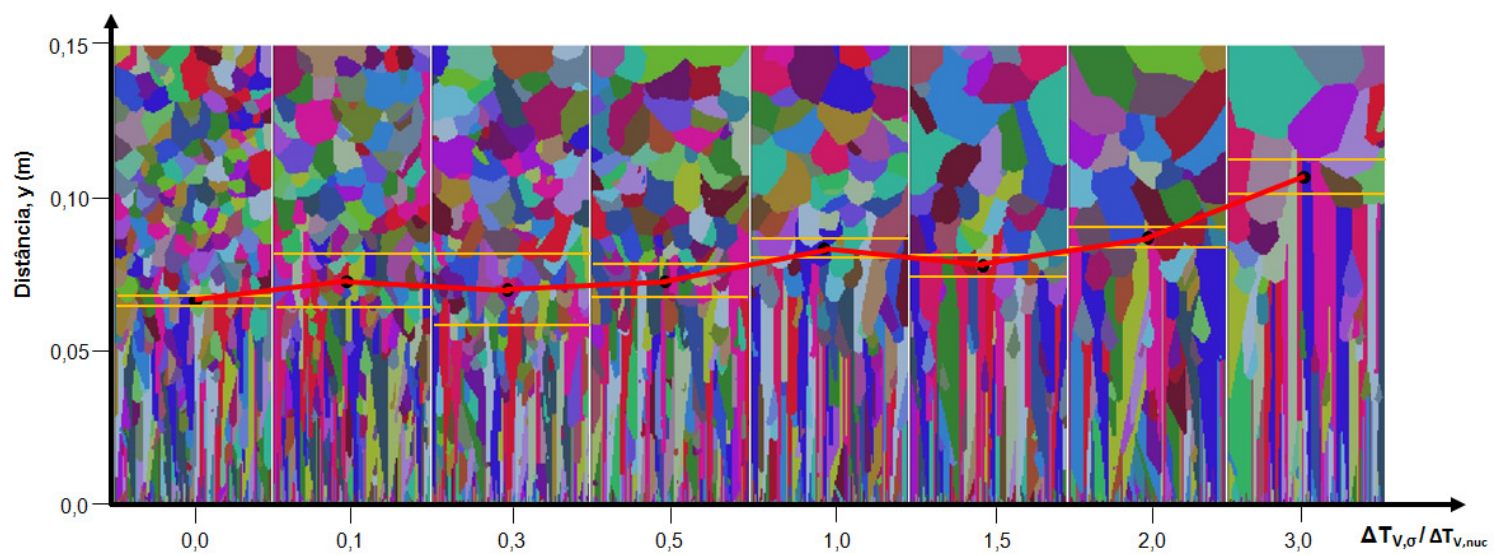

Figura 79- Posição da CET em função da largura relativa de distribuição ( $\Delta T_{V, \sigma} / \Delta T_{V, \text { nuc }}$ ) para $\Delta T_{V, n u c}=3 \mathrm{~K}$.

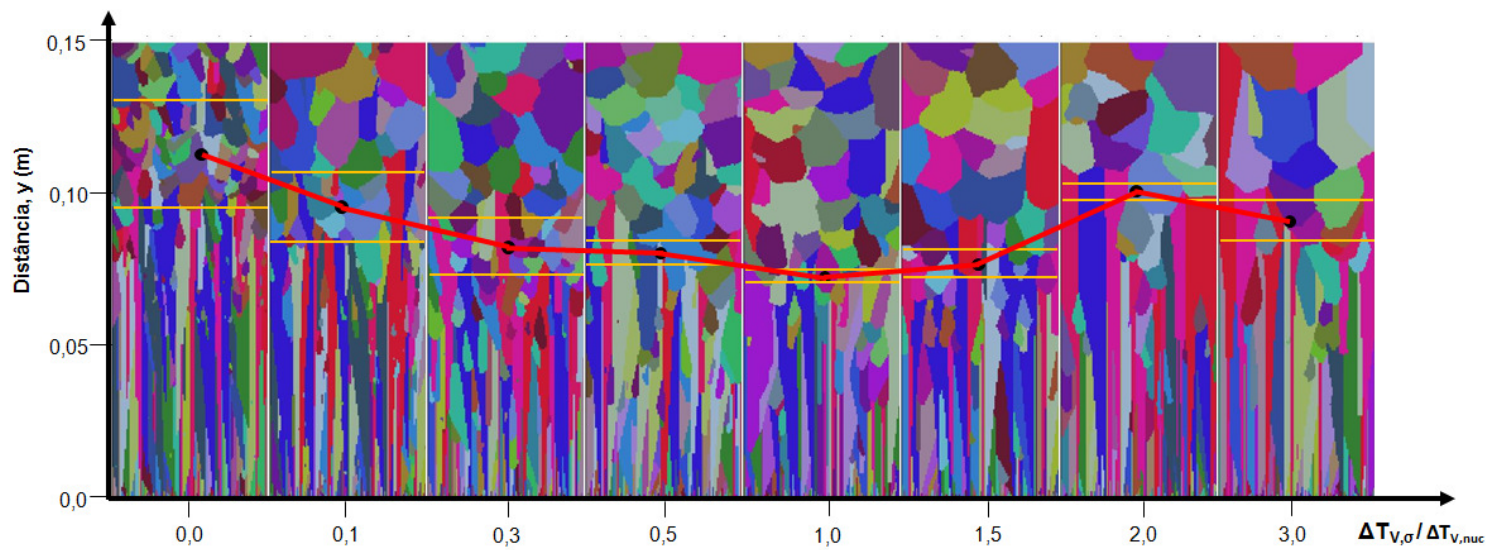

Figura 80- Posição da CET em função da largura relativa de distribuição ( $\Delta T_{V, \sigma} / \Delta T_{V, n u c}$ ) para $\Delta T_{V, n u c}=4 \mathrm{~K}$.

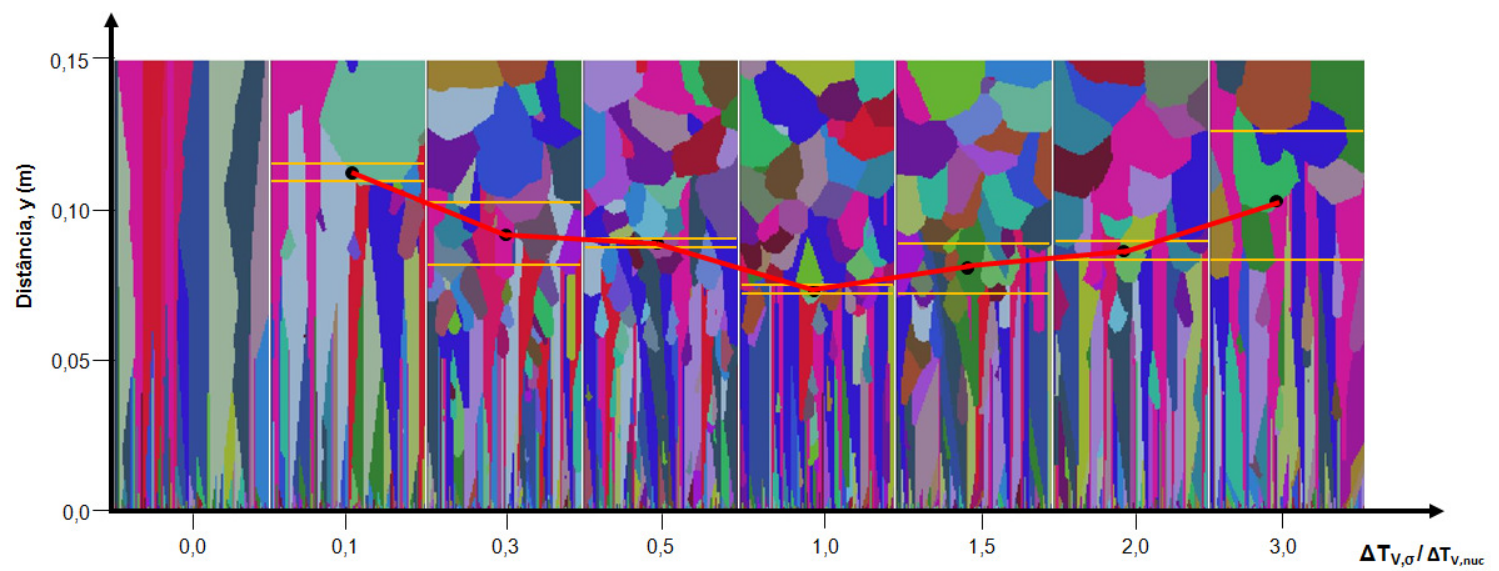

Figura 81- Posição da CET em função da largura relativa de distribuição ( $\Delta T_{V, \sigma} / \Delta T_{V, n u c}$ ) para $\Delta T_{V, \text { nuс }}=5 \mathrm{~K}$. 
Percebe-se que, para distribuições com um valor de desvio padrão de até 0,3K, as macrografias da Figura 78 e Figura 79 são semelhantes às macrografias simuladas com o modelo de nucleação instantânea $\left(\Delta T_{V, \sigma}=0\right)$. Nestas figuras as duas primeiras macrografias não apresentam diferenças significativas na posição da CET e nem no tamanho médio dos grãos equiaxiais. Por outro lado, valores de $\Delta T_{V, \sigma}$ maiores do que 0,3K mostram alterações significativas na posição da CET e no tamanho médio de grão.

Nos dois últimos casos apresentados (Figura 80 e Figura 81) o aumento em $\Delta T_{V, \sigma}$, em um primeiro instante, deslocou a posição da CET para baixo. Posteriormente, o aumento em $\Delta T_{V, \sigma}$ deslocou a CET para cima, sendo que este comportamento não foi percebido nas figuras Figura 78 e Figura 79.

\subsubsection{Curvas de Resfriamento}

A utilização do modelo de nucleação normal também possibilitou a verificação da hipótese apresentada por Martorano, Beckermann e Gandin (2003) que visa explicar a presença de oscilações nas curvas de resfriamentos ("wiggles") apresentadas no item 5.2.2. A hipótese apresentada por estes autores associa o modelo de nucleação instantânea à presença das oscilações nas curvas de resfriamento (item 5.2.2). Para se verificar esta hipótese, realizou-se um teste onde foram levantadas as mesmas curvas de temperatura apresentadas na Figura 65, onde $\Delta T_{V, \sigma}=0$, mas se utilizou o modelo estocástico com uma distribuição normal de super-resfriamentos para a nucleação onde $\Delta T_{V, \sigma}>0$.

Três testes foram realizados adotando-se $\Delta T_{V, n u c}=3 K$ e três valores crescentes de $\Delta T_{V, \sigma}$, a saber: $0,3 \mathrm{~K}, 0,9 \mathrm{~K}$ e 1,5K. Nestas condições a posição da CET não variou significativamente. Os resultados da temperatura em função do tempo estão apresentados na Figura 82, Figura 83 e Figura 84. Percebe-se que a hipótese levantada por Martorano, Beckermann e Gandin (2003) realmente teve um efeito na redução das oscilações ("wiggles") nas curvas de resfriamento, sendo que o teste com um desvio padrão de 1,5K (Figura 84) surtiu um efeito maior na 
diminuição destes. A hipótese apresentada implica em uma melhor distribuição da liberação do calor latente em relação ao tempo. Uma liberação abrupta de uma grande quantidade de calor latente parece desestabilizar as equações matemáticas utilizadas.

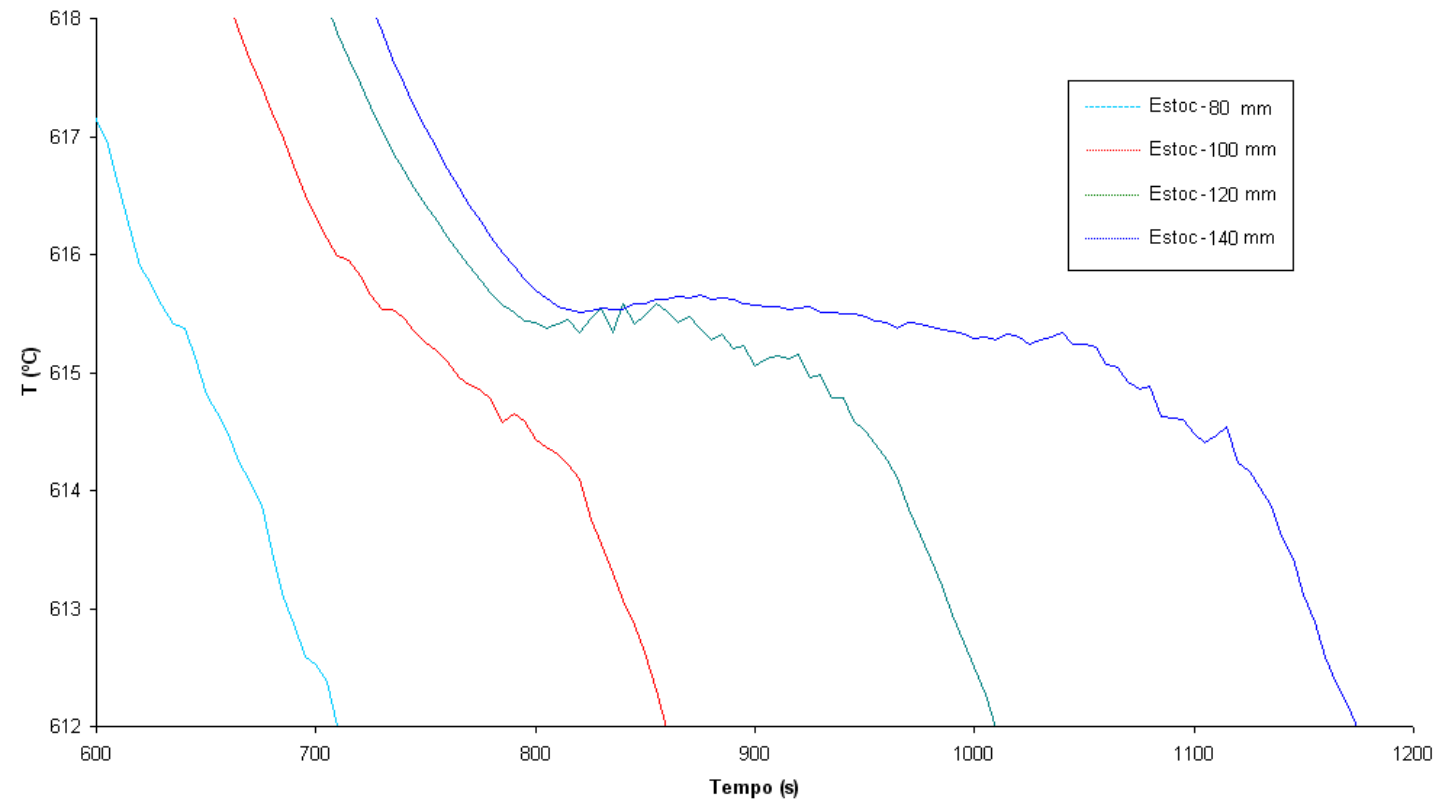

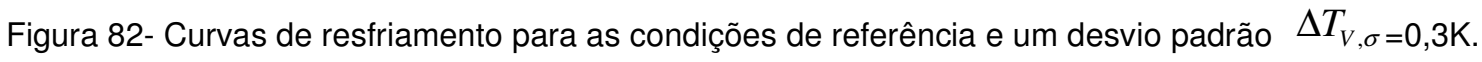

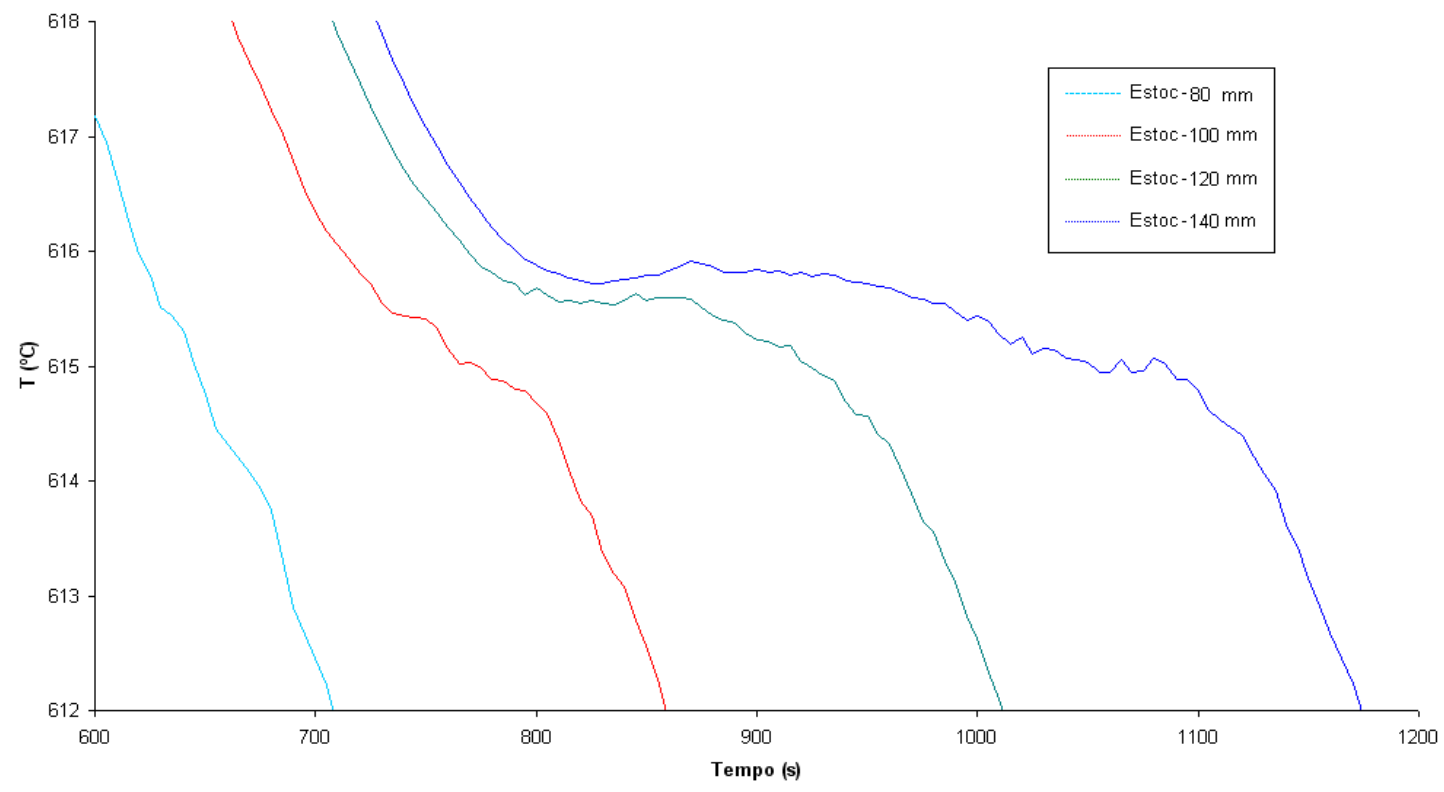

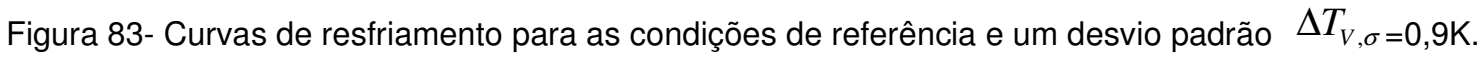




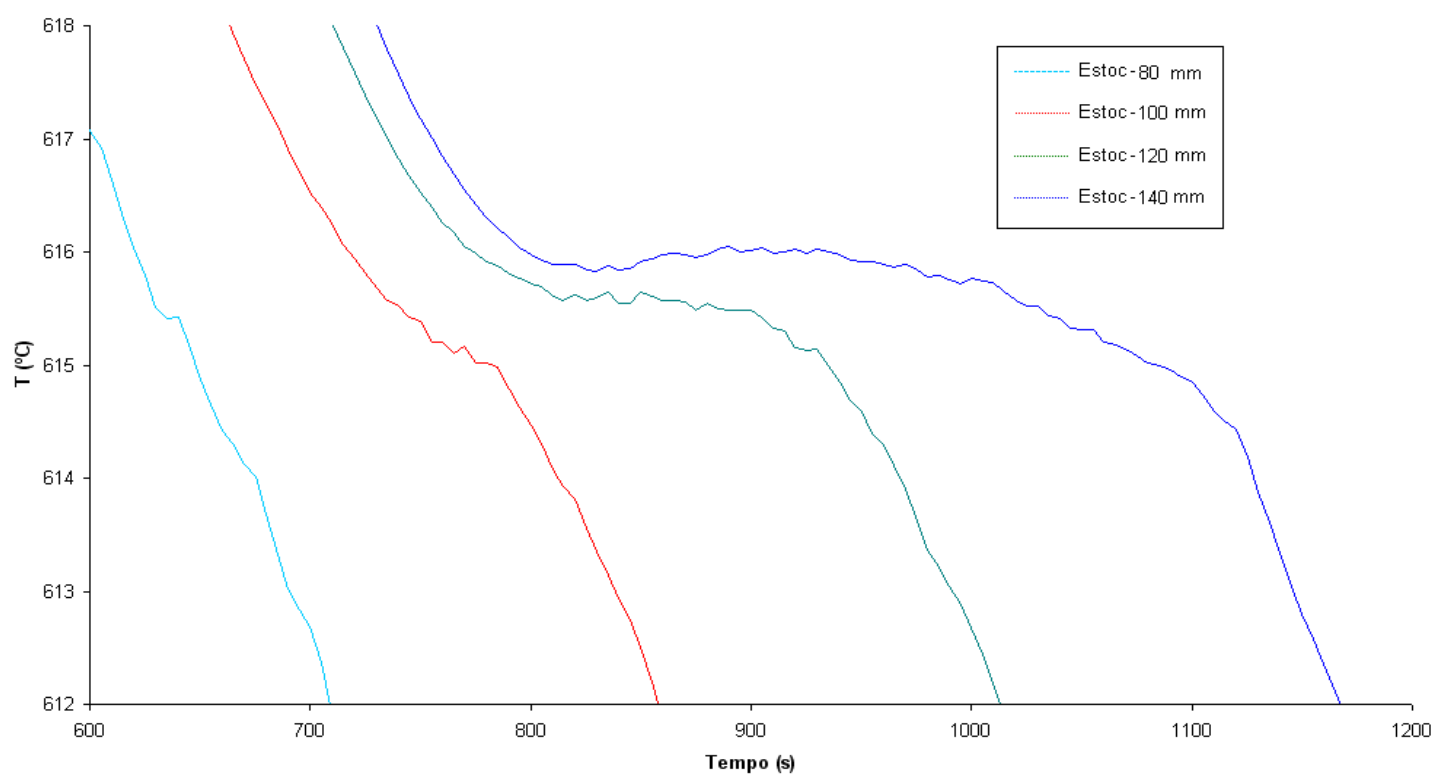

Figura 84- Curvas de resfriamento para as condições de referência e um desvio padrão $\Delta T_{V, \sigma=1,5 \mathrm{~K}}$.

Inicialmente os parâmetros de nucleação foram estudados quanto à sua influência na posição da CET, evidenciado que, para valores pequenos de desvio padrão (até $0,3 \mathrm{~K}$ ), o modelo de nucleação instantânea se assemelha ao modelo de nucleação normal no que tange a posição da CET. Por fim, a hipótese de Martorano, Beckermann e Gandin (2003) a respeito da formação de oscilações ("wiggles") nas curvas de resfriamento foi evidenciada através da utilização de um modelo de nucleação normal, que resulta em uma melhor distribuição da liberação de calor latente.

\subsection{Acoplamento Meso-Macroscópico do Modelo Estocástico}

No item 5.2.2, Figura 68, encontrou-se uma discrepância significativa entre a fração de sólido prevista pelo modelo estocástico e aquela prevista pelo modelo Scheil (Garcia, 2001). Este fato está em desacordo com as hipóteses do modelo estocástico já que se utilizou exatamente o modelo de Scheil em sua elaboração. Desta forma, decidiu-se neste item estudar esta discrepância em detalhes. Primeiramente no item 5.4.1 a fração de sólido prevista pelo modelo implementado 
será comparada com dados da literatura (Guillemot et al., 2004) gerados pelo mesmo modelo. Posteriormente, no item 5.4.2, uma análise detalhada do acoplamento meso-macroscópico será feita.

\subsubsection{Resultados do Modelo de Guillemot et al. (2004)}

Guillemot et al. (2004) realizaram um teste do modelo estocástico do autômato celular que consistiu na obtenção de curvas de temperatura e fração de sólido em função do tempo para algumas posições durante a solidificação unidirecional de uma liga Al-7\%Si. Guillemot et al. (2004) utilizaram o método dos elementos finitos para resolução da equação de conservação de energia e por isso o modelo recebeu o nome de CAFE. As propriedades e parâmetros utilizados no teste estão na Tabela 14 e Tabela 15.

Tabela 14- Propriedades da liga Al-7\%Si utilizada na simulação de Guillemot et al. (2004).

\begin{tabular}{cc|cc}
\hline Propriedade & Valor & Propriedade & Valor \\
\hline$\rho\left(\mathrm{kg} \mathrm{m}^{-3}\right)$ & 2452,0 & $C_{0}(\% \mathrm{peso})$ & $\mathrm{Al}-7 \% \mathrm{Si}$ \\
\hline $\mathrm{k} \mathrm{(-)}$ & 0,13 & $\mathrm{C}_{\mathrm{p}}\left(\mathrm{J} \mathrm{kg}^{-1} \mathrm{~K}^{-1}\right)$ & $2,6 \mathrm{E} 6$ \\
\hline$\kappa\left(\mathrm{W} \mathrm{m}^{-1} \mathrm{~K}^{-1}\right)$ & 70,0 & $T_{L}(\mathrm{~K})$ & 891 \\
\hline$\Delta H_{f}\left(\mathrm{~J} \mathrm{~kg}^{-1}\right)$ & $9,5 \mathrm{E} 8$ & $T_{\text {eut }}(\mathrm{K})$ & 850 \\
\hline & & $T_{f}(\mathrm{~K})$ & 963,5 \\
\hline $\mathrm{A}\left(\mathrm{m} \mathrm{s}^{-1} \mathrm{~K}^{-\mathrm{m}}\right)$ & $2,9 \mathrm{E}-6$ & $\mathrm{~m}(-)$ & 2,7 \\
\hline
\end{tabular}

Tabela 15- Parâmetros de simulação utilizados por Guillemot et al. (2004).

\begin{tabular}{|c|c|}
\hline Parâmetro & Valor \\
\hline Dimensão do domínio (m) & 0,1 \\
\hline Passo de tempo (s) & 0,001 \\
\hline Superaquecimento $(\mathrm{K})$ & 182 \\
\hline Temperatura do molde $(\mathrm{K})$ & 373 \\
\hline Malha para o CA (direção $x$ ) & 20 \\
\hline Malha de VF (direção $x$ ) & 100 \\
\hline $\mathrm{h}\left(\mathrm{W} \mathrm{m}^{-2} \mathrm{~K}^{-1}\right)$ & 500 \\
\hline
\end{tabular}


Um dos lados do domínio unidimensional da simulação foi considerado adiabático e a nucleação foi assumida ocorrer em um único substrato, localizado na primeira célula em contato com o outro lado, onde se realizou a extração de calor, conforme exemplificado na Figura 85. Este substrato possui um super-resfriamento nulo para a nucleação. Todas as outras células só foram ativadas pelo processo de crescimento, já que não receberam substratos.

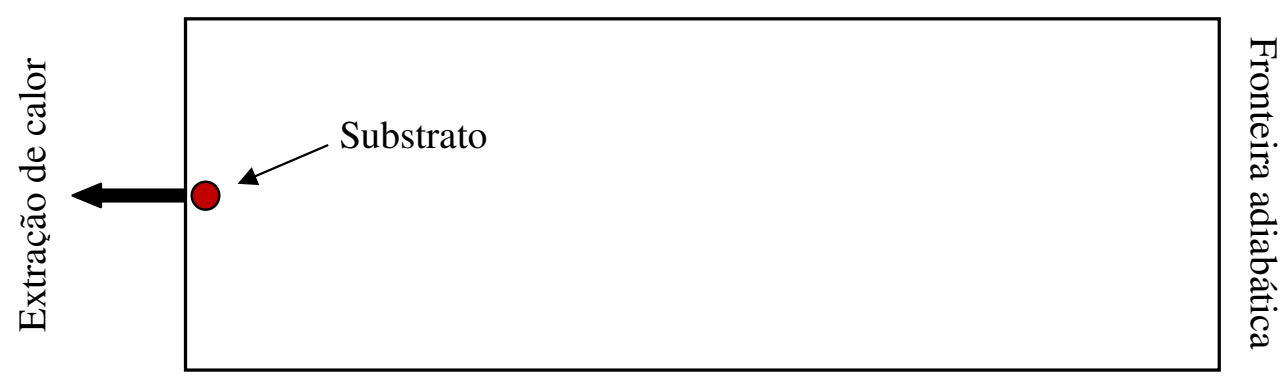

Figura 85- Ilustração do domínio unidimensional considerado.

O modelo estocástico implementado no presente trabalho foi ajustado nas mesmas condições do modelo de Guillemot et al. (2004) e utilizado para simular o caso estudado por estes autores. As curvas de resfriamento calculadas pelo presente modelo estão comparadas às de Guillemot et al. (2004) na Figura 86. A Figura 87 mostra uma comparação entre as frações de sólido obtidas pelo presente modelo e por Guillemot et al. (2004). A curva de fração de sólido calculada através da equação de Scheil, equação [38], utilizando a curva de resfriamento da posição $80 \mathrm{~mm}$ também esta mostrada na Figura 87.

Os resultados dos dois modelos apresentaram uma ótima aderência, afastando a possibilidade de erros de implementação. No entanto, ambos apresentam uma discrepância em relação à fração de sólido prevista pela equação de Scheil. Esta discrepância será examinada em detalhes no próximo item. 


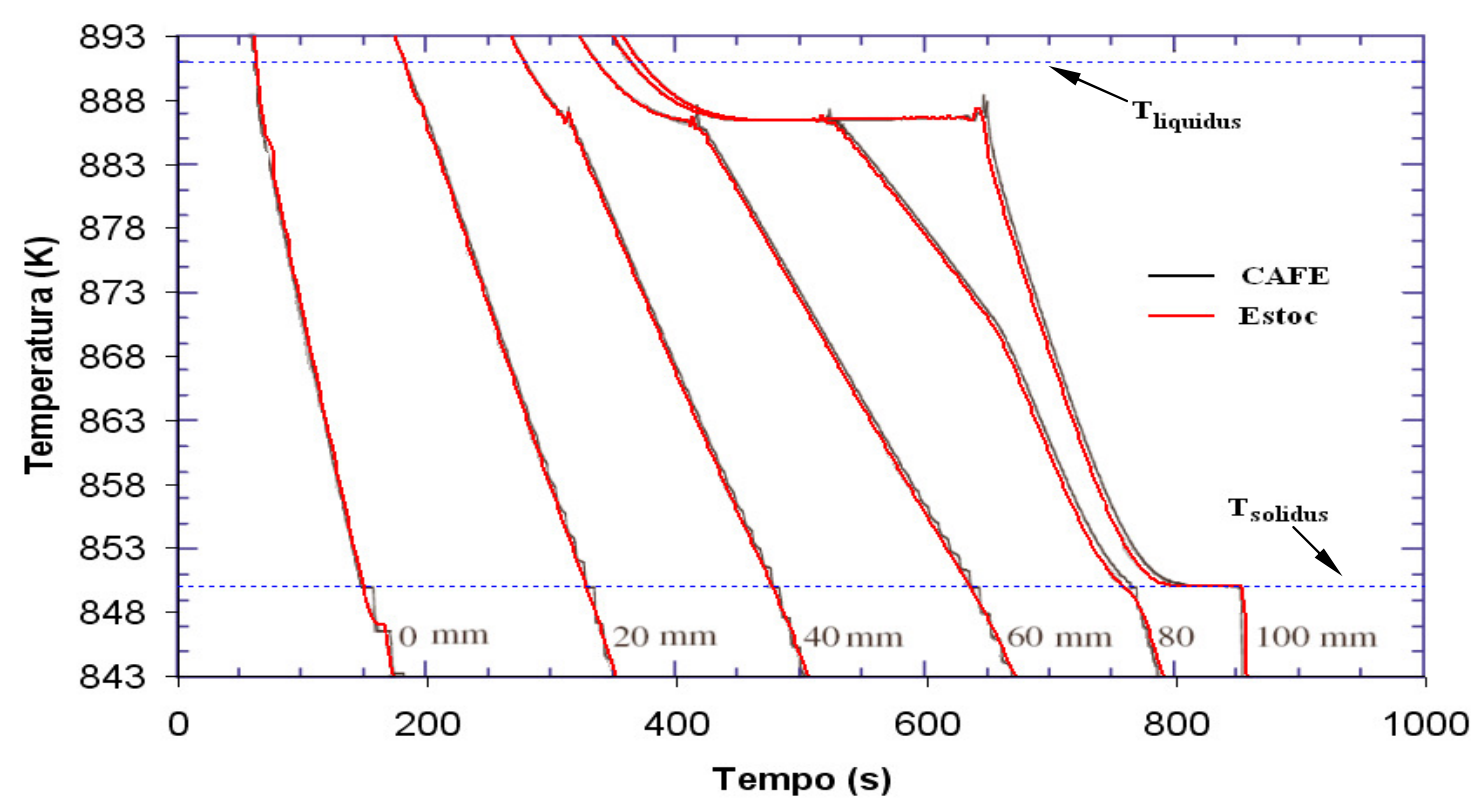

Figura 86- Comparação das curvas de resfriamento obtidas por Guillemot et al. (2004) (CAFE) e pelo modelo estocástico implementado no presente trabalho (Estoc) para as distâncias indicadas em relação à superfície de extração de calor.

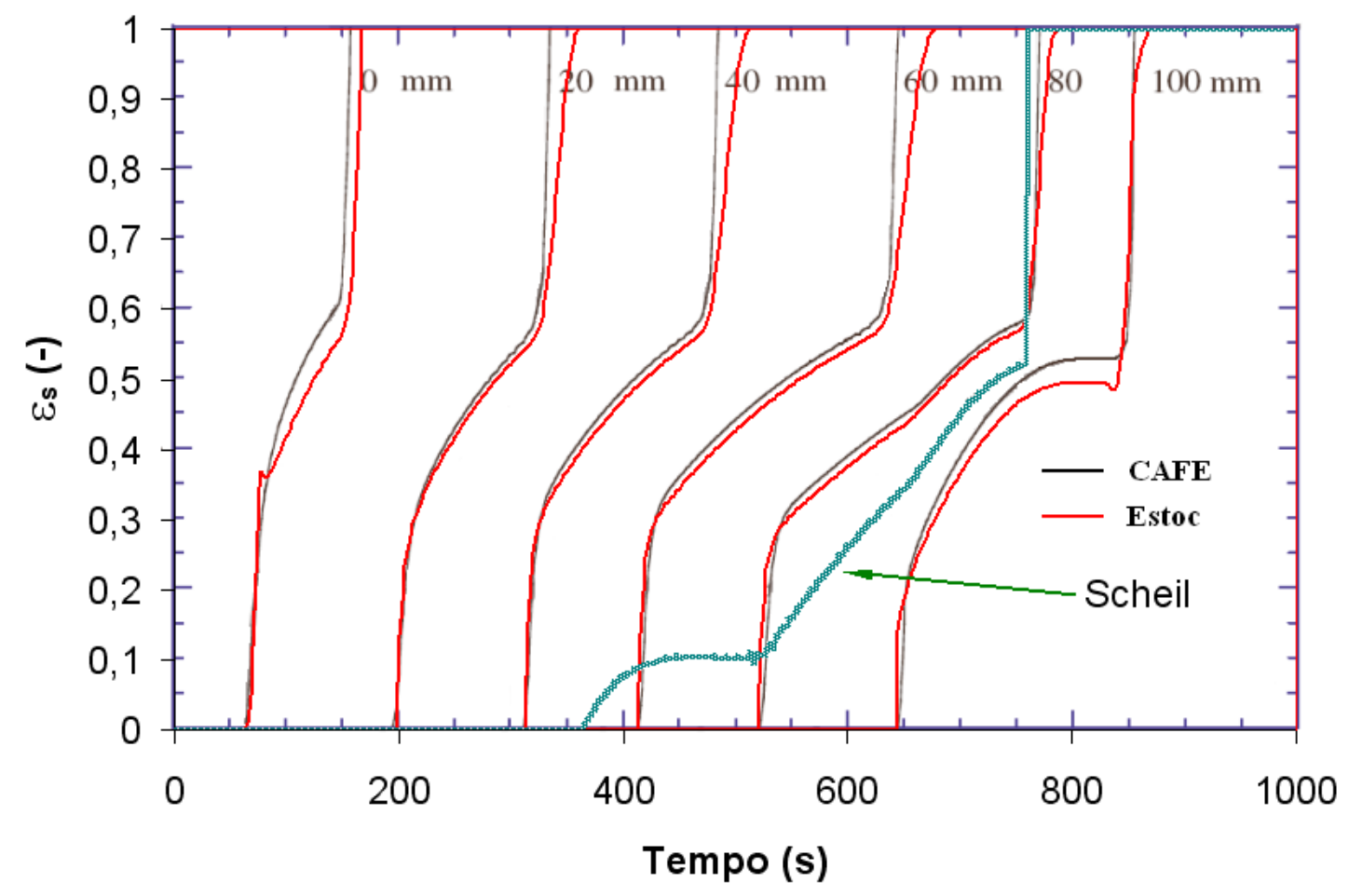

Figura 87- Comparação das curvas de fração de sólido ( $\mathcal{E}_{S}$ ) obtidas por Guillemot et al. (2004) (CAFE) pelo modelo estocástico implementado (Estoc) e pela equação de Scheil (aplicada à curva de temperatura da posição $80 \mathrm{~mm}$ ) para as distâncias indicadas em relação à superfície de extração de calor. 
5.4.2 Análise do acoplamento meso-macroscópico do modelo estocástico

A Figura 88 apresenta a macroestrutura de grãos, o perfil de temperatura e o perfil de fração de sólido resultantes da simulação realizada nas condições de referência (Figura 67). O perfil de temperatura fornecido pelo modelo foi utilizado para calcular a fração de sólido através da equação de Scheil, equação [38] (Garcia, 2001). Na Figura 88, esta fração está sobreposta à fração de sólido calculada pelo modelo implementado.

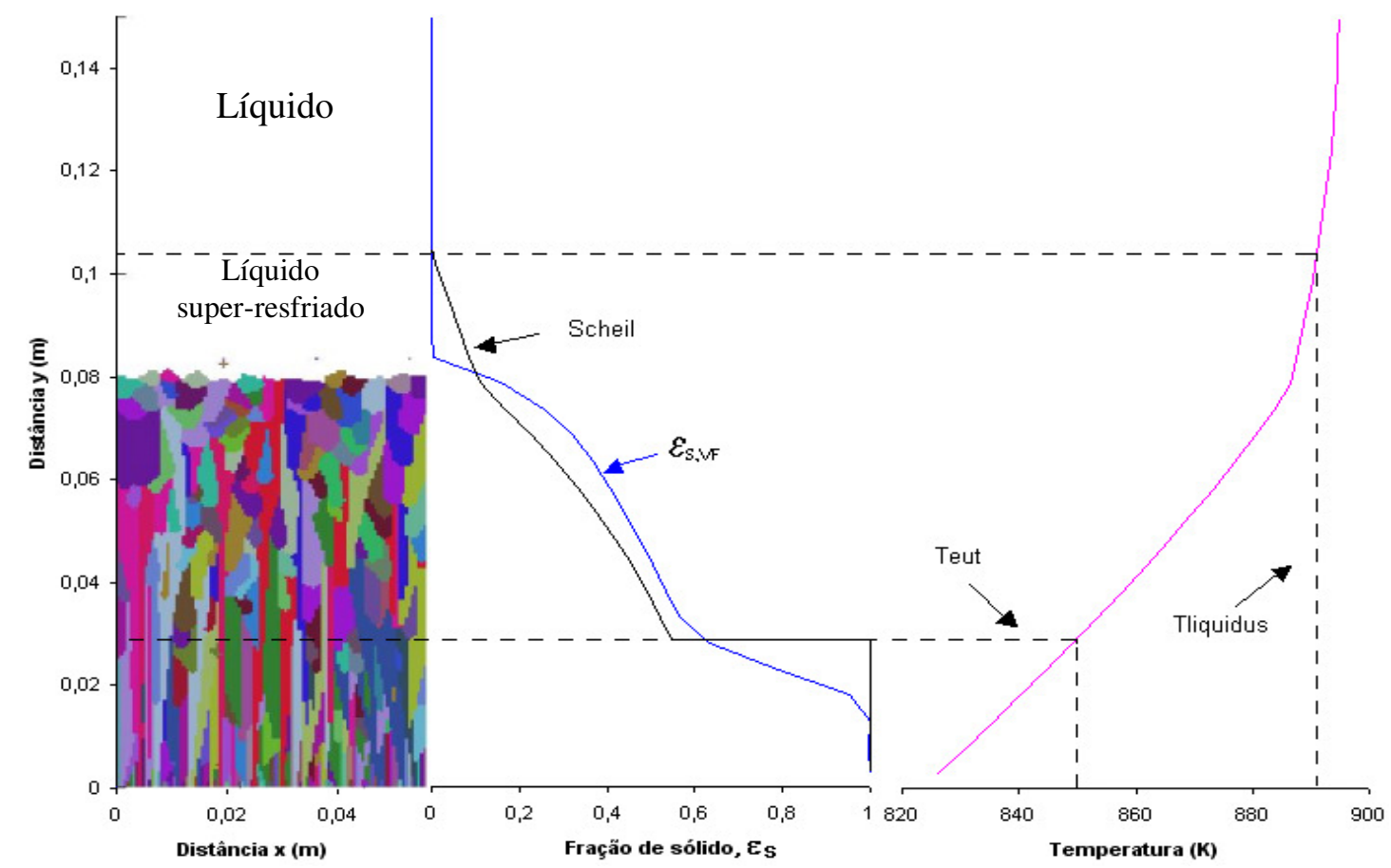

Figura 88- Macroestrutura de grãos, perfil de temperatura e perfil de fração de sólido ( $\left.\mathcal{E}_{S, V F}\right)$ previstos pelo modelo estocástico. O perfil de fração de sólido previsto pelo modelo de Scheil também está mostrado $(\mathrm{t}=670 \mathrm{~s})$.

A macroestrutura apresentada na Figura 88 consiste de grãos colunares que cresceram na direção do fluxo de calor, porém em sentido oposto, e alguns grãos equiaxiais. Nota-se que a frente de crescimento colunar está super-resfriada em relação à temperatura liquidus, resultando em uma região de aproximadamente 0,025m contendo líquido super-resfriado constitucionalmente, onde existem pequenos grãos equiaxiais em crescimento. Este super-resfriamento também foi 
observado nos resultados de modelos determinísticos (Martorano; Beckermann; Gandin, 2003).

A Figura 88 apresenta dois aspectos que não retratam o comportamento físico esperado. O primeiro aspecto é a presença de líquido em regiões da estrutura com temperaturas abaixo da temperatura da reação eutética $\left(\mathrm{T}_{\text {eut }}\right)$, ou seja, $\varepsilon_{S, V F}<1$ nestes locais. Esta situação não poderia existir, pois não se considerou o superresfriamento para o crescimento eutético. Os resultados da simulação mostram que a fração de sólido atinge a unidade, indicando o final da solidificação, apenas cerca de $15 \mathrm{~K}$ abaixo de $\mathrm{T}_{\text {eut }}$. Este aspecto representa uma inconsistência em relação ao comportamento esperado para o modelo.

O segundo aspecto que não retrata o comportamento físico esperado é notado ao se comparar a fração de sólido fornecida pelo modelo com aquela calculada pelo modelo de Scheil. Logo abaixo da temperatura liquidus, a fração de sólido dada pelo modelo estocástico é nula; entretanto, a fração fornecida pelo modelo de Scheil é diferente de zero. Como será discutido posteriormente, este comportamento pode ser explicado, pois no modelo de autômato celular consideramse envelopes dendríticos e o super-resfriamento para nucleação e crescimento dos mesmos. No modelo de Scheil, por outro lado, assume-se que todos os superresfriamentos são nulos. No entanto, a principal inconsistência aparece na região contendo envelopes dendríticos em solidificação, onde a fração de sólido deveria ser exatamente igual àquela fornecida pela equação de Scheil, já que esta equação foi utilizada no desenvolvimento do modelo de autômato celular (equação [38]). O comportamento esperado, chamado de Scheil "truncado" (Flood; Hunt, 1987a), não foi reproduzido pelo modelo do autômato celular (Figura 88). Estas inconsistências entre os resultados do modelo autômato celular e o comportamento físico esperado serão discutidas a seguir.

Após exame do modelo de autômato celular, concluiu-se que as inconsistências apresentadas anteriormente resultaram basicamente da metodologia empregada no acoplamento entre os submodelos meso e macroscópicos relembrada a seguir. No acoplamento, a temperatura no centro da célula do submodelo microscópico foi obtida através da interpolação linear das temperaturas calculadas em cada nó dos volumes finitos do submodelo macroscópico, como mostrado na Figura 37. No momento em que a temperatura interpolada na posição 
central da célula atingiu $T_{\text {eut }}$, assumiu-se que a reação eutética iniciaria no interior da célula. A partir deste instante, a equação [40] substituiu a equação [39] no cálculo da variação da fração de sólido da célula.

A equação [40] foi obtida assumindo-se que nenhum calor sensível era extraído, ou seja, todo calor era extraído da célula na forma de calor latente, representando uma transformação de fase isotérmica. Devido ao processo de interpolação no interior de um dado volume finito, existiam células que apresentavam temperaturas acima, igual ou abaixo de $\mathrm{T}_{\text {eut }}$, mesmo quando a temperatura do nó do volume era menor do que $\mathrm{T}_{\text {eut }}$. Portanto, a variação de fração de sólido nestas células foi calculada pela equação [39] ou [40], dependendo das condições. Após o cálculo das variações das frações de todas as células presentes em um volume finito, obteve-se a variação da fração total para este volume através da equação [41]. Desta forma, uma parte da variação da fração total foi calculada através de uma equação que considerou $T=T_{\text {eut }}$ e uma outra parte foi calculada através de uma

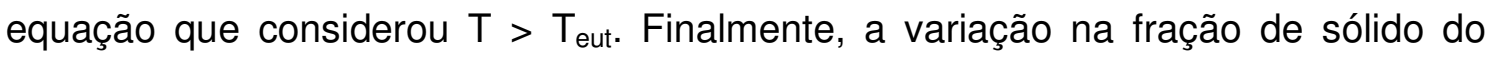
volume, $\varepsilon_{S, V F}$, foi utilizada na equação [42] para o cálculo da temperatura do volume finito. Em diversos casos, esta equação forneceu valores inferiores a $T_{\text {eut }}$, mesmo quando $\varepsilon_{S, V F}<1$, pois as temperaturas de algumas de suas células ainda eram maiores do que $T_{\text {eut }}$, explicando a primeira inconsistência observada.

A segunda inconsistência do modelo de autômato celular discutida anteriormente estava associada à diferença entre a fração de sólido fornecida pelo modelo e aquela calculada através da equação de Scheil na região com temperatura

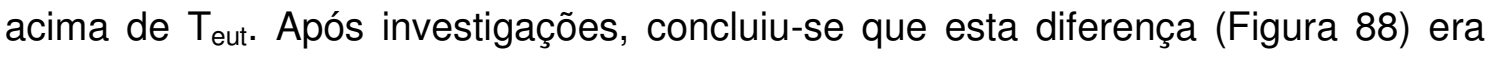
causada por dois efeitos: (1) o super-resfriamento necessário para a nucleação e crescimento dos envelopes dendríticos e (2) a interpolação dos valores de variação de entalpia dos volumes finitos (submodelo macroscópico).

Em relação ao primeiro efeito, deve-se entender que o modelo de autômato celular implementado considera os super-resfriamentos para a nucleação e crescimento dos grãos, enquanto que a equação de Scheil, não. Segundo o modelo de Scheil, a fração de sólido será maior do que zero em temperaturas imediatamente abaixo da temperatura liquidus da liga. Por outro lado, o modelo de autômato celular considera que a fase sólida se formará no interior da célula apenas quando esta já 
tiver sido ativada. Esta ativação pode ocorrer através da nucleação ou do crescimento de envelopes dendríticos vizinhos. Logo, quando o super-resfriamento para a nucleação for maior do que zero e quando os envelopes necessitarem de algum super-resfriamento para crescerem, esta célula poderá não estar ativa em regiões com temperaturas logo abaixo da temperatura liquidus. Portanto, o modelo de autômato celular indicará $\varepsilon_{S, V F}=0$ nesta região, enquanto a equação de Scheil indicará $\varepsilon_{S, V F}>0$. Estes dois comportamentos são observados na região entre a frente de crescimento colunar e a temperatura liquidus apresentada na Figura 88.

Uma simulação especial foi conduzida com o objetivo de analisar o efeito dos super-resfriamentos para a nucleação. Nesta simulação, um substrato para nucleação heterogênea com super-resfriamento crítico nulo foi posicionado em cada célula (malha do submodelo microscópico). Desta forma, eliminaram-se os superresfriamentos para nucleação e crescimento, pois no instante em que a temperatura da célula decrescia abaixo da temperatura liquidus, a célula era ativada imediatamente e já poderia conter sólido em seu interior. O resultado desta simulação está apresentado na Figura 89.

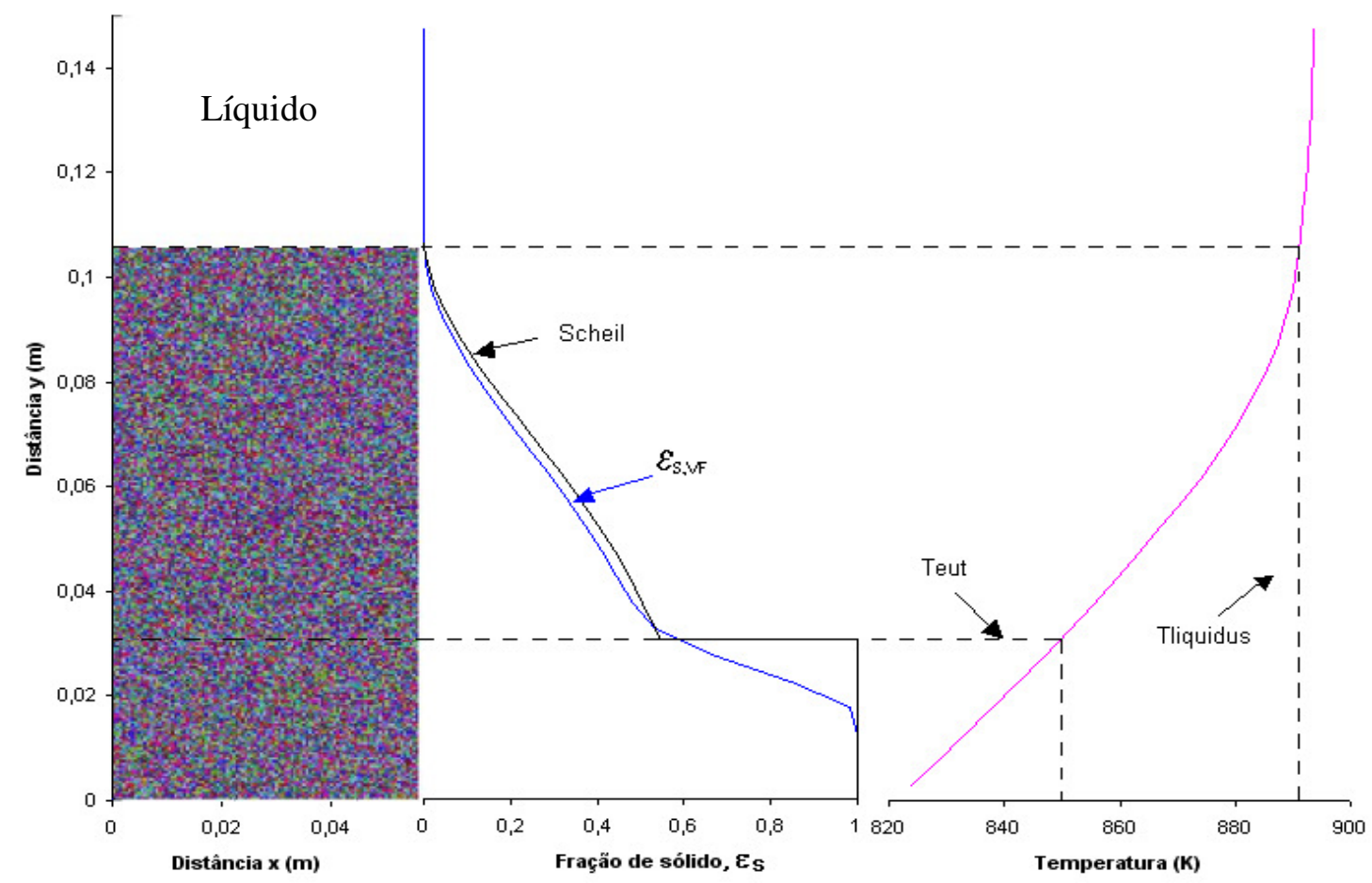

Figura 89- Macroestrutura de grãos, perfil de temperatura e perfil de fração de sólido previstos pelo modelo estocástico ( $\varepsilon_{S, V F}$ ). O perfil de fração de sólido previsto pelo modelo de Scheil também está mostrado ( $\mathrm{t}=670 \mathrm{~s})$. 
Apesar da eliminação dos super-resfriamentos para nucleação e crescimento, as frações de sólido da Figura 89 ainda apresentam uma diferença que não deveria estar presente, já que o modelo de Scheil foi utilizado na obtenção das equações de acoplamento do modelo do autômato celular. Acredita-se que esta diferença esteja associada à interpolação linear da variação de entalpia $\left(\delta H_{C A}\right)$, como explicado a seguir. Como descrito na metodologia, a equação [24] é utilizada para o cálculo da variação de entalpia do volume finito $\left(\delta H_{V F}^{t+\delta t}\right)$, que faz parte da malha do submodelo macroscópico. Segundo o método de discretização dos volumes finitos, este valor para o volume é assumido estar concentrado na posição do seu nó. A variação de entalpia da célula, por outro lado, é obtida através da interpolação dos valores calculados para os volumes finitos mais próximos. Posteriormente, o valor interpolado é introduzido na equação [39], que fornece a variação de fração de sólido na célula do submodelo microscópico.

Apesar da equação [39] representar uma relação entre $\delta H$ e $\delta \varepsilon_{S}$ que reflete exatamente o modelo de Scheil, o valor de $\delta H_{C A}$ utilizado foi interpolado a partir dos nós dos volumes finitos. Este valor não satisfaz exatamente o balanço de calor no volume finito. Desta forma, o valor de $\delta \varepsilon_{S, V F}$, calculado a partir de $\delta \varepsilon_{S, C A}$ (equação [41]), e a variação de entalpia do volume finito $\delta H_{V F}^{t+\delta t}$ não refletem o modelo de Scheil. Em uma tentativa de confirmar esta hipótese, o número de volumes finitos (malha do submodelo macroscópico) foi aumentado até igualar-se ao número de células (submodelo mesoscópico), ou seja, existe um volume finito para cada célula. Esta modificação não é vantajosa do ponto de vista computacional, pois o número de volumes finitos é desnecessariamente elevado, aumentando o tempo de processamento. Entretanto, ela será utilizada para testar a hipótese formulada.

O resultado desta malha de VF refinada está apresentado na Figura 90. Nesta figura, nota-se que o perfil de fração de sólido fornecido pelo modelo autômato celular é exatamente igual àquele fornecido pela equação de Scheil, confirmando a hipótese apresentada. 


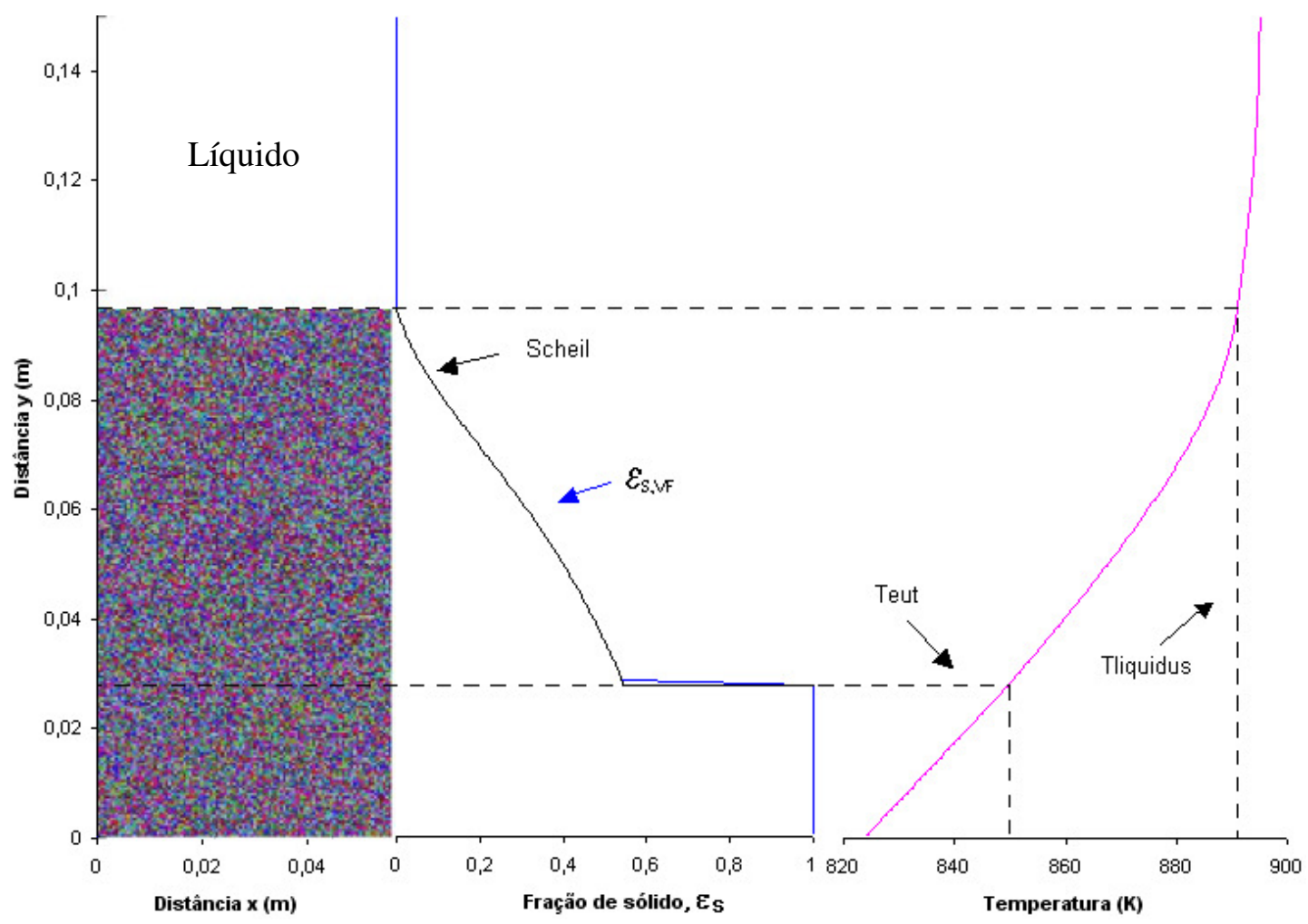

Figura 90- Macroestrutura de grãos, perfil de temperatura e perfil de fração de sólido previstos pelo modelo estocástico ( $\left.\mathcal{E}_{S, V F}\right)$. O perfil de fração de sólido previsto pelo modelo de Scheil também está mostrado $(\mathrm{t}=670 \mathrm{~s})$.

\subsection{Comportamento do Modelo Determinístico e Hipóteses de Scheil}

A razão da não adequação do modelo determinístico ao modelo de Scheil (Garcia, 2001) para posições além de 0,08m (Figura 68) e a adequação para posições inferiores devem ser analisadas através da comparação entre as hipóteses utilizadas na elaboração do modelo de Scheil com as hipóteses e o comportamento do modelo determinístico.

O equacionamento do modelo de Scheil é feito adotando-se primeiramente um volume de controle que possui um tamanho invariável e paredes impermeáveis, ou seja, não há troca de massa com o meio externo. Dentro deste volume de controle assume-se a existência de um líquido com concentração uniforme de soluto e completa ausência de difusão no sólido. 
Ao se comparar tais hipóteses com as utilizadas na elaboração do modelo determinístico (Martorano; Beckermann; Gandin, 2003), verifica-se que uma destas hipóteses não é compatível. O volume de controle utilizado no desenvolvimento das equações do modelo determinístico é chamado de volume elementar representativo (REV) e possui no seu interior uma certa quantidade de envelopes dendríticos. Este volume possui um tamanho invariável e paredes impermeáveis ao exterior. Dentro deste volume de controle assume-se uma concentração uniforme de soluto no líquido interdendrítico e no líquido extradendrítico, porém estas concentrações podem ser diferentes. Além disso, considerou-se completa ausência de difusão no sólido, como assumido no modelo de Scheil.

Diante do exposto, nota-se que, apesar das concentrações de soluto serem uniformes no líquido interdendrítico e no líquido extradendrítico, estas não são iguais $\left(C_{l} \neq C_{l}^{*}\right)$. Desta forma, a hipótese de concentração uniforme de soluto dentro do volume de controle, utilizada na elaboração do modelo de Scheil, não é verificada, explicando a discrepância entre os perfis de fração de sólido nas regiões próximas ao início de solidificação.

No entanto, a adequação ao modelo de Scheil observada em outras regiões pode ser explicada por uma análise mais aprofundada do comportamento do modelo determinístico. Na Figura 91 estão apresentadas as curvas de concentração do líquido interdendrítico $\left(C_{l}^{*}\right)$ e do extradendrítico $\left(C_{l}\right)$ em função da distância para um tempo de 670s.

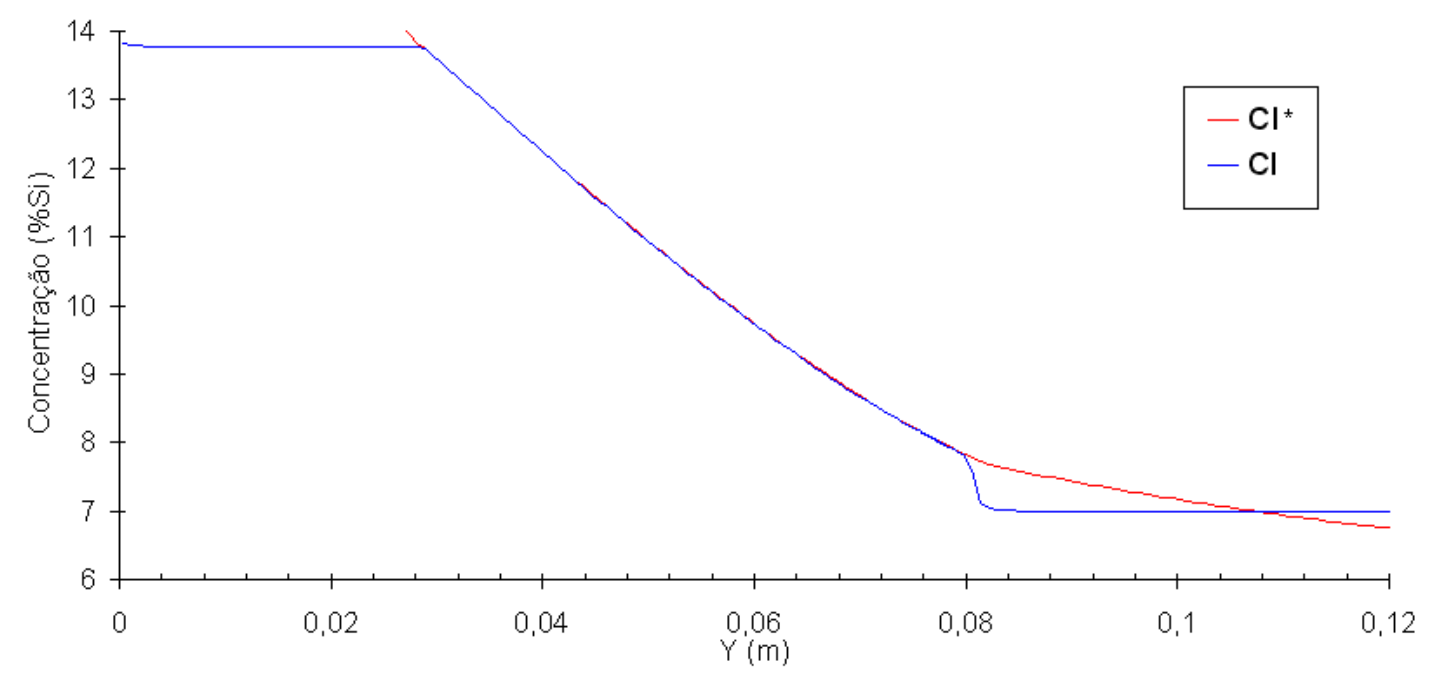

Figura 91- Curvas de concentração em função da distância para o modelo determinístico em um tempo de 670s (líquido interdendrítico $C_{\mid}^{*}$ e líquido extradendrítico $C_{\mid}$). 
As curvas de concentração mostram que, devido aos parâmetros utilizados na simulação, as hipóteses do modelo de Scheil se tornam válidas para regiões inferiores a $0,08 \mathrm{~m}$ e maiores que $0,28 \mathrm{~m}$. Nestas regiões as concentrações de soluto no líquido interdendrítico e no extradendrítico tornam-se iguais $\left(C_{l}=C_{l}^{*}\right) \mathrm{e}$, com isso, toda a fase líquida no REV possui a mesma concentração.

Estas observações podem ser verificadas nas equações do modelo determinístico. Substituindo a equação [45] na equação [46], obtem-se:

$$
(1-k) C_{l}^{*} \frac{\partial \varepsilon_{S}}{\partial t}=\varepsilon_{d} \frac{\partial C_{l}^{*}}{\partial t}+\frac{\partial\left(\varepsilon_{l} C_{l}\right)}{\partial t}-C_{l}^{*} \frac{\partial \varepsilon_{l}}{\partial t}
$$

Nas condições da Figura 91, em regiões entre 0,08m e 0,28m, tem-se que $C_{l}=C_{l}^{*}$. Substituindo esta igualdade na equação [110]:

$$
(1-k) C_{l}^{*} \frac{\partial \varepsilon_{S}}{\partial t}=\varepsilon_{d} \frac{\partial C_{l}^{*}}{\partial t}+C_{l}^{*} \frac{\partial \varepsilon_{l}}{\partial t}+\varepsilon_{l} \frac{\partial C_{l}^{*}}{\partial t}-C_{l}^{*} \frac{\partial \varepsilon_{l}}{\partial t}
$$

Porém $\varepsilon_{d}+\varepsilon_{l}=\left(1-\varepsilon_{S}\right)$, logo:

$$
(1-k) C_{l}^{*} \partial \varepsilon_{S}=\left(1-\varepsilon_{S}\right) \partial C_{l}^{*}
$$

A equação [112] é exatamente a equação diferencial do modelo de Scheil, explicando a adequação do modelo determinístico aos resultados de Scheil.

Para regiões inferiores a 0,28 a mesma equação pode ser obtida, pois nesta região o envelope dendrítico ocupa todo o volume e só existe líquido interdendrítico, resultando em:

$$
\begin{gathered}
\varepsilon_{l}=0 \\
\varepsilon_{d}=\left(1-\varepsilon_{S}\right)
\end{gathered}
$$

substituindo-se estas relações na equação [111], obtem-se novamente a equação [112].

Esta mesma adequação da fração de sólido calculada pelo modelo determinístico àquela calculada pelo modelo de Scheil já havia sido observada por 
Rappaz e Thévoz (1987) em uma dada condição de simulação. Mas os autores não explicaram a razão desta adequação.

Pode-se observar as diferenças entre o modelo proposto por Scheil e o modelo determinístico estudado para a previsão da fração de sólido, evidenciando ainda em quais situações os modelos apresentam os mesmos resultados.

\subsection{Modelo CADE}

Neste item o novo modelo proposto (equacionamento apresentado no item 4.4), denominado híbrido estocástico-determinístico (CADE), será primeiramente testado quanto à implementação do seu código computacional. Posteriormente, seus resultados serão comparados com os de um modelo determinístico proposto por Martorano, Beckermann e Gandin (2003) em uma situação de solidificação sem gradientes de temperatura (solidificação isotérmica ou "0D"). Em seguida, o modelo será utilizado para simular as condições de referência definidas no item 5.2.2, onde se tem transferência de calor unidirecional para analisar sua capacidade de prever a CET. Finalmente, o modelo será utilizado em uma situação de transferência de calor bidimensional (2D) e seus resultados comparados com os resultados de modelos determinísticos e estocástico para também avaliar sua capacidade de previsão da CET.

5.6.1 Verificação do crescimento de grão no modelo mesoscópico

O primeiro teste para verificação da implementação do código computacional consistiu na validação do crescimento do algoritmo do autômato celular e dos cálculos de $S_{e}$ e $\varepsilon_{g}$. O teste foi executado mediante a definição de um único grão no centro do domínio bidimensional e posterior comparação dos resultados obtidos pelo modelo com os resultados de uma solução analítica do mesmo problema. O domínio foi mantido a uma temperatura constante que resulta em uma velocidade de crescimento dendrítico constante de $10^{-4} \mathrm{~m} / \mathrm{s}$. O domínio bidimensional escolhido foi um retângulo com dimensões de 0,0015x0,0015m. 
Verificou-se a influência do tamanho da malha de células e da orientação do envelope de grão relativo à malha na previsão dos resultados. Nestas simulações utilizaram-se dois tamanhos de malha de células no modelo mesoscópico, a saber, uma com 201×201 e outra com 401×401 células. A influência da orientação do envelope de grão em relação à malha foi analisada simulando-se o crescimento com três diferentes orientações iniciais em relação ao eixo horizontal, a saber, $0^{\circ}, 1^{\circ}$ e $45^{\circ}$.

$\mathrm{Na}$ Figura 92 estão representados os resultados das simulações para 0 instante de tempo de 7,4s, utilizando-se um passo de tempo de $10^{-4} \mathrm{~s}$. A linha vermelha representa o resultado previsto pela solução analítica e a parte em verde representa o grão em crescimento calculado pelo modelo. Percebe-se que os contornos dos grãos calculados pelo modelo concordam muito bem com o contorno obtido pela solução analítica mesmo para a malha menos refinada (201x201 células), apesar desta malha produzir um contorno com menor resolução (aspecto serrilhado).

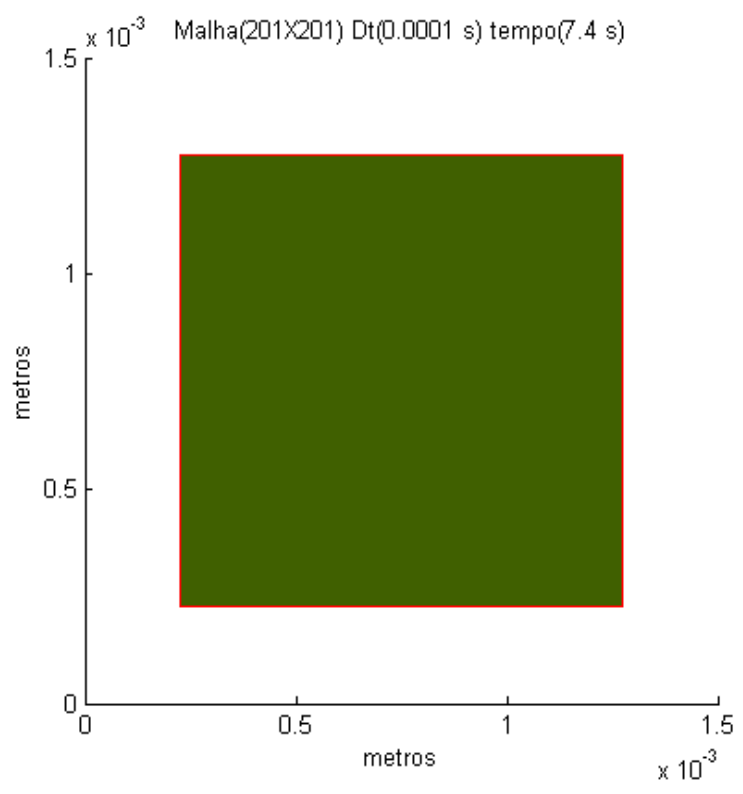

(a)

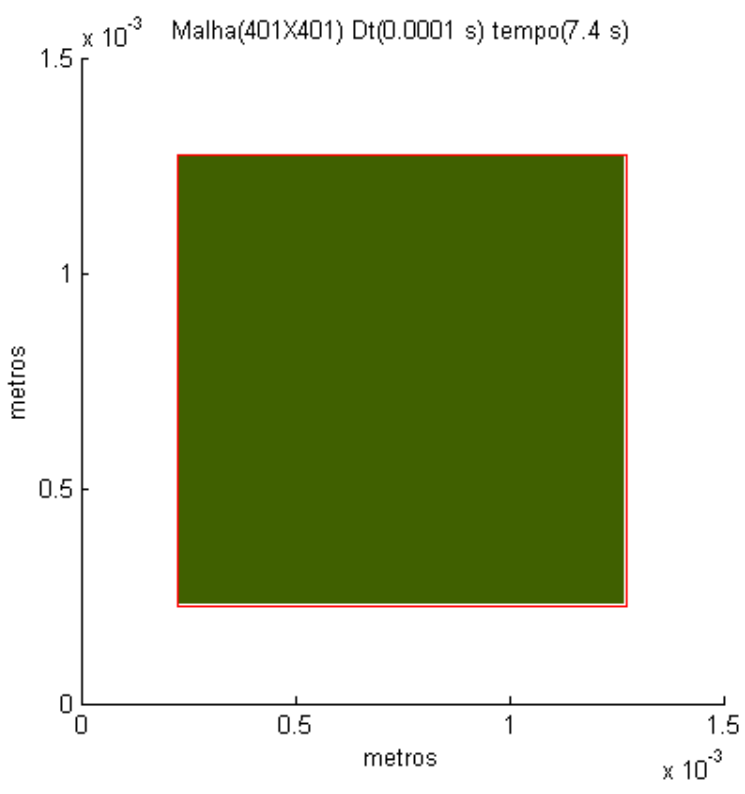

(b) 


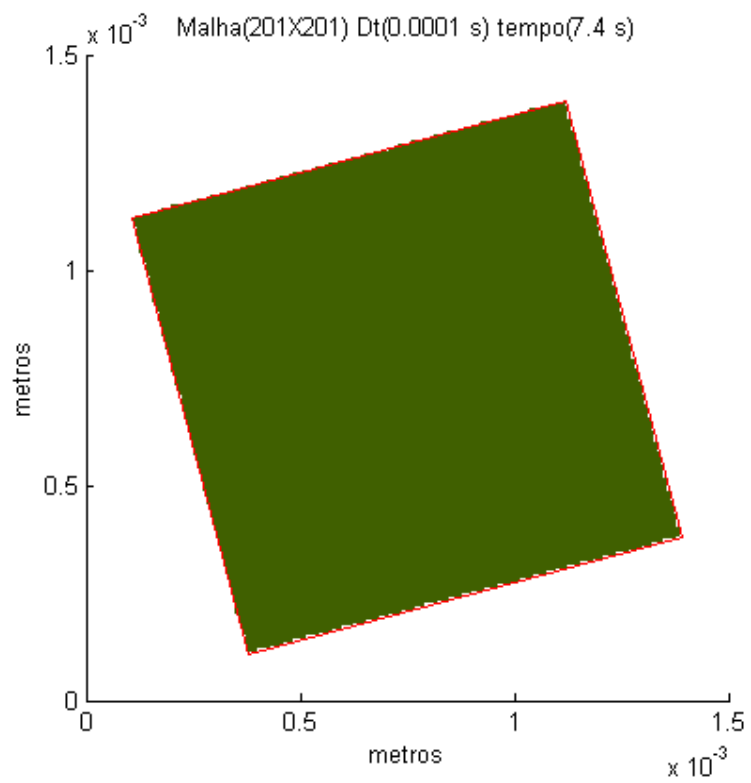

(c)

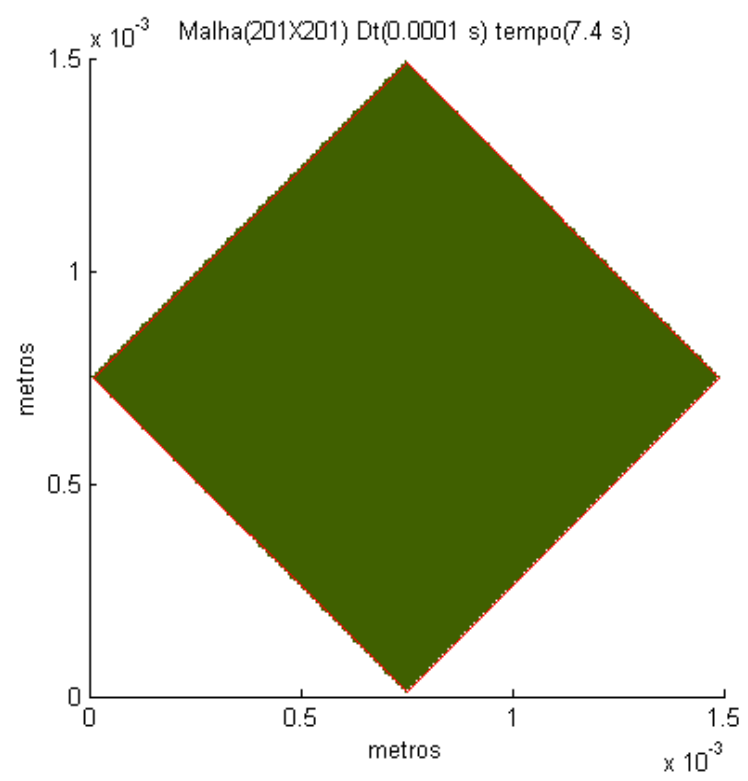

(e)

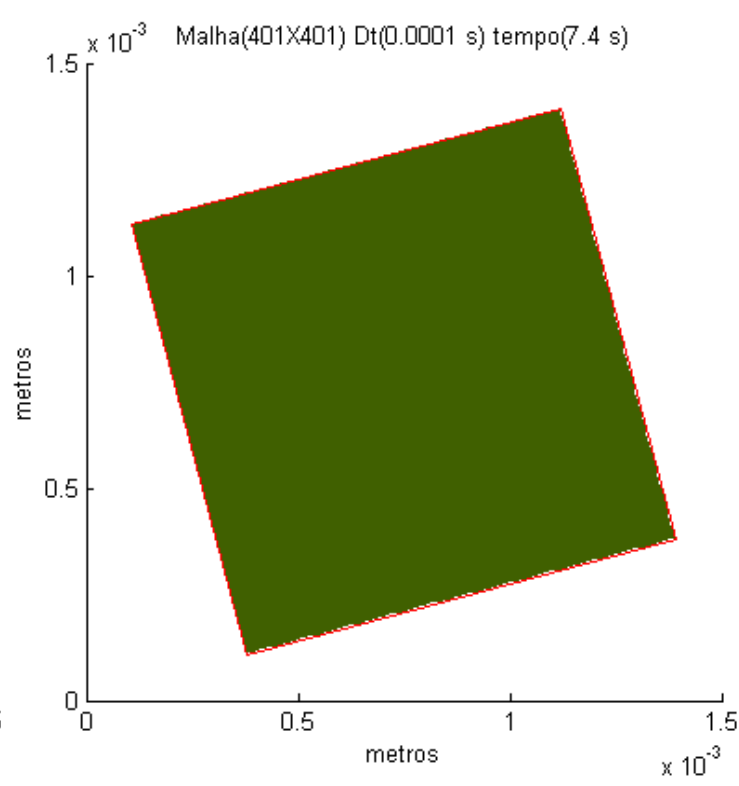

(d)

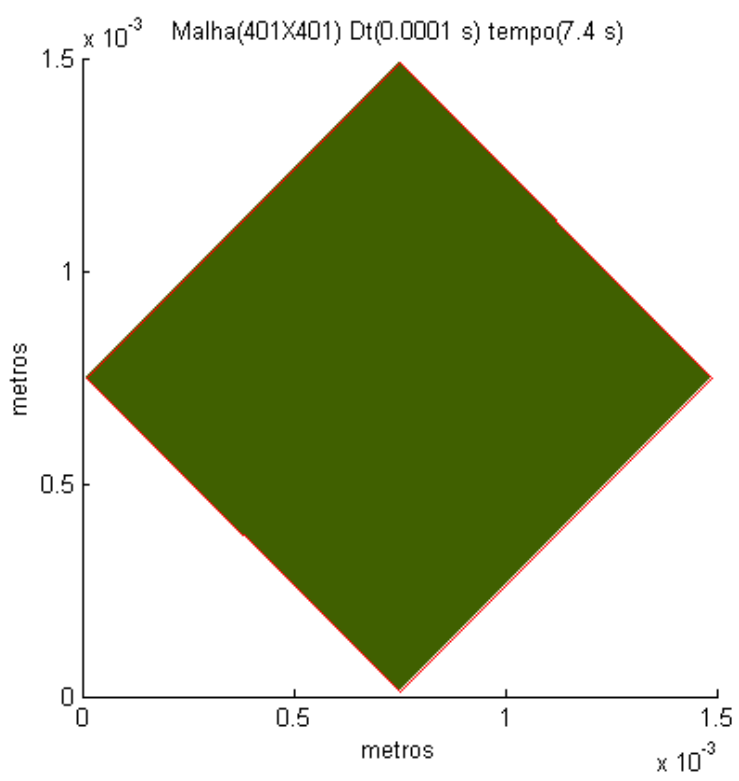

(f)

Figura 92 - Comparação da imagem do envelope de grão após crescimento calculado pelo modelo mesoscópico (verde) com a solução analítica (fronteira vermelha). As figuras a, c e d foram obtidas para uma malha de $201 \times 201$ células, enquanto nas outras utilizaram-se $401 \times 401$ células. As orientações do grão inicial nestas simulações foram: $0^{\circ}$ (a e b), 15(c e d) e 45 (e e f).

Para a verificação do cálculo da evolução da concentração de área interfacial entre o envelope e o líquido extradendrítico $\left(S_{e}\right)$, escolheram-se as simulações apresentadas na Figura 92 (e) e (f). Os resultados destas simulações 
foram comparados com a solução analítica. Desta forma a Figura 93 apresenta uma comparação entre os cálculos de $S_{e}$ para malhas de 201x201 células (denominado por Se CA200) e de 401x401 células (Se CA400) com a solução analítica (Se calculado). A inclinação do grão foi sempre de $45^{\circ}$ em relação ao eixo horizontal.

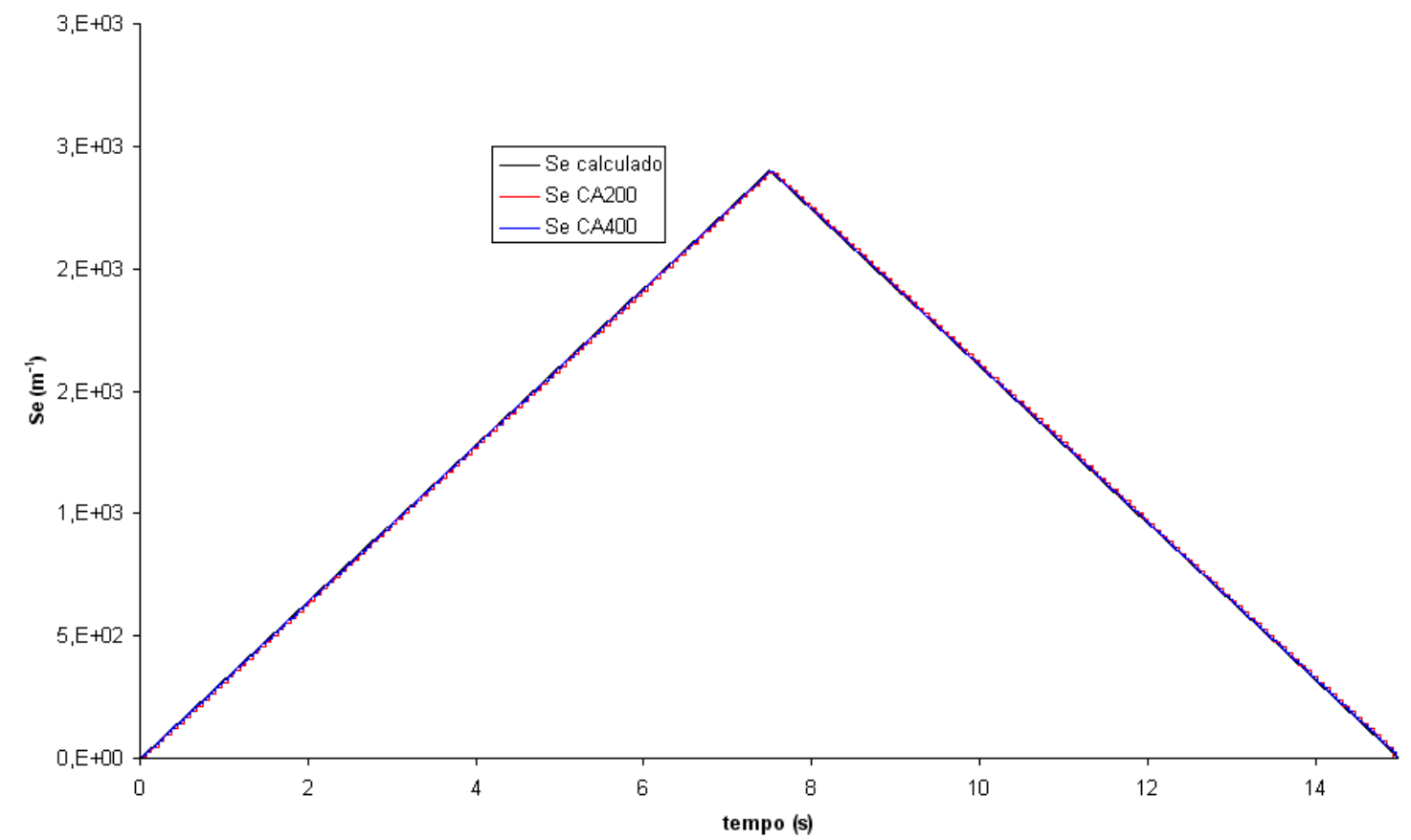

Figura 93 - Comparação entre os resultados de $S_{e}$ obtidos pelo CADE para malhas de 201x201 (Se CA200) e 401x401 células (Se CA400) com a solução analítica (Se calculado) para um grão com orientação de $45^{\circ}$.

Observa-se que todas as curvas apresentam a mesma tendência, ou seja, primeiramente os valores crescem até atingir o seu valor máximo, correspondente ao tempo imediatamente anterior ao momento em que o grão toca as margens do domínio considerado. A partir deste momento os valores começam a decair até que o grão preenche totalmente o domínio e não apresenta mais interfaces com o líquido fora do envelope (extradendrítico). Caso o grão possuísse uma orientação igual à do domínio ( $0^{\circ}$ no caso considerado), o valor de $S_{e}$ cresceria até o momento em que o contorno do grão coincidisse completamente com as bordas do domínio e depois decairia a 0 abruptamente.

Observa-se uma pequena oscilação na curva, principalmente para a malha menos refinada $(201 \times 201)$, mas os resultados apresentados se mostraram muito 
próximos da solução analítica, validando, assim, esta parte da implementação do modelo CADE.

As curvas de evolução da fração volumétrica de envelope $\varepsilon_{g}$ previstas pelo CADE com malhas de 201x201 células (denominado Eg CA200), 401x401 células (Eg CA400) e a solução analítica (Eg Calculado) também foram comparadas (Figura 94). Todas estas simulações apresentaram resultados muito próximos, comprovando o cálculo obtido com o modelo CADE. Diferentemente do cálculo de $S_{e}$, o cálculo de $\varepsilon_{g}$ não apresentou oscilações.

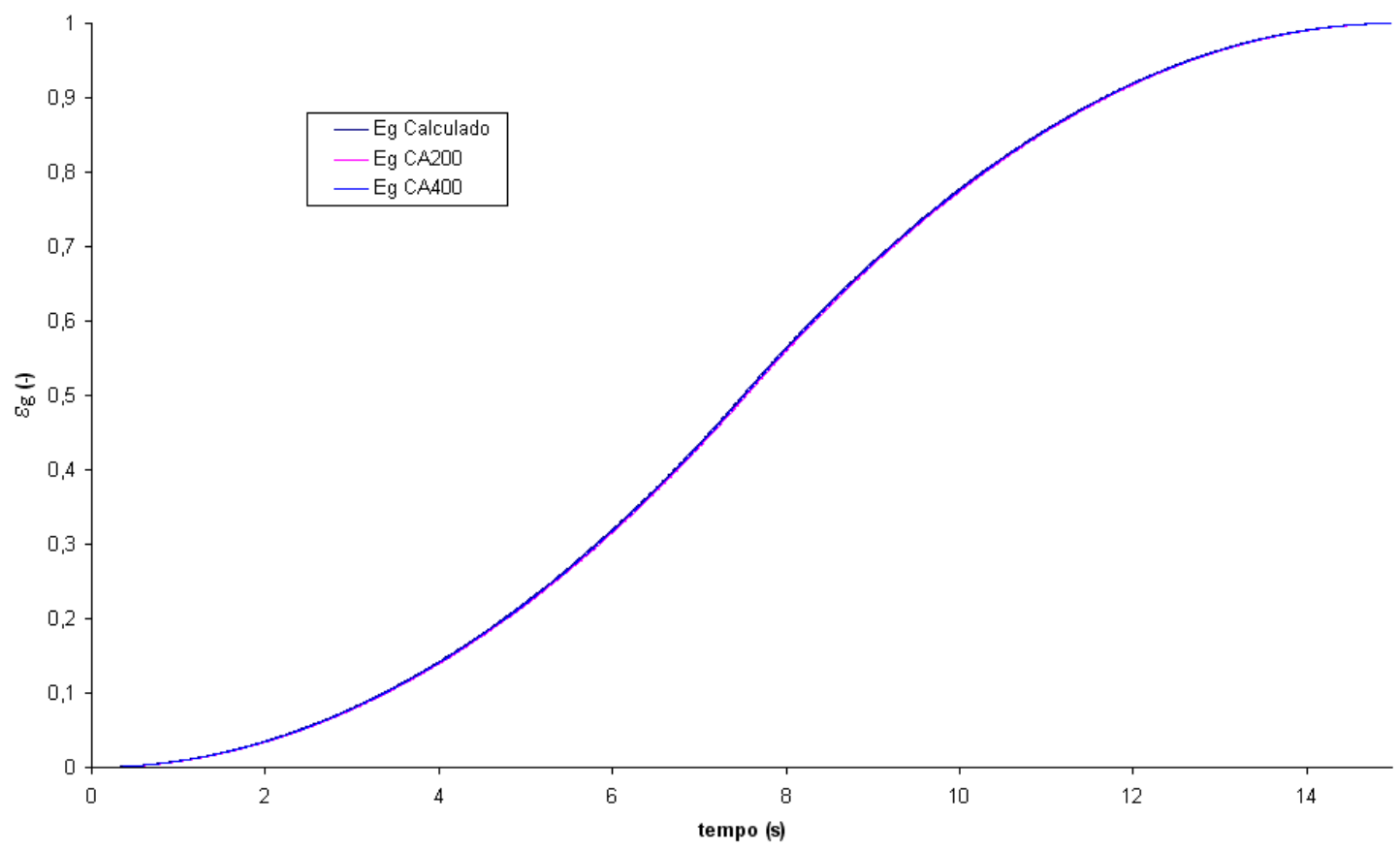

Figura 94 - Comparação entre os resultados de $\mathcal{E}_{g}$ obtidos pelo modelo CADE para malhas de $201 \times 201$ (Eg CA200) e de 401x401 células (Eg CA400) e a solução analítica (Eg Calculado) para o crescimento de um grão isolado com orientação de $45^{\circ}$.

\subsubsection{Modelo Determinístico e CADE com Envelope Cúbico}

Um outro teste para validação do código implementado foi feito mediante comparação de resultados do CADE com resultados obtidos através de uma modificação do modelo proposto por Martorano, Beckermann e Gandin (2003). Neste modelo considera-se que os envelopes de grão são esféricos, mas para 
permitir uma comparação, o modelo foi modificado para considerar envelopes cúbicos, mostrado esquematicamente em corte na Figura 95, como considerado no submodelo mesoscópico do CADE. No caso do envelope cúbico, onde $R_{e}$ seria o meio-lado instantâneo deste envelope, adotaram-se as seguintes relações no modelo determinístico de Martorano et al. (2003):

$$
\begin{gathered}
A_{e}=6\left(2 R_{e}\right)^{2} \\
V_{e}=\left(2 R_{e}\right)^{3}
\end{gathered}
$$

onde $A_{\mathrm{e}}$ é a área instantânea deste envelope e $V_{e}$ é o volume instantâneo. O volume máximo ou final $\left(V_{f}\right)$ deste envelope pode ser escrito em função do meio lado máximo ou final $\left(R_{f}\right)$ da seguinte forma:

$$
V_{f}=\left(2 R_{f}\right)^{3}
$$

A partir das equações [115], [116] e [117] pode-se estabelecer as seguintes relações:

$$
\begin{gathered}
\frac{V_{e}}{V_{f}}=\frac{\left(2 R_{e}\right)^{3}}{\left(2 R_{f}\right)^{3}}=\varepsilon_{g} \\
\frac{R_{e}}{R_{f}}=\varepsilon_{g}^{1 / 3} \\
n=\frac{1}{V_{f}}=\frac{1}{\left(2 R_{f}\right)^{3}} \rightarrow R_{f}=\left(\frac{1}{8 n}\right)^{1 / 3}
\end{gathered}
$$

Uma relação para $S_{e}$ também pode ser obtida:

$$
S_{e}=n A_{e}=\frac{3}{R_{f}}\left(\varepsilon_{g}\right)^{2 / 3}
$$




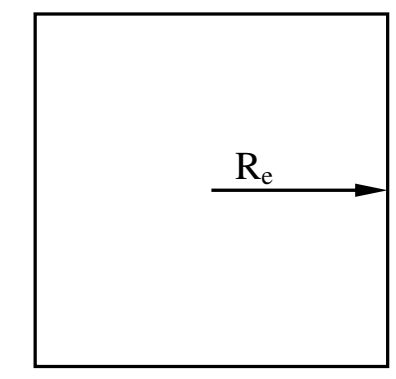

Figura 95 - Representação de uma seção do envelope cúbico considerado.

As mesmas transformações foram empregadas no modelo CADE. Ao se utilizar um envelope dendrítico cúbico (3D) em lugar de um envelope quadrado (2D), as relações estabelecidas nas equações [72], [67] e [64] tornam-se inválidas e, novas relações devem ser encontradas. Estas novas relações estão abaixo apresentadas para o mesmo envelope mostrado na Figura 95:

$$
\begin{gathered}
n=\frac{1}{\left(2 R_{f}\right)^{3}} \quad n_{2 D}=\frac{1}{\left(2 R_{f}\right)^{2}} \rightarrow n=\left[n_{2 D}\right]^{3 / 2} \\
S_{e}=n 6\left(2 R_{e}\right)^{2} \quad S_{e 2 D}=8 n_{2 D} R_{e} \rightarrow S_{e}=\frac{3}{8 \sqrt{n_{2 D}}}\left(\sum_{0}^{n_{C A}} \frac{S_{e C A}}{n_{C A}}\right)^{2} \\
\varepsilon_{g}=\frac{\left(2 R_{e}\right)^{3}}{\left(2 R_{f}\right)^{3}} \quad \varepsilon_{g 2 D}=\frac{\left(2 R_{e}\right)^{2}}{\left(2 R_{f}\right)^{2}} \rightarrow \varepsilon_{g}=\left(\sum_{0}^{n_{C A}} \frac{\varepsilon_{g C A}}{n_{C A}}\right)^{3 / 2}
\end{gathered}
$$

onde $S_{e 2 D}$ é a concentração de área interfacial entre envelopes e líquido extradendrítico calculada no modelo bidimensional, ou seja, é a razão entre o perímetro dos envelopes e a área do REV, que coincide com a área do volume finito (malha do submodelo macroscópico). O termo $\varepsilon_{g 2 D}$ é a fração de envelopes calculada também no modelo bidimensional, ou seja, é a área de envelopes dividida pela área do REV.

Após a implantação destas alterações nos dois modelos considerados, escolheu-se um caso de solidificação isotérmica (modelo "OD") de uma liga Al-5\%Si definido por Wang e Beckermann (1993b) para ser analisado. As propriedades utilizadas estão na Tabela 16. 
Tabela 16 - Propriedades da liga Al-5\%Si (Wang; Beckermann, 1993b).

\begin{tabular}{cc|cc}
\hline Propriedade & Valor & Propriedade & Valor \\
\hline$\rho\left(\mathrm{kg} \mathrm{m}^{-3}\right)$ & 2452,0 & $C_{0}(\% \mathrm{peso})$ & $\mathrm{Al}-5 \% \mathrm{Si}$ \\
\hline $\mathrm{k}(-)$ & 0,117 & $\mathrm{C}_{\mathrm{p}}\left(\mathrm{J} \mathrm{kg}^{-1} \mathrm{~K}^{-1}\right)$ & 958,4 \\
\hline$\Delta H_{f}\left(\mathrm{~J} \mathrm{~kg}^{-1}\right)$ & $3,874 \times 10^{5}$ & $m_{l}\left(\mathrm{~K} \mathrm{\% Si}^{-1}\right)$ & $-7,7$ \\
\hline$D_{l}\left(\mathrm{~m}^{2} \mathrm{~s}^{-1}\right)$ & $3,0 \times 10^{-9}$ & $T_{\text {eut }}(\mathrm{K})$ & 850,0 \\
\hline$\Gamma(\mathrm{m} \mathrm{K})$ & $9,0 \times 10^{-8}$ & $T_{f}(\mathrm{~K})$ & 933,0 \\
\hline
\end{tabular}

Para se realizar a simulação da solidificação isotérmica, o cálculo da variação da entalpia volumétrica apresentada para o modelo CADE deve ser alterado para considerar uma taxa de resfriamento $(\dot{T})$ definida para o domínio. Desta forma, a equação [73] é substituída por:

$$
\delta H_{V F}^{t+\delta t}=\dot{T} \cdot \delta t \cdot \rho \cdot C_{p}
$$

onde $\delta H_{V F}^{t+\delta t}$ é a variação de entalpia por unidade de volume de um volume finito entre os instantes $t$ e $t+\delta t ; \delta t$ é o passo de tempo; $\rho$ é a densidade da liga considerada; e $C_{p}$ é o calor específico.

O primeiro teste visa comparar os dois modelos quanto ao crescimento de um único grão com uma orientação de $30^{\circ} \mathrm{em}$ relação ao eixo horizontal em um domínio isotérmico. Nesta simulação utilizaram-se: uma taxa de resfriamento $\dot{T}=-45 \mathrm{~K} \mathrm{~s}^{-1}$; uma densidade de número de núcleos $(n)$ igual a $2,4 \times 10^{8} \mathrm{~m}^{-3}$; um domínio de 0,001609 × 0,001609 $\mathrm{m}$; um passo de tempo igual a $10^{-4} \mathrm{~s}$; um superaquecimento de $0 \mathrm{~K}$ em relação à temperatura liquidus; uma malha do modelo mesoscópico com 200×200 células e um modelo de nucleação instantânea na temperatura liquidus, ou seja, com um super-resfriamento para nucleação igual a 0 K. Primeiramente compararam-se os resultados da evolução da fração de envelopes de grão, como pode ser observado na Figura 96. 


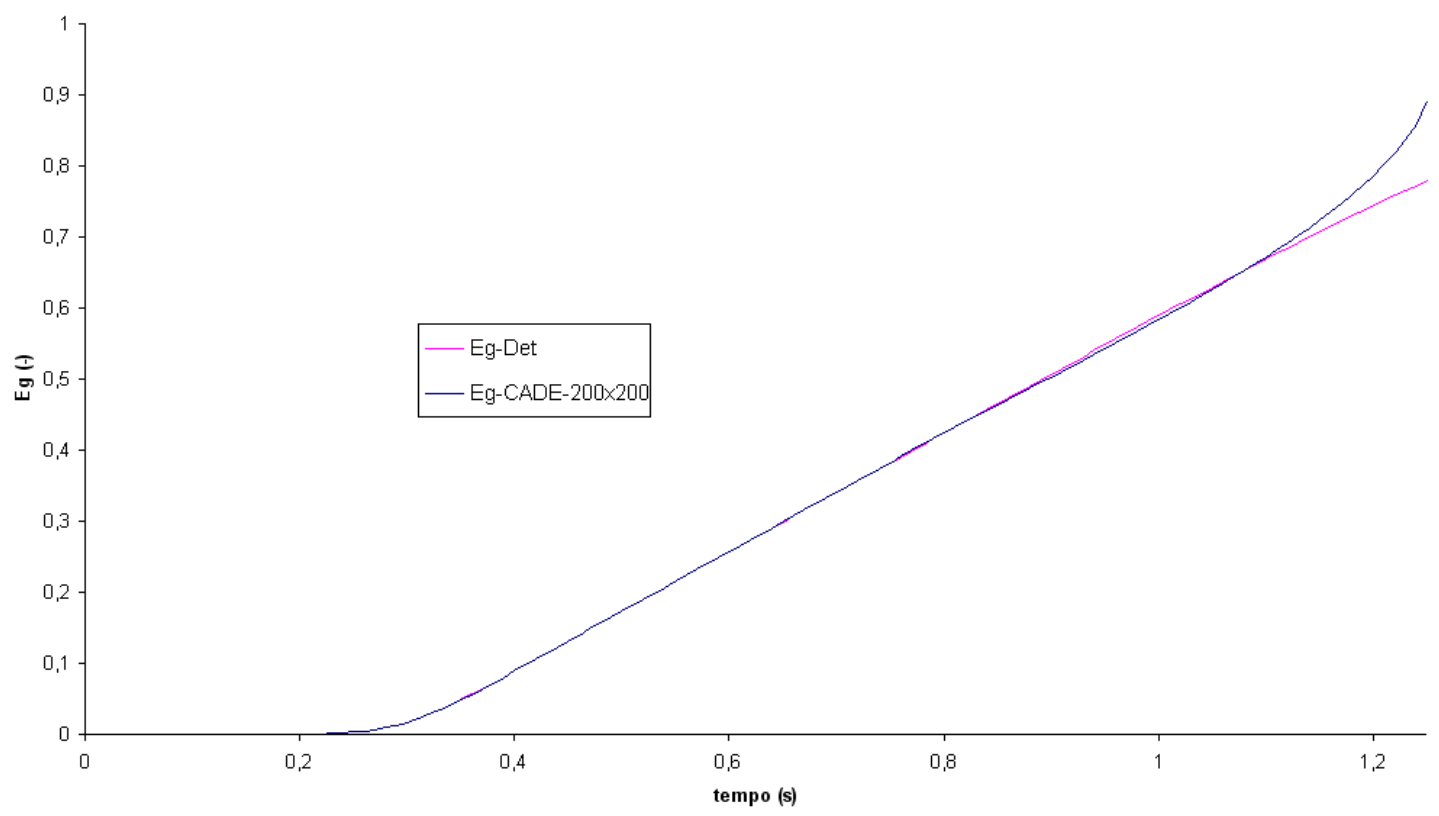

Figura 96 - Evolução da fração de envelope em função do tempo prevista pelo modelo CADE (Eg-

CADE-200x200) e pelo modelo determinístico (Eg-Det), assumindo um envelope cúbico com orientação de $30^{\circ}$.

Os modelos apresentaram frações de envelopes de grão muito próximas até aproximadamente $0,8 \mathrm{~s}$, que é o instante no qual o envelope do CADE encosta nas bordas do domínio considerado. A Figura 97 apresenta um grão em crescimento com uma inclinação de $30^{\circ} \mathrm{em}$ relação ao eixo horizontal nos instante de tempo anterior ao toque nas bordas do domínio $(0,6 \mathrm{~s})$, durante o toque $(0,8 \mathrm{~s})$ e após o toque $(1,0 \mathrm{~s})$ mostrando a diminuição da concentração de área interfacial com o líquido externo ao envelope.

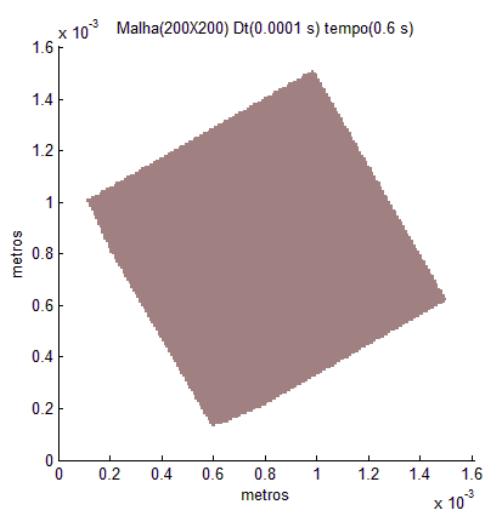

(a) $t=0,6 s$

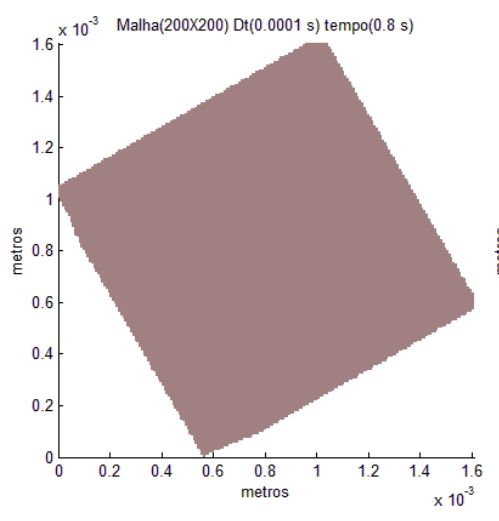

(b) $\mathrm{t}=0,8 \mathrm{~s}$

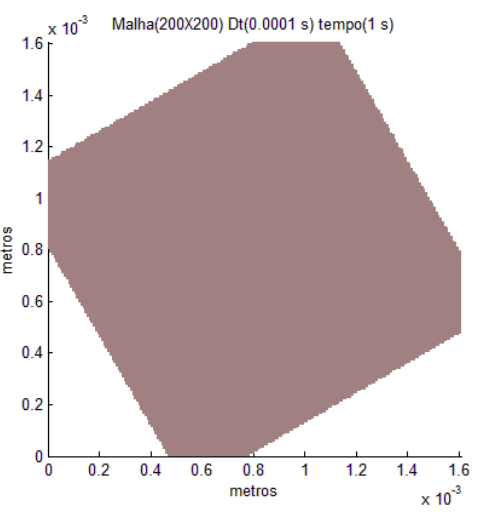

(c) $\mathrm{t}=1,0 \mathrm{~s}$

Figura 97 - Crescimento do grão com orientação de 30: (a) no instante anterior ao toque nas bordas do domínio; (b) no instante do toque e (c) posterior ao toque. 
A diferença entre as curvas de fração de envelopes mostrada na Figura 96 para tempos maiores que $0,8 \mathrm{~s}$, mas principalmente para tempos maiores que $1,1 \mathrm{~s}$ é atribuída ao fato de que o modelo determinístico, diferentemente do modelo CADE, não considera a diminuição da concentração da área interfacial dos envelopes no momento em que eles se esbarram ("impingement"), a qual pode ser melhor visualizada nas curvas da Figura 98.

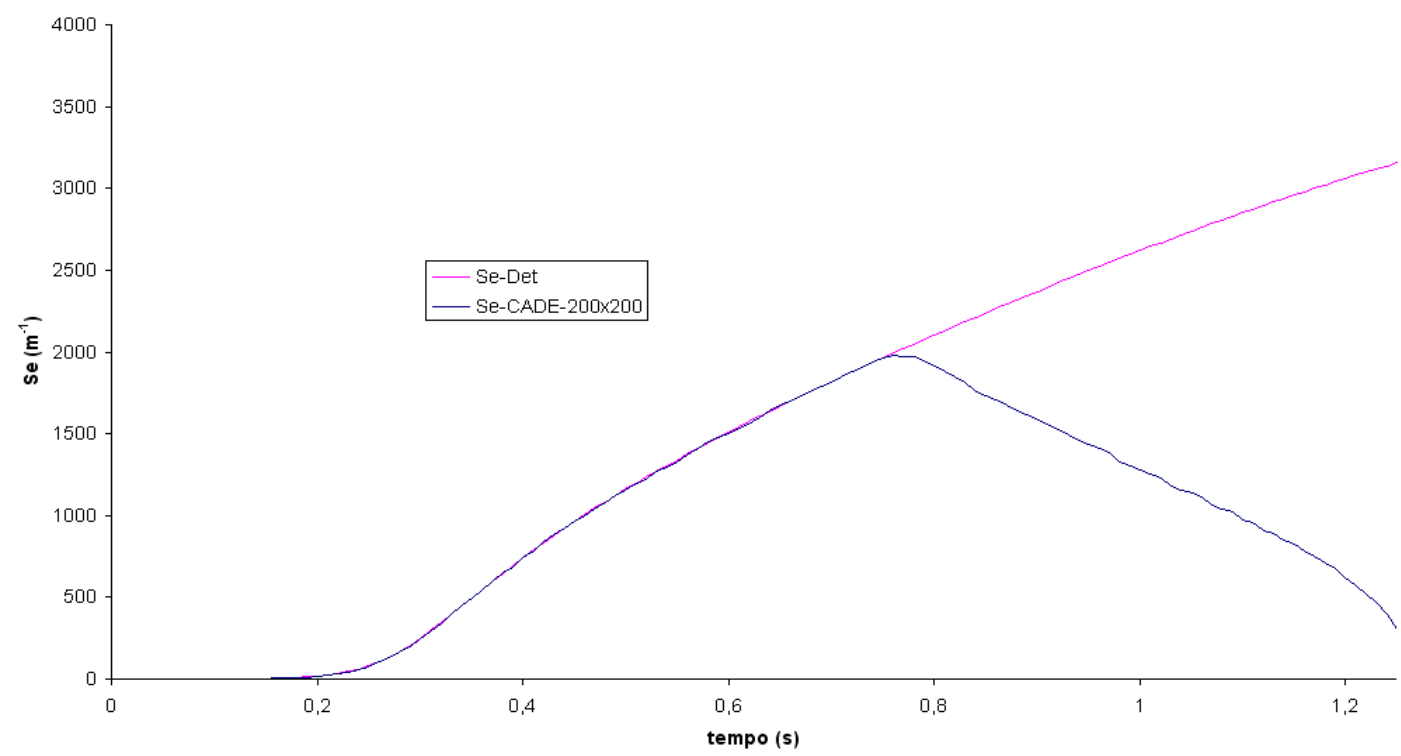

Figura 98 - Evolução da concentração de área interfacial de envelope e líquido extradendrítico em função do tempo prevista pelo modelo CADE (Se-CADE-200x200) e pelo modelo determinístico (SeDet) com um envelope cúbico e orientação cristalográfica de $30^{\circ}$.

Nestas curvas, a concentração de área interfacial de envelopes prevista pelo modelo CADE atingiu um valor máximo próximo ao instante de tempo 0,8s e depois diminuiu devido ao encontro do envelope com as bordas do domínio (Figura 97), enquanto o modelo determinístico não prevê este fato e sim um aumento desta área até o término da simulação. Esta diferença no cálculo da concentração de área interfacial influencia o cálculo da fração de sólido, que influencia os resultados de temperatura, como pode ser visto na Figura 99 e Figura 100. 


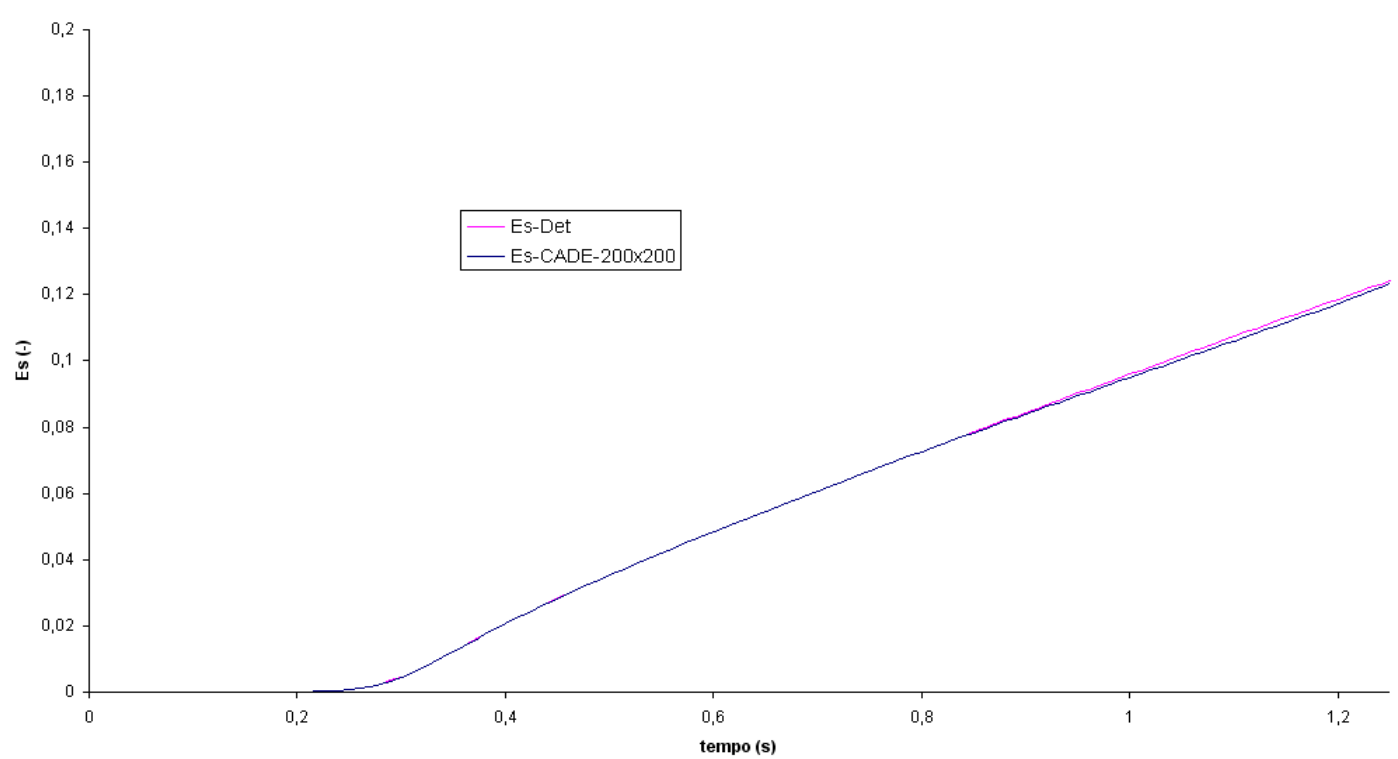

Figura 99 - Evolução da fração de sólido em função do tempo prevista pelo modelo CADE (Es-CADE200x200) e pelo modelo determinístico (Es-Det) com um envelope cúbico de orientação 30ํ․

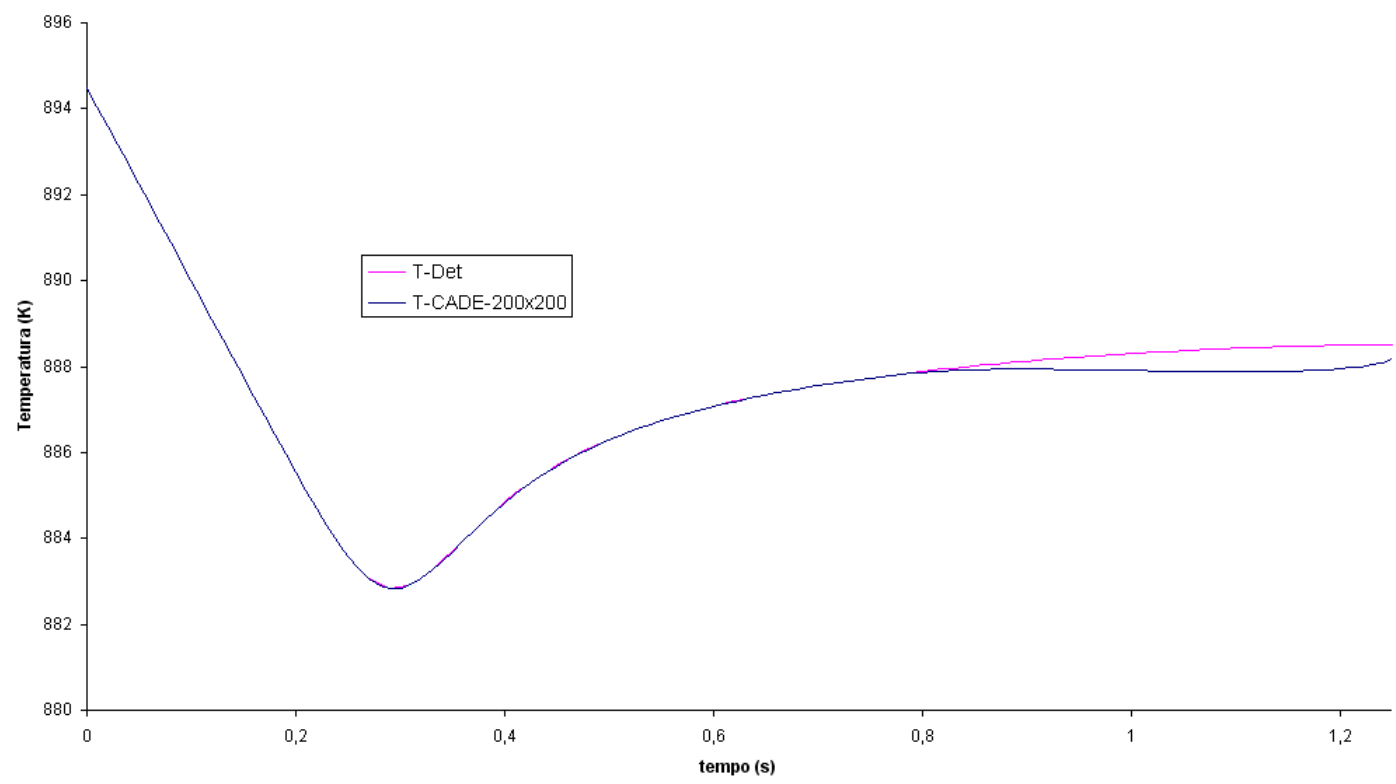

Figura 100 - Curvas de resfriamento em função do tempo previstas pelo modelo CADE (T-CADE200x200) e pelo modelo determinístico (T-Det) com um envelope cúbico de orientação 30ํ․

As curvas de resfriamento foram influenciadas pela diminuição da concentração de área interfacial de envelopes prevista pelo modelo CADE em comparação com o modelo determinístico, enquanto as curvas de fração de sólido apresentaram uma pequena diferença. Este mesmo teste foi repetido para um grão 
com uma orientação de $0^{\circ}$, pois com esta orientação, a concentração de área interfacial de envelopes prevista pelos modelos CADE e determinístico (ambos com envelope cúbico) deveria ser exatamente a mesma até o momento em que o grão encosta nas bordas do domínio, como pode ser visto na Figura 101. Na Figura 102 pode-se ver o crescimento do grão no instante anterior ao encontro com as bordas do domínio (a) e após (b).

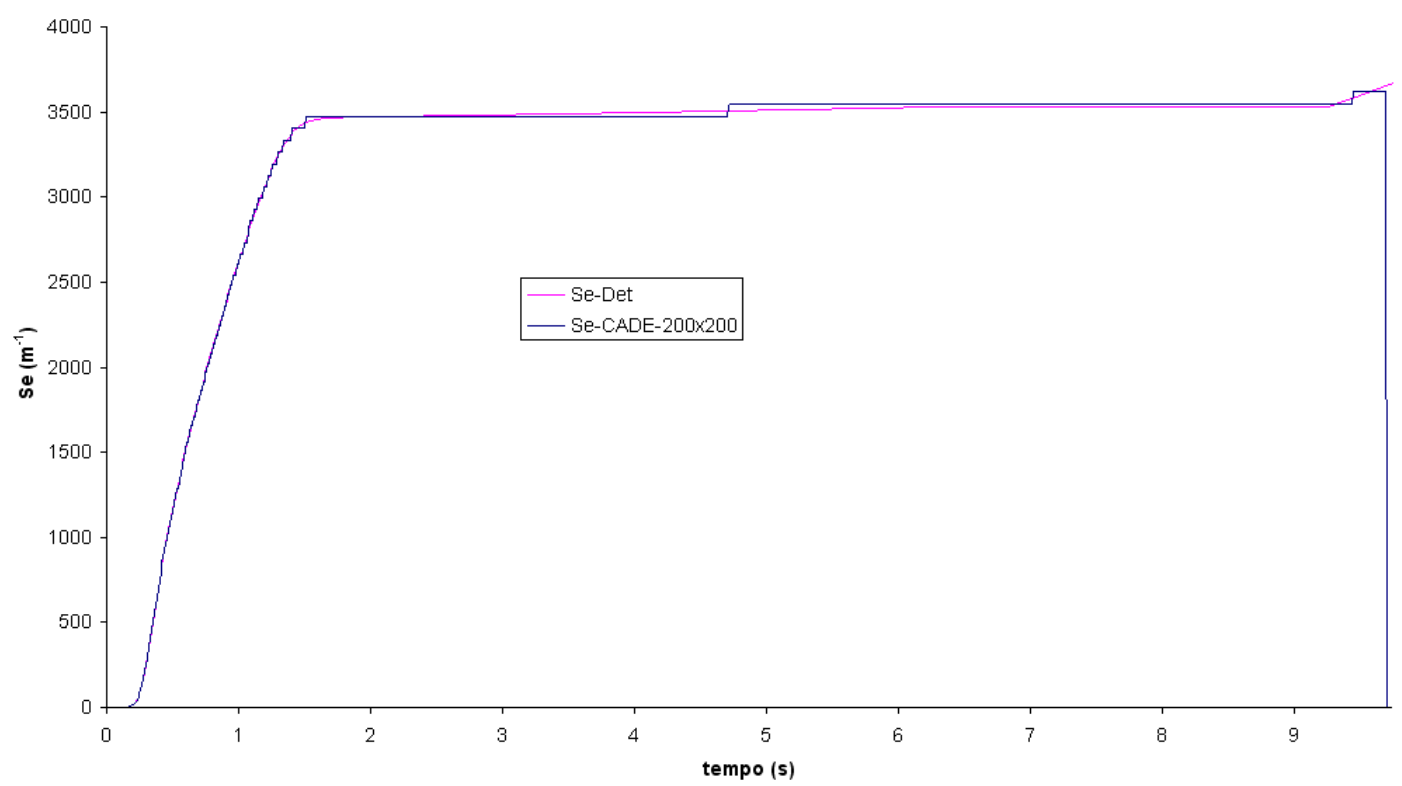

Figura 101 - Evolução da concentração de área interfacial de envelope em função do tempo prevista pelo modelo CADE (Se-CADE-200x200) e pelo modelo determinístico (Se-Det) com um envelope cúbico de orientação $0^{\circ}$.

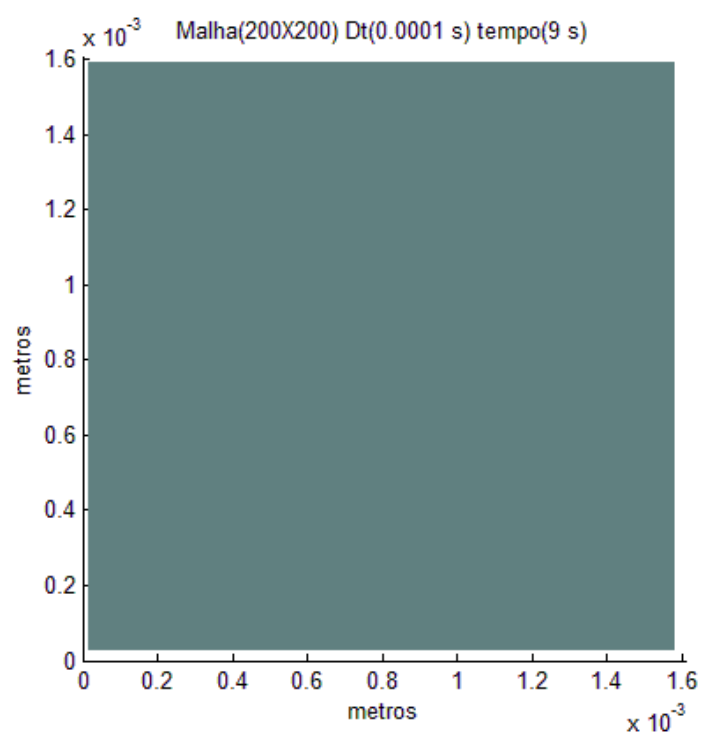

(a) $\mathrm{t}=9,0 \mathrm{~s}$

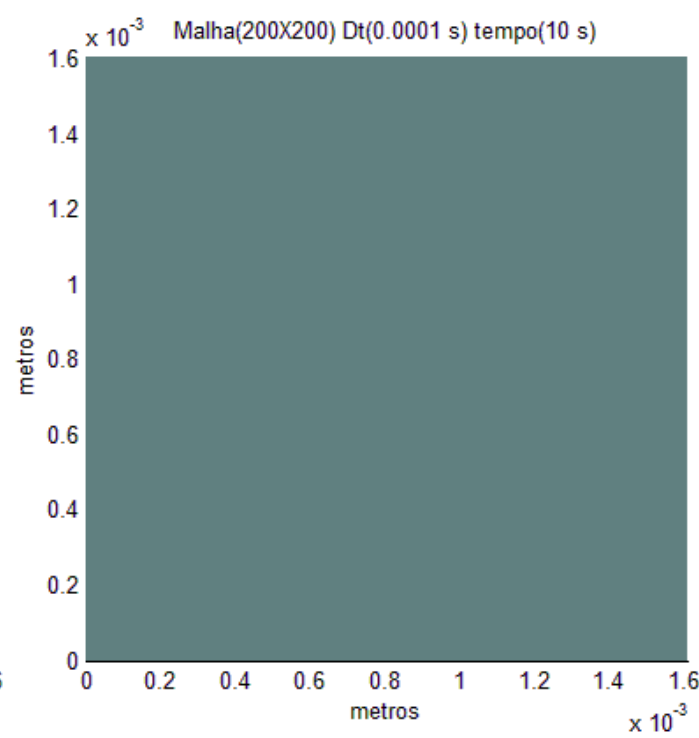

(b) $\mathrm{t}=10,0 \mathrm{~s}$

Figura 102 - Crescimento do grão com orientação de $0^{\circ}$ no instante anterior ao encontro com as bordas do domínio (a); e posterior ao encontro (b). 
A concentração de área interfacial de envelope (Figura 101) torna-se constante após $1,5 \mathrm{~s}$, causando uma diminuição na velocidade de crescimento do envelope, que pode ser observada na Figura 103. Esta figura mostra que as velocidades de crescimento previstas pelos dois modelos foram exatamente iguais e que decaem até aproximadamente 0.

A velocidade de crescimento é determinada pelo super-resfriamento presente na ponta do braço dendrítico, que por sua vez depende da concentração de soluto no líquido interdendrítico e no extradendrítico. A evolução da diferença da concentração de soluto no líquido extra e interdendrítico, verificada através das curvas de concentração presentes na Figura 104 para os dois modelos, apresenta inicialmente um aumento e uma posterior diminuição, causando também um aumento e uma diminuição na velocidade de crescimento. Este efeito não foi considerado pelo modelo estocástico tradicional de Gandin e Rappaz (1997).

Nota-se na Figura 102 (a) uma pequena região ao redor do grão com líquido extradendrítico. Este líquido, enriquecido ( 11\%Si) com o soluto rejeitado pelo sólido durante a solidificação, apresenta menor super-resfriamento, resultando em velocidades de crescimento do envelope muito reduzidas e impedindo que o grão finalize o seu crescimento atingindo o contorno do domínio.

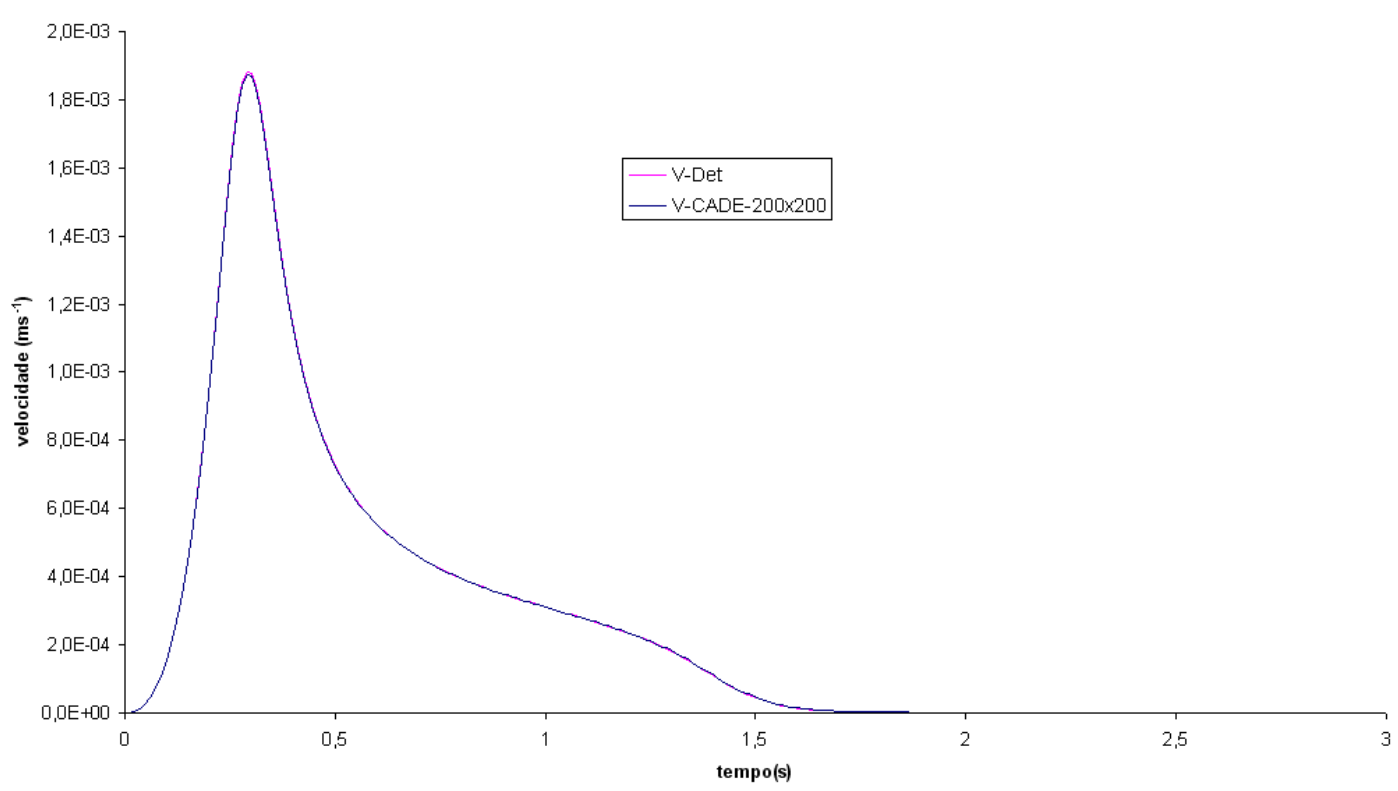

Figura 103 - Velocidade de crescimento em função do tempo prevista pelo modelo CADE (V-CADE200x200) e pelo modelo determinístico (V-Det) para um envelope cúbico de orientação 0ํ․ 


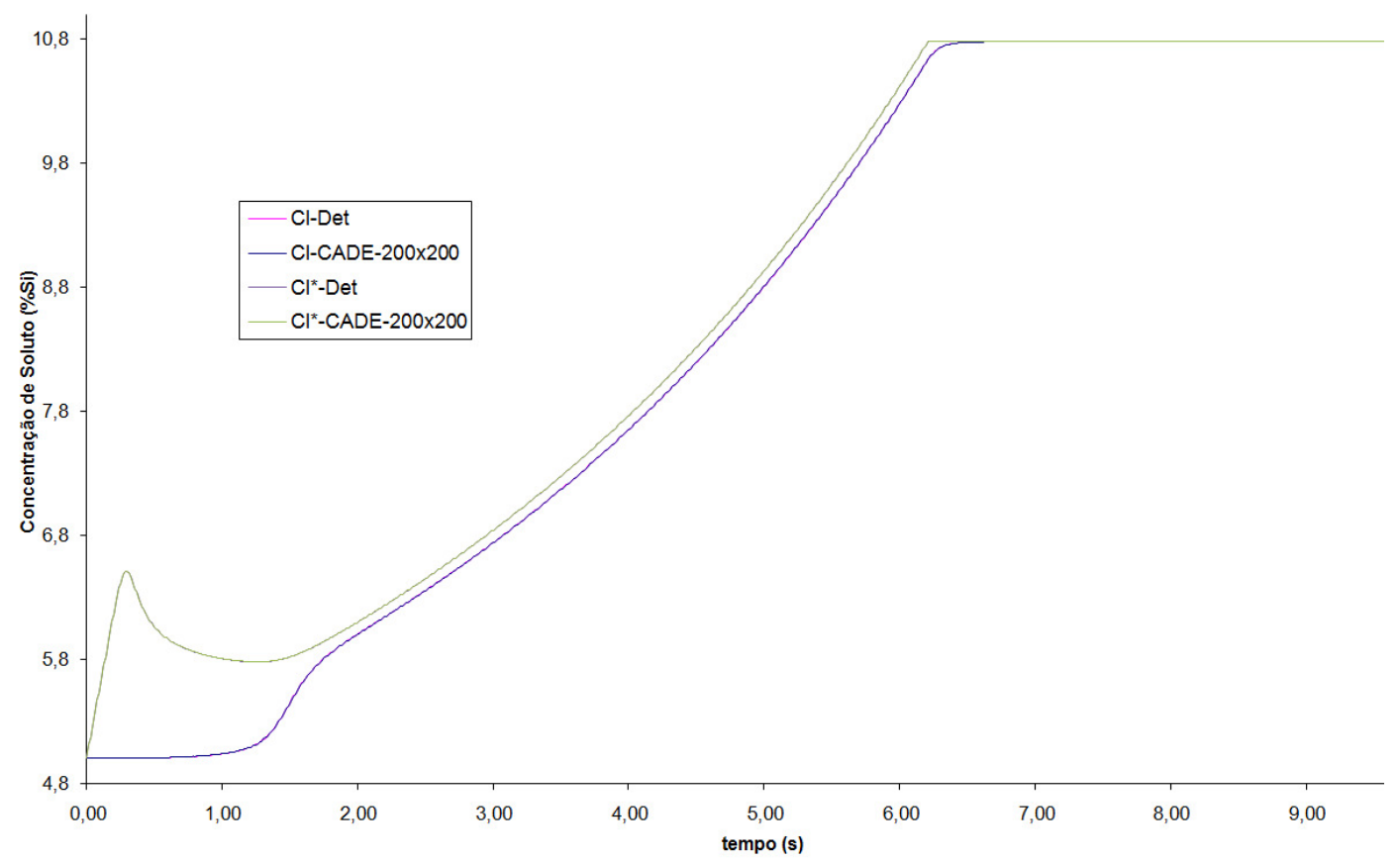

Figura 104 - Gráfico da concentração de soluto no líquido extradendrítico $(\mathrm{Cl})$ e extradendrítico $\left(\mathrm{Cl}^{\star}\right)$ em função do tempo previsto pelo modelo CADE (-CADE-200x200) e pelo determinístico (Det) com um envelope cúbico e orientação cristalográfica de $0^{\circ}$.

Os resultados até aqui apresentados atestam a correta implementação do algoritmo do modelo proposto (CADE). Fica evidente também um avanço em relação ao modelo estocástico tradicional (Gandin; Rappaz, 1997), já que o modelo CADE tem a capacidade de prever a rejeição de soluto e o seu efeito na velocidade de crescimento dendrítico.

Utilizou-se o modelo CADE com o envelope cúbico em uma orientação de $0^{\circ}$ também para simular outras duas densidades de núcleos, a saber, $2,4 \times 10^{5} \mathrm{~m}^{-3} \mathrm{e}$

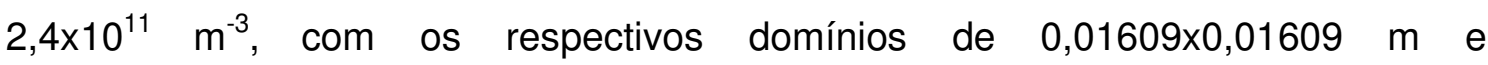
$0,0001609 \times 0,0001609 \mathrm{~m}$. As curvas de resfriamento calculadas foram utilizadas para comparação com os resultados do modelo determinístico de Wang e Beckermann (1993b) para três densidades de núcleos diferentes $\left(2,4 \times 10^{5} \mathrm{~m}^{-3}, 2,4 \times 10^{8} \mathrm{~m}^{-3} \mathrm{e}\right.$ $2,4 \times 10^{11} \mathrm{~m}^{-3}$ ). Os resultados (Figura 105) foram adimensionalizados como proposto por estes autores, ou seja:

$$
T^{*}=\frac{T_{L}-T}{T_{L}-T_{E}}
$$




$$
t^{*}=t \frac{45 C_{p}}{\Delta H_{f}}
$$

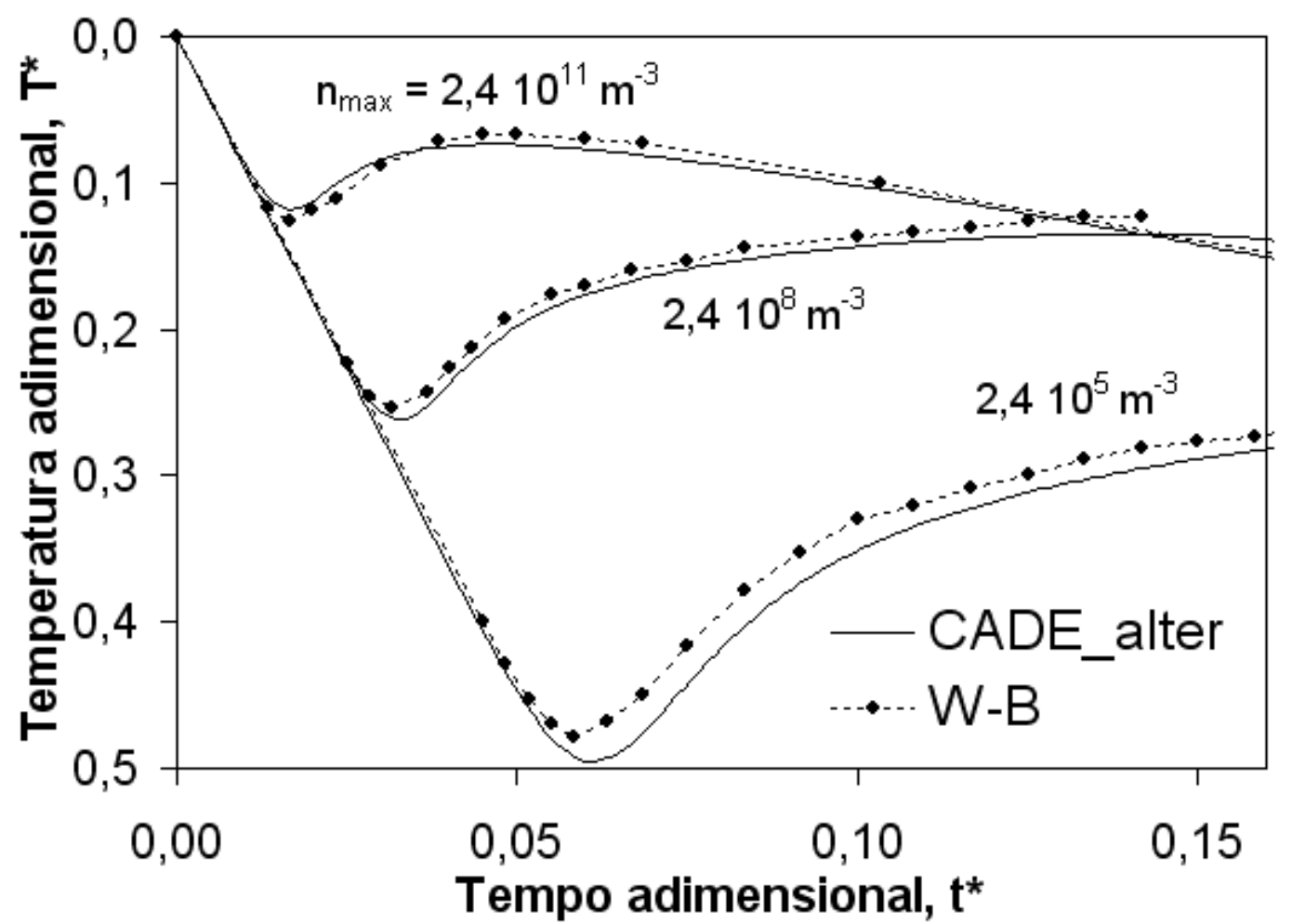

Figura 105 - Curvas de resfriamento adimensionalisadas para o modelo CADE com envelope cúbico e o modelo determinístico de Wang e Beckermann (1993b) para três densidades de núcleos $\left(\mathrm{n}_{\max }\right)$.

Os resultados do modelo CADE para as densidades de $2,4 \times 10^{8} \mathrm{~m}^{-3} \mathrm{e}$ $2,4 \times 10^{11} \mathrm{~m}^{-3}$ mostraram-se muito próximos aos resultados de Wang e Beckermann (1993b), enquanto os resultados apresentados pelo CADE para a densidade de $2,4 \times 10^{5}$ apresentaram uma diferença um pouco maior, mas ainda muito próximos aos de Wang e Beckermann (1993b).

\subsubsection{Comparação com modelo Determinístico (OD)}

Após os testes para verificar a correta implementação do modelo CADE, dois casos foram simulados para permitir uma comparação entre os seus dados e os obtidos por um modelo determinístico proposto por Martorano, Beckermann e Gandin (2003), na sua forma original. Em ambos os casos simulados utilizaram-se as propriedades listadas na Tabela 16, sendo que: no primeiro caso simulou-se o 
crescimento de um único grão posicionado no centro do domínio e com uma orientação de $30^{\circ}$ em relação ao eixo horizontal; no segundo caso, trinta núcleos foram distribuídos aleatoriamente pelo domínio e a estes foram dadas orientações aleatórias.

Nos dois casos utilizou-se um modelo de nucleação instantânea com um super-resfriamento nulo para nucleação, um passo de tempo de $1 \times 10^{-4} \mathrm{~s}$ e os seguintes tamanhos de domínio: 0,015x0,0015m para o teste com um único grão e $0,0079 \times 0,0079 m$ para o teste com 30 grãos. Utilizou-se uma malha de $200 \times 200$ células no modelo CADE. Os dados obtidos para o primeiro teste encontram-se na seqüência da Figura 106 até a Figura 110.

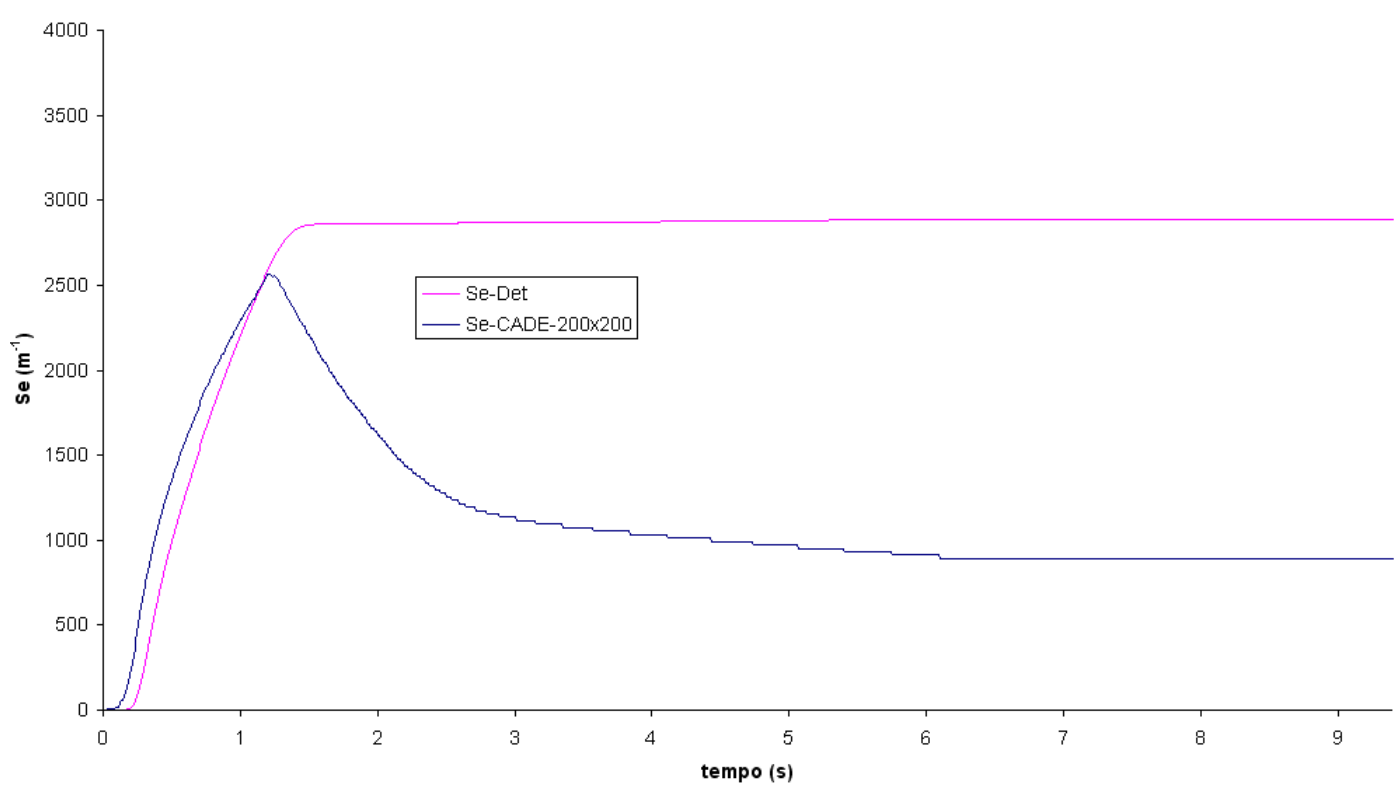

Figura 106 - Evolução da concentração de área interfacial de envelopes $\left(S_{e}\right)$ prevista pelos modelos CADE $\left(S_{e}-C A D E-200 x 200\right)$ e determinístico $\left(S_{e}-\right.$ Det) para um grão central com orientação de 30ํ․

Nota-se novamente pela Figura 106 uma característica importante deste modelo, a previsão da diminuição da concentração de área interfacial de envelopes. Apesar da diferença entre os resultados até agora analisados, a fração de sólido prevista por ambos os modelos (Figura 108) mostrou uma ótima aderência. Pode-se perceber pela Figura 109 que o modelo CADE apresenta uma descontinuidade na sua curva de concentração $C_{\mid}$no momento em que o envelope toca as bordas do domínio e começa a diminuição da sua concentração de área interfacial de 
envelopes. Este comportamento não é observado na curva do modelo determinístico considerado, pois este não é capaz de prever o encontro dos grãos.

Verifica-se também que o modelo CADE apresentou uma curva de temperatura com um perfil mais suave, ou seja, a sua curva apresentou mudanças de inclinação mais suaves, como demonstrado na Figura 110.

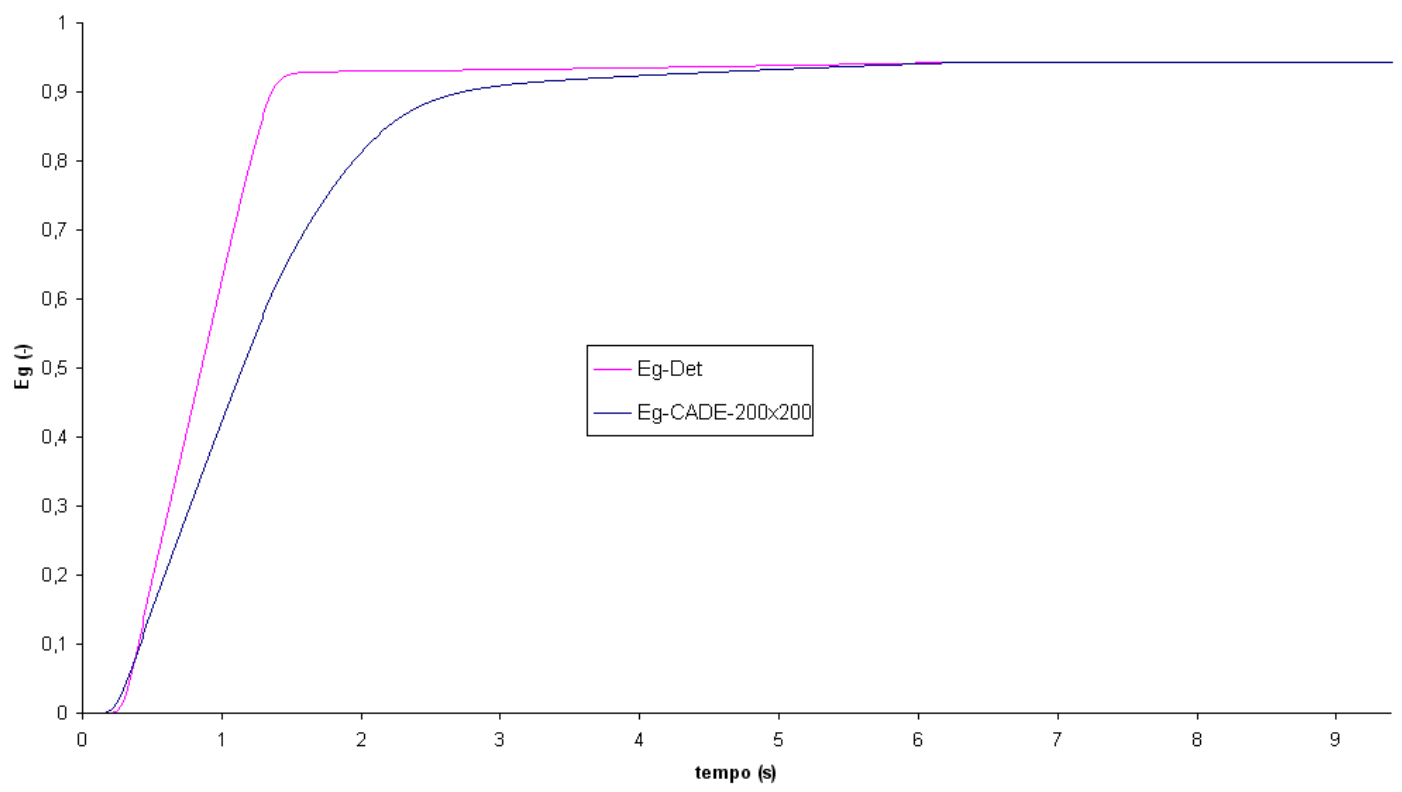

Figura 107 - Evolução da fração de envelopes $\left(\mathcal{E}_{g}\right)$ prevista pelos modelos CADE ( $\varepsilon_{g}$-CADE$200 \times 200)$ e determinístico ( $\mathcal{E}_{g}$-Det) para um grão central com orientação cristalográfica de 30 .

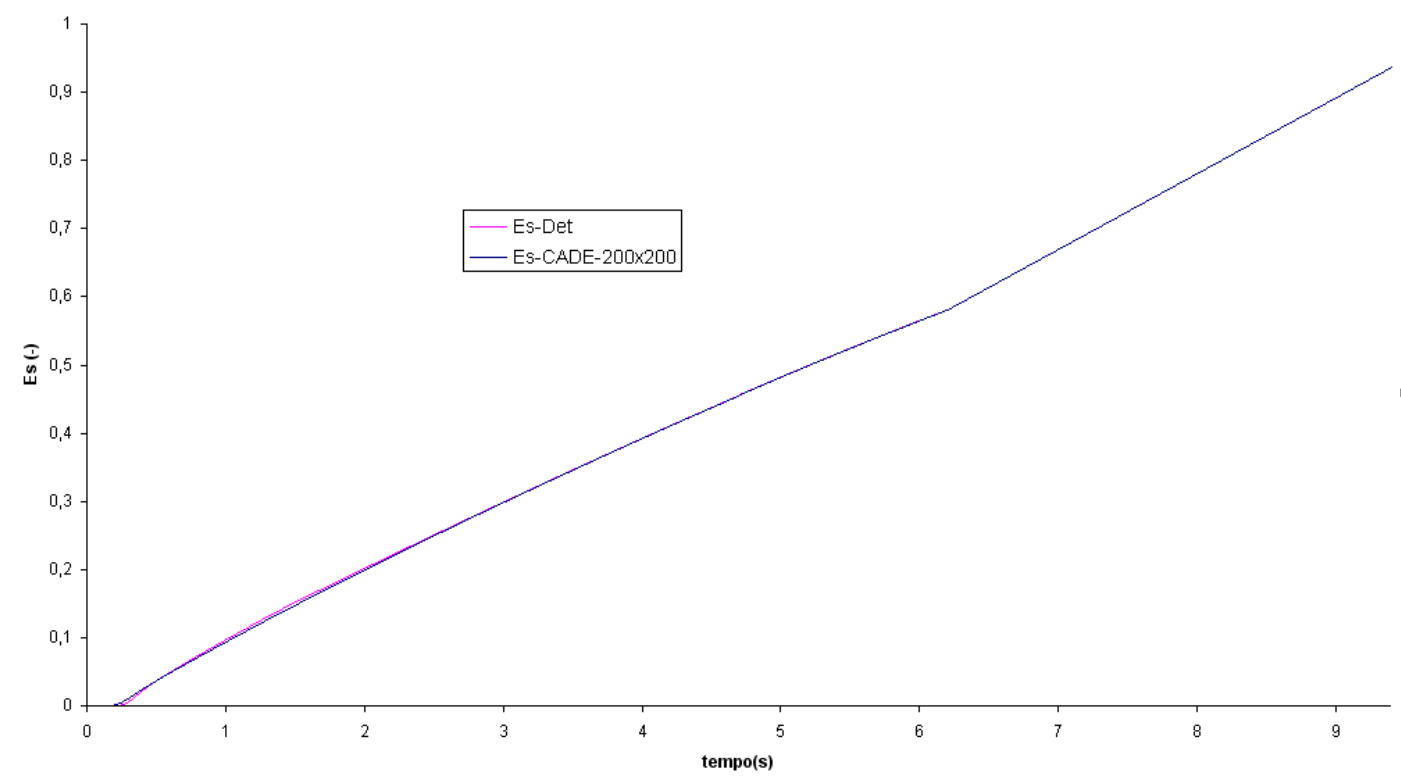

Figura 108- Evolução da fração de sólido ( $\mathcal{E}_{S}$ ) prevista pelos modelos CADE ( $\varepsilon_{S}$-CADE-200x200) e determinístico ( $\mathcal{E}_{S}$-Det) para um grão central com orientação cristalográfica de 30 . 


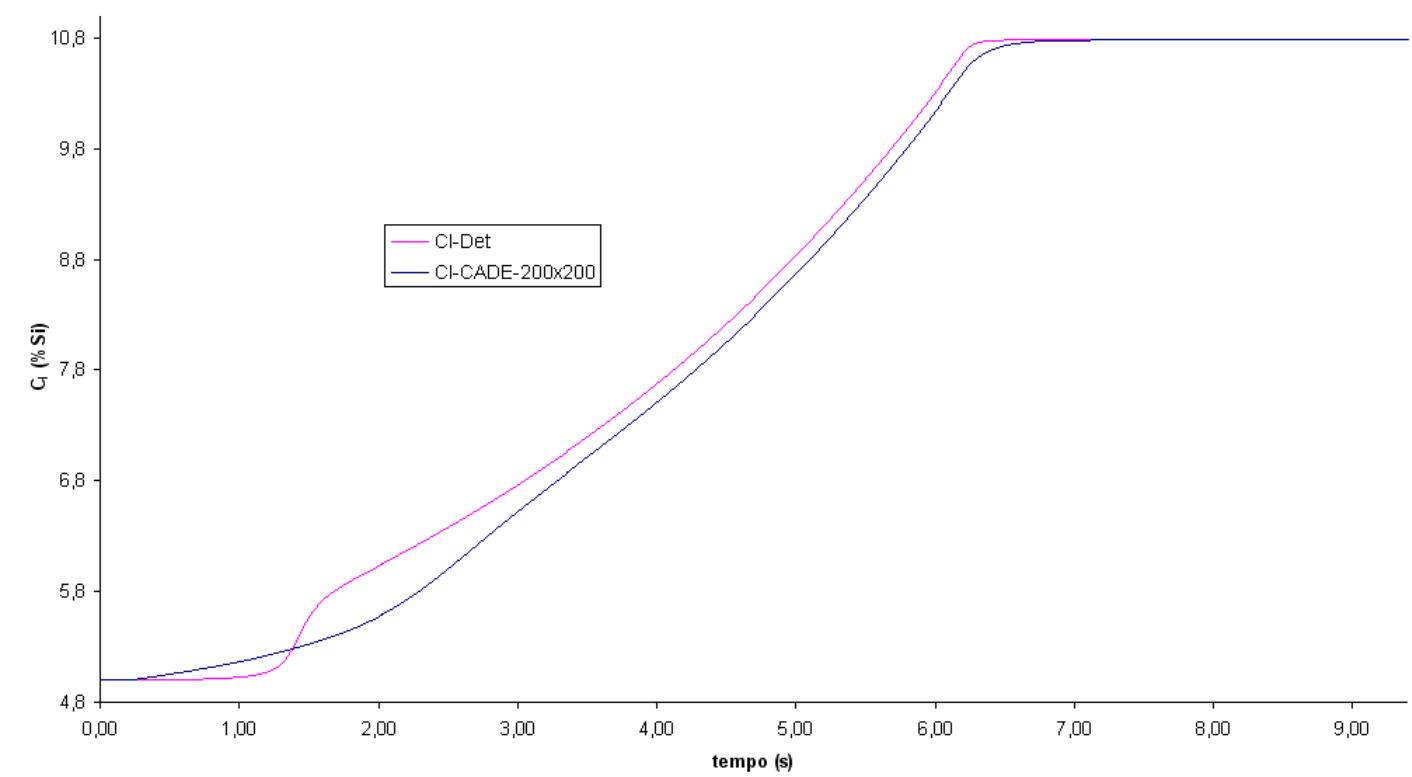

Figura 109- Evolução da concentração de soluto no líquido extradendrítico $\left(\mathrm{C}_{l}\right)$ prevista pelos modelos

CADE (Cl-CADE-200x200) e determinístico (Cl-Det) para um grão central com orientação cristalográfica de $30^{\circ}$.

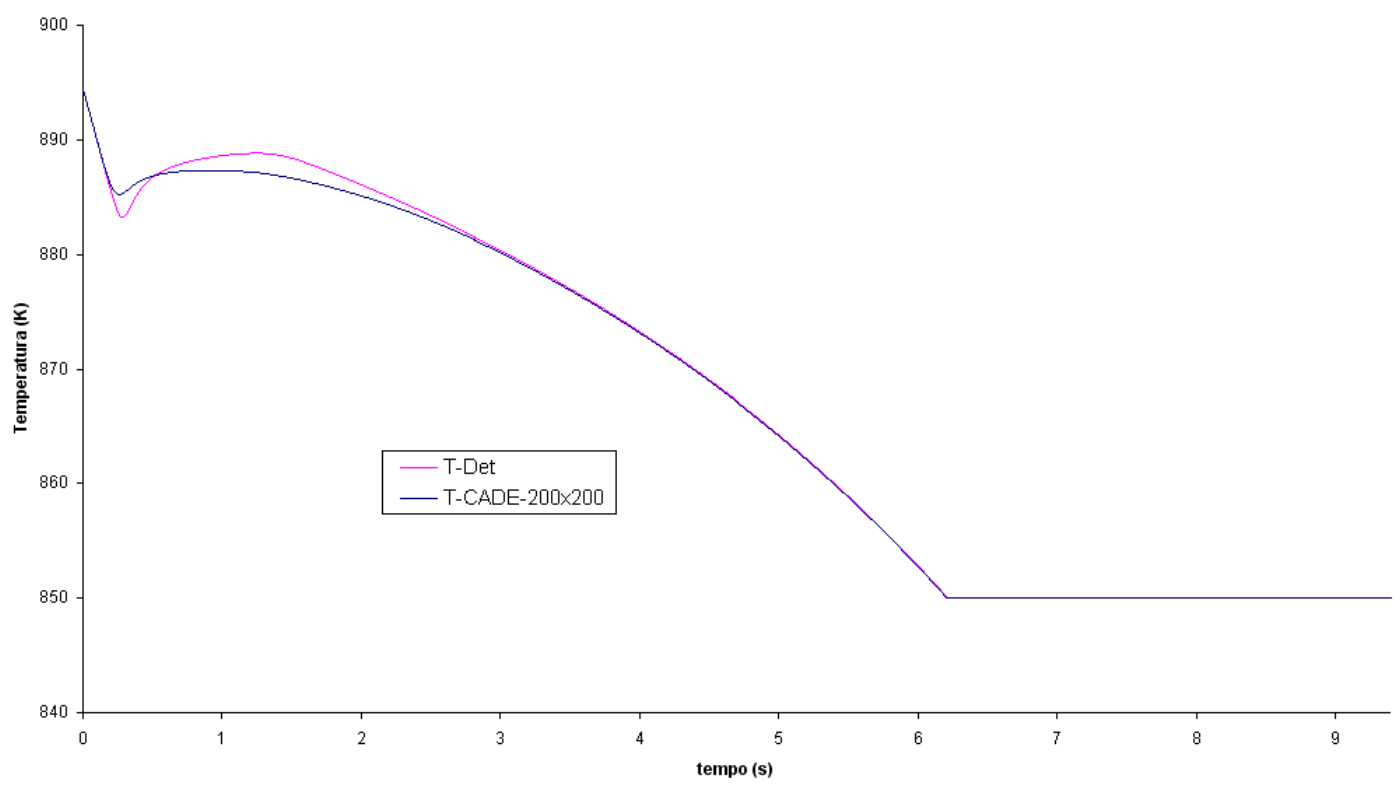

Figura 110- Curvas de temperatura previstas pelos modelos CADE (T-Det) e determinístico (T-CADE200x200) para um grão central com orientação cristalográfica de $30^{\circ}$.

Os dados obtidos para o segundo teste, no qual são considerados trinta grãos, encontram-se na seqüência da Figura 111 a Figura 114. Após comparação dos dados resultantes da simulação nota-se que a evolução da fração de envelopes prevista pelo modelo CADE possui uma mudança de inclinação mais amena em 
relação ao modelo de Martorano, Beckermann e Gandin (2003), conforme mostrado na Figura 111. Apesar das diferenças nas curvas de fração volumétrica de envelopes, concentração de área interfacial de envelopes e concentração de soluto no líquido extradendrítico, as frações de sólido se apresentaram muito próximas, resultando em curvas de temperatura também próximas (Figura 114). A maior diferença encontrada entre as curvas de temperaturas foi menor que 2,5K, comprovando a boa aderência entre os modelos. As curvas de concentração de área de envelopes demonstraram novamente a capacidade do modelo CADE em prever o encontro de grãos (Figura 112).

Finalmente a grande diferença entre o modelo híbrido (CADE) e o modelo determinístico está mostrada na Figura 115: o modelo CADE calcula a macroestrutura final de grãos, o que não pode ser fornecido pelos modelos determinísticos atuais.

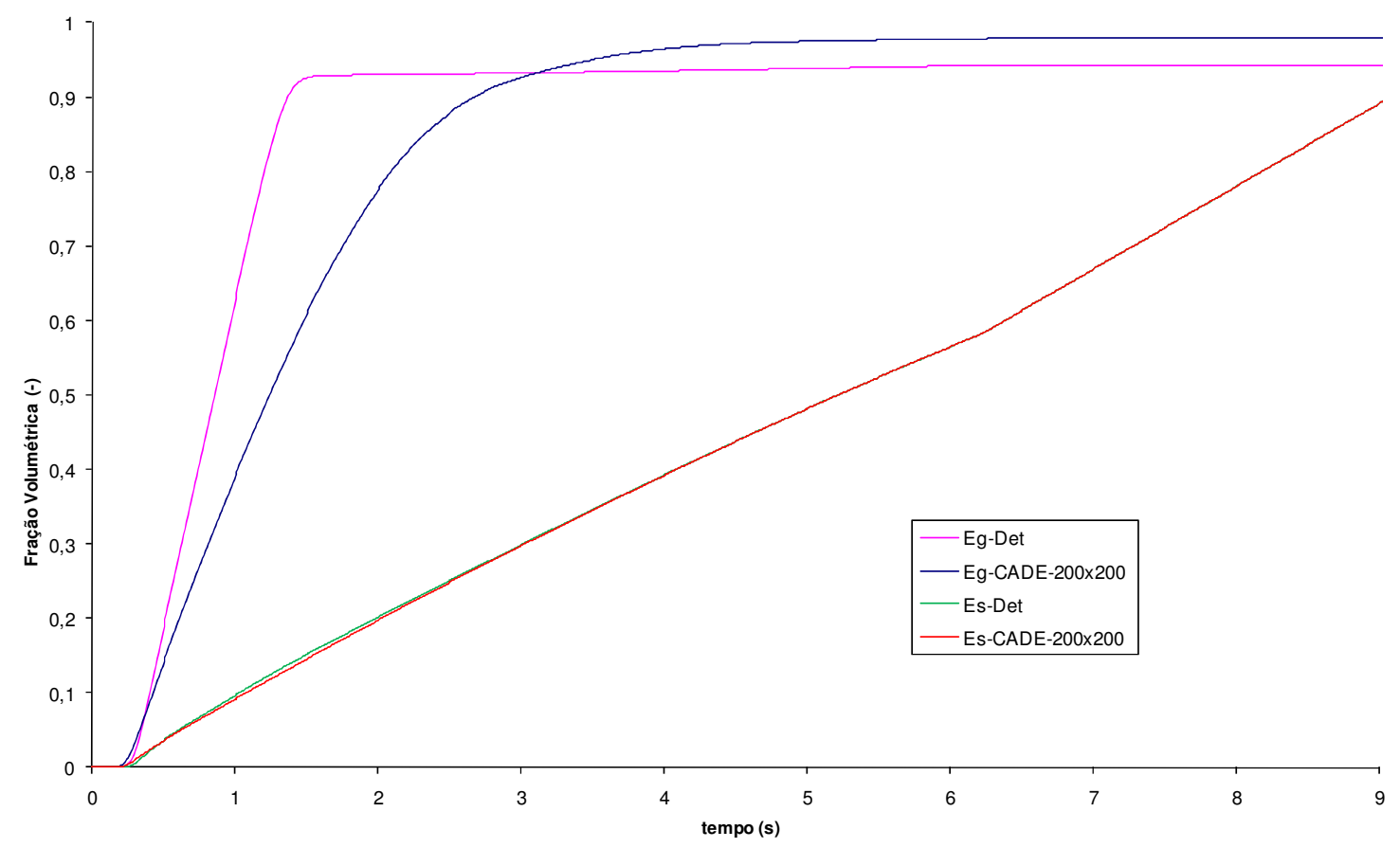

Figura 111 - Frações volumétricas de sólido e envelopes em função do tempo para o modelo híbrido (CADE-200x200) e o modelo determinístico (Det) calculadas para 30 grãos. 


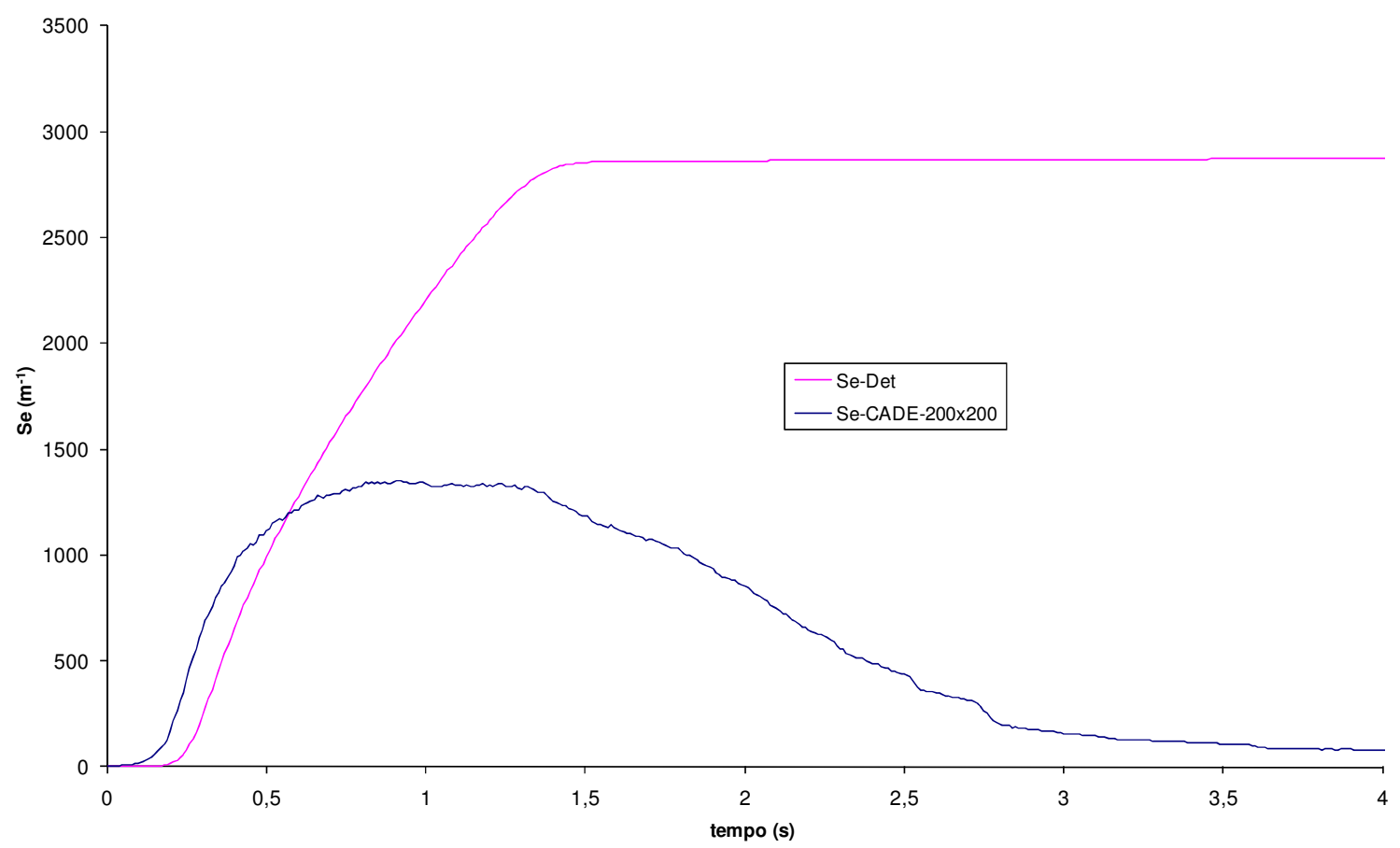

Figura 112 - Concentração de área interfacial de envelopes em função do tempo para o modelo híbrido (Se-CADE-200x200) e o modelo determinístico (Se-Det) calculada para 30 grãos.

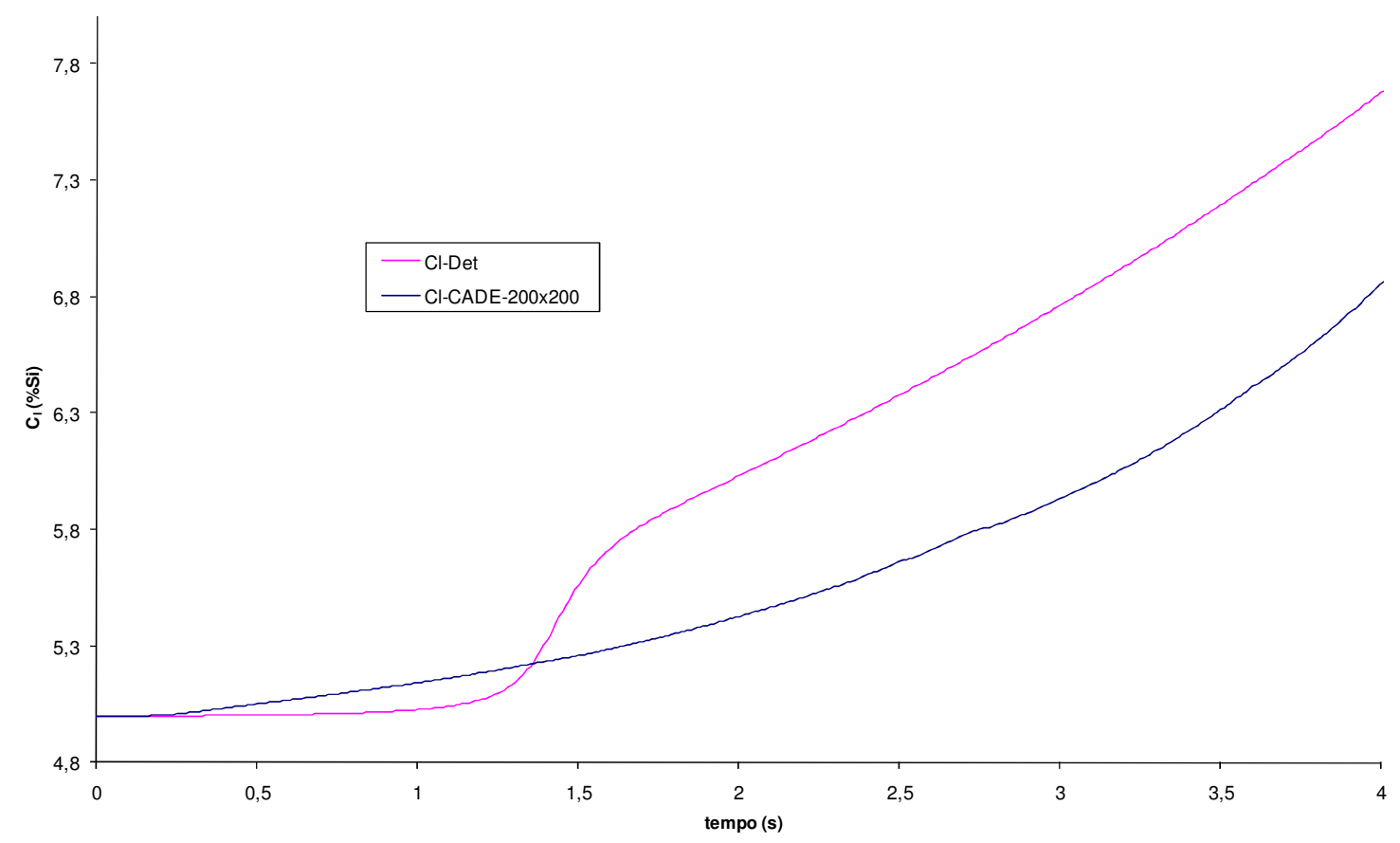

Figura 113 - Concentração de soluto no líquido extradendrítico em função do tempo para o modelo híbrido (Cl-CADE-200x200) e o modelo determinístico (Cl-Det) calculada para 30 grãos. 


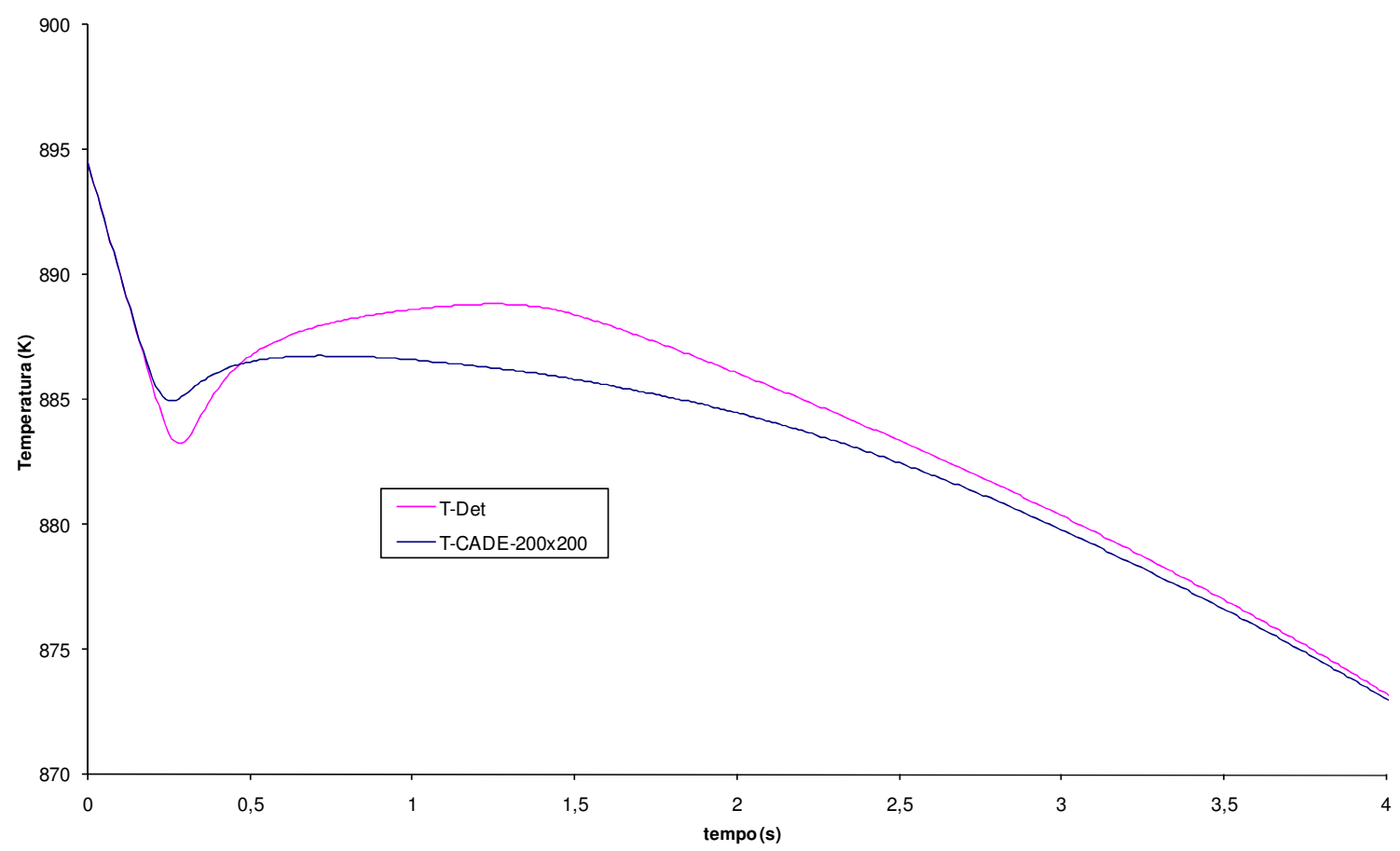

Figura 114 - Curvas de temperatura em função do tempo para o modelo híbrido (T-CADE-200x200) e o modelo determinístico (T-Det) calculadas para 30 grãos.

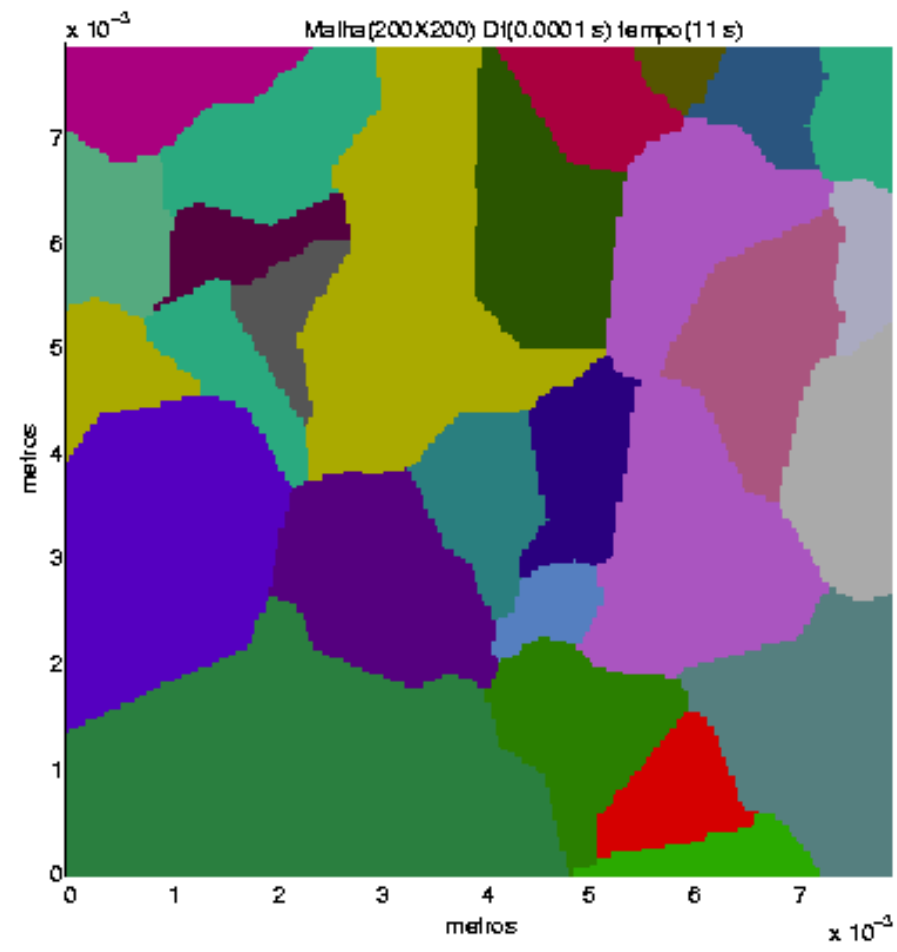

Figura 115 - Macroestrutura de grãos calculada para o modelo CADE para a nucleação e crescimento de 30 grãos distribuídos aleatoriamente no domínio. 
Nos dados apresentados para ambos os modelos (CADE e determinístico) observa-se um acúmulo de soluto no líquido extradendrítico ao longo do tempo (Figura 113), causando uma diminuição na velocidade do crescimento dos envelopes e do crescimento da sua fração volumétrica (Figura 111) a partir do instante de tempo de aproximadamente 2s. Este efeito já foi observado no modelo determinístico de Martorano, Beckermann e Gandin (2003). No modelo CADE, este efeito também aparece na imagem da evolução da macroestrutura calculada, como mostrado na Figura 116.

$1 \mathrm{~s}$
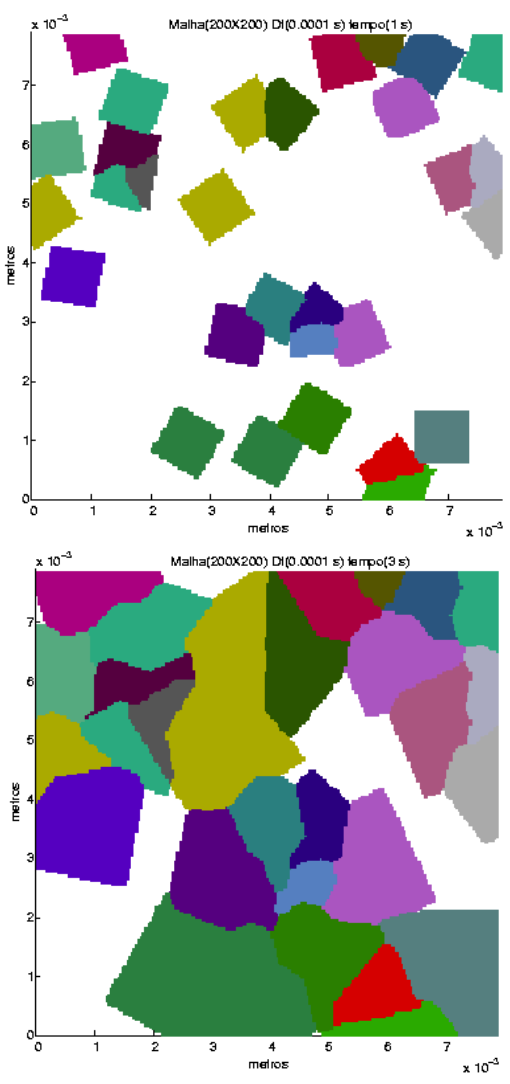

$3 \mathrm{~s}$

$5 s$

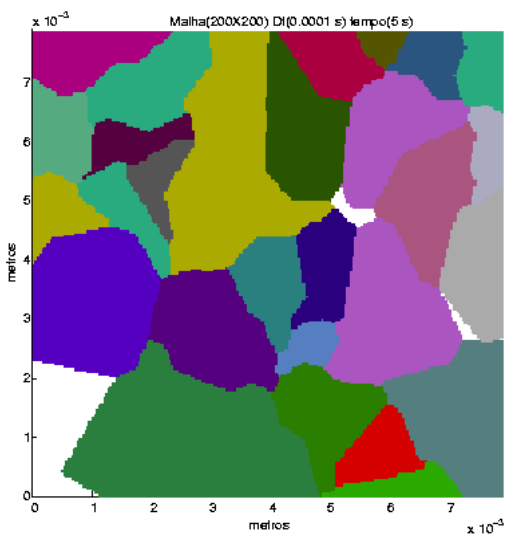

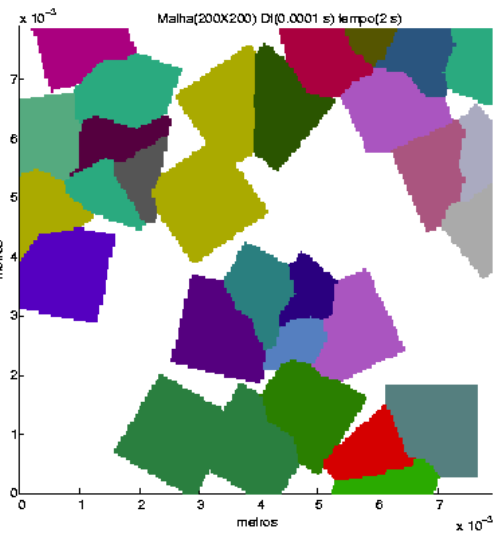
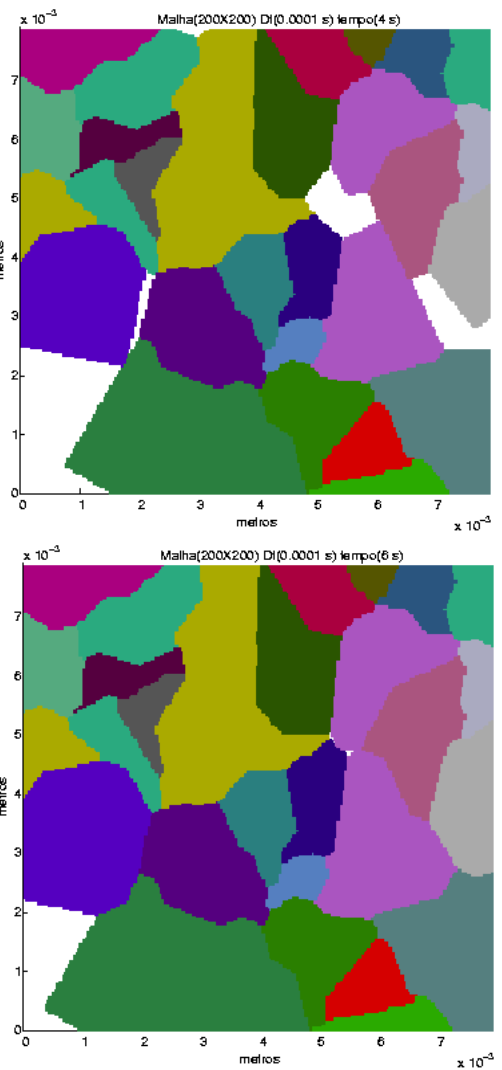

$2 s$

$4 s$

$6 s$ 

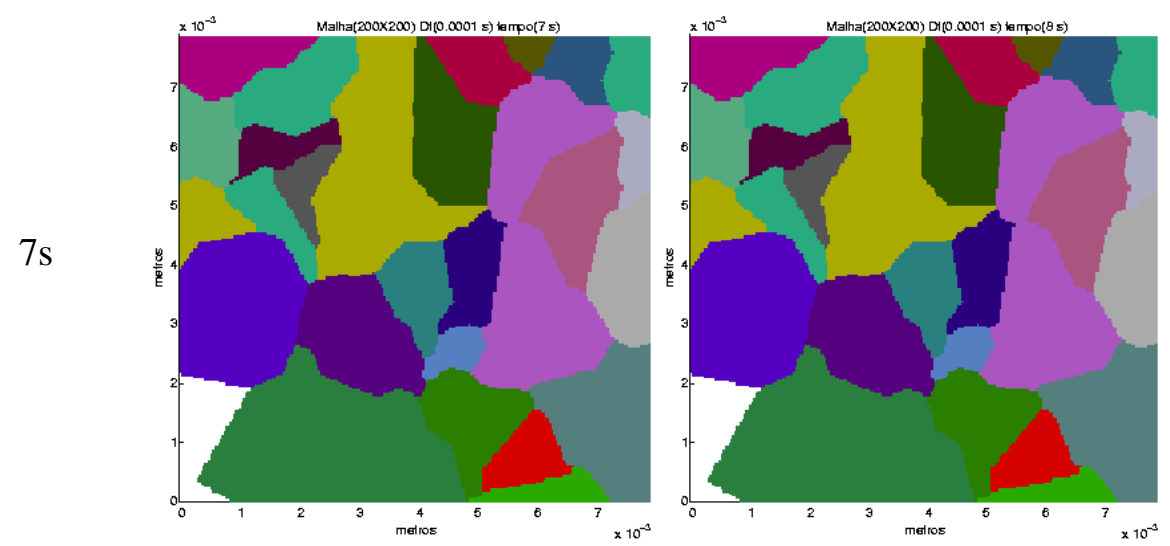

$8 \mathrm{~s}$

Figura 116 - Evolução da macroestrutura entre os instantes de tempo 1 e 8 s prevista pelo modelo CADE durante a simulação da nucleação e crescimento de 30 grãos.

Nota-se uma evolução mais rápida dos grãos entre os instantes 1 e 4s, que passa a ser mais lenta entre os instantes 5 e $6 \mathrm{~s}$ e imperceptível entre 7 e $8 \mathrm{~s}$. A partir do instante $6 \mathrm{~s}$, a temperatura do domínio atinge o ponto eutético, onde toda a extração de calor é utilizada para a remoção do calor latente liberado e o incremento da fração de sólido, devido à transformação eutética.

\subsubsection{Comparação com os Modelos Determinístico e Estocástico (1D)}

Neste item o modelo híbrido proposto (CADE) é comparado, nas condições de transferência de calor unidirecional (1D), com os modelos estocástico e determinístico já apresentados. O modelo CADE foi utilizado para simular a solidificação nas condições definidas anteriormente para o caso de referência (item $5.2 .1)$.

Nestas simulações com o modelo CADE, o cálculo do super-resfriamento de soluto necessário para prever a velocidade de crescimento foi alterado substituindose a Eq. [62] pela equação abaixo:

$$
\Omega=\frac{C_{l}^{*}-C_{0}}{C_{l}^{*}(1-k)}
$$

onde $C_{0}$, que representa a concentração inicial de soluto no líquido extradendrítico foi colocada no lugar de $C_{l}$, concentração de soluto instantânea neste líquido. Esta 
simples alteração removeu a possibilidade de simular o bloqueio por soluto, porém permitiu que um problema encontrado no cálculo da velocidade de crescimento dos envelopes fosse mitigado, como explicado a seguir.

No equacionamento utilizado pelo modelo, parte do soluto rejeitado pelo crescimento dos grãos é expulso do envelope dendrítico para o líquido extradendrítico, causando o seu enriquecimento, o que pode diminuir ou até cessar o crescimento dos grãos. Para a solução numérica das equações, o domínio foi dividido em volumes finitos onde as equações são resolvidas, fazendo com que em situações que se necessite mais de um volume finito no domínio (1D, 2D e 3D), o crescimento dos grãos enriqueça o soluto do líquido extradendrítico dentro de cada volume finito. O enriquecimento do soluto extradendrítico torna a velocidade de crescimento dos grãos cada vez menor até que estes ultrapassem as fronteiras do volume finito original e adentre em um dos volumes finitos ao seu redor. Caso a concentração de soluto neste novo volume seja menor, ocorre um brusco aumento da velocidade de crescimento e todo o processo é recomeçado.

Este efeito faz com que a frente colunar em crescimento não atinja uma velocidade constante, já que a mesma tende a desacelerar enquanto dentro de um volume finito, acelerar bruscamente ao atravessar para outro volume finito e novamente desacelerar dentro deste até que a mesma seja barrada mecanicamente ou pela rejeição de soluto dos grãos equiaxiais. O gráfico da velocidade da frente colunar em função da distância está representado esquematicamente na Figura 117.

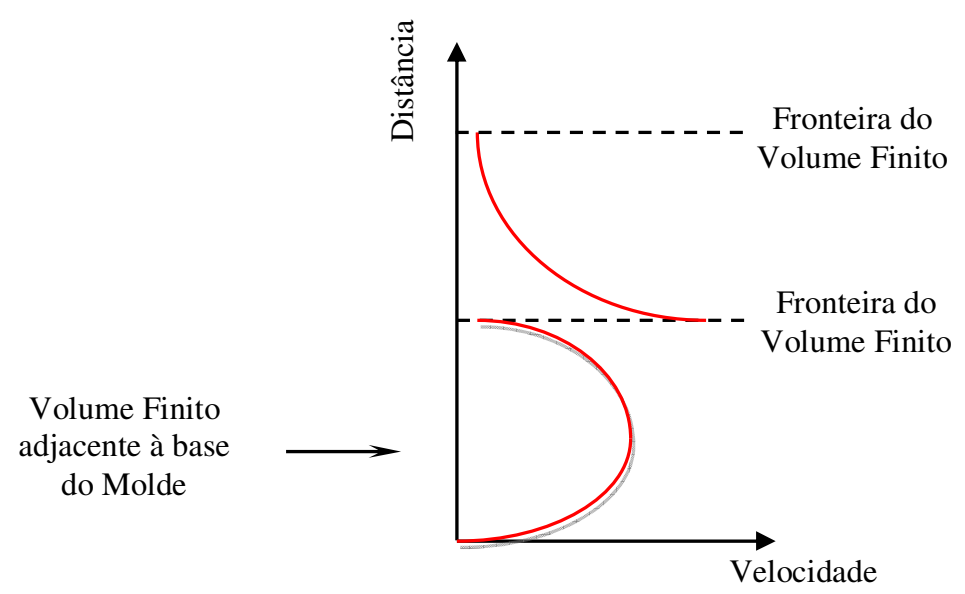

Figura 117- Representação esquemática da velocidade da frente colunar em função da distância. 
Primeiramente na Figura 118 estão comparados os resultados de temperatura obtidos em função do tempo e em 7 posições para o modelo estocástico (Estoc), determinístico (Determ) de Martorano, Beckermann e Gandin (2003) e o novo modelo proposto (CADE). A aderência dos resultados calculados com o novo modelo, aos outros modelos, é muito boa e comprova a correta implementação do novo modelo em situações de transferência de calor unidirecional. Novamente podese observar a presença de oscilações ("wiggles") a partir da ampliação das curvas de resfriamento (Figura 119). Este fenômeno já fora relatado para os outros modelos, através da Figura 65, e ocorre da mesma forma no novo modelo proposto.

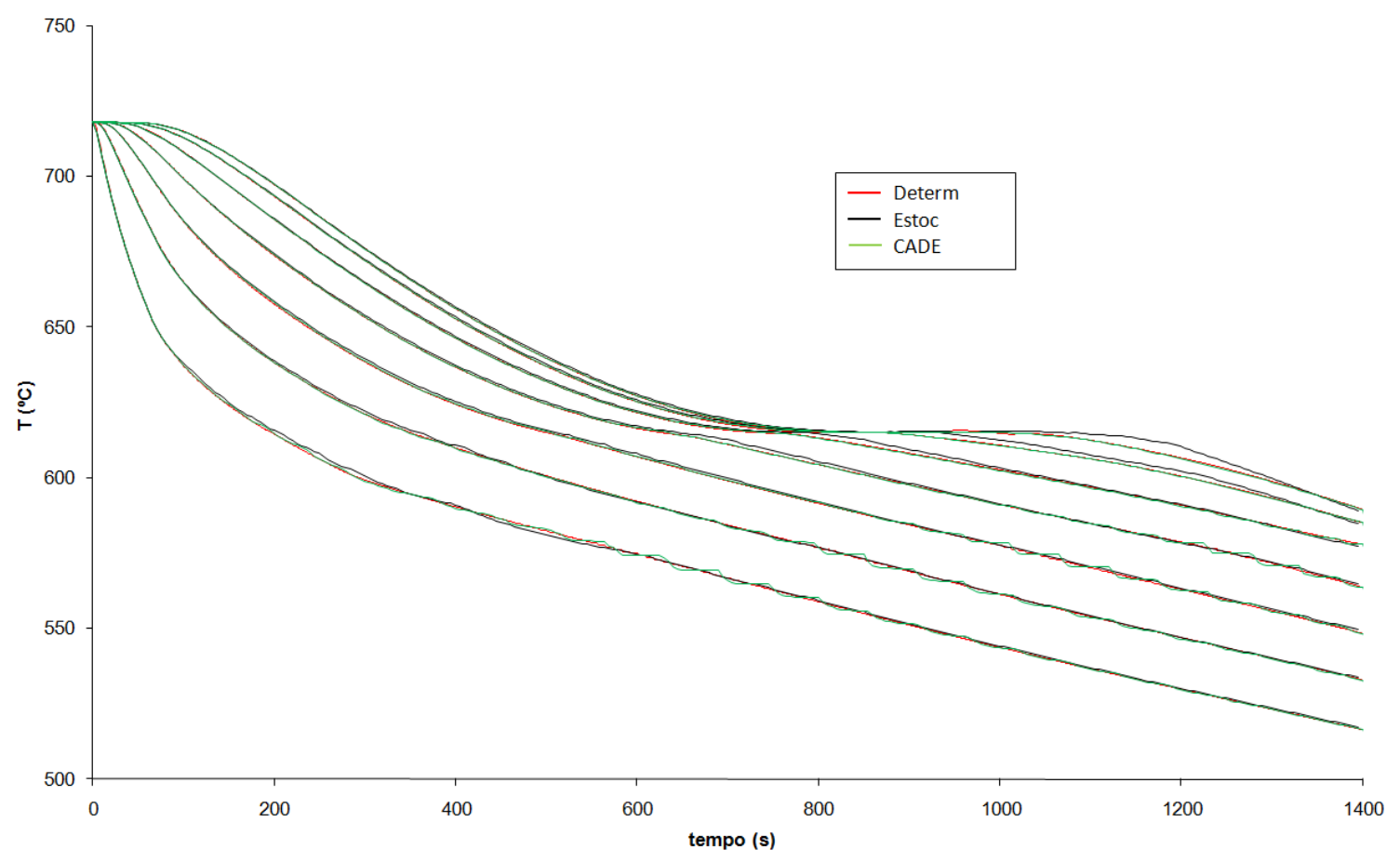

Figura 118 - Curvas de resfriamento previstas pelos modelos estocástico (Estoc), determinístico (Determ) e o novo modelo proposto (CADE) para o caso de referência nas posições de 20,40,60,80,100,120 e 140 definidos a partir da superfície inferior do domínio. 


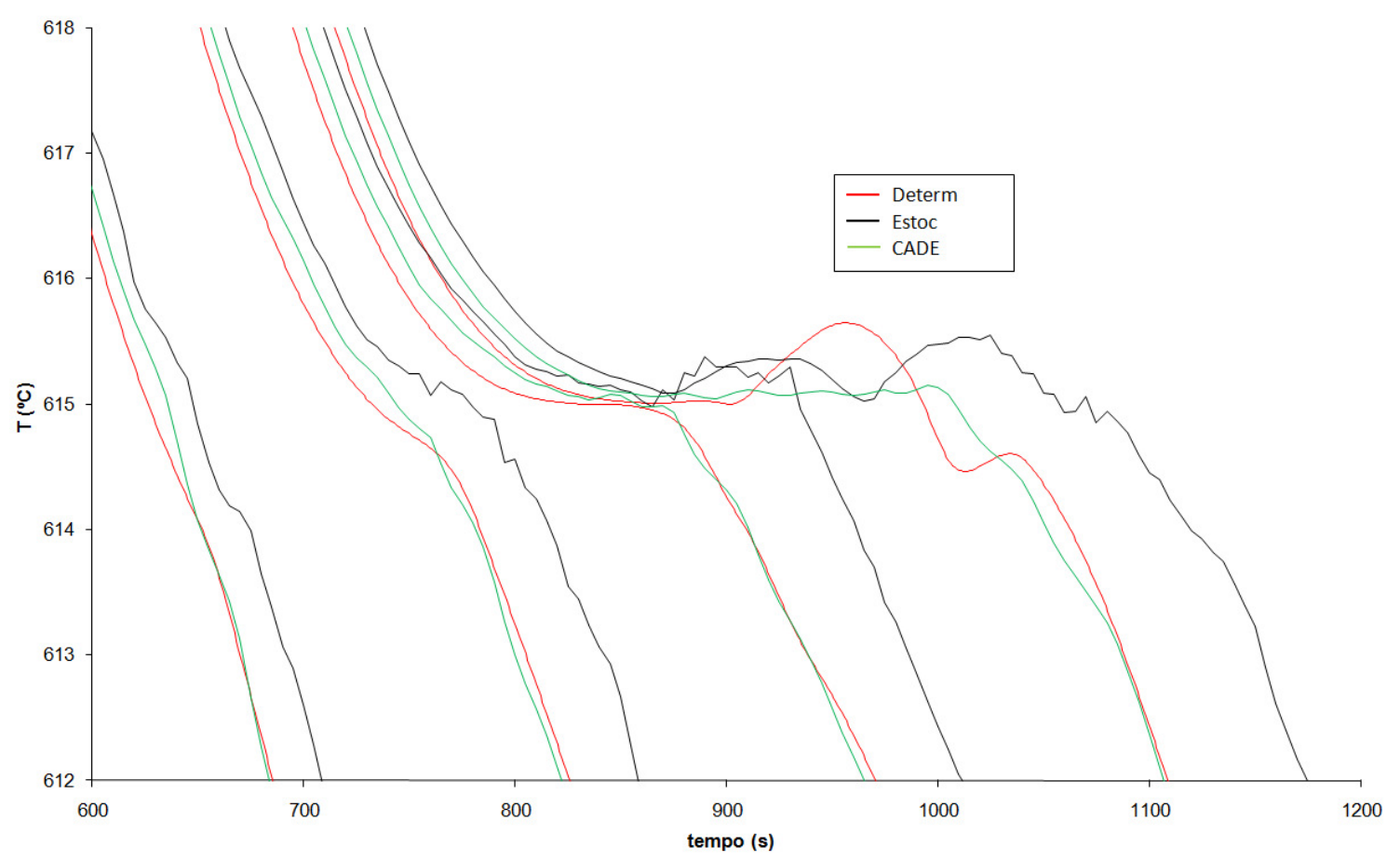

Figura 119 - Oscilações apresentadas nas curvas de resfriamento para uma região ampliada da Figura 118.

Para a comparação das posições da transição colunar-equiaxial (CET) e do comportamento da mesma em função da variação do super-resfriamento para nucleação, foi realizado o mesmo tipo de teste já apresentado no item 5.2.3. Neste caso, utilizaram-se as propriedades e parâmetros de simulação definidos para o caso de referência, porém variou-se o super-resfriamento para nucleação no interior do domínio no intervalo de 0 a $5 \mathrm{~K}$. As macroestruturas obtidas com a utilização do novo modelo e as respectivas regiões da CET previstas estão mostradas na Figura 120, juntamente com a Figura 69 para comparação entre as previsões dos diversos modelos. 


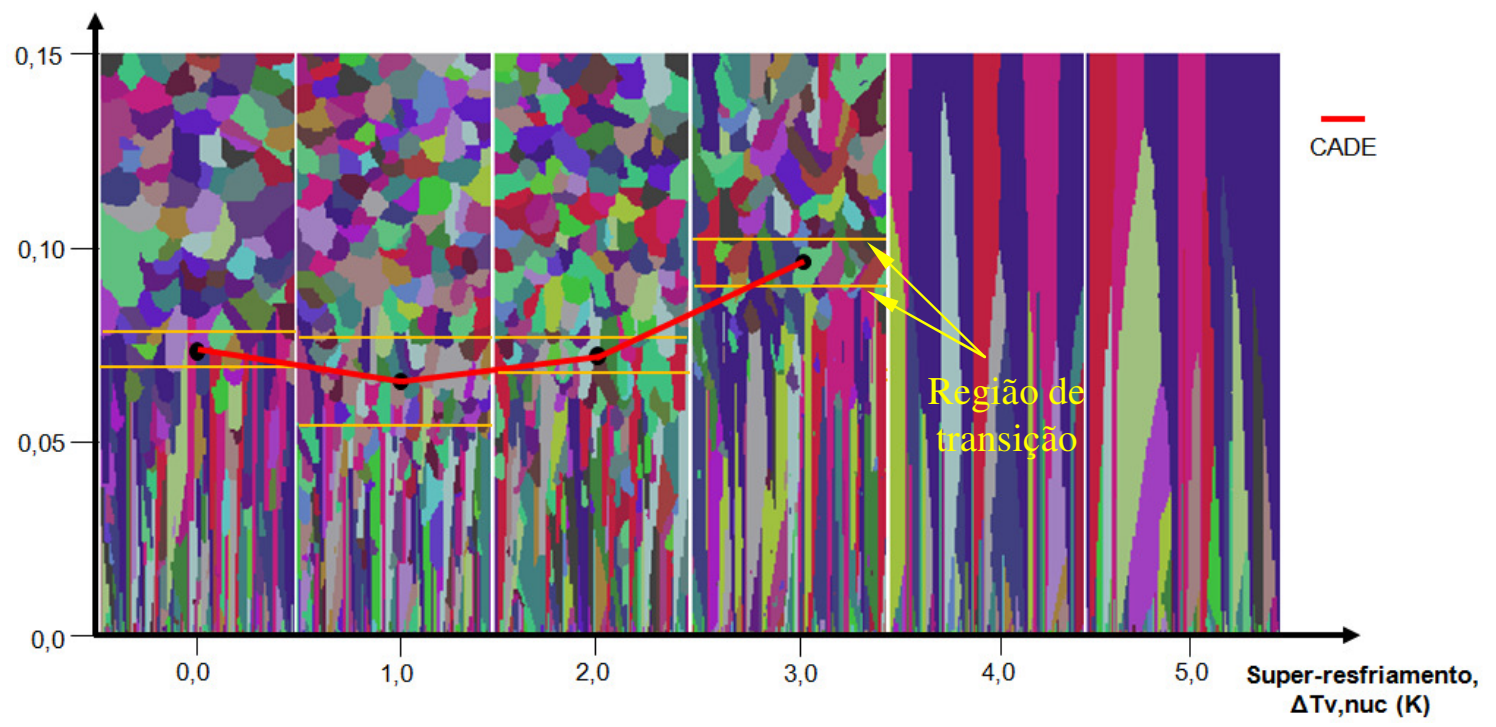

(a)

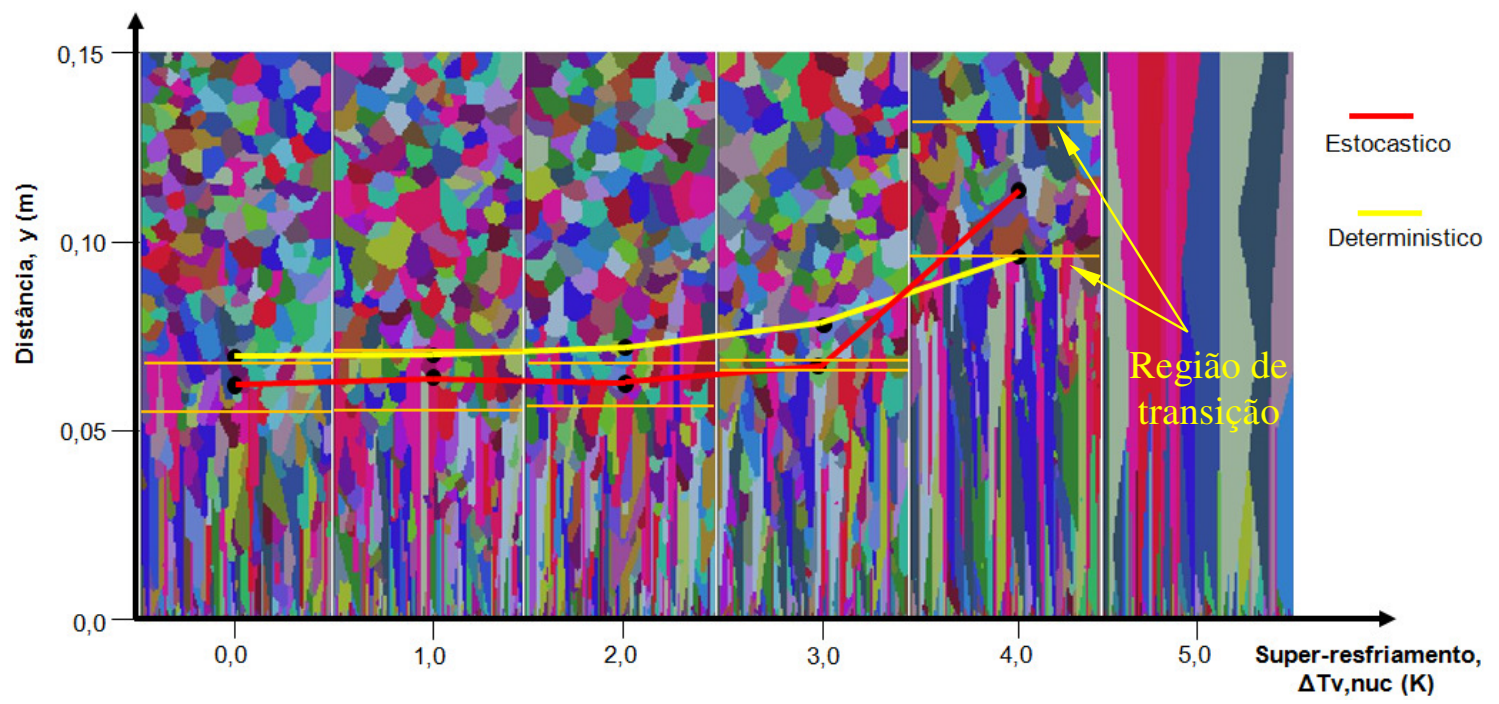

(b)

Figura 120 - Posição da CET em função do super-resfriamento para nucleação no interior do domínio para: (a) novo modelo proposto (CADE) e as macroestruturas simuladas; (b) modelo determinístico com bloqueio de soluto (Deterministico), e modelo estocástico (Estocastico) juntamente com a macroestrutura obtida.

Comparando-se os modelos nota-se que as posições da CET previstas pelo novo modelo proposto estão próximas às previstas pelos outros modelos até o super-resfriamento para nucleação de $2 \mathrm{~K}$. O novo modelo apresentou uma zona colunar mais extensa no super-resfriamento de 3K, apesar de se encontrar dentro da faixa de aleatoriedade investigada no item 5.2.2 de aproximadamente $1,5 \mathrm{~cm}$, e não mostrou qualquer CET para $4 \mathrm{~K}$, diferentemente dos outros modelos. Para se 
investigar esta diferença, o mesmo estudo já realizado para os outros modelos (Figura 66), no qual a evolução da frente colunar e seu super-resfriamento são acompanhados em relação ao tempo até o momento da CET, foi realizado para o modelo CADE e seus resultados apresentados na Figura 121, juntamente com a Figura 66 para a comparação entre os modelos.

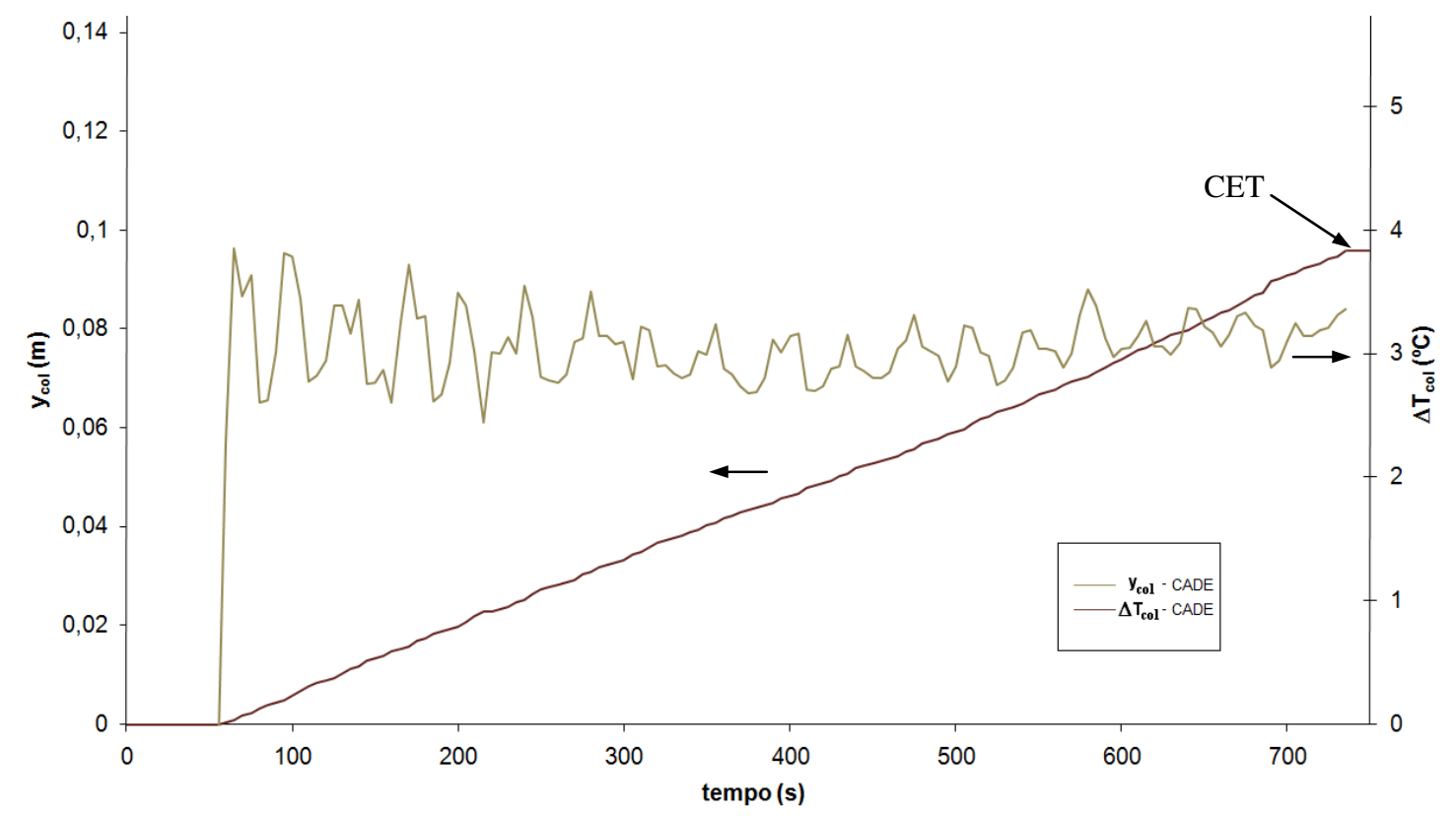

(a)

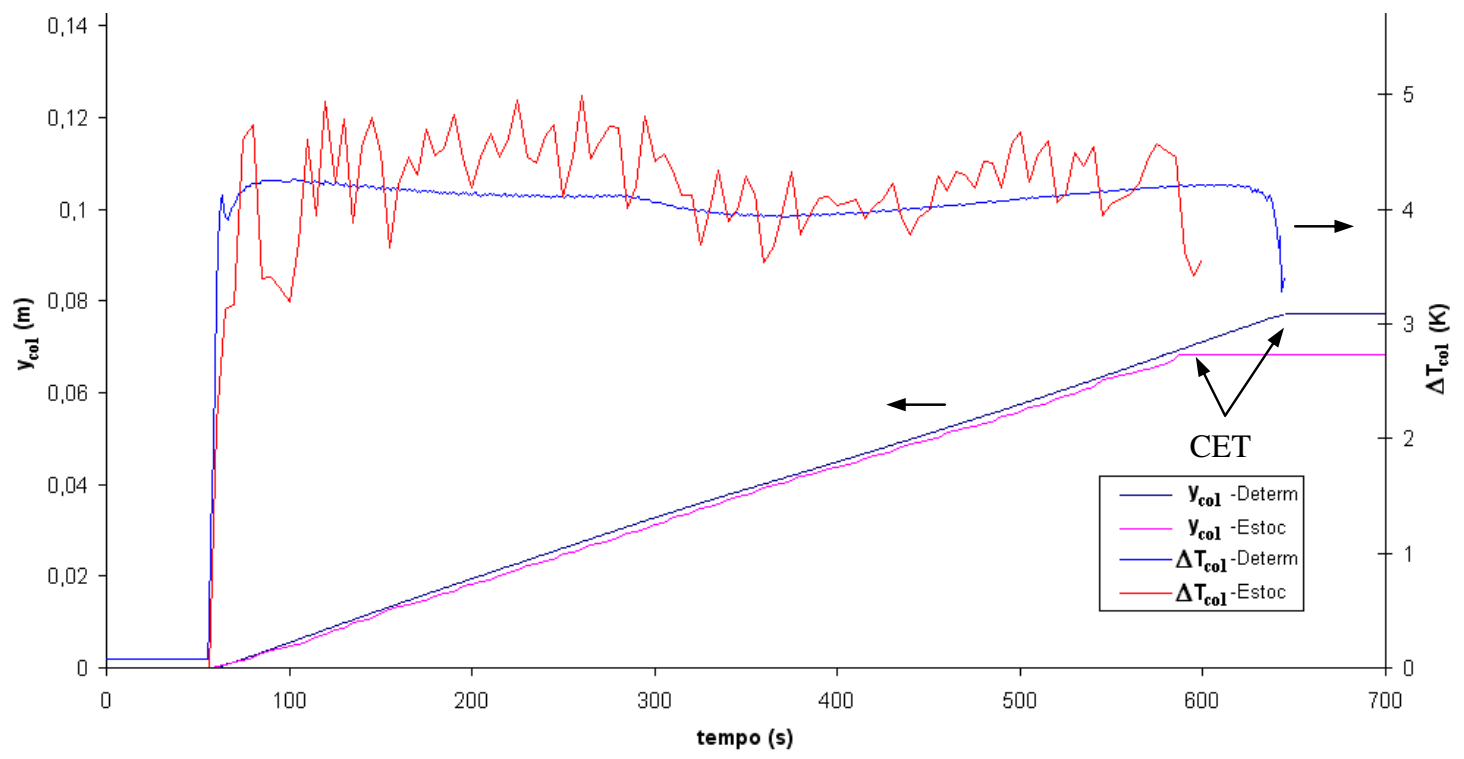

(b)

Figura 121 - Posição ( $\left.\mathrm{y}_{\text {col }}\right)$ e super-resfriamento da frente colunar $\left(\Delta T_{c o l}\right)$ previstos pelos modelos: (a) CADE; (b) Estocástico (Estoc) e determinístico (Determ). 
Primeiramente com a análise dos dados nota-se que o modelo CADE apresentou o mesmo tipo de oscilação nos valores de super-resfriamento da frente colunar já verificado no modelo estocástico e tal semelhança é explicada pela utilização do autômato celular em ambos os modelos. Verifica-se também que o super-resfriamento da frente colunar no modelo CADE é menor que nos outros dois modelos estudados e sua média teve o valor de $3,1^{\circ} \mathrm{C}$, estando em torno de $1,0^{\circ} \mathrm{C}$ menor que os outros modelos. Este fato faz com que grãos que possuam um superresfriamento para nucleação maior não possam nuclear à frente da frente colunar e barrá-la, tornando a estrutura totalmente colunar para super-resfriamentos para nucleação maiores.

Conforme também observado na Figura 118 as curvas de temperatura apresentaram boa aderência entre os modelos e, desta forma, podemos considerar que os gradientes de temperatura apresentados pelos modelos também são próximos e, com isso, podemos concluir que a região de liquido super-resfriado entre a frente colunar no modelo CADE e a isoterma liquidus é menor que nos outros modelos. Este fato faz com que a probabilidade de um grão que nucleie nesta região super-resfriada cresça até um tamanho capaz de bloquear mecanicamente a frente de crescimento seja menor se comparada aos outros modelos. Com isso, a ocorrência da CET tende a ser mais tardia, conforme observado na Figura 120.

\subsubsection{Comparação com os Modelos Determinístico e Estocástico (2D)}

Neste item procurou-se demonstrar a possibilidade de utilização do novo modelo proposto (CADE) na simulação de condições bidimensionais de extração de calor com previsão da região da CET. Escolheu-se um caso para simulação já estudado por Martorano e Biscuola (2006), que adotaram as condições de solidificação utilizadas por Wang e Beckermann (1994) para a liga Al-3\%Cu. Martorano e Biscuola (2006) utilizaram um domínio quadrado com extração de calor pela fronteira esquerda e inferior, simulando assim uma situação bi-dimensional de extração de calor, conforme demonstrado esquematicamente na Figura 122. É importante ressaltar que, nesta condição bidimensional, métodos extremamente complexos de acompanhamento da frente colunar devem ser implementados para permitir que os modelos determinísticos sejam capazes de prever a região da CET. 
As propriedades e parâmetros utilizados por Martorano e Biscuola (2006) e Wang e Beckermann (1994) estão listados na Tabela 17, Tabela 18 e Tabela 19.

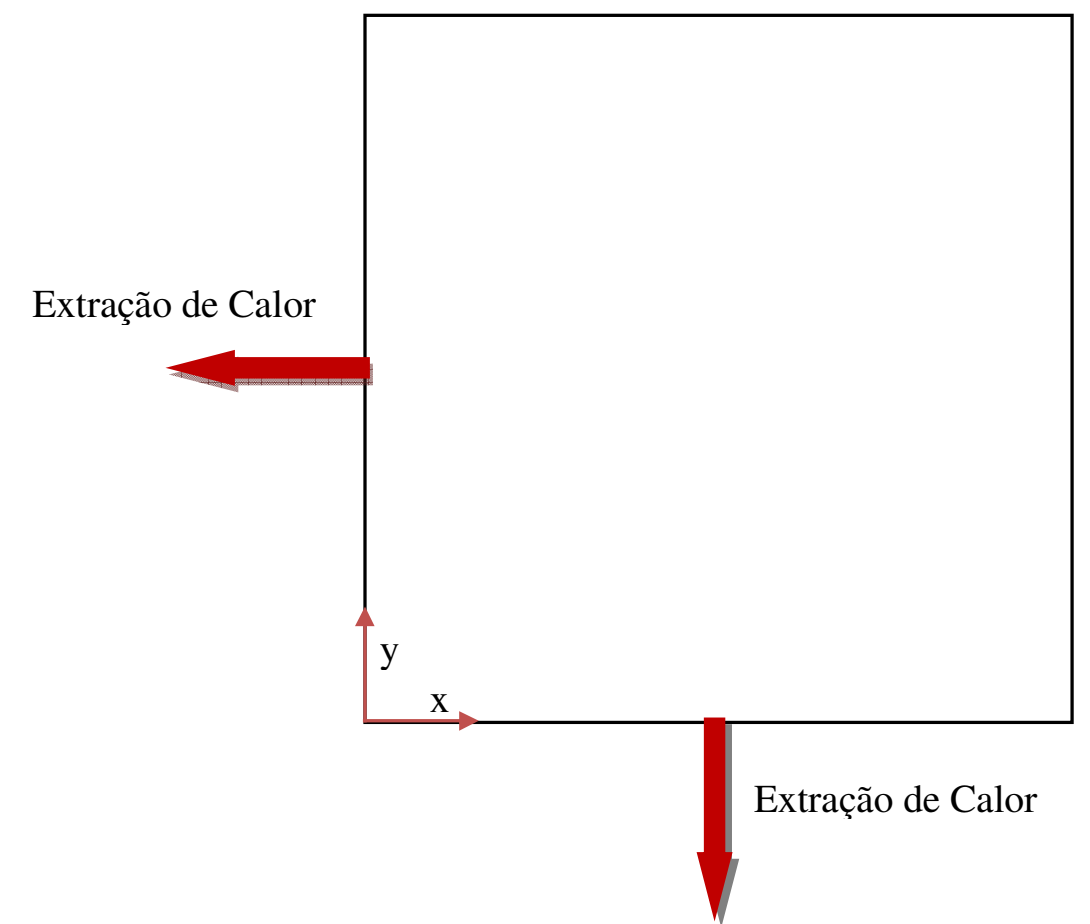

Figura 122 - Representação do domínio e sistema de coordenadas utilizados para a simulação de transferência de calor bidimensional.

As equações para as condições de contorno apresentadas esquematicamente na Figura 122 foram:

$$
\begin{gathered}
\frac{\partial T}{\partial x}=0 \text { contorno lateral direito } \\
\kappa \frac{\partial T}{\partial x}=h\left(T-T_{W}\right) \quad \text { contorno lateral esquerdo } \\
\frac{\partial T}{\partial y}=0 \text { contorno superior } \\
\kappa \frac{\partial T}{\partial y}=h\left(T-T_{W}\right) \text { contorno inferior }
\end{gathered}
$$


Tabela 17- Propriedades da liga Al-3\%Cu utilizada na simulação de Martorano e Biscuola (2006).

\begin{tabular}{cc|cc}
\hline Propriedade & Valor & Propriedade & Valor \\
\hline$\rho\left(\mathrm{kg} \mathrm{m}^{-3}\right)$ & 2550,0 & $C_{0}$ (\%peso) & $3 \%$ \\
\hline $\mathrm{k} \mathrm{(-)}$ & 0,17 & $\mathrm{C}_{\mathrm{p}}\left(\mathrm{J} \mathrm{kg}^{-1} \mathrm{~K}^{-1}\right)$ & $1,3 \mathrm{E} 3$ \\
\hline$\kappa^{L}\left(\mathrm{~W} \mathrm{~m}^{-1} \mathrm{~K}^{-1}\right)$ & 77,0 & $T_{L}(\mathrm{~K})$ & 922,89 \\
\hline$\kappa^{S}\left(\mathrm{~W} \mathrm{~m}^{-1} \mathrm{~K}^{-1}\right)$ & 153,0 & $T_{\text {eut }}(\mathrm{K})$ & 821,2 \\
\hline$\Delta H_{f}\left(\mathrm{~J} \mathrm{~kg}^{-1}\right)$ & $4,0 \mathrm{E} 5$ & $T_{f}(\mathrm{~K})$ & 933,0 \\
\hline$D_{l}\left(\mathrm{~m}^{2} \mathrm{~s}^{-1}\right)$ & $5,0 \times 10^{-9}$ & $m_{l}\left(\mathrm{~K}_{0 \mathrm{Si}}^{-1}\right)$ & $-3,37$ \\
\hline$\Gamma\left(\mathrm{m} \mathrm{K}^{-1}\right.$ & $2,41 \times 10^{-7}$ & & \\
\hline
\end{tabular}

Tabela 18- Parâmetros de simulação utilizados por Martorano e Biscuola (2006).

\begin{tabular}{c|c}
\hline Parâmetro & Valor \\
\hline Dimensão do domínio $(\mathrm{m})$ & $0,1 \times 0,1 \mathrm{~m}$ \\
\hline Passo de tempo $(\mathrm{s})$ & 0,001 \\
\hline Superaquecimento $(\mathrm{K})$ & 20,0 \\
\hline Temperatura do molde $(\mathrm{K})$ & 298,0 \\
\hline $\mathrm{h}\left(\mathrm{W} \mathrm{m}^{-2} \mathrm{~K}^{-1}\right)$ & 65,0 \\
\hline Malha para o CA & $4 \times 4$ \\
\hline Malha de VF & $42 \times 42$ \\
\hline $\mathrm{h}\left(\mathrm{W} \mathrm{m}^{-2} \mathrm{~K}^{-1}\right)$ & 65
\end{tabular}

Tabela 19- Parâmetros para distribuição dos substratos para nucleação utilizados por Martorano e Biscuola (2006) (os subscritos indicam a posição de aplicação destes parâmetros, sendo: $V$ no interior e $S$ nas bordas esquerda e inferior do domínio).

\begin{tabular}{cccccc}
\hline$\Delta T_{S, \text { nuc }}[\mathrm{K}]$ & $\Delta T_{S, \sigma}[\mathrm{K}]$ & $n_{S, \max }\left[\mathrm{m}^{-1}\right]$ & $\Delta T_{V, n u c}[\mathrm{~K}]$ & $\Delta T_{V, \sigma}[\mathrm{K}]$ & $n_{V, \max }\left[\mathrm{m}^{-2}\right]$ \\
\hline 0,0 & 0,0 & 1700 & 0,0 & 0,0 & 2700 \\
\hline
\end{tabular}

Primeiramente, o método para a identificação da posição da transição colunar-equiaxial apresentado no item 4.2, e que utiliza a razão de aspecto de cada grão, foi aplicado na macroestrutura obtida por Martorano e Biscuola (2006). Na Figura 123 pode-se verificar a macroestrutura prevista pelos autores ao lado de um gráfico de superfície mostrando os valores de razão de aspecto obtidos para todos 
os volumes finitos. Finalmente observa-se a sobreposição dos dados e a definição da região da CET, representada pela cor verde clara.

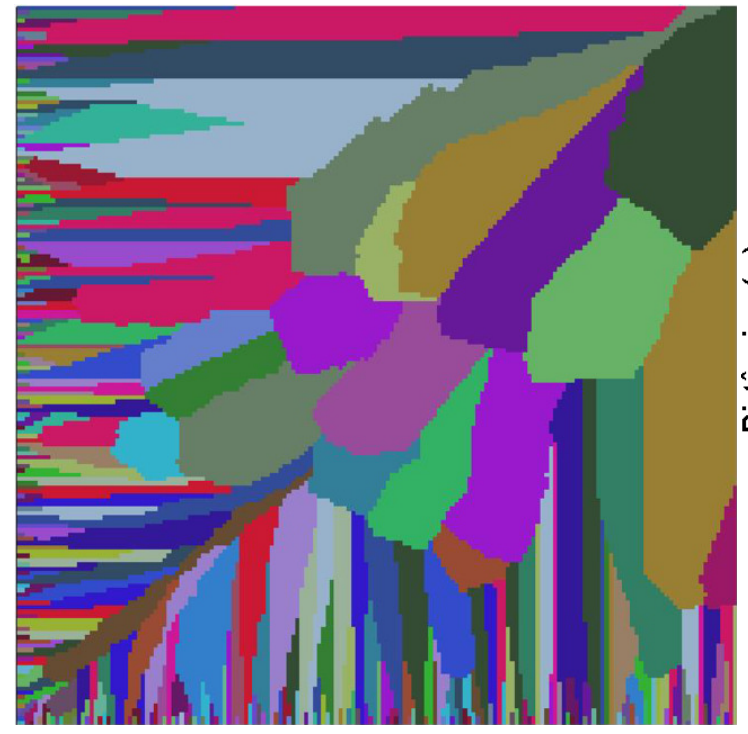

(a)

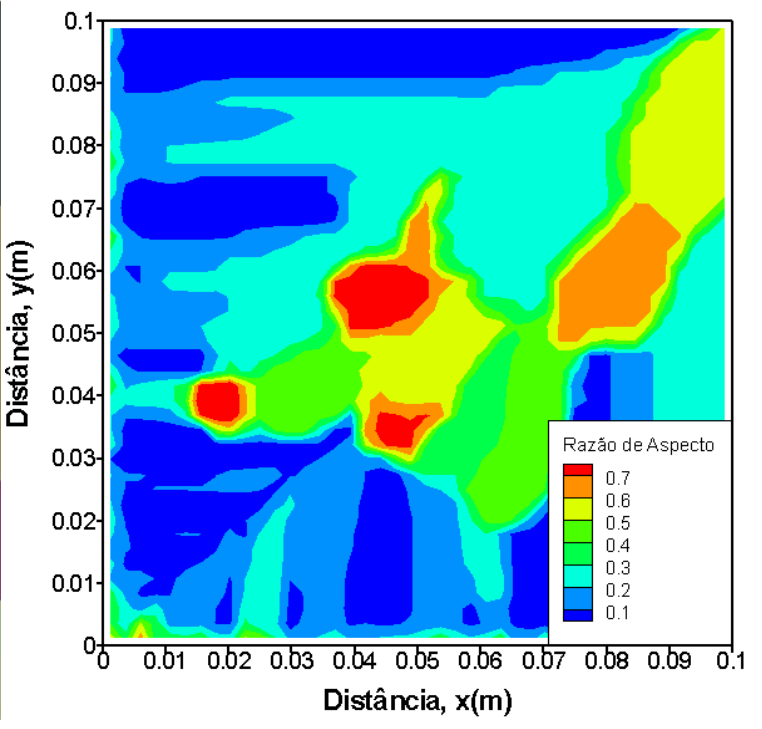

(b)

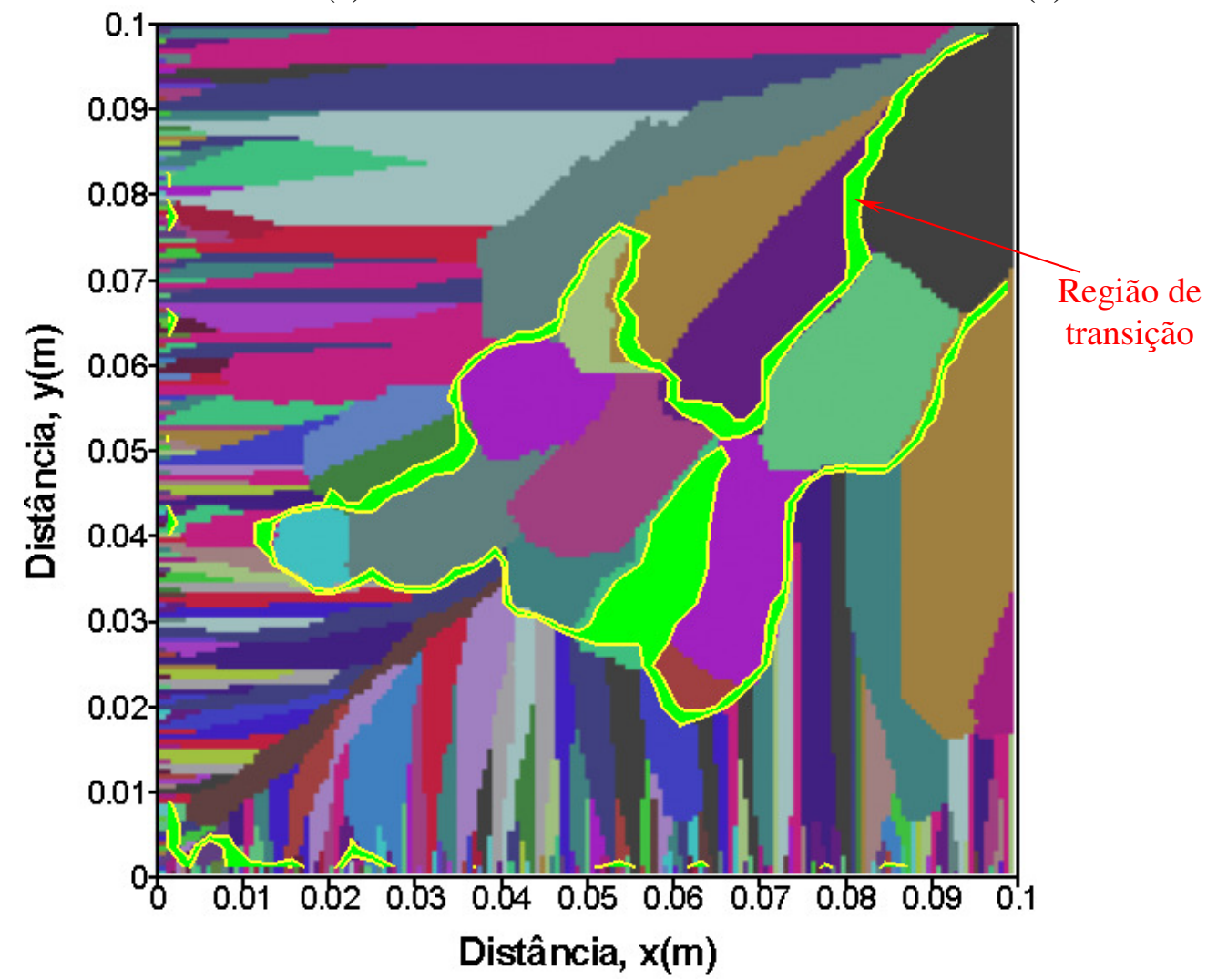

(c)

Figura 123 - (a) Macroestrutura obtida por Martorano e Biscuola (2006) utilizando um modelo estocástico; (b) mapa de razão de aspecto; (c) sobreposição dos dados e definição da posição da CET. 
Na Figura 124 podemos verificar os resultados de definição da CET obtidos pelo modelo apresentado por Martorano e Biscuola (2006), denominado Model, o modelo proposto por Wang e Beckermann (1994), denominado W-B, sobrepostos na macroestrutura simulada pelos autores.

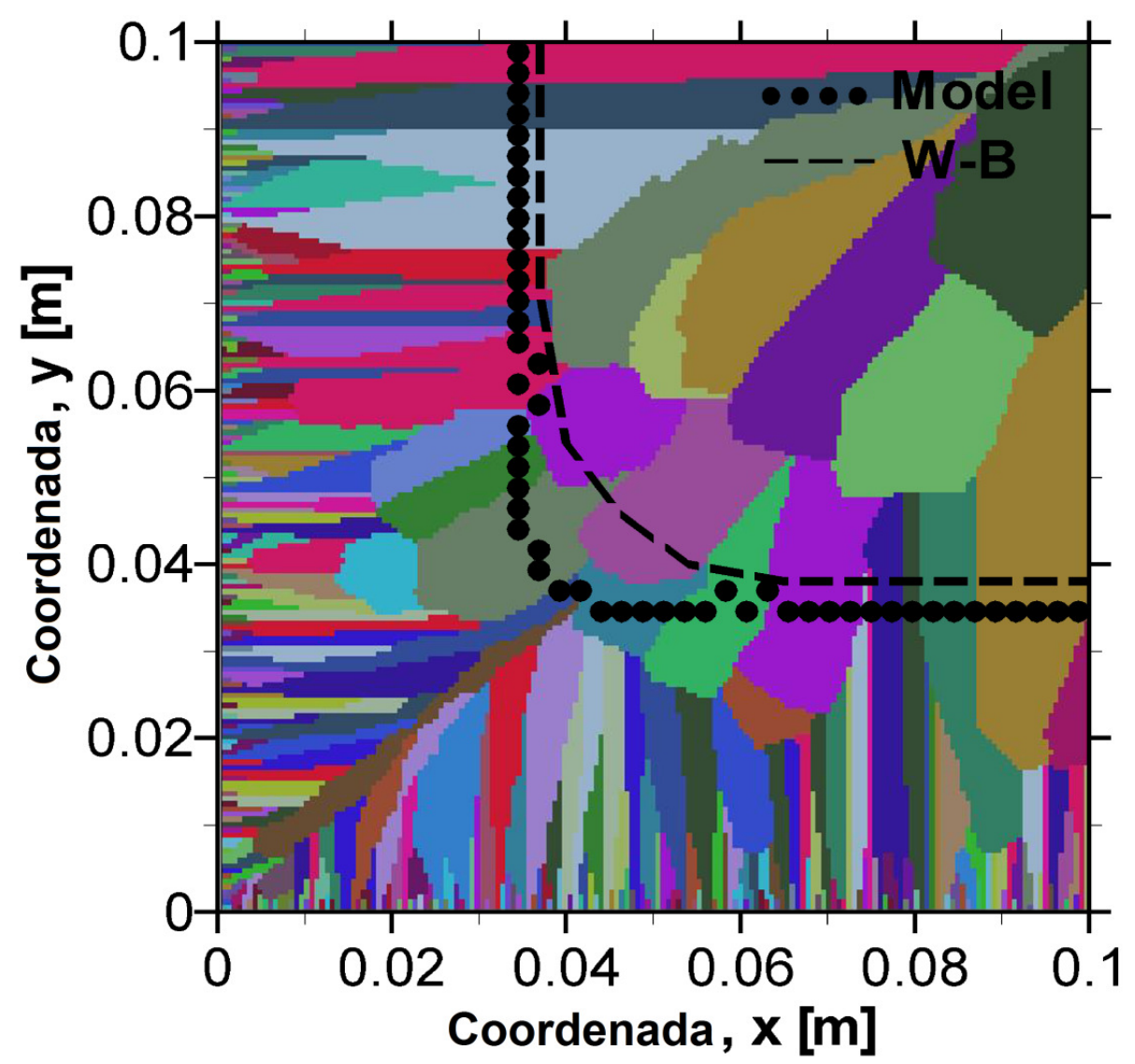

Figura 124 - Posição da CET definida pelo modelo proposto por Martorano e Biscuola (2006) - Model; Wang e Beckermann (1994) - W-B; sobrepostos na macroestrutura simulada por Martorano e Biscuola (2006).

Após comparação das posições de CET, nota-se que o modelo de razão de aspecto proposto delineia a interface dos grãos, enquanto os outros modelos apresentam retas que atravessam todos os grãos. Este comportamento não está fisicamente correto, uma vez que a CET é definida como sendo a transição entre grãos colunares e equiaxiais e, desta forma, deve ser delineada pelos contornos dos grãos. 
Para verificar a capacidade do novo modelo em simular situações de transferência de calor bi-dimensionais, o mesmo caso simulado por Martorano e Biscuola (2006) foi utilizado pelo novo modelo, empregando-se os parâmetros numéricos mostrados na Tabela 20. Na Figura 125 está apresentada a macroestrutura prevista pelo novo modelo proposto, juntamente com a posição da CET.

Tabela 20- Parâmetros de simulação utilizados por Martorano e Biscuola (2006).

\begin{tabular}{c|c}
\hline Parâmetro & Valor \\
\hline Passo de tempo (s) & 0,001 \\
\hline Malha para o CL & $1 \times 1$ \\
\hline Malha para o CA & $10 \times 10$ \\
\hline Malha de VF & $20 \times 20$ \\
\hline
\end{tabular}




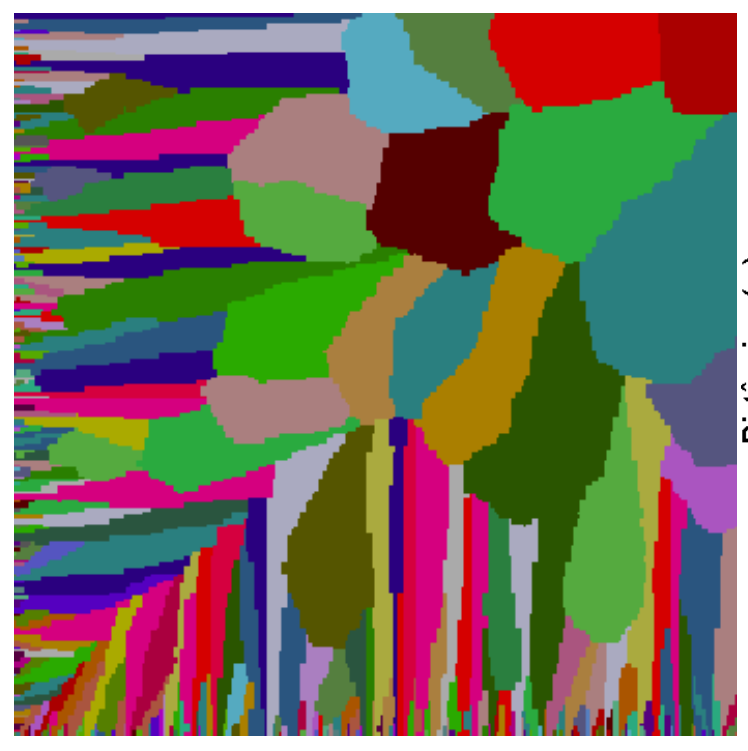

(a)

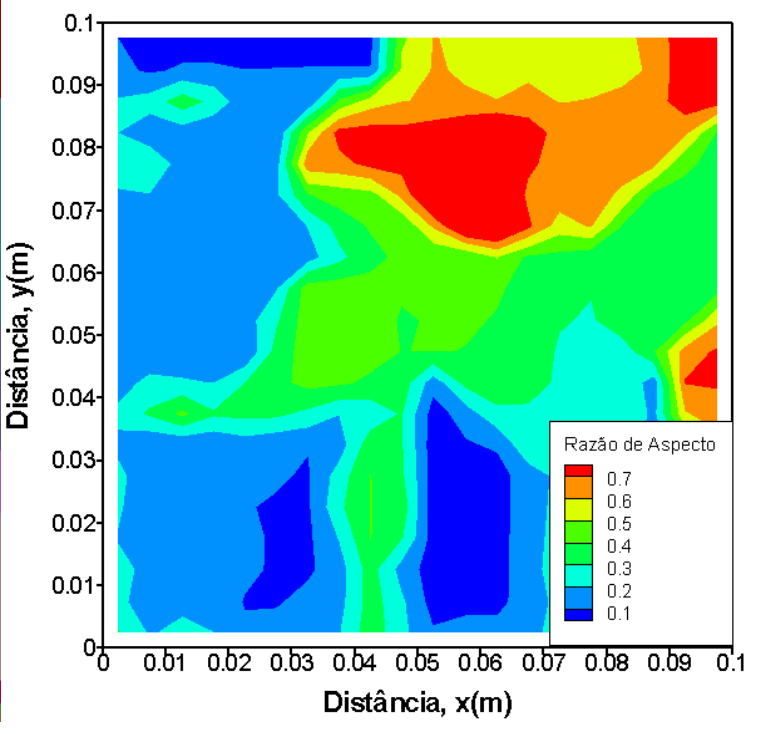

(b)

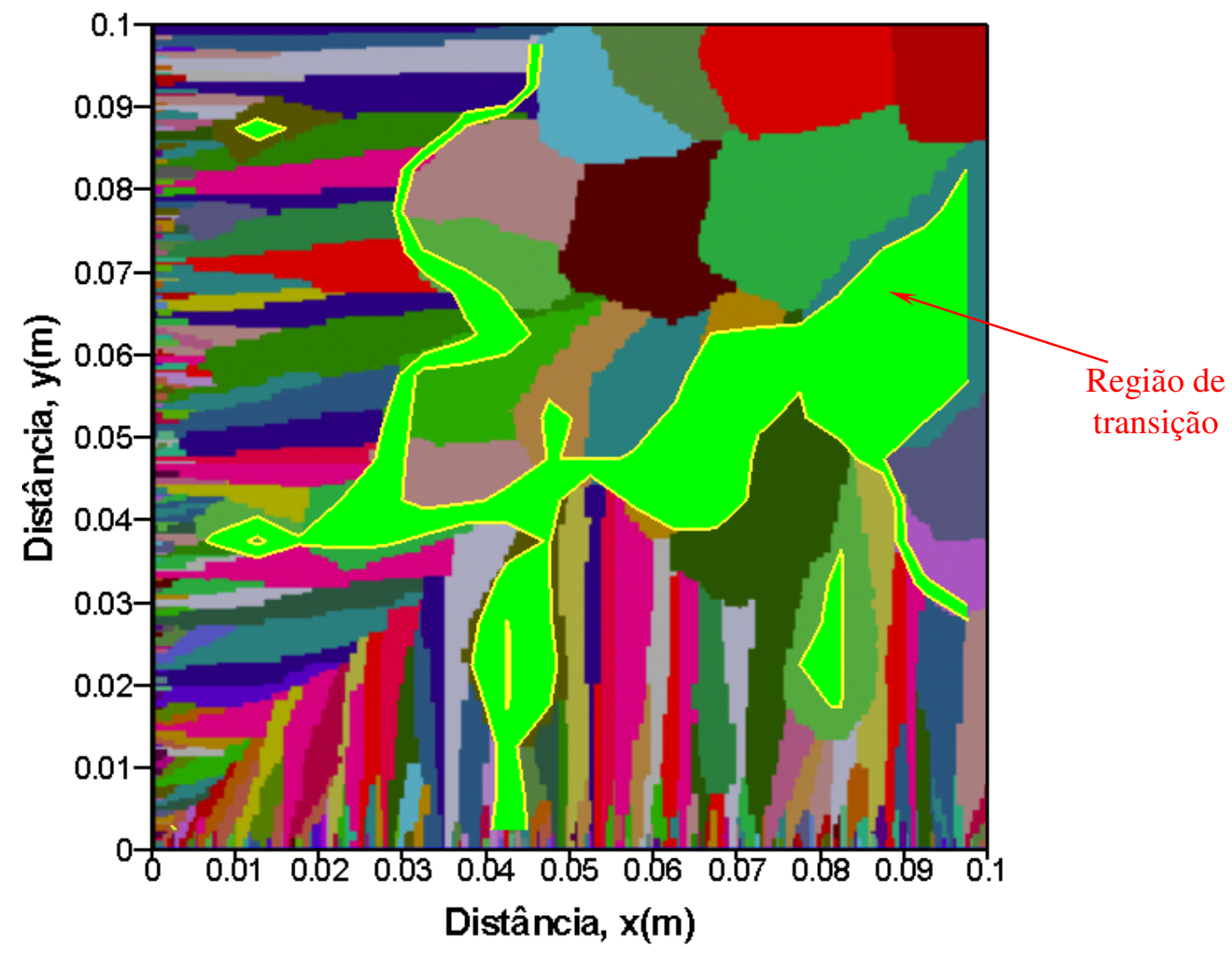

(c)

Figura 125 - (a) Macroestrutura simulada pelo novo modelo; (b) mapa de razão de aspecto; (c) sobreposição dos dados e definição da posição da CET. 
Na macroestrutura calculada pelo novo modelo (Figura 125 (c) ) é possível verificar os grãos colunares aflorando das superfícies onde se é extraído o calor, e rumando na direção do interior do domínio. É possível notar também nos grãos entre as posições $0 \times 0$ e 0,04×0,04 na região da diagonal do domínio quadrado um certo entortamento dos grãos direção contrária a extração de calor.

Verifica-se na macroestrutura calculada pelo novo modelo a presença de grãos equiaxiais com um formato mais arredondado em comparação à macroestrutura obtida pelo modelo estocástico utilizado por Martorano e Biscuola (2006), sendo este fato refletido no gráfico de superfície de razão aspecto apresentado (Figura 125 (b)). No caso do novo modelo o gráfico apresenta uma maior quantidade de regiões em vermelho e laranja, representando regiões com razão de aspecto mais próximas de 1, que representam um grão mais esférico.

Novamente, pode-se concluir a correta implementação do novo modelo proposto e sua capacidade em prever as macroestruturas e conseqüentemente a CET sem a necessidade de modelos extras para acompanhar a frente de crescimento, enquanto utiliza as mesmas equações já consagradas para os modelos determinísticos. Pode-se verificar também a versatilidade do modelo em simular as várias situações de transferência de calor: 0D, 1D e 2D. 


\section{6 - CONCLUSÕES}

Diante dos resultados obtidos e das discussões apresentadas, pode-se estabelecer as seguintes conclusões:

1) As curvas de temperatura previstas pelo modelo estocástico tradicional e pelo modelo determinístico de Martorano, Beckermann e Gandin (2003) em uma situação de transferência de calor unidirecional apresentam boa concordância.

2) $O$ critério proposto para identificação da região de transição colunar equiaxial (CET) a partir do formato dos grãos das macroestruturas calculadas possibilita a comparação das previsões desta região obtidas pelo modelo estocástico tradicional e por modelos determinísticos.

3) O tamanho da zona colunar e a ocorrência da CET são favorecidos pelo aumento da densidade de partículas substratos no interior do líquido e pela diminuição do super-resfriamento médio para nucleação nestes substratos.

4) As posições da CET previstas pelo modelo estocástico tradicional e pelo modelo determinístico de Martorano, Beckermann e Gandin (2003) são semelhantes quando se utiliza o mesmo modelo de nucleação. No entanto, estas mesmas previsões obtidas por estes modelos implementados na sua forma original, ou seja, com nucleação instantânea (modelo determinístico) e nucleação contínua normal (estocástico), mostram discrepâncias significativas.

5) O tamanho da zona colunar prevista pelo modelo determinístico de Hunt modificado, com fração de bloqueio de 0,49, é, em geral, maior que a prevista pelo modelo estocástico tradicional. No entanto, quando a fração de bloqueio é alterada para 0,2 a concordância entre os modelos é excelente. Esta fração de bloqueio de 0,2 pode ser razoavelmente explicada por uma proposta de mecanismo (modelo geométrico) apresentada neste trabalho de como os grãos equiaxiais impedem o crescimento dos grãos colunares. 
6) Apesar do modelo estocástico tradicional não considerar o transporte de soluto, a evolução da posição e do super-resfriamento da frente colunar com o tempo prevista por este modelo e pelo modelo determinístico de Martorano, Beckermann e Gandin (2003) mostram-se semelhantes.

7) O perfil de fração de sólido obtido pelo modelo estocástico tradicional não concorda com o perfil obtido através da equação de Scheil, apesar da hipótese de Scheil ter sido usada na construção do modelo.

8) O perfil de fração de sólido calculado pelo modelo determinístico (Martorano; Beckermann; Gandin, 2003) apresenta boa aderência com o modelo de Scheil nas regiões onde as concentrações de soluto no líquido interdendrítico e no líquido extradendrítico são próximas.

9) A utilização do modelo de nucleação com super-resfriamentos críticos que obedecem a uma distribuição normal para um desvio padrão maior do que zero ( $\Delta T_{V, \sigma}>0$ ) diminui as oscilações ('wiggles') apresentadas nas curvas de resfriamento e causa um aumento no tamanho da zona colunar presente nas macroestruturas simuladas pelo modelo estocástico tradicional.

10)Os resultados do novo modelo híbrido proposto (CADE) apresentam boa concordância com os resultados do modelo determinístico proposto por Martorano; Beckermann e Gandin (2003) ao se utilizar envelopes cúbicos.

11)Apesar das discrepâncias observadas na evolução da concentração de área interfacial entre envelopes e líquido extradendrítico, da concentração de soluto no líquido extradendrítico e da fração volumétrica de envelopes prevista pelo modelo CADE e determinístico (Martorano; Beckermann; Gandin, 2003), as curvas de fração de sólido apresentam uma boa concordância e as curvas de temperatura mostram uma diferença máxima de 2,5K (0,3\%).

12)O novo modelo proposto (CADE) é capaz de simular a diminuição da concentração de área interfacial de envelopes causada pelo encontro entre os grãos ("impingement") sem a necessidade de utilização de correções adicionais, como por exemplo a correção de Avrami. 
13)O novo modelo proposto (CADE) foi utilizado em condições de transferência de calor unidirecional e bidirecional, mostrando-se capaz de prever a região de transição colunar-equiaxial sem a necessidade de qualquer alteração em seu algoritmo ou critério extra de bloqueio dos grãos colunares.

14)As posições da região de transição colunar-equiaxial extraídas das macroestruturas calculadas em condições de transferência de calor uni e bidirecional através do critério do fator de forma proposto no presente trabalho concordam razoavelmente com as posições extraídas visualmente.

15)Assim como o modelo estocástico tradicional, o modelo proposto no presente trabalho (CADE) é capaz de prever a macroestrutura de grãos, porém com a vantagem de permitir a utilização das consagradas equações empregadas nos modelos determinísticos e os seus esquemas numéricos de acoplamento. 


\section{7 - REFERÊNCIAS BIBLIOGRÁFICAS}

ALLEN T. Particle size measurement. New York: Chapman and Hall, 1981. p. 130135.

AVRAMI, M. Kinetics of Phase Change. I. Journal of Chemical Physics, v. 7, p. 1103-1112, dezembro 1939.

AVRAMI, M. Kinetics of Phase Change. II. Journal of Chemical Physics, v. 8, p. 212-224, fevereiro 1940.

BANASZEK, J.; McFADDEN, S.; BROWNE, D. J.; STURZ, L.; ZIMERMANN, G. Natural convection and columnar-to-equiaxed transition prediction in a front-tracking model of alloy solidification. Metallurgical and Materials Transaction A, v. 38A, p. 1476-1484, julho 2007.

BECKERMANN, C.; WANG, C. Y. Equiaxed dendritic solidification with convection: Part III. Comparisons with $\mathrm{NH}_{4} \mathrm{Cl}-\mathrm{H}_{2} \mathrm{O}$ experiments. Metallurgical and Materials Transactions A, v. 27A, p. 2784-2795, setembro 1996.

BELTRAN-SANCHEZ, L.; STEFANESCU, D. M. Growth of solutal dendrites: a cellular automaton model and its quantitative capabilities. Metallurgical and Materials Transaction A, v. 34A, p. 367-382, fevereiro 2003.

BOWER, T. F.; FLEMINGS, M. C. Formation of the chill zone in ingot solidification. Transactions of the Metallurgical Society of AIME, v. 239, p.216-219, fevereiro 1967.

BROWN, S. G. R.; SPITTLE, J. A.; JARVIS, D. J.; WALDEN-BEVAN R. Numerical determination of liquid flow permeabilities for equiaxed dendritic structures. Acta Materialia, v. 50, p. 1559-1569, 2002. 
BROWNE, D. J. A new equiaxed solidification predictor from a model of columnar growth. ISIJ International, v. 45, no. 1, p. 37-44, 2005.

BROWNE, D. J.; HUNT, J. D. A fixed grid front-tracking model of the growth of a columnar front and an equiaxed grain during solidification of an alloy. Numerical Heat Transfer, Part B, v. 45, p. 395-419, 2004.

CARLSON, K. D.; LIN, Z.; BECKERMANN, C.; MAZURKEVICH, G.; SCHNEIDER, M. Modeling of porosity formation in aluminum alloys. Materials Science Forum, v. 519-521, p. 1699-1706, 2006.

CHALMERS, B. The structure of ingots. The Journal of the Australian Institute of Metals, v. 8 no. 3, p. 255-263, agosto 1963.

CHALMERS, B. The Structure of cast metals. In: Principles of solidification. New York: John Wiley e Sons, 1964. p. 265-268.

$\mathrm{CHO}$, I.-S.; HONG, C.-P. Modeling of microstructural evolution in squeeze casting of an Al-4.5mass\%Cu alloy. ISIJ International, v. 37 no. 11, p. 1098-1106, 1997.

CHO, S.-H; OKANE, T; UMEDA, T. CA-DFD analysis of nucleation parameter effects on the grain structures of castings. Internacional Journal of Cast Metals Research, v. 13 no. 6, p. $327-335,2001$.

DONG, H. B.; LEE, P. D. Simulation of the columnar-to-equiaxed transition in directionally solidified Al-Cu alloys. Acta Materialia, v. 53, p. 659-668, 2005.

DONG, H. B.; YANG, X. L.; LEE P. D. Simulation of equiaxed growth ahead of an advancing columnar front in directionally solidified Ni-based superalloys. Journal of Materials Science, v. 39, p. 7207-7212, 2004.

FLOOD, S. C.; HUNT, J. D. Columnar to equiaxed transition. In: Casting: Metals Handbook. Ohio: ASM International, 1988. v. 15, p.130-136. 
FLOOD, S. C.; HUNT J. D. Columnar and equiaxed growth : I. A model of a columnar front with a temperature dependent velocity. Journal of Crystal Growth, v. 82, p. 546-551, 1987a.

FLOOD, S. C.; HUNT, J. D. Columnar and equiaxed growth: II. Equiaxed growth ahead of a columanr front. Journal of Crystal Growth, v. 82, p. 552-560, 1987b.

FORTUNA, A. O. Técnicas Computacionais para dinâmica dos fluídos: Conceitos Básicos e Aplicações. EDUSP, São Paulo, 2000.

GANDIN, Ch.-A. Experimental study of the transition from constrained to unconstrained growth during directional solidification. ISIJ International, v. 40 no. 10, p. 971-979, 2000a.

GANDIN, Ch.-A. From constrained to unconstrained growth during directional solidification. Acta mater., v. 48, p. 2843-2501, 2000b.

GANDIN, Ch.-A. Stochastic modelling of dendritic grain structures. La Revue de Métallurgie, p. 1073-1077, dezembro 2001.

GANDIN, Ch.-A; CHARBON, Ch; RAPPAZ, M. Stochastic modelling of solidification grain structures. ISIJ International., v. 35 no. 6, p. 651-657, 1995.

GANDIN, Ch.-A.; Rappaz, M. A coupled finite element-cellular automaton model for the prediction of dendritic grain structures in solidification processes. Acta metall. mater., v. 42 no. 7, p. 2233-2246, 1994.

GANDIN, Ch.-A; RAPPAZ, M. A 3D cellular automaton algorithm for the prediction of dendritic grain growth. Acta mater., v. 45 no. 5, p. 2187-2195, 1997.

GANDIN, Ch.-A.; SCHAEFER, R. J.; RAPPAZ M. Analytical and numerical predictions of dendritic grain envelopes. Acta mater., v. 44 no. 8, p. 3339-3347, 1996. 
GARCIA, A. Redistribuição de Soluto. In: Solidificação: fundamentos e aplicações. Campinas: Editora da Unicamp, 2001. p. 64-67.

GÄUMANN, M.; TRIVEDI, R.; KURZ, W. Nucleation ahead of the advancing interface in directional solidification. Materials Science \& Engineering A., v. 226-228, p. 763769, 1997.

GENDERS, R. The interpretations of the macrostructure of cast metals. J. Int. of Metals. v. 35, p.259-293, 1926.

GERMAN, R. M. Powder metallurgy science. New Jersey: Metal Powder Industries Federation, 1984. p. 27-39.

GREER, A. L. Grain refinement of alloys by inoculation of melts. Phil. Trans. R. Soc. Lond. A, v. 361, p.479-495, 2003.

GREER, A. L.; BUNN, A. M.; TRONCHE, A.; EVANS, P. V.; BRISTOW, D. J. Modelling of inoculation os metallic melts: application to grain refinement of aluminium by Al-Ti-B. Acta mater., v. 48, p. 2823-2835, 2000.

GUILLEMOT, G.; GANDIN, Ch.-A.; COMBEAU, H.; HERINGER, R. A new cellular automaton-finite element coupling acheme for alloy solidification. Modelling and Simulation in Materials Science and Engineering, v. 12, p. 545-556, 2004.

HUNT J. D. Steady state columanar and equiaxed growth of dendrites and eutectic. Materials Science and Engineering, v. 65, p. 75-83, 1984.

HUTT J.; StJOHN, D. The origins of the equiaxed zone - Review of theoretical na experimental work. Int. J. Cast. Metals Res., v. 11, p. 13-22, 1998.

HUTT J. E. C.; StJOHN, D. H.; HOGAN, L.; DAHLE, A. K. Equiaxed solidification of Al-Si alloys. Materials Science and Technology, v. 15, p. 495-500, maio 1999. 
JACKSON, K. A.; HUNT, J. D.; UHLMANN, D. R.; SEWARD, T. P. On the origin of the equiaxed zone in castings. Transactions of the Metallurgical Society of AIME, v. 236, p. 149-158, fevereiro 1966.

JACOT, A.; MAIJER, D.; COCKCROFT, S. Two-dimensional model for the description of the columnar-to-equiaxed transition in competing gray and white iron eutectics and its application to calender rolls. Metallurgical and Materials Transactions A, v. 31A, p. 2059-2068, agosto 2000.

JARVIS, D. J.; BROWN S. G. R.; SPITTLE J. A. Modelling of non-equilibrium solidification in ternary alloys: comparioson of 1D, 2D, and 3D cellular automaton finite difference simulation. Materials Science and Technology, v. 16, p.1420-1424, novembro-dezembro 2000a.

JARVIS, D. J; BROWN, S. G. R.; SPITTLE, J. A. A 2D cellular automaton-finite difference (CAFD) model of the solidification of aluminum-rich Al-Cu-Si alloys. Light Metals 2000, 2000b.

KURZ, W.; BEZENÇON, C.; GÄUMANN, M. Columnar to equiaxed transition in solidification processing. Science and Technology of Advanced Materials, v. 2, p. 185-191, 2001.

KURZ, W.; FISHER, D. J. Athom transfer at the solid/liquid interface. In: Fundamentals of solidification. Switzerland: TansTech Publications, 1998. p. 2832.

LEE, K.-Y.; HONG, C. P. Stochastic modeling of solidification grain structures of AlCu crystalline ribbons in planar flow casting. ISIJ International, v. 37 no. 1, p. 38-46, 1997.

LEE, S. Y.; LEE, S. M.; HONG, C. P. Numerical modeling of deflected columnar dendritic grains solidified in a flowing melt and its experimental verification. ISIJ International, v. 40 no. 1 , p. 48-57, 2000. 
LIPTON, J.; GLICKSMAN, M. E.; KURZ, W. Dendritic growth into undercooled alloy melts. Materials Science and Engineering, v. 65, p.57-63, 1984.

LIU, D. R.; GUO, J. J.; WU, S. P.; SU, Y. Q.; FU, H. Z. Stochastic modeling of columnar-to-equiaxed transition in Ti-(45-48 at\%) Al alloy ingots. Materials Science and Engineering A, v. 415, p. 184-194, 2006.

LUDWIG, A.; WU, M. Modeling the columnar-to-equiaxed transition with a threephase Eulerian approach. Materials Science and Engineering A, v. 413-414, p. 109-114, 2005.

MARTORANO, M. A.; BECKERMANN, C.; GANDIN Ch.-A. A solutal interaction mechanism for the columnar-to-equiaxed transition in alloy solidification. Metallurgical and Materials Transaction A, v. 34A, p. 1657-1674, agosto 2003.

MARTORANO, M. A.; BISCUOLA, V. B. Columnar front-tracking algorithm for prediction of the columnar-to-equiaxed transition in two-dimensional solidification. Modelling and Simulation in Materials Science and Engineering, v. 14, p. 12251243, 2006.

MAXWELL, I.; HELLAWELL, A. A simple model for grain refinement during solidification. Acta Metallurgica, v. 23, p. 229-237, fevereiro 1975.

McCLURG, R. B. Homogeneous nucleation theory. California: California Institute of Technology, 1997.

McFadden, S.; Browne, D. J. A front-tracking model to predict solidification macrostructures and columnar to equiaxed transitions in alloy castings. Applied Mathematical Modelling, v. 33, p. 1397-1416, 2009.

McFadden, S.; Browne, D. J. Meso-scale simulation of grain nucleation, growth and interaction in castings. Scripta Materialia, v. 55, p. 847-850, 2006. 
M'HANDI, M.; BOBADILLA, M.; COMBEAU, H.; LESOULT, G. Numerical modeling of the columnar to equiaxed transition in continuous casting of steel. In. Modeling of casting, welding and advanced solidification processes - VIII, 1998, California. Proceedings... 1998. p. 375-382.

$\mathrm{NI}$, J.; BECKERMANN, C. A volume-average two-phase model for transport phenomena during solidification. Metallurgical Transactions B, v. 22B, p. 349-361, junho 1991.

OHNO, A. Formation of granular Crystals. In: The solidification of metals. Tokyo: Chijin Shokan, 1976. p. $56-57$.

OHNO, A. Solidification: The separation theory and its practical applications. Berlin: Springer Verlag, 1987.

OHNO, A.; MOTEGI, T. Grains size control in castings. In: INTERNATIONAL CONFERENCE ON SOLIDIFICATION TECHNOLOGY IN THE FOUNDRY AND CAST HOUSE, 1980, Conventry. London: MS, 1983.

OHNO, A.; MOTEGI, T. Principles of grain refining of cast structures. AFS Cast Metals Research Journal, p. 45-51, junho 1975.

OHNO, A.; MOTEGI, T; SODA, H. Origin of the equiaxed crystals in castings. Transactions ISIJ, v. 11, p. 18-23, 1971.

OHNO, A.; SODA, H. Formation of the equiaxed zone in ingots and macrosegregation in steel ingots. Transactions ISIJ, v. 10, p. 13-20, 1970.

OLDFIELD, W. A qualitative approach to casting: Freezing of cast iron. Transactions of the ASM, v. 59, p. 945-961, 1966.

PATANKAR, S. V. Numerical heat transfer and fluid flow. New York: Hesphere Publishing Corp, 1980. 
POIRIER, D. R; GEIGER, G. H. Laminar Flow and the Momentum Equation. In: Transport Phenomena in Materials Processing. Pennsylvania: TMS, 1994. p. 302303.

QUESTED, T. E; GREER, A. L; COOPER, P. S. The variable potency of $\mathrm{TiB}_{2}$ nucleant particles in the grain refinement of aluminium by Al-Ti-B additions. Materials Science Forum, vols. 396-402, p. 53-58, 2002.

RAABE, D. Computacional materials science: the simulation of materials microstructure and properties. New York: Wiley-VCH, Weinheim, 1998.

RAPPAZ, M. Modelling of microstructure formation in solidification processes. International Materials Reviews., v. 34 no. 3, p. 93-123, 1989.

RAPPAZ, M.; GANDIN, Ch.-A. Probabilistic modelling of microstructure formation in solidification processes. Acta metall. mater., v. 41 no. 2, p. 345-360, 1993.

RAPPAZ, M.; GANDIN, Ch.-A.; DESBIOLLES, J.-L.; THÉVOZ, Ph. Prediction of grain structures in various solidification processes. Metallurgical and Materials Transaction A, v. 27A, p. 695-705, março 1996.

RAPPAZ, M.; STEFANESCU, D. M. Modeling of microstuctural evolution. In: Computer Applications in Metal Casting: Metals Handbook. Ohio: ASM International, 1988. v. 15, p.883-891.

RAPPAZ, M.; THÉVOZ, Ph. Solute diffusion model for equiaxed dendritic growth. Acta metall, v. 35 no. 7 , p. 1487-1497, 1987a.

RAPPAZ, M. THÉVOZ, Ph. Solute diffusion model for equiaxed dendritic growth: Analytical solution. Acta metall, v. 35 no. 12, p. 2929-2933, 1987b.

RAPPAZ, M.; THÉVOZ, Ph.; JIE, Z.; GABATHULER, J.-P.; LINDSCHEID, H. Micro/macroscopic modelling of equiaxed solidification. In: STATE OF THE ART OF 
COMPUTER SIMULATION OF CASTING AND SOLIDIFICATION PROCESSES, XIV, 1986, Strasbourg. France: Les éditions de physique, 1986. p. 277-284.

RAVINDRAN, K.; BROWN, S. G. R.; SPITTLE, J. A. Prediction of the effective thermal conductivity of three-dimensional dendritic regions by the finite element method. Materials Science and Engineering, v. A269, p. 90-97, 1999.

RUSS, J. C.; DeHOFF, R. T. Practical stereology. Kluwer Academic/Plenum, New York, 2000.

SHEWMON, P. G. Solidification. In: Transformation in metals. New York, 1969. p. $156-160$.

SHIN, Y. H.; HONG, C. P. Modeling of dendritic growth with convection using a modified cellular automaton model with a diffuse interface. ISIJ International, v. 42 no. 4, p. 359-367, 2002.

SOUTHIN, R. T. Nucleation of the equiaxed zone in cast metals. Transactions of the Metallurgical Society of AIME, v. 239, p. 220-225, fevereiro 1967.

SPITTLE, J. A. Columnar to equiaxed grain transition in as solidified alloys. International Materials Reviews, v. 51 no. 4, p. 247-269, 2006.

SPITTLE, J. A.; BROWN, G. R. A computer simulation of the influence of processing conditions on as-cast grain structures. Journal of Materials Science, v. 23, p. 17771781, 1989a.

SPITTLE, J. A.; BROWN, G. R. Computer simulation of the effects of alloy variables on the grain structures of castings. Acta metall., v. 37 no. 7, p. 1803-1810, 1989b.

STEFANESCU, D. M. Methodologies for modeling of solidification microstructure and their capabilities. ISIJ International, v. 35 no. 6, p. 637-650, 1995. 
TAKATANI, H.; GANDIN, Ch.-A.; RAPPAZ, M. EBSD characterisation and modelling of columnar dendritic grains growing in the presence of fluid flow. Acta mater., v. 48, p. $675-688,2000$.

TARSHIS, L. A; WALKER, J. L; RUTTER, J. W. Experiments on the solidification structure of alloy castings. Metallurgical Transactions, v. 2, p. 2589-2597, setembro 1971.

THÉVOZ, Ph.; DESBIOLLES, J. L.; RAPPAZ, M. Modeling of equiaxed microstucture formation in casting. Metallurgical Transactions A, v. 20A, p. 311-322, 1989.

THOMAS, P. M.; SPITTLE, J. A. The influence of constitucional convection during solidification on equiaxed-grain formation in large ingots. Journal of the institute of Metals, v. 99, p. 167-168, 1971.

VANDYOUSSEFI, M.; GREER, A. L. Application of cellular automaton-finite element model to the grain refinement of directionally solidified Al-4.15 wt\% Mg alloys. Acta Materialia, v. 50, p. 1693-1705, 2002.

WANG, C. Y.; BECKERMANN, C. A unified solute diffusion model for columnar and equiaxed dendritic alloy solidification. Materials Science and Engineering, v. A171, p. 199-211, 1993a.

WANG, C. Y.; BECKERMANN, C. A multiphase solute diffusion model for dendritic alloy solidification. Metallurgical Transactions A, v. 24A, p. 2787-2802, dezembro 1993b.

WANG, C. Y.; BECKERMANN, C. Equiaxed dendritic solidification with convection: Part I. Multiscale/multiphase modelng. Metallurgical and Materials Transactions A, v. 27A, p. 2754-2764, setembro 1996a.

WANG, C. Y.; BECKERMANN, C. Equiaxed dendritic solidification with convection: Part II. Numerical simulations for an Al-4 Wt Pct $\mathrm{Cu}$ alloy. Metallurgical and Materials Transactions A, v. 27A, p. 2765-2783, setembro 1996b. 
WANG, C. Y.; BECKERMANN, C. Prediction of columnar to equiaxed transition during difusion-controlled dendritic alloy solidification. Metallurgical and Materials Transactions A, v. 25A, p. 1081-1093, maio 1994.

WANG, T.; JIN, J.; ZHENG, X. A CA/MC model for the simulation of grain structures in solidification processes. Journal of Materials Science, v. 37, p. 2645-2650, 2002.

WANG, W.; LEE, P. D.; MCLEAN, M. A model of solidification microstructures in nickel-based superalloys: predicting primary dendrite spacing selection. Acta Materialia, v. 51, p. 2971-2987, 2003.

WINEGARD, W. C.; CHALMERS, B. Supercooling and dendritic freezing in alloys. Transactions of American Society for Metals, v. 46, p. 1214-1224, 1954.

ZHU, M. F.; HONG, C. P. A modified cellular automaton model for the simulation of dendritic growth in solidification of alloys. ISIJ International, v. 41 no. 5, p. 436-445, 2001.

ZHU, M. F.; HONG, C. P. A three dimensional modified cellular automaton model for the prediction of solidification microstructures. ISIJ International, v. 42 no. 5, p. 520526, 2002.

ZHU, M. F; KIM, J. M; HONG, C. P. Modeling of globular and dendritic structure evolution in solidification of na Al-7mass\%Si alloy. ISIJ International, v. 41 no. 9, p. 992-998, 2001. 